\title{
Pain in neonates : a nursing perspective $=$ pijn bij neonaten : een verpleegkundig perspectief
}

Citation for published version (APA):

Cignacco-Müller, E. L. (2007). Pain in neonates : a nursing perspective = pijn bij neonaten : een verpleegkundig perspectief. [Doctoral Thesis, Maastricht University]. Maastricht University. https://doi.org/10.26481/dis.20071205ec

Document status and date:

Published: 01/01/2007

DOI:

10.26481/dis.20071205ec

Document Version:

Publisher's PDF, also known as Version of record

\section{Please check the document version of this publication:}

- A submitted manuscript is the version of the article upon submission and before peer-review. There can be important differences between the submitted version and the official published version of record. People interested in the research are advised to contact the author for the final version of the publication, or visit the DOI to the publisher's website.

- The final author version and the galley proof are versions of the publication after peer review.

- The final published version features the final layout of the paper including the volume, issue and page numbers.

Link to publication

\footnotetext{
General rights rights.

- You may freely distribute the URL identifying the publication in the public portal. please follow below link for the End User Agreement:

www.umlib.nl/taverne-license

Take down policy

If you believe that this document breaches copyright please contact us at:

repository@maastrichtuniversity.nl

providing details and we will investigate your claim.
}

Copyright and moral rights for the publications made accessible in the public portal are retained by the authors and/or other copyright owners and it is a condition of accessing publications that users recognise and abide by the legal requirements associated with these

- Users may download and print one copy of any publication from the public portal for the purpose of private study or research.

- You may not further distribute the material or use it for any profit-making activity or commercial gain

If the publication is distributed under the terms of Article $25 \mathrm{fa}$ of the Dutch Copyright Act, indicated by the "Taverne" license above, 
PAIN IN NEONATES:

A NURSING PERSPECTIVE 


\section{PAIN IN NEONATES: A NURSING PERSPECTIVE}

\section{PIJN BIJ NEONATEN:}

EEN VERPLEEGKUNDIG PERSPECTIEF

\section{Proefschrift}

ter verkrijging van de graad van doctor

aan de Universiteit Maastricht

op gezag van de rector magnificus

Prof. mr. G.P.M.F. Mols

volgens het besluit van het College van Decanen

in het openbaar te verdedigen

op woensdag 5 december 2007 om 14.00 uur

door

Eva Lucia Cignacco Müller

Geboren te Basel (Zwitserland) 
ISBN 978-3-033-01354-4

(C) Cignacco Eva, Bern 2007

Pain in neonates: A nursing perspective

Printed by: Burger Druck, Waldkirch

Layout and cover design by: Arlette T. Bernasconi

Chapters 2, 3 and 7 have been published and are reproduced with the permission of the publisher.

Chapters 4, 5 and 6 are submitted to a scientific journal. 
Promotoren:

Co-Promotoren:

Review Committee:
Prof. Dr. JPH Hamers

Prof. Dr. LJI Zimmermann

Dr. RA van Lingen (Isala Clinics, Zwolle) Dr. M Nelle (University Hospital Bern, Switzerland)

Prof. Dr. R de Wit (Chair)

Prof. Dr. T van Achterberg

(Radboud University Nijmegen)

Dr. M Marcus

Prof. Dr. M Peters

Prof. Dr. D Tibboel

(Erasmus University Rotterdam)

The research of this thesis has been supported in part by:

Children's Hospital, Department of Neonatology,

University Hospital Bern (Switzerland)

Executive Directory of Nursing, University Hospital Bern (Switzerland)

Reach Out-Project of the "Kinderspital Zürich - Eleonoren Foundation" of the Children's University Hospital Zürich (Switzerland)

"Ettore e Valeria Rossi Foundation" in Bern (Switzerland)

Publication of this thesis was supported by:

Scientific funds of the Department of Neonatology, University Hospital Inselspital Bern (Switzerland) 


\section{CONTENTS}

\section{CHAPTER 1}

INTRODUCTION

\section{CHAPTER 2}

PAIN ASSESSMENT IN NEONATES. A LITERATURE REVIEW

Cignacco E.

Published in Pflege. Die wissenschaftliche Zeitschrift für Pflegeberufe 2001; 14:171-181.

\section{CHAPTER 3}

PAIN ASSESSMENT IN THE NEONATE USING THE BERNESE PAIN SCALE FOR NEONATES

Cignacco E, Gessler P, Müller R, Hamers JPH.

Published in Early Human Development 2004; 78 (2): 125-131.

\section{ChAPTER 4}

FACTORS INFLUENCING THE SUBJECTIVE ASSESSMENT OF PROCEDURAL PAIN IN NICUS

Cignacco E, Hamers JPH, Stoffel L, van Lingen RA, Schütz N, Müller R,

Zimmermann LJI, Nelle M.

Submitted 2007

\section{ChAPTER 5}

NEONATAL PROCEDURAL PAIN EXPOSURE AND PAIN MANAGEMENT IN VENTILATED PRETERM INFANTS DURING THE FIRST 14 DAYS OF LIFE

Cignacco E, Hamers JPH, van Lingen RA, Stoffel L, Büchi S, Müller R, Schütz N, Zimmermann LJI, Nelle M.

Submitted 2007

\section{ChAPTER 6}

PAIN RELIEF IN VENTILATED PRETERMS DURING ENDOTRACHEAL SUCTIONING.

A RANDOMIZED CONTROLLED TRIAL

Cignacco E, Hamers JPH, van Lingen RA, Zimmermann LJI, Müller R, Gessler P, Nelle M.

Submitted 2007 


\section{ChAPTER 7}

THE EFFICACY OF NON-PHARMACOLOGICAL INTERVENTIONS FOR PAIN TREATMENT IN PRETERM AND TERM NEONATES. A SYSTEMATIC REVIEW.

Cignacco E, Hamers JPH, Stoffel L, van Lingen RA, Gessler P, Mc Dougall J, Nelle M. Published in European Journal of Pain 2007; 11: 139-155.

\section{CHAPTER 8}

GENERAL DISCUSSION AND FUTURE DIRECTIONS FOR RESEARCH

SUMMARY

SAMENVATTING

ACKNOWLEDGEMENT

PUBLICATION LIST SINCE MASTER THESIS

Curriculum Vitae 
Chapter 1

INTRODUCTION 


\section{Pain in neonates: A nursing perspective}

"Pain should be considered to be the fifth vital sign and be measured and documented as carefully and regularly as heart rate, blood pressure, respiratory rate and temperature."

(International Association of Pain, 2005)

\subsection{General introduction}

In Switzerland around $8 \%$ of infants are premature (Swiss Minimal Neonatal Data Set, 2004) and of these around $3 \%$ need artificial ventilation. Without intensive care many preterm infants would have no chance of survival. The limits of viability of these neonates have been advanced thanks to the ongoing development of neonatal intensive care medicine, although the rates of mortality and morbidity vary according to gestational age (Wood et al., 2000; El-Metwally et al., 2000; Jacobs et al., 2000, Swiss Minimal Neonatal Data Set, 1996, 2000, 2004). In connection with morbidity, questions are being raised as to the effects of diagnostic and therapeutic treatment which is often associated with pain in particular for preterm infants and which could have deleterious consequences (Anand 1999; Bhutta et al., 2001; Gagnon 1999; Grunau et al., 2005; 2002; 2001; 1998; 1994; Oberlander et al,, 2000; Peters et al., 2005; Ren et al., 2004; Ruda et al., 2000; Taddio and Katz, 2005). As indicated by several studies, preterm infants in an intensive care unit are subjected to many painful procedures (Stevens et al., 2003; Simons et al., 2003; Benish and Suresh, 2001; Johnston et al., 1997; Barker and Rutter, 1995). Most of the painful procedures are routine procedures like heelsticks, tape removal and continuous positive airway pressure-manipulations (CPAP). Mechanical ventilation, with a mean intubation time of 6.75 days (Swiss Minimal Neonatal Data Set, 2004), and the resulting need of endotracheal suctioning as an effective aspect of airway management, are performed very frequently in neonatal intensive care and are potentially painful interventions. However, there is a lack of evidence concerning pain relief for this nursing intervention, particularly for preterm infants.

It has been suggested that it is the interaction between neonatal risk factors such as gestational age, severity of illness and environmental factors that have been developed to support life and the multitude of painful procedures performed on preterm neonates that has altered the neurobehavioral outcome for this high-risk population (Als et al., 1986; Merenstein, 1994). Repeated exposure to pain, as is common in the treatment in neonatology intensive care units (NICU), may lead to serious changes during the sensitive developmental phase of the central nervous system, as demonstrated in several human and animal studies (Anand 1999; Gagnon 1999; Grunau et al., 2005; 2002; 2001; 1998; 1994; Oberlander et al., 2000; Bhutta et al., 2001; Bhutta and Anand, 2002; Peters et al., 2005; Ren et al., 2004; Ruda et al., 2000; Taddio and Katz, 2005). Studies of long-term effects of early pain experience show that neonatal pain leads to different responses to subsequent painful events when compared to infants with no early and frequent pain exposure (Hermann et al., 2006; Taddio et al., $1995 ; 1997 ; 2005$ Johnston et al., 1996). The frequency of exposure to pain and the adequate treatment 
of that pain are therefore important factors in later motor and cognitive development in preterm infants requiring intensive care, who experience rapid neurological development during the first weeks of life. Although the immature pain system in preterm infants predisposes them to greater clinical and behavioural sequelae (Anand, 2000), there has been little progress in the provision of effective procedural pain management (Anand, 2001; Anand and Selankio, 1996; Stevens, 1996).

Pain therefore remains a central issue in NICUs and is one of the most important nursing diagnoses for nursing care in this setting. Considering the infant's right to appropriate pain management, the nursing and medical profession should act with the goal of improving the wellbeing and an undisturbed growth of preterm infants undergoing a high number of painful procedures. The assessment, the treatment and the evaluation of pain relieving interventions are therefore imperative for nursing care, which is guided by the ethical principle of beneficence. However, effective pain treatment requires an interdisciplinary approach, where both non-pharmacological and pharmacological options should be discussed and implemented systematically.

\subsection{Nursing steps toward effective pain management in neonates}

The steps of the nursing process are an integrative part of the studies described in this thesis (assessment - interventions - evaluation). We focussed on questions regarding the assessment of neonatal pain and the underlying factors that can influence the subjective assessment. As interventions, we describe systematically the efficacy of non-pharmacological interventions and of one pharmacological agent. The evaluation of the efficacy of the two approaches was part of a study concerning pain relief during and after endotracheal suctioning. The single steps of the nursing process and their contribution to efficacy in pain management were the organising structure for the studies presented in this thesis and are described below:

\subsubsection{Pain assessment}

As neonates cannot verbally report their pain, it is the responsibility of healthcare professionals to recognise, assess and manage their pain by relying on physiological, behavioural or biochemical indicators. The science of pain assessment for infants and children has grown substantially in the past several decades to the point that valid and reliable methods for pain measurement are available for use in the clinical setting (Hummel and van Dijk, 2006; Duhn and Medves, 2004; van Dijk et al., 2004; Stevens and Franck, 2001; Franck et al., 2000; Stevens et al., 2000; Franck and Miaskowski, 1997). The purpose of the measurement of pain is to discriminate between pain or no pain. In order to do this a value must be assigned to it for each particular child at a particular time. Using the cut off point for the pain scale used, further steps must be taken for pain management. It is known that nurses working in the NICU face difficulties in defending and validating their assessment of pain in the neonate they care for. Without objective data, the nurses" request for pain relief on behalf of the infant may be rejected. The purpose of pain assessment is therefore to provide a picture of pain, that is as complete as possible, and that also includes some quantification of the pain. Neonatal pain scales have been developed to improve this quantification of an infant's reaction to noxious stimuli. However, in spite of these developments, many conceptual and measurement issues remain. Thus, the influence of contextual factors on the expression of pain, such as the gestational age and the associated immaturity of the central nervous system, as well as the influence of states of illness and of consciousness (for example, in the case of sedation during mechanical ventilation) has not yet been comprehensively explained. No instruments have been definitively validated with regard to these influences. However, measurement and assessment are a crucial issue to protect the neonate to harm and deleterious consequences of the many painful diagnostic and therapeutic procedures in the clinical setting and they should be part of a patient care quality program especially in the NICU. 


\subsubsection{Interventions for pain treatment}

\subsubsection{Pharmacological interventions}

Although pharmacological treatment is an issue which belongs to the competences of medical care, the nursing profession is confronted with the fact that up to $80 \%$ of the medications which are used among sick preterm and term neonates in NICU are either not approved for the illness concerned (off-label use), or are administered in a form or dose other than that officially approved (unlicensed use) (Conroy, 1999; Roth, 2004). As a rule, their use is based on clinical guidelines. Pharmacological interventions are based on a variety of different opioids (Morphin, Fentanyl, Pethidin) and non-opioid analgesics (Paracetamol). The reticence in systematic application for routine short interventions can be justified with a view to their long-term effects and possible side-effects (Anand et al., 2004). Off-label pharmacological treatment has a three fold increase risk for adverse events (Lindner, 2006). Several studies have been conducted on the pharmacokinetic and pharmacodynamic effects of analgesics in recent years (van Lingen et al., 1999; 2000; 2002; Simons et al., 2003; 2004; Bouwmeester et al., 2003a, 2003b, 2001; van Dijk et al., 2002; Saarenmaa et al., 1999) showing that there are several factors affecting drug metabolism in neonates which should be considered in connection with administration.

\subsubsection{Non-pharmacological pain management}

As significant side effects are associated with analgesics, non-pharmacological methods of pain prevention and relief are increasingly being recommended (American Academy of Pediatrics, Canadian Paediatric Society, 2006). References to non-pharmacological treatment of pain are becoming more and more frequent in the literature. Non-pharmacological treatment of pain is a prophylactic and complementary approach for the reduction of acute pain (Franck and Lawhon, 1998). This type of intervention includes methods that involve reducing the sensitivity of the neonates during and after painful procedures, which have been shown to effectively reduce pain from minor procedures in neonates (Axelin et al., 2006; Stevens et al., 2004; Stevens et al., 1997; Blass et al., 1999). These include use of oral sucrose/glucose, breastfeeding, non-nutritive sucking, kangaroo care, facilitated tucking, swaddling and the use of supportive bedding. These interventions activate the attention of neonates, distract them from the pain, and thus modify pain perception (Bellieni et al., 2001). It is postulated that they reduce the pain by pre-empting hypersensitivity (Stevens et al., 2000). These measures are of importance for the nursing profession since they can be performed according to the nurse's own clinical decision-making related to the infant's behavioural state, independently from medical prescriptions. Although there are methods for pain relief currently in use in the neonatal setting, there is a paucity of data about their efficacy. This underlines the need for further research into the efficacy and safety of non-pharmacological management of pain in preterm infants.

\subsubsection{Evaluation of pain relieving in terventions}

Evaluation of the effectiveness of nursing interventions is considered to be one of the achievements nursing research should focus on the next 10 years in Switzerland (Imhof et al., 2007). In the case of pain in neonates, nursing care should contribute to reducing or eliminating the neonate's pain experience. Moreover, it is known that one of the most stressful experiences reported by parents of infants in the NICU is seeing their infants experience of pain (Brunssen and Miles, 1996; Miles and Holditch-Davis, 1997; Miles et al., 1993). Memories of the infants pain and the mother's inability to protect her infant from pain may continue to be a source of stress long after their infant's discharge from the NICU (Wereszczak et al., 1997). These facts are a challenge for health care providers of a NICU. Pain management in neonates requires conducting an ongoing assessment and evaluation of 
interventions taken to relieve pain. Measures that are used to control pain may or may not be effective. They need to be evaluated through observing the child's behaviour or preferably by objective pain assessment tools. If measures are ineffective the nurse should seek alternative measures that help to achieve the goal of controlling the pain the neonate is exposed to. To achieve optimum efficacy of pain relief nurses have to assess whether additional measures such as a reduction of external stimuli like loud noises and glaring light (Franck and Lawhon, 1998; Stevens et al., 2000) are necessary. Thus the effectiveness of the nursing intervention must be evaluated over time.

\subsection{Need for data gathering in Switzerland}

In countries like Canada, the USA, the Netherlands and England numerous studies on the topic of neonatal pain in connection with neonatal intensive care have been conducted in recent years; however, in German-speaking countries - and particularly in Switzerland - very little research has been done. Official statistical, demographical and outcome-related data on preterm and newborn infants from a NICU have only been available since 1995 (Neonatal Minimal Data Set, 1995), and even these were in a rather incomplete and non-standardised form until the year 2004. For example, frequency and type of pain exposure are not covered in this databank. This thesis is thus the first of its kind for Switzerland in that it will deal systematically with questions concerning the topic of pain management, and in particular with the frequency of pain exposure among the highly vulnerable patient group of ventilated preterm infants.

\subsection{Scope of this thesis and research questions}

The studies described in this thesis generally aim to contribute to an improvement of neonatal pain management. We investigated questions of accurate pain assessment by means of an objective tool and the underlying influencing factors of subjective pain intensity assessment. Further, we detected gaps in ongoing pain management in NICUs, we revealed the effect of an analgesic agent during the nursing intervention of endotracheal suctioning in ventilated preterm infants and we described the efficacy of non-pharmacological intervention as measures for the nursing profession to perform them as a matter of routine in the everyday clinical setting.

The studies were driven by the following research questions: (1) What are the parameters known to be reliable for measuring pain in the neonates? What kind of instruments have been developed and are in use in the clinical setting? (2) What are the psychometric properties of the inductively developed "Bernese Pain Scale for Neonates" (BPSN)? Is the BPSN a valid and reliable tool for pain assessment in term and preterm neonates? (3) Are there factors influencing subjective pain assessment of health care professionals of NICUs? Which NICU routine procedures are considered to be painful and which are not considered to be painful by health care providers? (4) How high is the number of pain exposure in ventilated preterm infants during the first 14 days of life? Is pain assessed by a tool during clinical routine and what kind of analgesia do infants receive for pain prevention and pain treatment? (5) Is an intermittent intravenous dose of morphine applied before endotracheal suctioning effective to reduce pain? (6) And what kind of non-pharmacological interventions are described to be effective in the prevention and treatment of pain?

\subsection{Structure of this thesis}

Chapter 2 gives answers to the question what kind of parameters are described to be important and clinical feasible for pain assessment in a NICU. The chapter gives an overview of different pain assessment instruments which are described to be in use in NICUs till the year 2000. Over the past few years a number of further tools for determining pain have been developed. There are pain assessment 
tools based either on behavioural indicators of pain only, or on a combination of behavioural and physiological indicators (Hummel and van Dijk, 2006; Duhn and Medves, 2004; van Dijk et al., 2004; Stevens and Franck, 2001; Franck et al., 2000; Stevens et al., 2000; Abu-Saad et al., 1998; Franck and Miaskowski 1997). In view of the complexity of the expression of pain in neonates, the use of multidimensional tools is recommended (McGrath et al., 1985; Abu-Saad et al., 1990), which include both behavioural and physiological - and thus objective - criteria. The review describes the difficulties accompanying an objective appreciation of pain among the newborn, in particular in the case of premature infants. Most of the existing scales of pain have been developed for the purposes of research and their practical application in a regular clinical context has never been tested. This review was undertaken in preparation for the validation of the "Bernese Pain Scale for Neonates".

The "Bernese Pain Scale for Neonates" has been inductively developed by experienced nurses in the years 1995-1996. A time period in which some of the described assessment tools in chapter 2 were themselves being established or not developed. The nurses felt the need of developing a tool in German language to be feasible for clinical assessment. After inductive development the tool was in use in the clinical setting without testing it for psychometric properties. To improve quality of care the medical and nursing leaderhip of the clinic requested for a validation trajectory of the BPSN which was performed in the year 2000-2001.

Chapter 3 gives an answer to the question if whether the BPSN is a valid tool for pain assessment in neonates. We therefore describe the validation trajectory of the "Bernese Pain Scale for Neonates" (BPSN). Beside validity and reliability, for a measure to be clinically useful or possess clinical utility, it must evolve toward high levels of acceptability and convenience for those who use it. We validated the "Bernese Pain Scale for Neonates" comparing it with the "Premature Infants Pain Profile" (Ballantyne et al., 1999) and with the "Visual Analogue Scale" (Price et al., 1994).

Although there are a number of validated pain assessment tools, pain associated with routine procedures in NICUs is often inadequately managed. Barriers to more appropriate pain management are related to nurses' and physicians' knowledge and the challenges of collaborative decision-making. Chapter 4 gives an answer to the question which factors are influencing subjective pain assessment and what kind of procedures performed in a NICU are to be considered to be painful. We describe the results of a survey of 431 neonatal health care professionals designed to explore the factors influencing pain intensity assessment and to gain insight into a possible pain intensity categorization of routine procedures in NICUs.

In Chapter 5 the aim was to investigate the current management of pain in two NICUs in which 120 preterm neonates requiring mechanical ventilation were under investigation. We studied frequency and painfulness of daily-performed procedures retrospectively and simultaneously analyzed the use of analgesic therapy in these neonates.

Mechanical ventilation is used largely in the case of severely underdeveloped preterms born before the 27th week of gestation showing clinical signs of dyspnoea. Regular endotracheal suctioning by qualified nurses is therefore necessary. Endotracheal suctioning is linked to stress and pain for the preterm in question. In the Neonatology Department in Berne analgesics are not regularly and systematically administered to ventilated preterms when they undergo endotracheal suctioning. All preterm infants who are ventilated are not systematically given morphine, nor do they receive an analgesic before endotracheal suctioning. The study described in chapter 6 aimed to test the hypothesis that morphine will reduce pain during the suctioning intervention and that the multisensorial stimulation, as a non pharmacological nursing consolation intervention after the painful stimulus, helps preterm infants to recover better from pain. 
Chapter 7 contains a systematic review of the efficacy of non-pharmacological interventions in the management of procedural pain in preterm and term neonates. These interventions are increasingly being discussed with regard to pain prevention and relief in acute pain situations either alone or in combination with pharmacological treatment.

In Chapter 8 the results of our studies are incorporated into the discussion of the main remaining questions about neonatal pain management. Furthermore, suggestions are presented for future research.

„...neonates need to be comfortable and as free of pain as possible to grow and develop normally. "

(Stevens et al., 1995, 849) 


\section{References}

Abu-Saad H, Bours G, Stevens B, Hamers J. Assessment of pain in the neonate. Semin Perinatol 1998; 22:402-416.

Als H, Lawhon G, Brown E, Gibes R, Duffy FH, Mc Anulty G, Blickman JG. Individualized behavioural and environmental care for the very low birth weight preterm infant at high risk for bronchopulmonary dysplasia: neonatal intensive care unit and developmental outcome. Pediatrics 1986; 78:1123-1132.

American Academy of Pediatrics, Committee on Fetus and Newborn and Section on Surgery. Canadian Paediatric Society. Fetus and Newborn Committee. Prevention and management of pain in the neonate: An Update. Pediatrics 2006; 118:2231-41.

American and Canadian Academy of Pediatrics. Prevention and management of pain and stress in the neonate. Pediatrics $2000 ; 15: 454-61$.

Anand KJS, Coskun V, Thrivikraman KV, Nemeroff CB, Plotsky PM. Long-term behavioral effects of repetitive pain in neonatal rat pups. Physiol Behav 1999; 66:627-37.

Anand KJS, Whit Hall R, Desai N, Shephard B, Bergqvist L, Young T, Boyle E, Carbajal R, Bhutani V, Moore N, Kronsberg S, Barton B (NEOPAIN Trial Investigators Group). Effects of morphine analgesia in ventilated preterm neonates: Primary outcomes from the NEOPAN randomized trial. Lancet 2004; 363:1673-82.

Anand KJS, International evidence-based group for neonatal pain. Consensus statement for the prevention and management of pain in the newborn. Arch Pediatr Adolesc Med 2000; 155:173-80.

Anand KJS. Effects of perinatal pain and stress. Prog Brain Res 2000; 122:117-29.

Anand KJS, Selankio JD. SOPAIN study group. Routine analgesia practices in 109 neonatal intensive care units (NICUs) \{abstract $\}$. Pediatr Res 1996; 39:192A.

Axelin A, Salanterä S, Lehtonen L. Facilitated tucking by parents' in pain management of preterm infants - a randomized crossover trial. Early Hum Dev 2006; 82:241-247.

Ballantyne M, Stevens B, Mc Allister M, Dionne K, Jack A. Validation of the Premature Infant Pain Profile in the clinical Setting. Clin J Pain 1999; 15:297-303.

Bellieni CV, Buoncore G, Nenci A, Franci N, Cordelli DM, Bagnoli F. Sensorial saturation: an effective analgesic tool for heel-prick in preterm infants. Biol Neon 2001; 80:15-8.

Bellieni C, Bagnoli F, Sisto, Neri L, Cordelli D, Buonocore G. Development and validation of the $A B C$ pain scale for healthy full-term babies. Acta Paediatr 2005; 94:1432-1436. 
Benis MM, Suresh GK. Frequency of invasive procedures in very low birth weight (VLBW) infants in the neonatale intensive care unit (NICU) (abstract). Pediatric Res 2001; 49:392A.

Bhutta AT, Anand KJS. Vulnerability of the developing brain. Neuronal mechanism. Clin Perinatol $2002 ; 29: 357-372$.

Bhutta AT, Rovnaghi C, Simpson PM, Gosset JM, Scalzo FM, Anand K.IS. Interactions of inflammatory pain and morphine in infant rats: Long-term behavioral effects. Physiol Behav $2001 ; 73: 51-8$.

Blass EM, Watt LB. Suckling- and sucrose-induced analgesia in human newborns. Pain 1999; 83:611-23.

Bouwmeester NJ, van den Anker JN, Hop WC, Anand KJ, Tibboel D. Age- and therapy-related effects on morphine requirements and plasma concentrations of morphine and its metabolites in postoperative infants. Br J Anaesth 2003a; 90:642-52.

Bouwmeester NJ, Hop WC, van Dijk M, Anand KJ, van den Anker JN, Tibboel D. Postoperative pain in the neonate:age-related differences in morphine requirements and metabolism. Intensive Care Med 2003b; 29:2009-15.

Bouwmeester NJ, Anand KJ, van Dijk M, Hop WC, Boomsma F, Tibboel D. Hormonal and metabolic stress responses after major surgery in children aged 0-3 years. A double-blind, randomized trial comparing the effects of continuous versus intermittent morphine. $\mathrm{Br} \mathrm{J}$ Anaesth 2001 ; 87:390-9.

Brunssen SH, Miles MS. Sources of environmental stress experience by mothers of hospitalized medically fragile infants. Neonatal Network 1996; 15:88-89.

Conroy S, McIntyre J, Choonara I. Unlicensed and off label drug use in neonates. Arch Dis Child Fetal Neon Ed 1999; 80:F142-5.

Duhn LJ, Medves JM: A systematic integrative review of infant pain assessment tools. Adv Neonatal Care 2004; 3:126-140.

El-Metwally D, Vohr B, Tucher R. Survival and neonatal morbidity at the limits of viability in the mid 1990s: 22 to 25 weeks. J. Pediatr 2000;137:616-22.

Franck LS, Greenberg CS, Stevens B. Pain assessment in infants and children. Acute pain in children. Pediatr Clin North Am 2000; 47:487-512.

Franck LS, Lawhon G. Environmental and behavioral strategies to prevent and manage neonatal pain. Semin Perinatol 1998; 22:434-43.

Franck LS, Miaskowski C. Measurement of neonatal responses to painful stimuli: A research review. J Pain Symptom Manage 1997; 14:343-378.

Gagnon R, Leung A, Macnab A. Variations in regional cerebral blood volume in neonates associated with nursery care events. Am J Perinatol 1999; 16:7-11.

Grunau RE, Holsti L, Haley DW, Oberlander T, Weinberg J, Solimano A, Whitffield MF, Fitzgerald C, Yu W. Neonatal procedural pain exposure predicts lower cortisol and behavioral reactivity in preterm infants in the NICU. Pain 2005; 113:293-300.

Grunau R.: Early pain in preterm infants. A model of long-term effects. Clin Perinatol 2002; 29:373-94, vii-viii. 
Grunau R, Oberlander TF, Whitfield MF, Fitzgerald C, Lee SK. Demographic and therapeutic determinants of pain reactivity in very low birth weight neonates at 32 weeks' postconceptional age. Pediatrics 2001; 107:105-12.

Grunau R, Whitfield MF, Petrie JH. Children's judgements about pain at age 8-10 years. Do extremely low birthweight $(<1000 \mathrm{~g})$ children differ from full birthweight peers? J Child Psychol Psychiatr 1998; 39:587-94.

Grunau R, Whitfield MF, Petrie JH, Fryer EL. Early pain experience, child and family factors as precursors of somatization: A prospective study of extremely premature and fullterm children. Pain 1994; 56:353-9.

Hermann C, Hohmeister J, Demirakca S, Zohsel K, Flor H. Long-term alteration of pain sensitivity in school-aged children with early pain experiences. Pain 2006; 125:278-285.

Hummel P, van Dijk M. Pain assessment current status and challenges. Semin Fetal Neonatal Med $2006 ; 11: 237-45$

Imhof L, Abderhalden C, Cignacco E, Eicher M, Mahrer-Imhof R, Shaha M, Schubert M. Swiss research agenda for nursing 2007-2017

(www.pflegeforschungvfp.ch/index.php?language $=$ de\&page $=$ agenda)

Retrieved 9.12.2006.

Jacobs SE, O'Brien K, Inwood S, Kelly EN, Whyte HE. Outcome of infants 23-26 weeks' gestation pre and post surfactant. Acta Paediatr 2000; 137:616-22.

Johnston CC, Collinge JM, Henderson SJ, Anand KJ. A cross-sectional survey of pain and pharmacological analgesia in Canadian neonatal intensive care units. Clin J Pain. 1997; $13: 308-12$

Johnston CC, Stevens BJ. Experience in a neonatal intensive care unit affects pain response. Pediatrics $1996 ; 98: 925-30$.

Lindner M. Versuchskaninchen. Die meisten Medikamente sind weder an Kindern getestet worden noch für sie zugelassen. DIE ZEIT, 31. August 2006, No. 36: 31.

Merenstein B. Individualized developmental care: an emerging new standard for neonatal intensive care units? JAMA 1994; 272:890-891.

Miles MS, Holditch-Davis D. Parenting the prematurely born child: pathways of influence. Semin Perinatol 1997; 21:254-266.

Miles MS, Funk SG, Carlson J. Parent stressor scale: neonatal intensive care unit. Nurs Res 1993; 42:148-152.

Oberlander TF, Grunau R, Whitfield M, Fitzgerald C, Pitfield S, Saul JP. Biobehavioral pain responses in former extremely low birth weight infants at four months' corrected age. Pediatrics 2000; 105:e6.

Peters JW, Schouw R, Anand KJS, van Dijk M, Duivenvoorden HJ, Tibboel D. Does neonatal surgery lead to increased pain sensitivity in later childhood? Pain 2005; 114:444-54.

Price DD, Bush FM, Long S, Harkins SW. A comparison of pain measurement characteristics of mechanical visual analogue and simple numerical rating scales. Pain 1994; 56:217-26. 
Ren K, Anseloni V, Zou SP, Wade EB, Novikova SI, Ennis M, Traub RJ, Gold MS, Dubner R, Lidow MS. Characterisation of basal and re-inflammation-associated long-term alteration in pain responsivity following short-lasting neonatal local inflammatory insult. Pain 2004; 110:588-96.

Roth B. Medikamenteneinsatz bei Neugeborenen: Klinische Studien belegen die Wirksamkeit und erhöhen die Sicherheit. Written notification by the Federal Ministry of Education and Research, Berlin, dated 10 February 2004.

Ruda MA, Qing-Dong L, Hohmann AG, Peng YB, Tachibana T. Altered nociceptive neuronal circuits after neonatal peripheral inflammation. Science 2000; 289:628-30.

Saarenmaa E, Huttunen P, Leppaluoto J, Meretoja O, Fellmann V. Advantages of Fentanyl over Morphine in analgesia for ventilated newborn infants after birth: A randomized trial. J Pediatr $1999 ; 134: 144-50$.

Simons SH, van Dijk M, Anand KS, Roofthooft D, van Lingen RA, Tibboel D. Do we still hurt newborn babies? A prospective study of procedural pain and analgesia in neonates. Arch Pediatr Adolesc Med. 2003 Nov; 157:1058-64.

Simons SH, van Dijk M, van Lingen RA, Roofthooft D, Duivenvoorden JH, Jongeneel N, Bunkers C, Smink, E, Anand $\mathrm{KJ}$, van den Anker $\mathrm{NN}$, Tibboel $\mathrm{D}$. Routine morphine infusion in preterm newborns who received ventilatory support: a randomized controlled trial. JAMA 2003; 290:2419-27.

Simons SH, van Dijk M, van Lingen RA, Roofthooft D, Boomsma F, van den Anker JN, Tibboel D. Randomised controlled trial evaluating effects of morphine on plasma adrenaline/ noradrenaline concentrations on newborns. Arch Dis Child Fetal Neonatal Ed 2005; 90:F36-F40.

Stevens B, Yamada J, Ohlsson A. Sucrose analgesia in newborn infants undergoing painful procedures. Cochrane Database Syst Rev 2004; 3:CD001069.

Stevens B, McGrath P, Gibbins S, Beyene J, Breau L, Camfield C, Finley A, Franck L, Howlett A, McKeever P, O'Brien K, Ohlsson A, Yamada J. Procedural pain in newborns at risk for neurologic impairment. Pain 2003; 105:27-35.

Stevens B, Franck LS. Assessment and management of pain in neonates. Paediatr Drugs 2001; 3:539-558.

Stevens B, Gibbins S, Franck L. Treatment of pain in the neonatal intensive care unit. Pediatr Clin North Am 2000; 3:633-650.

Stevens B, Taddio A, Ohlsson A, Einarson T. The efficacy of sucrose for relieving procedural pain in neonates - a systematic review and meta-analysis. Acta Paediatr 1997; 86:837-42.

Stevens B. Pain management in newborns: How far have we progressed in research and practice? Birth 1996; 23:229-35.

Stevens BJ, Johnston CC, Grunau RVE. Issues of assessment of pain and discomfort in neonates. J Obstet Gynecol Neonatal Nurs 1995; 24:849-855.

Swiss Minimal Neonatal Data Set (MNDS), 2004 (www.neonet.ch/en/02_Neonatal_Network/aimes.asp) Retrieved 9.12.2006. 
Taddio A, Katz J. The effects of early pain experience in neonates on pain responses in infancy and childhood. Paediatr Drugs 2005; 7:245-57.

Taddio A, Katz J, Ilersich AL, Koren G. Effect of neonatal circumcision on pain response during subsequent routine vaccination. Lancet 1997;349:599-603.

Taddio A, Goldbach M, Ipp M, Stevens B, Korenz G. Effect of neonatal circumcision on pain responses during vaccination in boys. Lancet 1995;345:291-2.

van Dijk M, Simons S, Tibboel D. Pain assessment in neonates. Paediatr Perinat Drug 2004; 6:97-103.

van Dijk M, Bouwmeester NJ, Duivenvoorden HJ, Koot HM, Tibboel D, Passchier J, de Boer JB. Efficacy of continuous versus intermittent morphine administration after major surgery in 0-3year-old infants; a double-blind randomized controlled trial. Pain 2002; 98:305-13.

van Dijk M, Boer JB, Koot HM, Duivenvoorden HJ, Passchier J, Bouwmeester N, Tibboel D. The association between physiological and behavioural pain measures in 0-to 3-year-old infants after major surgery. J Pain Symptom Manage 2001; 22:600-609.

van Dijk M, Boer JB, Koot HM, Tibboel D, Passchier J, Duivenvoorden HJ. The reliability and validity of the COMFORT scale as a postoperative pain instrument in 0 to 3 -year-old infants. Pain 2000; 84:367-377.

van Lingen $R$, Simons $S$, Anderson $B$, Tibboel $D$. The effect of analgesia on the vulnerable infant during the perinatal period. Clin Perinatol 2002, 29:511-534.

van Lingen RA. Pain assessment and analgesia in the newborn: An integrated approach. Doctoral thesis, Erasmus University, Rotterdam 2000.

van Lingen RA, Deinum JT, Quak JME, Kuizenga AJ, van Dam JG, Anand KJS, Tibboel D, Okken A. Pharmacokinetics and metabolism of rectally administered paracetamol on preterm neonates. Archives Dis Child Fet Neonatal Ed 1999; 80:59-63.

Wereszczak J, Miles MS, Holditch-Davis D. Maternal recall of the neonatal intensive care unit. Neonatal Network 1997; 16: 33-40.

Wood NS, Marlow N, Costeloe K, Gibson AT, Wilkinson AR. Neurologic and developmental disability after extremely preterm birth. EPICure Study Goup. N Engl J Med 2000; 343:378-384. 


\title{
CHAPTER 2
}

\section{PaIn ASsessment IN NEONATES:}

A Literature REVIEW

\author{
E. Cignacco \\ Published in Pflege. Die wissenschaftliche Zeitschrift für
} Pflegeberufe 2001; 14:171-181.

Translated and modified version 


\begin{abstract}
Summary
While adults and children can express pain verbally, it is not possible to assess pain directly in neonates owing to their lack of language. Pain in the newborn must therefore be indirectly assessed, thus involving the use of physiological, behavioural and biochemical parameters. The present review of the literature describes the difficuities accompanying an objective assessment of pain in the newborn, in particular in the case of premature infants. Most of the existing scales of pain have been developed for the purposes of research and their practical application in a regular clinical context has not yet been tested. Nurses and physicians are therefore still faced with the problem of having to use a small number of substantiated tools which, however, have hardly been tested in practice. This is all the more questionable since, according to the literature, the short and long-term consequences of continuous pain in neonates can include intraventricular haemorrhages, changes in feeding and sleep patterns and most importantly, disruption of the sensitive relationship between the infant and its parents.
\end{abstract}




\section{Introduction}

"The clinical measurement of pain, which is not easy in adults, is difficult in children, more difficult in infants, and most difficult, perhaps impossible, in sick neonates."

(Pigeon et al., 1989, 179)

The awareness that neonates are able to experience pain is about 25 years old. Up to the second half of the 20th century, it was believed that noxious stimuli would not be transmitted to the cerebral cortex due to the missing myelinisation of nerve fibers and therefore neonates would not feel pain. It was also assumed that neonates neither do remember painful experiences nor feel repeated and painful stimuli as such (Abu-Saad et al., 1998). The systematic research of the phenomenon of pain in neonates first began in the 1980's, parallel to the development of the technical advances which improved the chance of survival for neonates. Today there is sufficient evidence that the neonate has the neurological capacity to experience pain even as a foetus. Neurophysiological research has shown that the myelinisation of the central nervous system already takes place in the second and third trimester of pregnancy (Anand and Carr, 1989). The functional maturity of the cortex could be proven by fetal and neonatal electro-encephalographical patterns. It was possible to electro-encephalographically record the fetal behaviour and reactions to tactile stimulations both while sleeping and awake (Anand et al., 1987). The central nerve fibers leading to the brain stem and thalamus are completely myelinised in the 30 th week of pregnancy at the latest. Unmyelinised or simply thin myelinised nerve fibers are also able to transmit noxious stimulation, assuming that the incomplete myelinisation reduces the speed of the noxious impulse. Anand et al. (1987) claimed that the reduced speed of the impulse is neutralised by the shorter interneural and neuromuscular distance of the nervous system in neonates. This neurophysiological evidence led to a paradigmatic change concerning neonatal pain capacity and fostered research on the assessment of pain in neonates over the last 25 years. Although adults and children can express their experience of pain verbally, neonates cannot. Therefore various scales for indirect pain assessment have been developed in recent years in order to measure the physiological and/or behavioural parameters of neonatal pain expression Grunau and Craig (1987) describe changes in facial activity as the most important behavioural parameters, biochemical substances are also important parameters. Increased production of cortisol, catecholamine, endorphins and growth hormones could be documented after painful stimulations in neonates (Franck and Miaskowsky, 1997). Biochemical parameters provide important hints, but they are not suitable for pain assessment in the clinical setting, whereas physiological and behavioural factors are. Moreover, contextual factors like gestational age and the state of illness and/or consciousness can influence the reactions of pain (Stevens and Franck, 1995). Craig et al. (1993) report different pain reactions between preterm and term neonates. The reactions of the premature infants to a painful stimulus were weaker. Although pain was experienced, their reactions could be reduced or completely lacking. Neonates - especially ill and premature infants in neonatal intensive care units - are exposed to a high number of painful 
routine procedures. This repeated and prolonged pain exposure can cause short and long-term pathologic alterations in neonates: Pain can lead to intraventricular haemorrhages, changes in blood pressure or oxygen saturation and changes in the infant's behavioral patterns. Furthermore, changes in feeding and sleeping patterns as well in the sensitive interaction between infant and parents can be due to repeated exposure to pain and can indicate a long-term effect of pain (Anand et al., 1987).

This literature review has aimed to describe several pain assessment tools and the related problems surrounding an objective assessment of the phenomenon of pain in neonates.

\section{$2 \quad$ Method}

The databases MedLine and CINAHL were searched in May 2000 to find relevant literature on the subject. The search period covered the years from 1966 to 2000 . The following search key words were used in various combinations: "pain and neonates", "pain assessment in neonates", "pain and nursing", "pain measurement in neonates", "pain assessment tool and neonates", "nursing assessment and neonatal pain", "pain diagnosis". After the examination of 78 abstracts, 46 studies were selected for further analysis and studies focussing on pain assessment in neonates up to 44 weeks of gestation were considered. As a result of this selection process, the present literature review refers to 25 studies concerning the question of pain assessment in neonates. The selected studies concentrated on development and validation of instruments and referred to underlying problems of pain assessment. Secondary literature like unpublished reviews, an unpublished master thesis and a project report were also considered for this review.

\section{Results}

Appropriate pain management improves not only the well-being of the neonate exposed to a high number of potentially painful routine procedures, but also contributes to the unhindered motor and cognitive development of the neonate and premature infant. Therefore pain alleviation is one of the central tasks of nurses and physicians in neonatal intensive care units. Nurses and physicians must face the problemsof recognizing and assessing pain in neonates, which occurs indirectly and is based on physiological and behavioural factors. Due to the rapid maturation of the central nervous system in the last weeks of pregnancy, preterm and term neonates must be distinguished (Franck and Miaskowski, 1997). Contextual factors such as gestational age, illness, and consciousness play an important role. Mechanically ventilated children are not able to cry and their facial activity is restricted by the administration of sedatives. Single pain parameters are explained and difficulties in assessment are pointed out in the following sections.

\subsection{Pain parameters}

Soetenga et al. (1999) argue that to assess acute pain, physiological parameters like heart rate, blood pressure, breathing rate and arterial oxygen saturation have sufficient reliability. However, their reliability becomes questionable with long-lasting pain. The authors argue that the physiological reactions of neonates may become normotonic as a result of repeated experiences of pain. In order to assess pain the combination of physiological and behavioural parameters is recommended. This finding has caused controversy. Ballantyne et al. (1999) have also shown that the combination of physiological and behavioural parameters is important to adequately assess acute pain. 


\subsubsection{Physiological parameters}

Physiological reactions to pain may be expressed by increased heart rate, increased blood pressure, variations in oxygen saturation, changed breathing rate, enhancement of intraventricular pressure and increased palmar sweating (Franck and Miaskowski, 1997). The authors claim that these parameters are insufficient to assess pain, since they could be influenced by contextual factors like illness and gestational age. The difficulty of applying such parameters is discussed in Stevens at al's study (1993), in which these parameters are criticized for not being sufficiently specific to the phenomenon of pain. Heart rate may be altered by the administration of medicaments (e.g. caffeine) or the newborn's anxiety. A decrease in transcutaneous oxygen saturation can usually be measured during painful interventions, but this also occurs during unpainful procedures like handling neonates during diaper change. These parameters may be interpreted as parameters of stress rather than pain in neonates (Craig et al., 1993; Fuller and Conner, 1996). Although the assessment of physiological parameters is a clearly objective measure, it seems to be unreliable for pain if measured without reference to other parameters. Therefore, most authors recommend the combined use of both physiological and behavioural parameters.

\subsubsection{Behavioural parameters}

Various studies point out the relevance of behaviour-related parameters (Stevens et al., 1993; Stevens et al., 1995; Krechel and Bildner, 1995; Lawrence et al., 1992) among which crying, facial activity and motor function are important. Neonatal crying depends to a great extent on contextual factors like gestational age, illness and consciousness. In Stevens et al's study (1995) crying from pain in both preterm infants and term neonates could be distinguished from other forms of crying by the magnitude of the intonation and the duration of the crying peak. Sheeran (1997) discovered that the crying of premature infants compared to term neonates is higher, of a shrill quality, and of a shorter duration. Mechanical ventilated neonates cannot vocalise their crying, which is thus not reliable as an indicator of pain in these cases. Changes in facial activity, defined as contracting the eyebrows, broadening the alar wings, wrinkling the forehead, squeezing the eyes and opening the mouth, are claimed to be the most sensitive parameters for pain when combined with an increasing heart rate (Grunau et al., 1998; Craig et al., 1993; Johnston et al., 1995). Moreover, these changes in facial activity are the most frequently examined in connection with other behaviour-related pain factors and are therefore counted as the most significant pain parameters throughout all gestational ages (Stevens et al., 1995). As a pain indicator in neonates, a change in facial activity is closely connected with the state of consciousness. During heel lances, neonates reacted differently depending on whther they were awake or asleep (Grunau and Craig, 1987). Changes in body movement were also examined. Neonates react to pain with contractions and flexion of arms and legs, trembling, and vigorous motions (Coffmann et al., 1997; Fuller and Conner, 1996). However, such changes may also be influenced by contextual factors.

\subsubsection{Biochemical parameters}

Increased production of cortisol, catecholamine, endorphins, and growth hormones as well as peripheral insulin suppression could be detected in neonates after noxious stimulation (Franck and Miaskowsky, 1997). Although biochemical parameters seem to assess pain in infants very reliably, systematically sampling these parameters to detect pain is difficult to achieve in the clinical setting. To take samples of blood, urine, saliva, and sweat and then to wait for the laboratory is not feasible in the assessment of acute pain. 
Physiological, behavioural and biochemical parameters are important contributors to objective pain measurement. However, there is no certainty that pain has been reliably measured by these parameters because of the inherent problems previously mentioned in each parameter.

\subsection{Pain assessment in neonatology}

The assessment of pain in neonates, which often is performed on a subjective basis, confronts nurses and physicians with a complex task, since pain is a multidimensional phenomenon. Hamers et al. (1994) showed that in paediatrics the child's medical diagnosis has a great influence on the nurses' perception of pain. The more serious the medical diagnosis, the earlier analgesics were administrated. Shapiro's study (1993) revealed that the pain of premature newborns and very ill neonates is often underestimated in practice. A tool for pain evaluation might lead to objectivity concerning the phenomenon of pain, and may also enhance specific pain therapy. Such tools serve to assess pain, while the scoring system helps to evaluate its intensity. A pain assessment tool might also be used to measure the effects of a therapeutic intervention.

Although assessing pain using multidimensional pain scales, which consider physiological, behavioural, and contextual factors, is increasingly gaining in importance, Ballantyne et al. (1999) asserted in their study that none of these scales were valid. Most pain scales were developed for research purposes. The instruments were not tested for use in clinical practice.

The following table presents six multidimensional and two one-dimensional instruments for pain assessment which have been developed for use in the clinical setting of a neonatal intensive care unit. The selection concerns those instruments which have most frequently been described in the literature. The analysis of each instrument identifies the parameter that it investigates, which methods the validation procedure is based on, and conclusions drawn as to the instrument's validity. 
3.2.1 Analyses of the development and validation processes of multidimensional neonatal instruments for pain assessment

Premature Infant Pain Profile (PIPP) Ballantyne et al., 1999

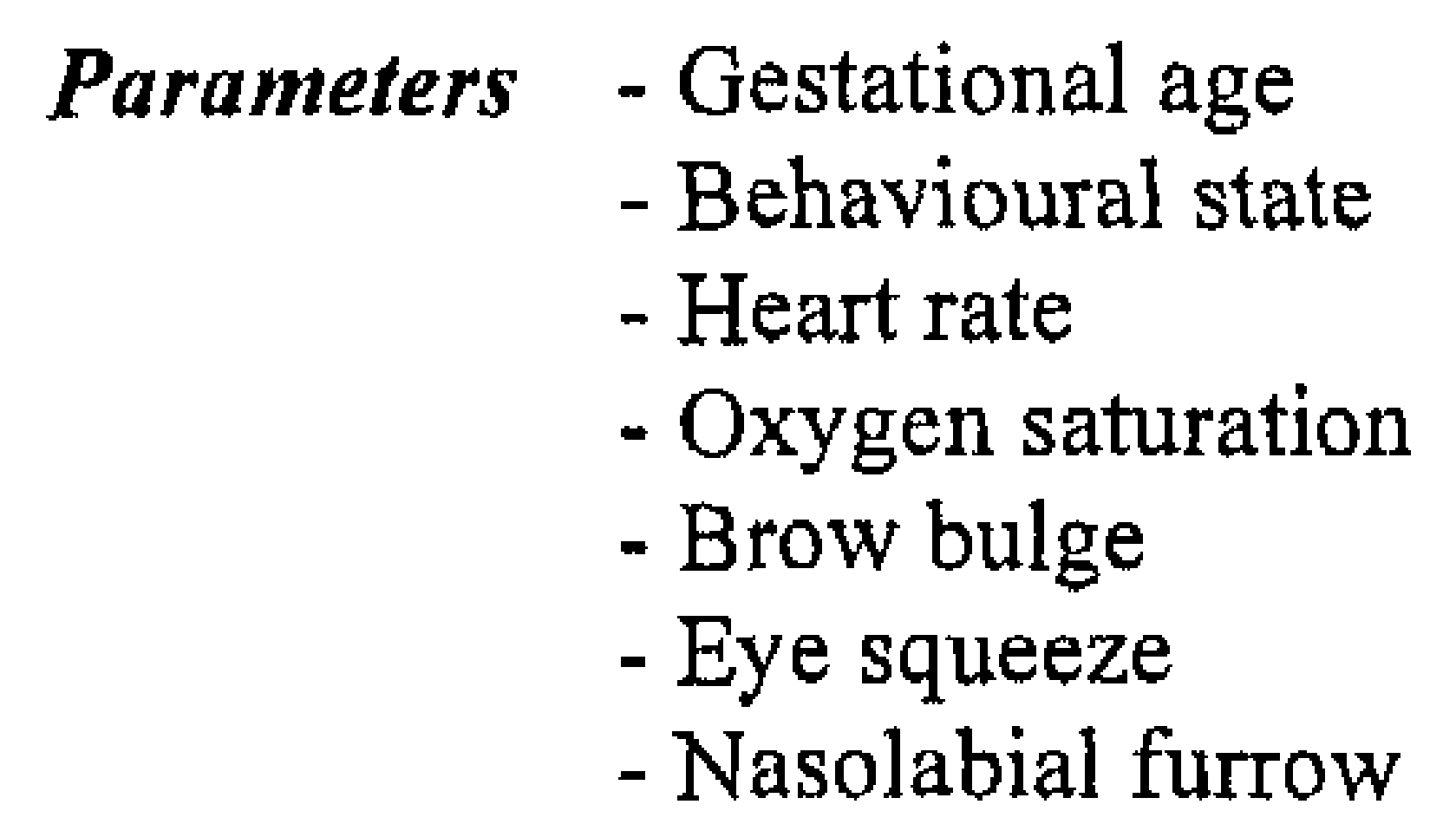

Aim \& Method Aim

Further validation (construct validity) and measurement of the inter- and intra-rater reliability of the instrument in clinical setting.

Design

Randomized cross-over design

Sample

Convenience sample of 43 neonates in a neonatal intensive care unit (NICU), selected according to gestational age.

Measurements

Every child was measured in the following situations. Baseline event: Infant sleeps calmly. Pain-free event: Diaper changing. Painful event: Heel-lancing or insertion of an intravenous cannula. Measurements were done by a nurse and by a nursing expert. Simultaneously a video was recorded, which was rated by two experts via PIPP.

Results \& Significant difference in the Premature Infant Pain Profile - scores (PIPP)

Conclusions between painful event, painfree event and baseline event $(p=<0.001)$ were established. Construct validity of the instrument could be determined.

Interrater reliability

Correlation coefficient $\mathrm{r}=0.93$ to 0.96 .

Intrarater-reliability

Correlation coefficient $r=0.94$ to 0.98 .

Lower pain scores were found in neonates with a gestational age of less than 28 weeks than in neonates between 32 and 36 weeks of gestation. PIPP is claimed to be a valid and reliable instrument for pain assessment in neonates.

Comment Due to the small sample, the question as to whether neonates under 28 weeks react to pain stimuli less significantly than those between 32 and 36 weeks could not be answered conclusively. The authors hypothesized that pain reaction depends on gestational age. The instrument was proven to have good construct validity and reliability. Neonates who were cognitively impaired were not included in the sample. 
Newnatal Facial C'oding Sustem (NFCS) Grunau et al., 1998

Parameters - Behavinural state

- racial action

- Hand movement

- Heart rate

Aim \& Method Aim

Examination of construct and concurrent validity as well as the reliability of the Neonatal Facial Coding System (NFCS) in the clinical setting of a NICU Level III.

Design

Descriptive-explorative study.

Random sample

Convenience sample of 42 neonates between 32 and 33 weeks of gestation with a birth weight of less than $1500 \mathrm{~g}$.

Measurements

Measurements with NFCS were taken before, during and after capillary blood sampling, Sleeping behaviour, facial activity, hand movement and heart rate were measured

Results \& Interrater reliability

Conclusions This study shows the interrater reliability for the single parameter, expressed by Cohen's Kappa: State of behaviour compared to sleep/wake state: $\mathrm{Kappa}=0.67 ;$ Facial action: $\mathrm{Kappa}=0.83 ;$ Hand movement: $\mathrm{Kappa}=$ 0.82 . A significant increase of the heart rate during tactile stimulation $(p=$ $<0.001 \mathrm{y}$. further rise during heel lancing $(p=<0.001)$. Changes in facial action, state of sleep/arousal and hand movement through heel lancing were measurable. During a painful stimulus, there was a high correlation between increasing heart rate and changes in facial action. Lip purse was dropped for being an unspecific indicator of facial action. NFCS was claimed to be applicable and feasible in practice.

Comment By adding the physiological parameter of heart rate, the original onedimensional NFCS instrument became multidimensional and was considered to be a valid instrument for pain assessment. Pain assessment with the NFCS score is time-consuming and requiress intensive training in facial observation and coding 


\section{CRIES Krechel and Bildner, 1995}

Parameters - Crying

- Requires oxygen to maintain saturation greater than $95 \%$

- Increased vital signs

- Expression

- Sleeplessness

\section{Aim \& Method Aim}

Examination of the instrument's validity and reliability

Design

Descriptive-explorative study

Sample

Convenience sample of 24 neonates between 32 weeks of gestation and infants up to the 5th month of life.

Measurements

Each child was evaluated by two nurses every hour concerning postoperative pain for 24 to 72 hours. Three kinds of measurements were applied:

1. Subjective pain assessment by nurses (VAS)

2. Evaluation with the instrument Objective Pain Scale (OPS)

3. Evaluation with CRIES.

Results \& Concurrent validity (subjective and objective measurement)

Conclusions Spearman rank correlation coefficient $r=0.49(p=<0.0001)$.

Convergence validity

Between both instruments CRIES and OPS

Spearman rank correlation coefficient $\mathrm{r}=0.73(\mathrm{p}=<0.0001)$

Construct validity

The rating using CRIES occurred after application of analgesic. The CRIES-score was significantly lower one hour after analgesic therapy than before its administration. This establishes the construct validity of the instrument.

\section{Interrater reliability}

Spearman rank correlation coefficient $r=0.73$ for OPS.

Spearman rank correlation coefficient $r=0.72$ for CRIES.

Comment The instrument is described as valid and reliable from a gestational age of 32 weeks up to 5 th month of life. Convergence validity between CRIES and OPS must be considered with care because the tool OPS was neither developed for nor tested on neonates. CRIES cannot be applied in ventilated neonates, because the crying cannot be measured. In general the nurses accepted CRIES to a great extent. The authors assumed that intubated and ventilated neonates do not feel pain due to sedation. 
Neonatal lnfant Pain Profile (NIPS) Law rence et al., 1992

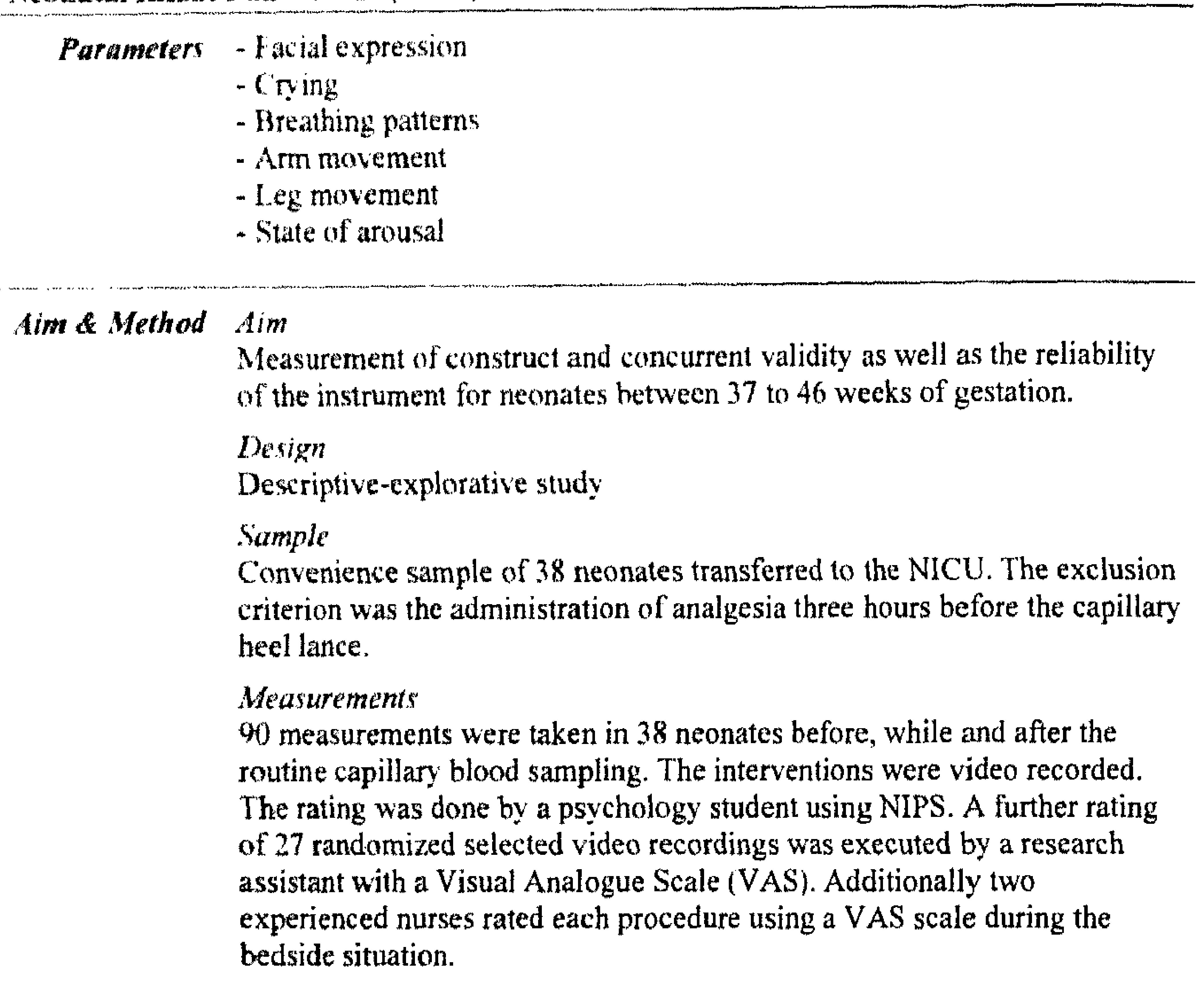

Results \& Interrater reliability

Conclusions Pearson comelation coefficient $\mathrm{r}=0.92$ to 0.97

Concurrent validity (NIPS - VAS)

Pearson correlation coefficient $\mathrm{I}=0.53$ to 0.84

Construct validit

The increase and decrease of pain reactions depended on the time factor (before, while and after the blood sampling) and had a significance of $p=$ $<0.001$. Due to this result the authors assumed that the tool had good validity.

Comment The instrument is regarded as suitable for documenting procedural pain. The instrument has been used for research purposes only. Information about its application in practice is thus missing. 
Distress Scale for Ventilated Newborn Infants (DSVNI) Sparshott, 1996

Parameters - Facial expression

- Body movement

- Skin colour

- Change in heart rate

- Change in blood pressure

- Change in oxygenation

- Difference in temperature

\section{Aim \& Method Aim}

Development of a tool for mechanical ventilated neonates.

Describes the development of parameters, with reference to the "Neonatal

Facial Coding System" (NFCS), the "Neonatal Behavioural Assessment

Scale" (NBAS), the "Assessment of Preterm Infant's Behaviour" (APIB), the "Gustave-Roussy Child Pain Scale" (DEGR) and the "Infant Body Coding System" (IBCS).

Sample

No empirical data available.

Results \& The instrument may be used with intubated neonates of any gestational age

Conclusions and measures physiological and behavioural reactions of ventilated neonates to invasive, procedural pain. On the vertical axis, DSVNI contains a time schedule, on which assessments could be documented at different moments. At least four different assessments were recommended:

(1) Before the intervention

(2) Directly after the end of intervention

(3) After comfort-giving measures or

(4) after the administration of analgesics.

Comment The report is restricted to a description of how the instrument was developed and includes no statement concerning the validity and reliability of the instrument.

Given no scientific report describing the testing of the instrument, it needs scientific validation. 
Bernese Pain Scale for Neonates (BPSN) Dyla and Stoffel, 1996

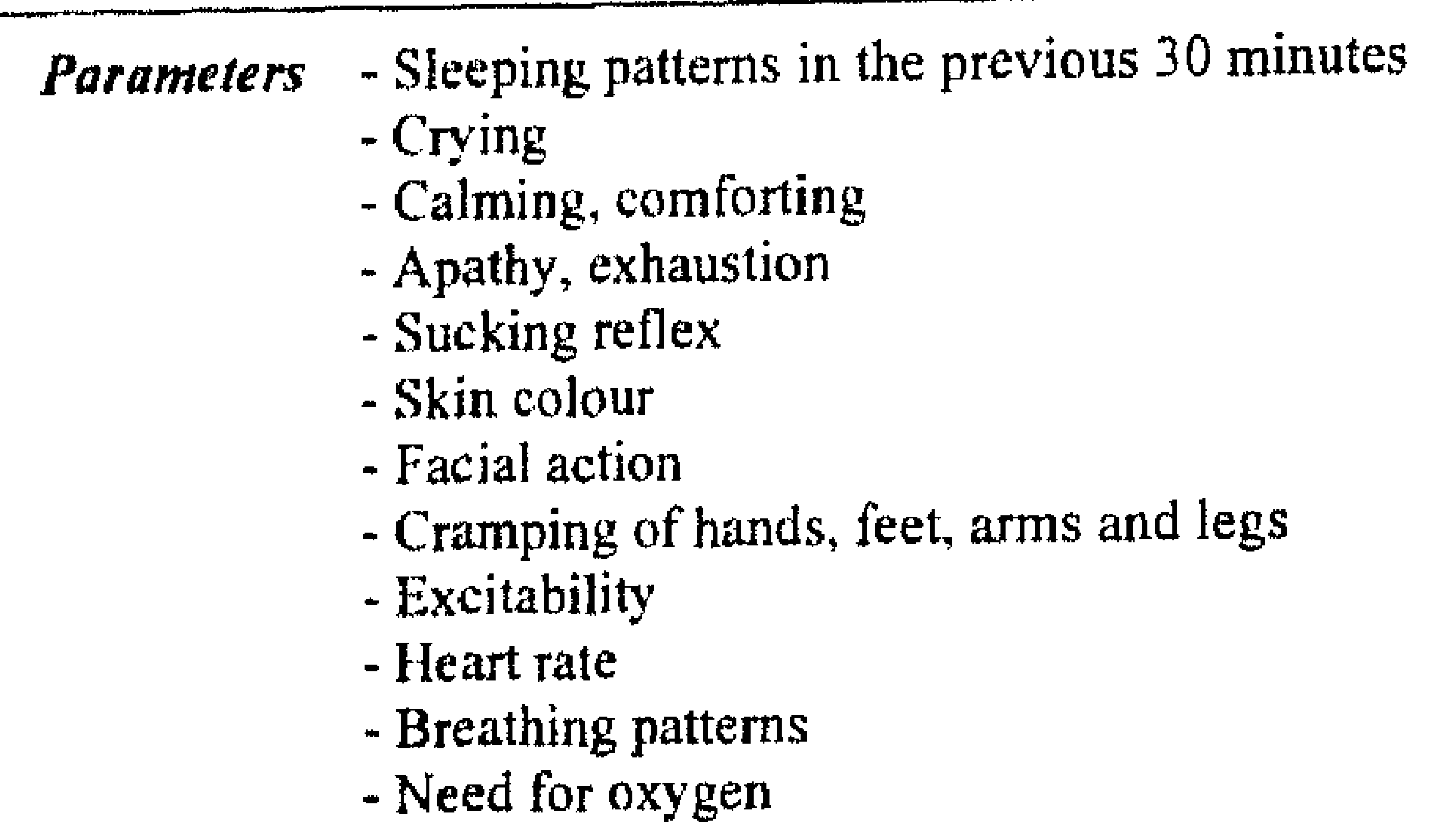

\section{Aim \& Method Aim}

Development of a German-language pain score. The parameters were developed inductively according to nurses' practical experience and an extended literature review.

Sample

Convenience sample of 10 ventilated and non-ventilated neonates between 25 and 31 weeks of gestation.

Measurements

54 independent measurements performed by two NICU nurses.

Results \& No statistical calculations were performed. The results are based on

Conclusions comparative values between the independent ratings.

Interrater Reliability

Scores of independent ratings differ minimally.

Conclusions

The parameters of blood pressure and carbon dioxide are criticized for being too unspecific and are not included in the development of the final score.

This inductively developed instrument was described as helpful and useful by nurses themselves for application in daily clinical practice.

Comment The project describes how the instrument was developed. The aim was to develop an instrument in German for practical use; the instrument requires testing for scientific validity. 
3.2.2 Study reports of validity procedures for one-dimensional neonatal pain assessment instruments

\section{Liverpool Infant Distress Score (LIDS) Horgan and Choonara, 1996}

Parameters - Spontaneous movements

- Spontaneous excitability

- Flexion of fingers and toes

- Tone

- Facial expression

- Crying quality

- Crying quantity

- Sleep pattern/amount

\section{Aim \& Method Aim}

Behaviour assessment of neonates on a surgical unit during a painful state using LIDS scores.

Design

Descriptive-explorative design.

Sample

Convenience sample of 16 neonates. No information about gestational age.

\section{Measurements}

Repeated measurements in pre- and postoperative situations.

Postoperatively the measurements were performed for 48 hours. Pain

reactions were video-recorded pre- and postoperatively. A tape-recorder was used to measure the quality of the crying. Four nurses and one psychologist participated in the assessment.

Results \& Interrater reliability

Conclusions Pearson correlation coefficient $r=0.74$ to 0.88

Intrarater reliability

Pearson correlation coefficient $\mathrm{r}=0.81$ to 0.96

Neonates with severe surgical interventions obtained the highest pain score pre- and postoperatively. No correlation between the severity of the surgical intervention and the perception of pain could be found 24 hours after surgery.

\section{Conclusions}

LIDS seems to be a valid tool for pre- and postoperative situations.

Comment Videos and measurements of the quality of crying using a tape-recorder are unsuitable methods in the daily work of a nurse. LIDS has not yet been validated in the clinical setting yet. 
Kindliche Unbehagens- und Stress-Skala (KUSS) Büttner et al., 1998

\author{
Parameters - Crying \\ - Facial expression \\ - Body tonus \\ - Leg posture \\ - Motor restlessness
}

Aim \& Method Question

Development of a pain monitoring system for infants and children after surgery. Initially the scale was a combination of 9 parameters.

Design

Prospective and controlled multicenter study, which was performed in four hospitals in Germany. Randomized-controlled design. One group received $15 \mathrm{mg} / \mathrm{kg}$ Paracetamol rectally while anaesthesia was administered. The second group received a one-sided blockade of the Nervus ilio-inguinalis and ilio-hypogastricus with a maximum of $2 \mathrm{ml}$ Bupivacain $0.5 \%$ while anaethesia was administered

Sample

139 infants from the age of 5 weeks up to the first birthday who underwent surgery.

Measurements

Blinded raters. The first measurement was done 10 minutes after extubation, further data collection followed every 5 minutes up to one hour.

Results \& Factor analysis was performed. Through discrimination analysis the scale

Conclusions was reduced from 9 to 5 parameters. Internal consistency of the items reached a Cronbach's Alpha Correlation coefficient of $p=0.94$. The KUSS scale is claimed to be a valid instrument for postoperative pain assessment in neonates and infants up to the first year of life. The authors mention that a combination of subjective parameters with physiological parameters and endocrine measurements shows a significantly higher sensitivity for pain assessment in neonates.

Comment Sound validity testing. No information as to whether pain expression differed in the two groups. The one-dimensional aspect of the instrument is criticized by the authors themselves. 


\section{Summary}

Eight tools for pain assessment in neonatology have been analyzed. Among the multidimensional instruments, the validity procedure of the Premature Infant Profile (PIPP) (Ballantyne et al., 1999) was of particular interest since it was tested in the clinical setting. PIPP, which also includes the state of consciousness as an important modifying factor, is the only tool which considers the gestational age as one of the contextual factors. The maximum score for preterm infants is 21 ; for older infants, the maximum score is 18 points. In addition, PIPP was demonstrated to be a most reliable and valid instrument of pain assessment. A highly significant difference was found between an unpainful intervention (diaper changing) and a painful intervention (capillary blood sampling), therefore establishing PIPP's construct validity. PIPP, often used for pain assessment in neonates, is accepted as the most valid multidimensional instrument for preterm and term neonates to date.

Grunau et al., (1998) developed the Neonatal Facial Coding System (NFCS), which measures changes in facial expression as a specific indicator of pain expression. Besides having good interrater reliability, the instrument enables highly accurate differentiation concerning the facial activity of the neonate in pain. This means that activities indicating pain, such as squeezing the eyebrows and eyes, the nasio-labial furrow, vertical twist of the mouth and lip position are rated. Other pain indicators heart rate, hand movement and behavioral factors - are also included. Rating these indicators accurately requires that health care providers are experienced and highly trained. However, doubt as to whether this instrument is applicable in the clinical setting has been raised, because ten parameters for facial activity alone need to be rated.

The tool CRIES of Krechel and Bildner (1995) is designed for pain assessment in the postoperative care of non-ventilated neonates. It measures the quality of neonatal crying (no crying, high-pitched crying, inconsolable crying), transcutaneous oxygen saturation, increase in vital parameters, facial activity, and changes in the rhythm of sleeping and waking. CRIES showed good convergence validity. The tool was tested within a study with preterm and term neonates. The gestational age of the infants ranged from 32 weeks of gestations up to the age of five months. Testing for validity with neonates of lower gestational age has not been performed. The authors critically discuss the application of CRIES in infants with a gestational age less than 32 weeks. Furthermore, in ventilated and sedated neonates, CRIES cannot be used, because crying and facial expression is inhibited in this group.

The "Neonatal Infant Pain Profile" (NIPS), which was developed by Lawrence et al. (1992), documents time periods in minute intervals on a horizontal axis before and after a painful intervention. Significantly higher scores could be detected during heel puncture. NIPS showed high interrater reliability when tested in neonates between the 37 and 46 weeks of gestation, but was not tested in ventilated preterm infants.

The "Distress Scale for Ventilated Newborn Infants" (DSVNI) by Sparshott (1996) was developed for pain assessment in intubated neonates of any gestational age. Unfortunately this instrument lacks scientific evidence.

The Bernese Pain Scale for Neonates (BPSN) (Stoffel and Dyla, 1996) was developed by two nurses on a neonatology ward for application in the clinical setting. Physiological as well as behavioural parameters are considered. During its development, it was tested in neonates between the 25 and 31 weeks of gestation. One disadvantage that should be noted is that, this tool with 12 parameters is difficult to apply in daily clinical practice. It has to be pointed out one disadvantage, as 
this complicates the application in clinical practice. Although the tool lacks a scientific basis, it will be validated in the near future.

It is remarkable that only Ballantyne et al. (1999) studied the measurement of pain in neonates with a gestational age of less than 28 weeks. No other tool was validated for this group of neonates. Here again, the different pain reactions between preterm and term neonates should be noted: Preterm infants display immature motoric abilities, whereby pain reaction is significantly reduced, thus making pain assessment more difficult. Existing pain assessment tools should be only used for the group for which they have been validated. The most reliable instruments for pain are those which allow measuring the phenomenon in a multidimensional way. Various studies postulate the consideration of contextual factors like gestational age or illness in order to interpret pain reactions more accurately. With the exception of the PIPP, none of the existing instruments considers this important indicator.

The present review is limited to two one-dimensional instruments: The "Liverpool Infant Distress Score" (LIDS) developed by Horgan and Choonara (1996) and the "Kindlichen Unbehagensund Schmerzskala" (KUSS) developed by Büttner et al. (1998). LIDS has not yet been validated for application in clinical practice. KUSS, tested on infants from the 45 weeks of gestation up to the first year of life, is a valid and reliable instrument for the assessment of postoperative pain. According to the authors, contextual factors must be considered while applying KUSS. The tool cannot be used for pain assessment in sedated or neurologically and cognitively impaired children. Although the authors claim that this instrument assesses pain in neonates, the proof of validity for this group is lacking.

Melke (1998) states that acute pain, e.g. during heel lance, is actually of primary interest in pain research. Therefore, testing for the validity of physiological and behavioural pain parameters is mainly focussed on acute and short-term pain. Philips (1995) found that infants suffering from chronic pain could be limited in their pain expression due to exhaustion caused by the disconcerting high number of interventions during intensive care. During long lasting pain, pain parameters became weaker and their assessment, more and more difficult (Philips, 1995). To date, no reliable parameters to assess chronic pain have been developed.

\section{Conclusions}

Pain assessment and the treatment of pain are significant factors for the improvement of the well-being and unimpeded growth of infants in neonatal intensive care. However, there is no gold standard for pain assessment in neonates to date. The instrument Premature Infant Pain Profile (PIPP) measures the pain of preterm neonates up to the 28 weeks of gestation and seems to be one of the most valid and reliable instruments for this patient population to date. The other tools for pain assessment described in this review are not valid for infants with a gestational age lower than 32 weeks. None of the tools considers the severity of illness as a further influencing factor.

Most of the instruments were developed for research purposes, except for the Premature Infant Pain Profile (PIPP), the "Kindliche Unbehagens und Schmerz Skala" (KUSS) and the Bernese Pain Scale for Neonates (BPSN), which needs to be tested for validity. Therefore, nurses and doctors still face the problem of using validated instruments which have not been tested for their applicability and utility in daily clinical practice.

Furthermore, the existing multidimensional instruments are only validated for acute pain. No report was found considering the assessment of chronic pain caused, for example, by a thoracic drain or during mechanical ventilation. To date, no instrument has been validated for chronic pain, severe illness or cognitive impairment in neonates. 
Due to nurses' continuous contact with the neonates, they play an important role in pain assessment. Pain therapy depends on the use of a valid and reliable pain assessment tool as well as on the ability of nurses and physicians to interpret the reactions of pain in the neonate. Today, nurses and physicians are often confronted with the difficulty of defending their subjective pain assessment, because they do not consistently work with valid pain assessment tools.

"A central goal of nursing is to provide comfort. The nurse must have tools for defending her judgement in requesting medication."

(Lawrence et al., 1992, 60) 


\section{References}

Abu-Saad H, Bours G, Stevens B, Hamers J. Assessment of pain in the neonate. Semin Perinatol 1998; 22:402-416.

Anand $\mathrm{K}$, Carr D. The Neuroanatomy, neurophysiology and neurochemistry of pain stress and analgesia in newborn and children. Pediatr Clin North Am 1989; 36:795-822.

Anand K, Phil D, Hickey P. Pain and its effects on the human neonate and fetus. N Engl J Med 1987; 317:1321-1329.

Ballantyne M, Stevens B, Mc Allister M, Dionne K, Jack A. Validation of the premature infant's pain profile in the clinical setting. Clin J Pain 1999; 15:297-303.

Büttner W, Finke W, Hilleke M, Reckert S, Vsianka L, Brambrink A. Entwicklung eines Fremdbeobachtungsbogens zur Beurteilung des postoperativen Schmerzes bei Säuglingen. Anästhesiol Intensivmed Notfallmed Schmerzther 1998; 33:353-361.

Coffman S, Alvarez Y, Pyngoil M, Petit R, Hall C, Smyth M. Nursing assessment and management of pain in critically ill children. Heart and Lung 1997; 26:221-228.

Craig K, Whitfield $M$, Grunau R, Linton J, Hadjistavropoulos $H$. Pain in the preterm neonate: behavioural and physiological indices. Pain 1993; 52:287-299.

Dyla B, Stoffel L. Schmerzen auf der neonatologischen Intensivstation. Frauenklinik Inselspital Bern. 1996, unpublished manuscript.

Franck L, Miaskowski Ch. Measurement of neonatal responses to painful stimuli: A research review. J Pain Symptom Manage 1997; 14:343-378.

Fuller B, Conner D. Distribution of cues across assessed levels of infant pain. Clin Nur Res 1996; 5:167-184.

Grunau R, Craig K. Pain expression in neonates: facial action and cry. Pain 1987; 28:395-410.

Grunau R, Oberlander T, Holsti L, Whitfield M. Bedside application of the neonatal facial coding system in pain assessment of premature neonates. Pain 1998; 76:277-286.

Hamers J, Abu-Saad H, Halfens R, Schuhmacher J. Factors influencing nurses pain assessment and interventions in children. J Adv Nurs 1994; 20: 853-860.

Horgan M, Choonara I. Measuring pain in neonates: An objective score. Paediatr Nurs 1996; $8(10): 24-27$.

Johnston C, Stevens B, Ynag F, Horton L. Differential response to pain by very premature neonates. Pain 1995; 65: 471-479. 
Krechel S, Bildner J. CRIES: a new neonatal postoperative pain measurement score. Initial testing of validity and reliability. Paediatric Anesthesia 1995; 5:53-61.

Lawrence J, Alcock D, McGrath P, Kay J, Mac Murray S, Dulberg C. The development of a tool to assess neonatal pain. Neonatal Netw 1992; 12: 59-67.

Melke M. Schmerzwahmehmung in der Neonatologie durch Pflegende: Ein Überblick über die Situation. Diplomarbeit des Fachbereichs "Pflege und Gesundheit" der Fachhochschule Frankfurt am Main 1998 (unpublished manuscript).

Philips P. Neonatal pain management: A call to action. Pediatric Nurs 1995; 21:195-199.

Pigeon H, McGrath P, Lawrence J, Brock Mac Murray S. Nurses perception of pain in the neonatal intensive care unit. J Pain Symptom Manage 1989; 4:195-199.

Shapiro C. Nurses judgements of pain in term and preterm newborns. JOGNN 1993; 22: 41-47.

Sheeran M. Pain in infants: A literature review. J Neonat Nurs 1997; 13-18.

Soetenga D, Pellino T, Frank J. Assessment of the validity and reliability of the University of Wisconsin Children's Hospital Pain Scale for preverbal and nonverbal children. Pediatric Nurs $1999 ; 25: 670-676$.

Sparshott, M.: The development of a clinical distress scale for ventilated newborn infants: Identification of pain and distress based on validated behavioural scores. J Neonat Nurs 1996: 5-10.

Stevens B, Johnston C, Horton L. Multidimensional pain assessment in premature neonates: A pilot study, JOGNN 1993; 22:531-541.

Stevens B, Johnston C, Grunau R. Issues of assessment of pain and discomfort in neonates. JOGNN $1995 ; 24: 849-855$.

Stevens B, Franck L. Special needs of preterm infants in the management of pain and discomfort. JOGNN 1995; 24:857-863. 


\section{CHAPTER 3}

PAIN ASSESSMENT IN THE NEONATE USING

THE BERNESE PAIN SCALE FOR NEONATES

Cignacco E, Gessler P, Müller R, Hamers JPH

Published in Early Human Development 2004, Vol 78 (2):125-131.

Modified version 


\section{Abstract}

Background: Nernates who require treatment in the neonatal intensive care unit (NICU) are subjected to many invasive painful procedures. Assessment of pain in preterm and term neonates with or without ventilation on continuous positive airway pressure is challenging. The development of a valid and feasible tool in the clinical setting is a precondition for adequate pain assessment and pain treatment.

Aims: To establish the validity and the reliability of the Bernese Pain Scale for Neonates (BPSN).

Study design and subjects: Pain assessments $(n=288)$ were performed by 6 health care workers in different situations of term and preterm neonates. Each neonate $(n=12)$ was observed in four given situations (after feeding, while a foot was being warmed, while a routine capillary blood sample was taken and 15 minutes after the blood sample was taken). Pain assessments were made by two nurses at the bedside using the BPSN, the Visual-Analogue Scale (VAS) and the Premature Infant Pain Profile (PIPP). At the same time, a video sequence was made which was shown later to four different nurses to assess pain using the BPSN, the PIPP, and the VAS.

Results: The construct validity of the BPSN was very good $(F=41.3 ; p=<0.0001)$. Moreover, concurrent and convergent validity of the BPSN compared to VAS and PIPP was $r=0.86$, and $r=$ $0.91 . p=<0.0001$, respectively. Finally, the study demonstrated high coefficients for interrater $(r=$ $0.86-0.97)$ and intrarater reliability $(r=0.98-0.99)$.

Conclusion: The BPSN was shown to be a valid and reliable tool for assessing pain in term and preterm neonates with and without ventilation on continuous positive airway pressure.

Key words: Pain assessment, neonates, prematurity, ventilation. 


\section{Introduction}

Neonates who are treated in the neonatal intensive care unit are subjected to a variety of painful procedures. The exposure to pain in preterm neonates during a critical time of brain development may have adverse consequences (Anand and Hickey, 1987; Bhutta and Anand, 2003; Grunau, 2002). In particular, repeated painful stimuli have been suggested to result in structural and functional reorganization of the nervous system, altering future pain responses (Anand and Scalzo, 2000; Grunau et al., 2001). Because neonates cannot verbalize their pain, they depend on others to recognize, assess, and manage their pain (American Academy of Pediatrics and Canadian Paediatric Socienty, 2000; Craig, 2002). Pain assessment in neonates is mostly based on physiological and behavioral factors. Moreover, information concerning the gestational age and the health status of the infant as well as contextual factors such as conditions likely to instigate other forms of distress (eg, fatigue, hunger) or the use of drugs, are also important, since they can influence reactions to pain (Craig, 2002; Stevens and Franck, 1995). The infant's ability to express pain has to be taken into account, ie a neonate who is intubated for mechanical ventilation cannot cry and facial expressions may be reduced by tapes used to fix the tube.

Several validated and reliable pain measures exist to assess acute pain in term and preterm neonates (Abu-Saad et al., 1998). However, there is a paucity of measures to evaluate pain in very low birth weight neonates or those who require mechanical ventilation (Ballantyne et al., 1999; Grunau et al., 1998; Sparshott, 1996). Moreover, the majority of these pain measures have been developed and used primarily for research purposes. For a measure to be clinically useful or possess clinical utility, it must evolve toward high levels of acceptability and convenience for those who use it (Stevens and Gibbins, 2002). The Bernese Pain-Scale for Neonates (BPSN) has been developed by the nurses of the NICU of the University Hospital of Berne and takes into account 9 parameters, both objective and subjective parameters. The aim of the present study was to determine the validity and reliability of the BPSN in term and preterm neonates without ventilation and in those with ventilation on continuous positive airway pressure (CPAP) using nasal prongs.

\section{Methods}

The study was approved by the local ethical board. Informed written consent was obtained from the parents. Capillary blood samples were only taken as part of routine clinical care. The studied population included 12 neonates (Table 3-1). According to their gestational age, they were divided into two groups. Only neonates who a) had not been given any sedative or analgesic drugs at the time when pain assessment was carried out, b) had no ultrasonographic signs of intraventricular bleeding, $c$ ) showed no signs of serious, life-threatening malformation, d) were not suffering from any condition involving hyposensitivity or total loss of sensitivity, and e) had not undergone any type of operation, were included. 
Table 3-1: Characteristics of the study population

\begin{tabular}{|c|c|c|}
\hline Gestational age & 32 to 41 week and 1 day & 27 to 31 weeks and 6 days \\
\hline Number & 6 & 6 \\
\hline Gender: male (female) & $3(3)$ & $1(5)$ \\
\hline Age at observation (days) & $4.6+1.2$ & $4.3 \pm 1.5$ \\
\hline Weight $(\mathrm{g})$ & $2649+996$ & $1076 \pm 271$ \\
\hline $\begin{array}{l}\text { Continuous positive airway } \\
\text { pressure (n) }\end{array}$ & 0 & 4 \\
\hline
\end{tabular}

The following situations were assessed: 1) 10 minutes after feeding (baseline), 2) warming of the foot with a warm towel (contact). 3) capillary blood sample from the heel (lance), and 4) 15 minutes after the blood sample has been taken (post). Assessment of the situations was done by two nurses at the bedside. In addition. video sequences were made $(n=48)$ in different situations, which were assessed by four different nurses. Thus. a total of $n=288$ analyses were performed. The situations were analyzed using three tools: the BPSN, PIPP and the VAS. The BPSN consists of 7 subjective (clinically observable) and 2 objective indicators (monitoring of heart rate and oxygen saturation). Each indicator is rated on a 4-point scale $(0,1,2,3)$ for a possible total score of 27 . The subjective indicators include alertness, duration of crying, time to calm, skin color, and eyebrow bulge with eye squeeze, posture, and breathing pattern. Alertness was defined as $0=$ sleep or quiet awake, 1 $=$ drowsy, $2=$ active awake. and $3=$ highly aroused and agitated. Duration of crying was classified into $0=$ no cry, $1=$ crying less than 2 minutes, 2 = crying more than 2 minutes, and $3=$ shrill crying more than 2 minutes. Time to calm was arranged accordingly into $0=$ no calm, $1=$ calm less than 1 minute, 2 = more than 1 minute, and $3=$ more than 2 minutes. Skin color was divided between pink (0) to mottled grey (3). Facial activity and posture was graded from relaxed to agitated. Breathing was arranged from normal to tachypnea with retractions. The objective indicators include changes of heart rate and transcutaneous measured oxygen saturation. All indicators were precisely written in a manual in German language and all raters were instructed in the use of the BPSN before the study evaluation. The PIPP has been selected because of its well established psychometric properties in the study carried out by Ballantyne et al. (1999). The VAS is a subjective self-report tool often used in research applications. The sequence of the three different tools was randomized.

The video sequences $(n=48)$ were shown in such a way that the raters were unaware of the respective situation. For each infant in each situation, one leg was masked, so that no manipulation of the infant could be seen. First, four nurses took part in the first video rating (nurses \# 3, \# 4, \# ,\# 6). They watched the video sequences and after each sequence, they used the three scales to assess the pain experienced by the neonates. The four nurses were supervised to ensure that they did not consult each other. Second, to determine the intrarater reliability, randomly selected video sequences $(n=24)$ were shown again to the same nurses (\# 3, \# 4, \# , \#6) after a time interval of 14 days after the first assessment.

\section{Data analysis}

Statistics were performed using SPSS 10.5 statistical package. Unless otherwise stated, numerical results are presented as means $\pm S D$. Tests of normality of distribution took place. Two-tailed tests were used for all statistical comparisons. Statistical significance was defined as a $p$ value of $<0.05$. In order to determine construct validity, the BPSN, PIPP and VAS scores for each neonate in each 
situation were subjected to variance analysis (repeated measurement in the general linear model), the situations and the raters being taken into account as "within-subjects factors". With regard to interrater and intrarater reliability (comparison of the different raters), Cronbach's Alpha reliability coefficient was used for the correlation calculations. The same procedure was used to compare the different tools.

\subsection{Results}

Validity of the BPSN

Construct validity was calculated using data of the video analyses (Figure 3-1).

Figure 3-1: Assessment of pain with the BPSN (mean \pm SD).

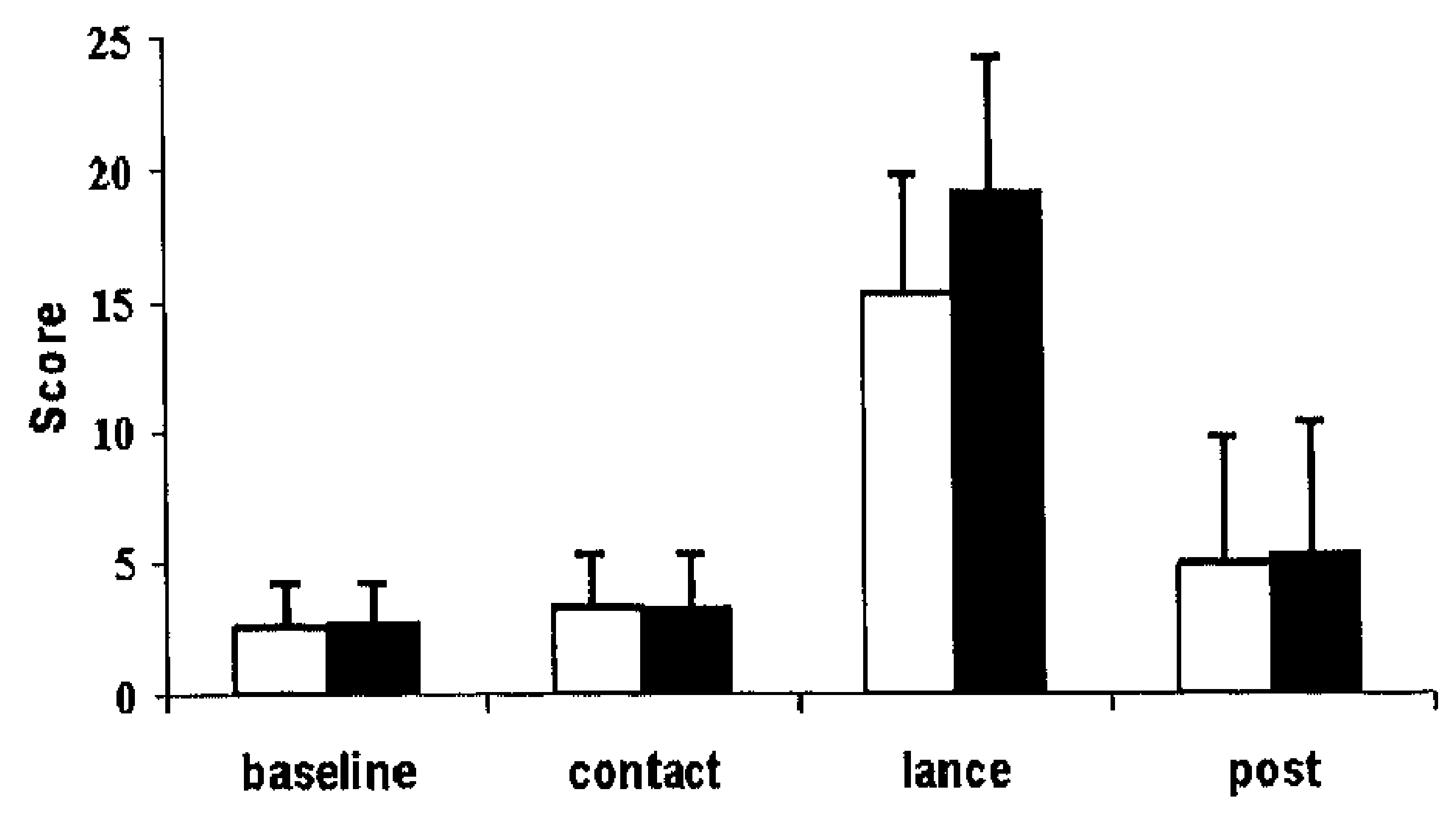

Subjective indicators (white boxes), $F=34.4 ; p=<0.0001$.

Subjective and objective indicators (black boxes), $F=41.3 ; p<0.0001$.

The difference between the situations was highly significant $(F=41.3 ; p=<0.0001)$. Taking into account only the subjective indicators, there was a statistically significant difference, too $(\mathrm{F}=$ $34.4 ; \mathrm{p}=<0.0001)$. According to these results, the BPSN may be divided into two groups with the following characters: group 'pain' (15.96 $\pm 5.7,95 \%$ confidence interval 12.7 to 19.2$)$ or group 'no pain' $(2.32 \pm 1.6,95 \%$ confidence interval -0.8 to 5.4$)$. With respect to the subjective indicators only, there still was a very good separation of the two groups ('pain' $12.7 \pm 1.3,95 \%$ confidence interval 10.1 to 15.3 , and 'no pain' $2.3 \pm 1.3,95 \%$ confidence interval 0.3 to 5.1 , respectively).

In order to determine the concurrent validity of the BPSN, a comparison to the VAS was made. There was a good correlation between the two scales (Cronbach's Alpha $r=0.855, p=$ $<0.0001)$. Convergent validity was determined by comparing the BPSN and the PIPP score $(r=0.907$, $\mathrm{p}=<0.0001)$.

\section{Reliability of the BPSN}

The correlation of the assessments between the different nurses, i.e. interrater reliability, was calculated for each of the four situations (Table 3-2). 
Table 3-2: Interrater reliability

\begin{tabular}{lcc}
\hline Situation & $\begin{array}{c}\text { subjective and objective } \\
\text { indicators }(\mathbf{n}=9)\end{array}$ & $\begin{array}{c}\text { subjective indicators } \\
(\mathbf{n}=7)\end{array}$ \\
\hline Baseline & 0.8661 & 0.7698 \\
\hline Contact & 0.9232 & 0.8970 \\
\hline Lance & 0.9792 & 0.9627 \\
\hline Post & 0.9724 & 0.9656 \\
\hline
\end{tabular}

The results of the pain assessments using the BPSN did not vary over time, i.e. intrarater was very good (Table 3-3).

Table 3-3: Intrarater reliability of raters \# 3 to \# 6

\begin{tabular}{lcc}
\hline Rater & $\begin{array}{c}\text { subjective and objective } \\
\text { indicators }(\mathbf{n}=9)\end{array}$ & $\begin{array}{c}\text { subjective indicators } \\
(\mathbf{n}=7)\end{array}$ \\
\hline$\# 3$ & 0.986 & 0.976 \\
\hline$\# 4$ & 0.989 & 0.984 \\
\hline$\# 5$ & 0.976 & 0.956 \\
\hline$\# 6$ & 0.991 & 0.983 \\
\hline
\end{tabular}

Furthermore, no statistically significant differences could be detected when comparing the results between the assessments of pain at bedside with those of the video ratings (Table 3-4).

Table 3-4: Comparison between bedside rating and video rating

\begin{tabular}{lcc}
\hline Situations & F-value & p-value \\
\hline Baseline & 1.986 & 0.115 \\
\hline Contact & 0.802 & 0.531 \\
\hline Lance & 0.461 & 0.764 \\
\hline Post & 2.163 & 0.091 \\
\hline
\end{tabular}

\section{Gestational age and ventilation}

Pain expression in neonates with a gestational age between 27 to 32 weeks was statistically not signficant different from those with a gestational age between 32 to 41 weeks. The same was true for neonates with and without ventilation on continuous positive airway pressure.

\section{Discussion}

Construct and convergent validity of the BPSN was demonstrated. In contrast to the subjective overall assessment, the BPSN demand a clearly differentiated assessment of the pain response in the neonate using various subjective and objective indicators. Knowing that intrapersonal factors, knowledge and experience in practice sometimes contribute to false pain assessments (Hamers et al., 1998; 1996), the use of an objective tool considering different indicators of pain will improve nurse's pain assessments. Therefore, the use of the BPSN is recommended, especially to found the decision-making regarding to the use of pain medication or other pain relieving interventions. 
The BPSN defines subjective and objective indicators for the assessment of pain. Interestingly, taking into account only the subjective indicators, the discrimination between the two states 'pain' and 'no pain' still was very good. For clinical use outside of the NICU, this may be important since measurement of the heart rate or the change of oxygen saturation used in the BPSN requires some technical equipment. However, for the use in the NICU, both subjective and objective indicators should be used because intensive care medicine may interfere with the assessment of pain. Subjective indicators may be influenced by the child's disease severity and physiological indicators may be influenced by drugs (Craig, 2002, Abu-Saad et al., 1998, Hadjistravropoulos et al., 1997).

Facial actions used as indicators of pain include brow lowering, eyes squeezed shut, deepening of the naso-labial furrow, open lips, vertical mouth stretch, taut tongue, chin quiver, lip purse, and tongue protrusion (Grunau et al., 1998, Oberlander and Saul, 2002). However, in neonates with mechanical ventilation, most of these signs may be influenced by the tubes or by the tapes used to fix the tubes. CPAP ventilation using nasal prongs is a common mode of ventilation in neonates. Although the mode of fixation of the tubes may vary, there is no doubt about, that some of the facial actions may be influenced. Therefore, the BPSN consists of two facial actions only: eyebrow bulge with eye squeeze summarized as one subjective indicator. Indeed, no difference could be detected between the pain expression in neonates with and without CPAP ventilation. It should be mentioned that the infant's crying is possible during CPAP ventilation. Thus in contrast to most other pain scales, the BPSN seems to be a valid tool for the assessment of pain in preterm neonates with ventilation on continuous positive airway pressure.

Premature infants have been shown to be capable of a multidimensional differential response to pain (Craig et al., 1993). The assessment of pain with the BPSN allows for the discrimination between 'pain' and 'no pain' in neonates with gestational age between 27 and 41 weeks. Since pain expression in premature neonates was well documented during the study irrespective of gestational age, there seems to be convincing evidence to use the BPSN in even more premature neonates.

Optimal pain control requires an understanding not only of the infant's pain, but also how observers attend to and interpret the infant's reaction and decide to use appropriate interventions for the child (Craig, 2002; Johnston et al., 1995). Indeed, the assessment of pain may be influenced by disease severity or gestational age of the neonates (Shapiro, 1993). Calculation of inter- and intrarater reliability demonstrates that the BPSN has a good consistency and repeatability. Since this pain measure was created by nurses, the BPSN proved a high level of acceptance and convenience during the study period (Stevens and Gibbins, 2002).

An important shortcoming of the study is the lack of enrollment of seriously ill neonates who require intubation and mechanical ventilation. However, after the validation of the BPSN has been fulfilled, this will be done in a further study.

In conclusion, the BPSN is a valid and reliable pain measure to assess acute pain in term and preterm neonates with and without CPAP ventilation. The tool seems to be of practical utility and is recommendes to be used for bedside pain assessment in NICUs. 


\section{References}

Abu-Saad HH, Bours GJJW, Stevens B, Hamers JPH. Assessment of pain in the neonate. Semin Perinatol 1998; 22:402-416.

American Academy of Pediatrics \& Canadian Paediatric Society. Prevention and management of pain and stress in the neonate. Pediatrics $2000 ; 15: 454-461$.

Anand KJS. Hickey PR. Pain and its effects in the human neonate and fetus. N Engl J Med 1987:317:1321-1329.

Anand KJS. Scalzo FM. Can adverse neonatal experiences alter brain development and subsequent behavior? Biol Neonate 2000; 77:69-82.

Ballantyne M. Stevens B. Mc Allister M, Dionne K, Jack A. Validation of the premature infant pain profile in the clinical setting. Clin J Pain 1999; 15:297-303.

Bhutta AT, Anand KJS. Vulnerability of the developing brain: Neuronal Mechanisms. Clin Perinatol 2002:29:357-372.

Craig KD. Challenges of judging pain in vulnerable infants. Clin Perinatol 2002; 29:445-457.

Craig K. Whitfield M. Grunau R. Linton J. Hadjistavropoulos H. Pain in the preterm neonate: behavioral and physiological indices. Pain 1993; 52:287-299.

Grunau RE. Early pain in preterm infants: A model of long-term effects. Clin Perinatol 2002; 29:373-394.

Grunau RE, Oberlander T, Whitfield M, Fitzgerald $C$, Lee S. Demographic and therapeutic determinants of pain reactivity in very low birth weight neonates at 32 weeks" postconceptional age. Pediatrics 2001; 107:105-112.

Grunau RE, Oberlander T, Holsti L, Whitfield MF. Bedside application of the neonatal facial coding system in pain assessment of premature neonates. Pain 1998; 76:277-286.

Hadjistravropoulos HD, Craig KD, Grunau RE, Whitfield MF. Judging pain in infants: behavioral, contextual, and developmental determinants. Pain 1997; 73:319-324.

Hamers JPH, Abu-Saad HH, van den Hout MA, Halfens RJ, Kester AD. The influence of children's vocal expression, age, medical diagnosis and information obtained from parents on nurses' pain assessments and decisions regarding interventions. Pain 1996; 65:53-61.

Hamers JPH, Abu-Saad HH, van den Hout MA, Halfens RJ. Are children given insufficient painrelieving medication postoperatively? J Adv Nurs 1998; 27:37-44.

Johnston CC, Stevens BJ, Yang F, Horton L. Differential response to pain by very premature neonates. Pain 1995: 61:471-479. 
Oberlander T, Saul JP. Methodological considerations for the use of heart rate variability as a measure of pain reactivity in vulnerable infants. Clin Perinatol 2002; 29:427-444.

Price DD, Bush FM, Long S, Harkins SW. A comparison of pain measurement characteristics of mechanical visual analogue and simple numerical rating scales. Pain 1994, 56:217-226.

Shapiro C. Nurses' judgements of pain in term and preterm newborns. J Obstet Gynecol Neonatal Nurs 1993; 22:41-47.

Sparshott MM. The development of a clinical distress scale for ventilated newborn infants: identification of pain and distress based on validated behavioral scores. J Neonatal Nurs 1996; 2:5-11.

Stevens B, Franck L. Special needs of preterm infants in the management of pain and discomfort. J Obstet Gynecol Neonatal Nurs 1995; 24:857-863.

Stevens B, Gibbins S. Clinical utility and clinical significance in the assessment and management of pain in vulnerable infants. Clin Perinatol 2002; 29:459-468. 


\title{
CHAPTER 4
}

\author{
FACTORS INFLUENCING
}

THE SUBJECTIVE ASSESSMENT OF

PROCEDURAL PAIN IN NICUS

Cignacco E, Hamers JPH, Stoffel L, van Lingen RA, Schütz N, Müller R, Zimmermann LJI Nelle M 


\begin{abstract}
Background: Pain associated with routine procedures in NICUs is often inadequately managed. Barriers to mote appropriate pain management are related to nurses' and physicians' knowledge and the challenges of collaborative decision-making. Few studies describe differing perceptions of procedural pain intensity among nurses and physicians in NICUs, which could lead to difficult common decision-making.
\end{abstract}

Aims: To explore the factors influencing pain intensity assessment and to gain insight into a possible pain intensity categorization of routine procedures in a NICU.

Method: A survey was conducted involving 431 neonatal health care professionals from 4 tertiary level NICUs. Each routine procedure was assessed on a 10-point Visual Analogue-Scale (VAS) assuming the absence of analgesia.

Results: A MANOVA showed that nurses significantly rated the procedures as being more painful than did physicians $(p=<0.05$ ). There was no difference in pain assessment according to professional experience. gender or age. Of the procedures listed $70 \%$ were rated as being painful and $44 \%$ were judged very painful. A ranking and categorization of the pain intensity of routine procedures was delineated. The general ranking of the median across all procedures shows that the "insertion of a thoracic drain" is assessed as the most painful procedure.

Conclusions: The majority of routine procedures in a NICU are considered to be painful. Nurses generally rate almost all procedures as more painful than do physicians. This difference in assessment deserves exploration in terms of its impact on collaborative decision-making in neonate pain management. 


\section{Introduction}

In the last decade the nature and frequency of procedural pain has been actively explored (Carbajal et al., 2006; Simons et al., 2003; Benis and Suresh, 2001; Porter and Anand, 1998; Johnston et al. 1997; Barker and Rutter, 1995) pain assessment tools have been developed and validated (Hummel and van Dijk, 2006; Duhn and Medves, 2004; van Dijk et al., 2004; Stevens and Franck, 2001; Franck et al., 2000; Stevens et al., 2000; Franck and Miaskowski 1997) and pain relieving interventions systematically evaluated (Ohlsson et al., 2000, Taddio et al., 2002; Carbajal et al., 2005, Anand et al., 2001; 2004; Cignacco et al., 2007). Today there is sufficient evidence that repetitive pain is harmful in newborns with possible short and long term consequences (Table 4-1). Therefore, pain management and strategies for stress reduction are central issues in neonatal intensive care. Despite these advances in neonatal pain management and the increased awareness among health care providers regarding the consequences of early pain exposure of neonates there is evidence that such pain is not adequately managed (Walker, 2005; Simons et al., 2003; Sabrine and Sinha, 2000; Stevens et al., 2003) due to different influencing factors. The importance placed on pain management by researchers seems not to be reflected in practice.

Table 4-1: Possible short and long term consequences of pain exposure in humans

\begin{tabular}{|c|c|}
\hline Short term consequences & Long term consequences \\
\hline $\begin{array}{l}\text { Specific hemodynamic reactions in the } \\
\text { somatosensory cortex with significant rise } \\
\text { in HBO2 (Bartocci et al., 2006) }\end{array}$ & $\begin{array}{l}\text { Acitivity - induced changes in the functioning } \\
\text { of pain pathways that persist beyond infancy in } \\
\text { former preterm infants at the age of } 9-14 \text { years } \\
\text { (Hermann et al., 2006) }\end{array}$ \\
\hline $\begin{array}{l}\text { Lower cortisol response to stress and lower } \\
\text { facial reactivity to pain at } 32 \text { weeks post } \\
\text { conceptional age among infants born < or } \\
28 \text { weeks (Grunau et al., 2005) }\end{array}$ & $\begin{array}{l}\text { Increased need of fentanyl and morphine as well } \\
\text { as significantly higher pain values in infants } \\
\text { who have already experienced operative } \\
\text { interventions as neonates (Peters et al., 2005) }\end{array}$ \\
\hline $\begin{array}{l}\text { Transient loss of the brain-blood-volume } \\
\text { from } 20 \% \text { to } 50 \% \text { (Grunau, 2002) }\end{array}$ & $\begin{array}{l}\text { Negative hospital experiences, as evidenced by } \\
\text { higher number of major surgical procedures } \\
\text { andlonger stays in the NICU evoqued greater } \\
\text { facial pain expression at the age of } 14 \text { months } \\
\text { (Peters et al., 2003) }\end{array}$ \\
\hline $\begin{array}{l}\text { Reduction of cerebral perfusion for a } \\
\text { period of 5-60 seconds (Grunau, 2002) }\end{array}$ & $\begin{array}{l}\text { Former preterm infants had significantly more } \\
\text { tender points and lower tender thresholds at } 12 \\
-18 \text { years of age than former term born infants } \\
\text { (Buskila et al., 2003) }\end{array}$ \\
\hline
\end{tabular}


Higher sensitivity to cutaneous stimuli of infants following surgery, not only in the wound area but also on the contralateral. intact side of the abdomen (Andrews and Fitzgerald. 20021

Alteration of autonomic pain reactivity imimicry and heart rate where associated with a greater number of previous invasive procedures in very low birth weight neonates at 32 weeks postconceptional age (Grunau et al., 2001)

Reduction of behavioural indicators the longer the neonate is exposed to pain (Johnston and Stevens, 1996)
Cognitive limitations of learning and behavioural consequences (more fear during surgery in infancy as well as signs of posttraumatic stress disorders) (Rennick et al., 2002)

Subtle alterations (parasympathetic, sympathetic and initial behavioural reactions) to acute pain reactivity at 4 month in former low birth weight infants (Oberlander et al., 2000)

Stress reaction with production of catecholamine. hypertension and hypoxemia (Barker and Rutter. 1995)

\subsection{Factors influencing pain management}

There is evidence that pain is generally not appropriately managed in acute care institutions (Brockopp et al., 2004; 1998). Pain management is affected by individual factors like knowledge, personal beliefs and the ability to cooperate in inter-disciplinary decision-making (Alpen and Titler, 1994; Pederson, 1997; Loveman and Gale, 2000) as well as by the increase in technical skills and rapidly changing situations, which are characteristic of intensive care units (Hamill-Ruth and Marohn, 1999). Furthermore the administration of analgesics may be guided by social prejudices: in one study, physicians working in emergency facilities in the US prescribed an analgesic treatment two times less frequently for patients of Hispanic American origin than for non Hispanic patients, while Afro American patients were given $66 \%$ fewer analgesics than white people (Todd et al., 1993).

Critically ill patients who are unable to communicate effectively (ventilated adults, geriatric patients or neonates) run the highest risk of suffering pain (Pooler-Lunse and Price, 1992). The underestimation and inadequate treatment of pain conditions in neonates has to some extent already been studied (Shapiro 1993; Stevens, 2003, Dodd, 2003). A survey of three neonatology departments in Great Britain confirmed that $53 \%$ of all nurses fail to use a tool for pain assessment in order to objectivize pain (Dodd, 2003). Despite the fact that pain assessment tool was already incorporated into the nursing flow sheet throughout the hospital, only $27 \%$ of nurses acknowledged that they used it, while 33\% indicated that they were not using any tools to assess pain (Brown and Timmins, 2005). Simons et al. (2003), showed that pre-emptive analgesic therapy was provided to fewer than $35 \%$ of neonates studied, while $40 \%$ of neonates received no analgesic therapy in a NICU. Johnston et al. (1997), studying a sample of 1'068 neonates, found that less than $2 \%$ received pre-emptive analgesia for procedural pain.

It is generally assumed that education and practical experience increase accuracy in decisionmaking about appropriate pain management. However, studies report conflicting results: While Corcoran (1986) and Tanner et al. (1987) found that nursing experts performed better than nursing novices, other authors have reported that knowledge and experience do not influence assessment of pain intensity (Shapiro, 1993). In a study with 695 nurses on three different experience levels, Hamers 
et al. (1997) were unable to confirm the influence of expertise on pain assessment. Influencing factors in nurses' decision making, such as medical diagnosis, the child's facial expressions and age as well as the nurses' knowledge, attitude deficits and workload were explored (Hamers et al., 1994a; 1996). Margolius et al. (1995) examined nurses' beliefs about pain in children and perceptions of the adequacy of pain management. They showed that those nurses who provided the most direct care had the most misconceptions about effective pain management. It is not known by current research whether nurses and physicians beliefs affect their willingness to prevent or to treat pain.

Accuracy in the decision making of nurses appears to depend on differences in judgements regarding particular nursing situations (Hamers et al., 1994b). Saläntera (1999) found that in the paediatric field, nurses' knowledge was inconsistent with current research. These results could not be confirmed by Porter et al., (1997), whose study indicated that most neonatal clinicians believed infants experience pain equal to or greater than that experienced by adults. But the study reported differences between nurses' and physicians' assessment of procedural pain. These results are consistent with a recent study on this topic, which confirms that nurses generally assess procedures as being more painful than do physicians (Simons et al., 2003). No studies could be found regarding possible differences in pain assessment between neonatal units. Moreover, no German or Swiss data are available concerning the assessment of pain intensity for routine procedures in a NICU and possible influencing factors.

\subsection{Aims of the study}

The study aimed at gaining insight into influencing factors in pain intensity assessment of routine procedures in NICUs. A further aim was to delineate a ranking and categorization of pain intensity of routine procedures.

\section{Method}

\subsection{Study design and Sample}

Following ethical approval by the ethical board of the Canton Bern, a descriptive-explorative study was carried out. A survey involving 431 neonatal health care professionals from 4 tertiary level NICUs in Switzerland ( 3 units) and Germany (1 unit) was conducted from April to June 2005, including the purposive sample of all staff present during this period. The NICUs were comparable in their function and in the basic educational level of their staff.

\subsection{Procedure and statistics}

A list of 27 routine procedures was developed on the basis of a literature search focusing on results of similar studies (Barker and Rutter, 1995; Johnston et al., 1997; Simons et al., 2003). The list was then supplemented with expert opinion in Switzerland (clinical nurse specialists and the medical heads of the neonatology units). To distinguish painful from non painful procedures, "diaper change", "cranial sonography" and " $\mathrm{x}$-ray", which had been previously classified as non painful by the studies mentioned, were included as well. To investigate subjective pain intensity assessment, each procedure was assessed on a 10 point Visual Analogue-Scale (VAS), assuming that no analgesia was given during the procedure. Following advice from the head of the pain research team of the University Hospital in Bern, the cut-off for painful procedures was set at $\geq 4$ points. The list designed for this study was tested in February 2005 in a pilot study including 9 nurses and 6 physicians from one unit under investigation. No refinement of the list was required. The results of the pilot study were included in the final study. Descriptive statistics, including MANOVA, were performed. Calculating MANOVA, the independent nominal variables "profession", "age", "gender", "professional 
experience" and "unit" were tested as the main effects (Pillai Spur-Test). The VAS-scores of all procedures were averaged and included as dependent variables for MANOVA analysis. To specify the detected overall effect of participating units a post hoc Scheffe-testing was performed to explore the differences between specific units. SPSS 13 statistical package was used for statistical testing.

\section{Results}

\subsection{Demographic features of the study sample}

A total of 431 questionnaires were distributed and 321 were completed. All grades of nursing staff and nursing manager participated. The response rate was $74 \%$ but varied between $68 \%$ and $85 \%$ among hospitals. The demographic features of the nurses and physicians are shown in Table 4-2. The total number of respondents answering questions on demographic data is not always the same as the total number asked, because some respondents failed to answer all questions.

\section{Table 4-2: Demographic features of the study sample}

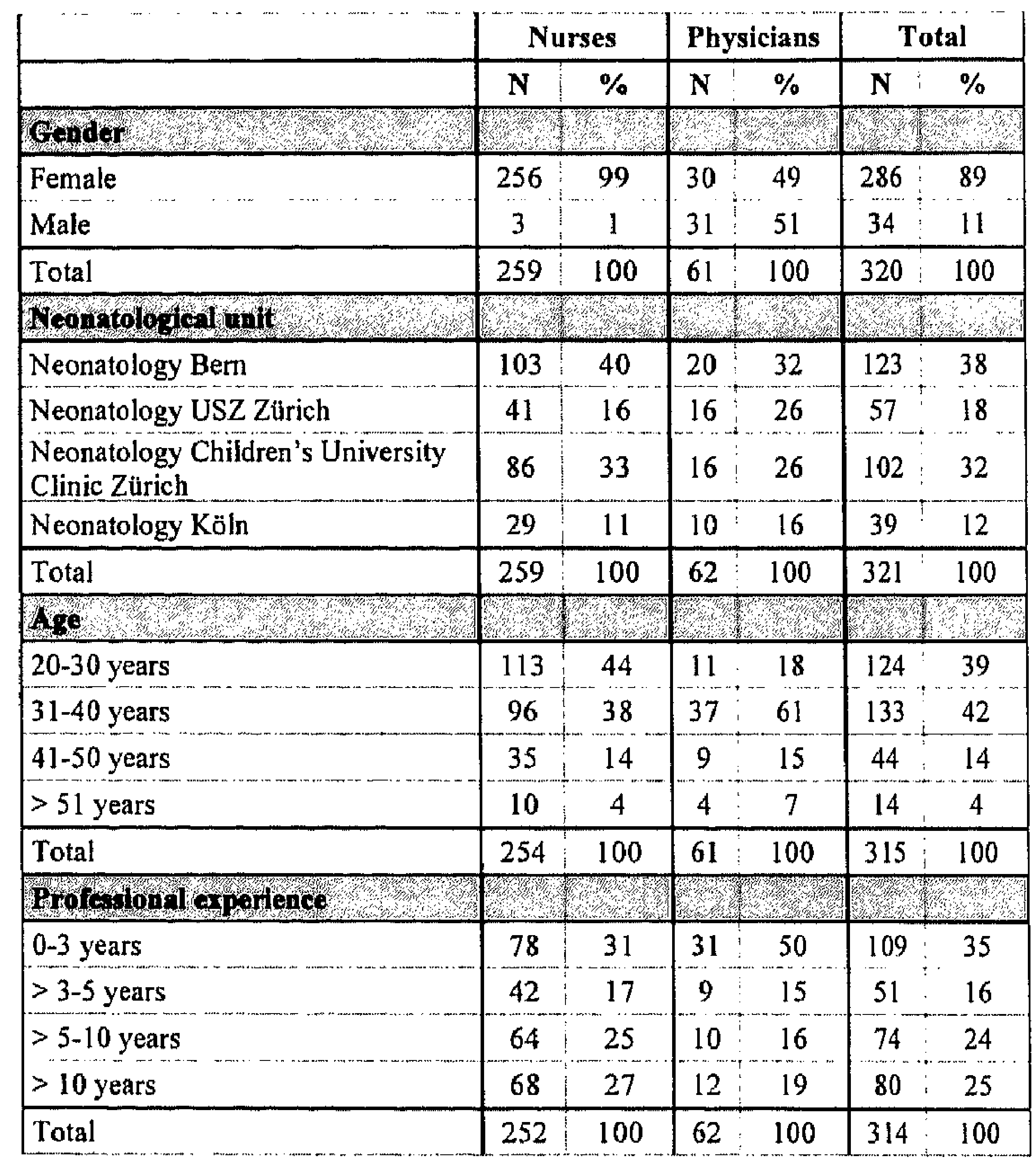

The demographic data show that the vast majority $(89 \%)$ of the responding health care professionals are female and belong to the nursing profession (99\%); men comprised only $11 \%$ of the sample. Among respondents in the nursing profession only $1 \%$ were male. The largest group of female health care providers in the nursing profession was 20 to 30 years old (44\%), while the majority of physicians belonged to the age group of 31 to 40 years $(61 \%)$. Regarding professional experience, it is 
noticeable that in both professional groups people with 0 to 3 years experience are predominant $(31 \%$ for nurses $/ 50 \%$ for physicians). The group of non-respondents $(n=110)$ consisted of $56 \%$ nurses and $43 \%$ physicians.

\subsection{Median pain score of all rated procedures}

Parallel to pain management in adults, where $\geq 4$ points on the VAS is usually the cut-off value for pain and therefore indicates the need for intervention, this survey also set the cut-off for a pain associated intervention at $\geq 4$ points. Figure 4-1 shows that the "insertion of a thoracic drain" is classified as the most painful intervention with a median pain score of 9 on the VAS. This intervention is followed by "intubation" and by "lumbar punction" (median pain score of 8). The "heelstick" and "endotracheal suctioning", which are done several times a day show a median pain score of 6 , and are therefore located as very painful procedures also. 8 procedures were assessed as not being painful with a median of less than 4 points, of which "diaper change" (median pain score 0 ) is clearly assessed as not painful at all.

Figure 4-1 shows that some procedures were assessed with scores along the whole range of possible points. Respondents' scores varied from 0 to 10 points on the VAS for 14 procedures (for instance for "insertion of a thoracic drain" or for "intubation").

Figure 4-1: Ranking by median of pain intensity of procedures

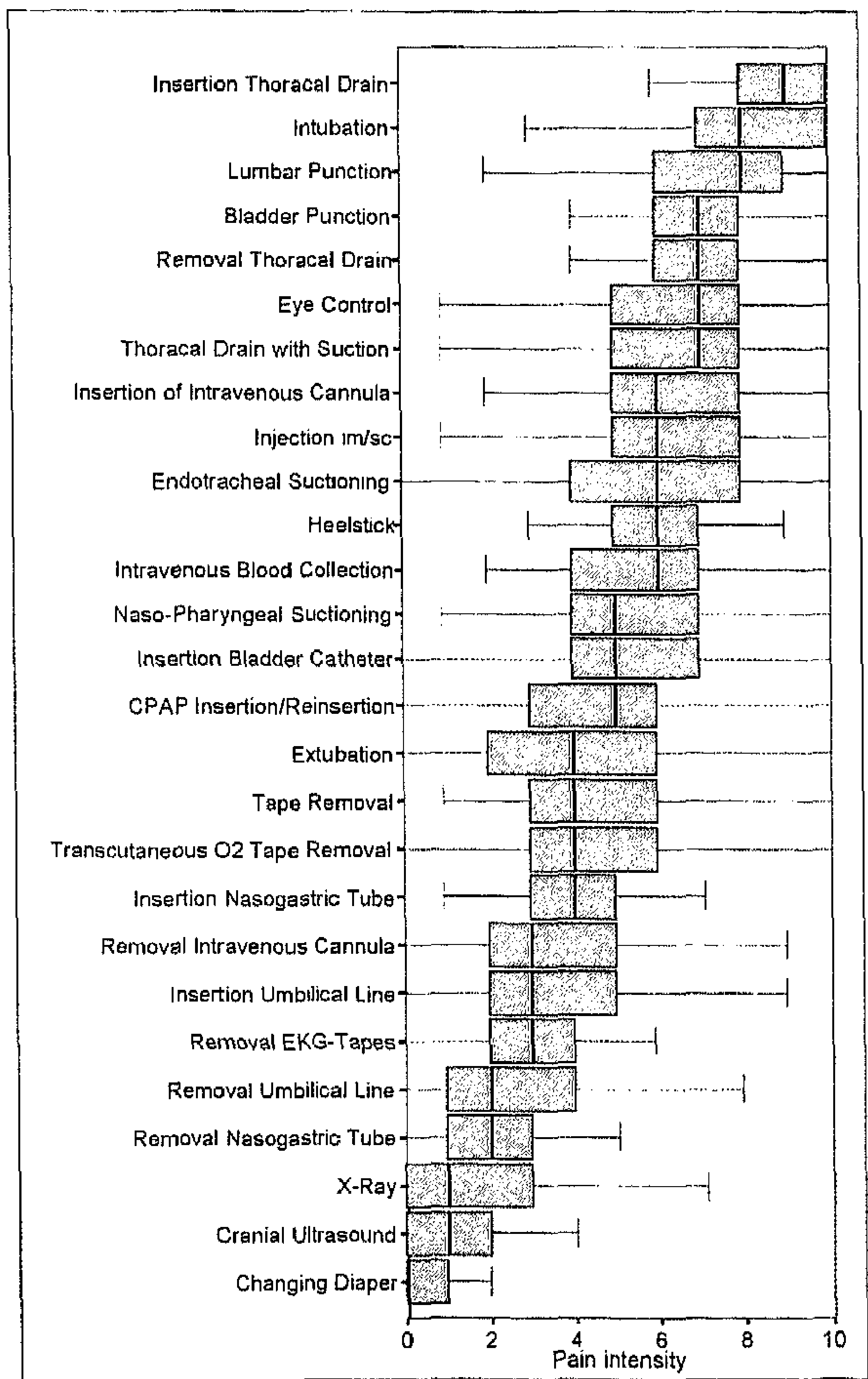

Values: boxes are inter-quartile ranges, the midpoints are mediansand whiskers are ranges without outliers. 
Categnoves were created in order to classify painful and non painful procedures according to the mean valueg. Using this classification, pain can he divided into three dimensions: 1) "very painful" (median pain score $\geq 6-101$. 2) ..painful" (median pain score $\geq 4-5$ ) and 3) "non painful" (median pain score $0 \ldots 3$. The classification shows that $70 \%(\mathrm{n}=19)$ of procedures in neonatology are considered to he painful and $44 \%(n=12)$ are regarded as very painful with scores $\geq 6$ points. Some of these procedures may be carried out daily ("venipuncture" "endotracheal suctioning", "heel stick") while other procedures are usually performed once (e.g. "insertion of a thoracic drain", "lumbar punction"". "bladder" and "eye control"). Finally, $26 \%(n=8)$ of the procedures are accorded less than 4 points and are therefore considered non painful.

Table 4-3: Categorization of procedures by median of pain intensity

\begin{tabular}{|c|c|c|c|c|c|c|}
\hline Categorization & Procedure & Min & $25 \%$ & Median & $75 \%$ & Max. \\
\hline \multirow{12}{*}{$\begin{array}{l}\Xi \\
E \\
E \\
z \\
z\end{array}$} & Insertion of a thoracic drain & 0 & 8 & 9 & 10 & 10 \\
\hline & Intubation & 0 & 7 & 8 & 10 & 10 \\
\hline & Lumbar puncture & 1 & 6 & 8 & 9 & 10 \\
\hline & Bladder puncture & 0 & 6 & 7 & 8 & 10 \\
\hline & Removal of a thoracic drain & 0 & 5 & 7 & 8 & 10 \\
\hline & Eve control & 0 & 5 & 7 & 8 & 10 \\
\hline & Thoracic drain with suction & 1 & 5 & 7 & 8 & 10 \\
\hline & Insertion of a peripheral line & 2 & 5 & 6 & 8 & 10 \\
\hline & Injections im/sc & 1 & 5 & 6 & 8 & 10 \\
\hline & Endotracheal suctioning & 0 & 4 & 6 & 8 & 10 \\
\hline & Heel stick & 1 & 5 & 6 & 7 & 10 \\
\hline & Venipuncture & 2 & 4 & 6 & 7 & 10 \\
\hline \multirow{7}{*}{$\begin{array}{l}E \\
E \\
E\end{array}$} & Nasopharyngeal suctioning & 1 & 4 & 5 & 7 & 10 \\
\hline & Insertion of a bladder catheter & 0 & 4 & 5 & 7 & 10 \\
\hline & Insertion /reinsertion CPAP & 0 & 3 & 5 & 6 & 10 \\
\hline & Extubation & 0 & 2 & 4 & 6 & 10 \\
\hline & Removal of a tape & 1 & 3 & 4 & 6 & 10 \\
\hline & Removal of transcutaneous $\mathrm{O} 2$ tape & 0 & 2 & 4 & 5 & 10 \\
\hline & Insertion of a nasogastric tube & 0 & 3 & 4 & 5 & 10 \\
\hline \multirow{8}{*}{ 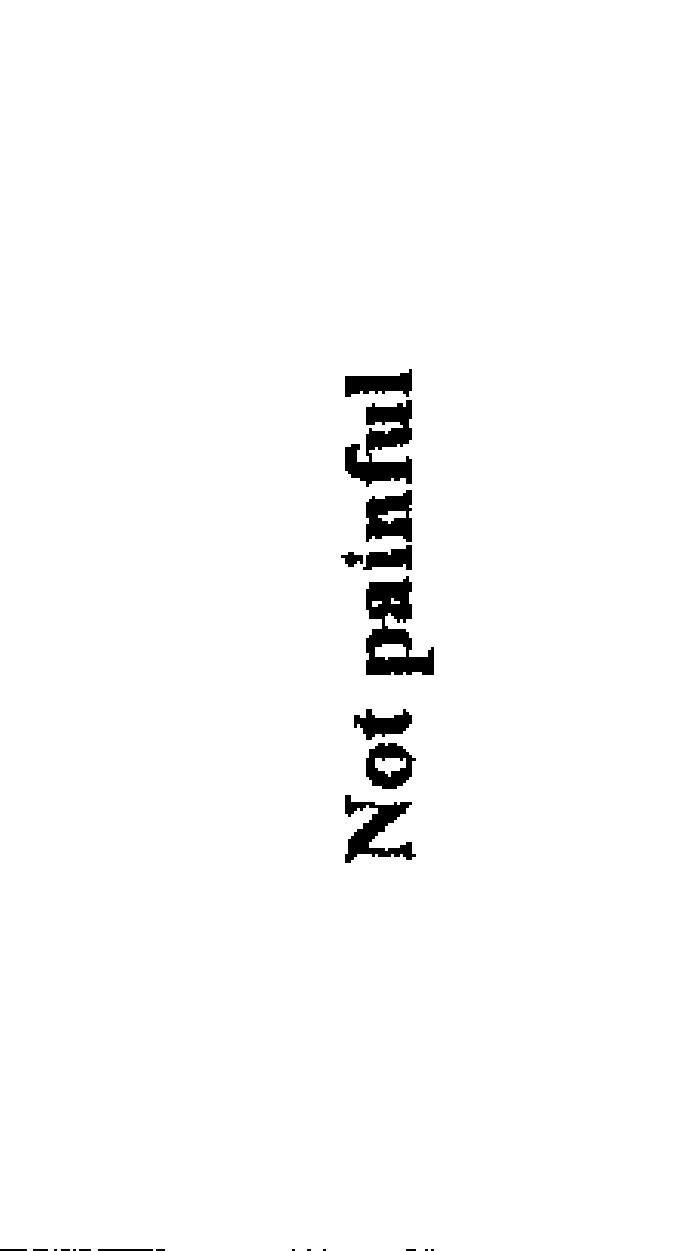 } & Removal intravenous cannula & 0 & 2 & 3 & 5 & 10 \\
\hline & Insertion of an umbilical line & 0 & 2 & 3 & 5 & 10 \\
\hline & Removal of EKG tapes & 0 & 2 & 3 & 4 & 10 \\
\hline & Removal of an umbilical line & 0 & 1 & 2 & 4 & 9 \\
\hline & Removal of a nasogastric tube & 0 & 1 & 2 & 3 & 9 \\
\hline & X-Ray & 0 & 0 & 1 & 3 & 8 \\
\hline & Cranial Ultrasound & 0 & 0 & 1 & 2 & 9 \\
\hline & Changing Diaper & 0 & 0 & 0 & 1 & 8 \\
\hline
\end{tabular}

\subsection{Comparison of assessment between nurses and physicians}

The results show that profession influences assessment of subjective pain intensity of the single procedures significantly $(p=0.05$ ). Nurses generally rated the procedures as more painful than physicians (Figure 4-2). It is remarkable that these differences are found for procedures that are closely connected with the highest pain levels $(p=<0.01$ for "insertion of a thoracic drain" and 
„intubation" and $\mathrm{p}=<0.05$ for "lumbar punction "). „Extubation" also shows a highly significant difference, although it is categorized as "painful" on the mean level $(p=0.01)$.

Figure 4-2: Differences in the assessment between nurses and physicians

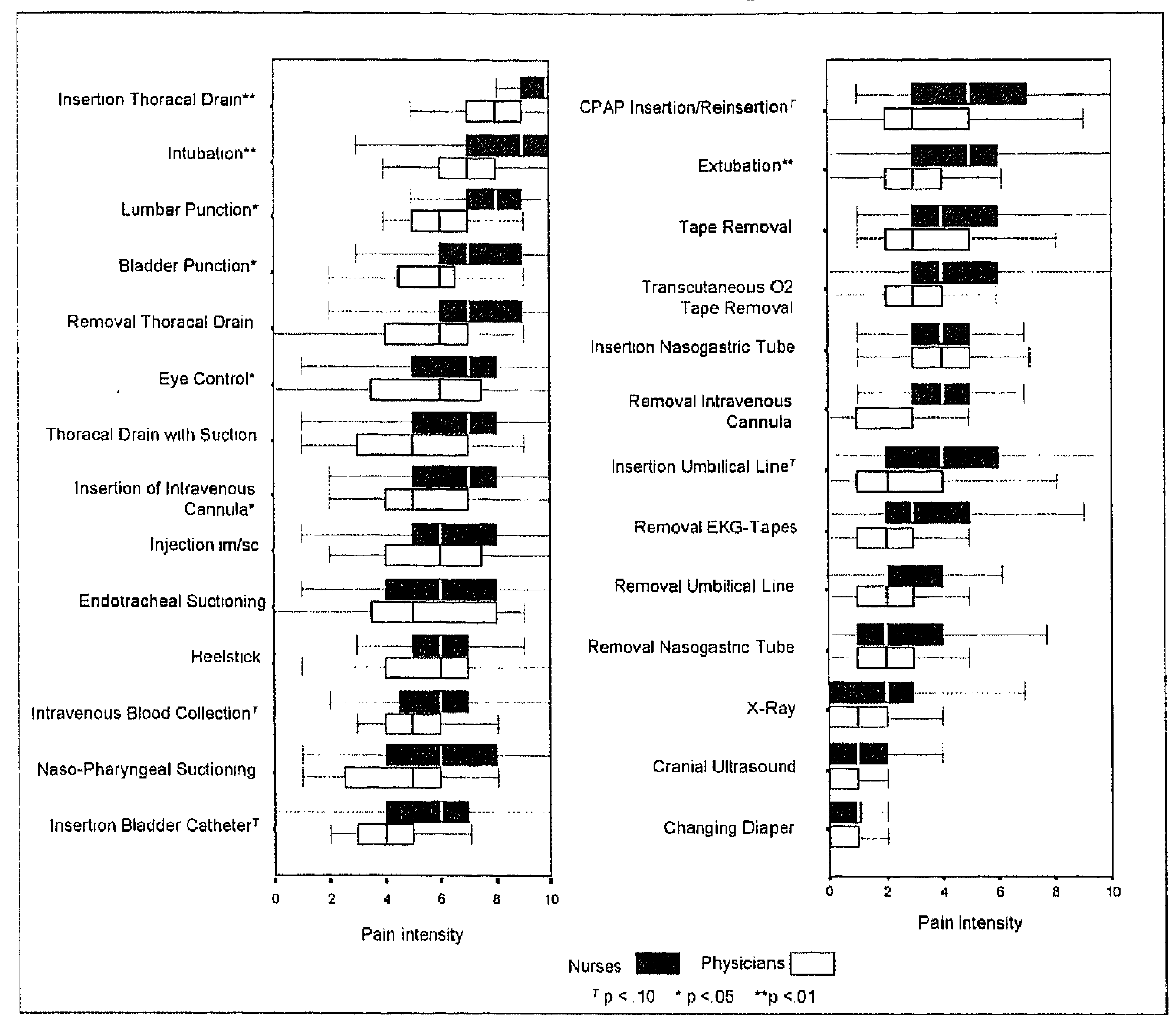

Values: boxes are inter-quartile ranges, the midpoints are medians and whiskers are ranges without outliers

Although only 7 of 27 procedures show a statistically significantly higher assessment by nurses, all other procedures - with the exception of „injection $\mathrm{im} / \mathrm{sc}^{\text {" }}$ - were also assessed as causing higher pain intensity by nurses than by physicians. On the level of single items there are even some major discrepancies between the dimensions "painful" $(\geq 4$ points on the VAS) and "non painful" (<4 points on the VAS) assessed by the two professions. While the "insertion/reinsertion of CPAP", the "extubation", the "tape removal", the "transcutaneous $\mathrm{O}_{2}$ tape removal and the "insertion of an umbilical line" are considered as being not painful by physicians ( $<4$ median points on the VAS), nurses consider all these procedures as being painful ( $\geq 4$ median points on the VAS).

\subsection{Influence of gender, age, professional experience and units}

Gender and age have no influence on pain assessment (4-4). MANOVA results indicate that professional experience was significant as main effect $(\mathrm{p}=0.036)$ (Model I). Analysis of the mean across all procedures for the four categories of professional experience $(0-3$ years $/>3$ years to 5 years $1>5-10$ years $/>10$ years) shows that health care providers with $5-10$ years professional experience rate the procedures with a mean of 5.2 points on the VAS, followed by the group with more than 10 
years of professional experience (mean $=4.9$ points). Those with professional experience of $3-5$ years showed a mean value of 4.7 points and beginners accorded the procedures the lowest mean rating with 4.7 points on the VAS.

Although this result is qualified by detailed analyses on the level of single items, the statistical significance of professional experience only had an impact on the item ,diaper change“. As this item is classified as clearly "not painful"(mean pain score of 0.8 ), this result is not relevant for clinical practice. The average pain value in the nurses group was 1.0 points for "diaper change"and in the physicians group it was only 0.7 points.

Moreover, a modified calculation model (Model II) including the 19 painful procedures only (,cut-off" value of $\geq 4$ points) failed to show that professional experience had an influence on subjective pain assessment. In this model the main effect of professional experience slipped off any statistical significance $(p=0.928)$.

Table 4-4: Results of multivariate analysis of the main effects (Model I and Model II)

\begin{tabular}{|c|c|c|c|c|c|c|c|c|}
\hline & \multicolumn{4}{|c|}{ Model I: All Procedures $(n=27)$} & \multicolumn{4}{|c|}{ Model II: Painful procedures $(n=19)$} \\
\hline Main effect & $\mathbf{F}$ & $\begin{array}{c}\text { Hypo- } \\
\text { thesis } \\
\text { DF }\end{array}$ & $\begin{array}{c}\text { error } \\
\text { df }\end{array}$ & p-value & $\mathbf{F}$ & $\begin{array}{c}\text { Hypo- } \\
\text { thesis } \\
\text { DF }\end{array}$ & $\begin{array}{c}\text { error } \\
\text { df }\end{array}$ & p-value \\
\hline Neonatology unit & 1.565 & 81 & 405 & $.003^{* *}$ & 1.773 & 57 & 453 & $0.001 * *$ \\
\hline Profession & $1.602(a)$ & 27 & 133 & $.043^{*}$ & $2.090(a)$ & 19 & 149 & $.008 * *$ \\
\hline Gender & $1.306(a)$ & 27 & 133 & .163 & $1.590(\mathrm{a})$ & 19 & 149 & .065 \\
\hline Age & 1.031 & 81 & 405 & .414 & 1.220 & 57 & 453 & .141 \\
\hline $\begin{array}{l}\text { Professional } \\
\text { experience }\end{array}$ & 1.343 & 81 & 405 & $.036^{*}$ & .731 & 57 & 453 & .928 \\
\hline
\end{tabular}

(a) Exact Statistics

$T \mathrm{p}=<0.10, * p=<0.05, * * \mathrm{p}=<0.01$

Although the four hospitals involved in the study are comparable regarding their function as tertiary level NICUs, and regarding the basic education level of the staff, a significant difference conceming the rating of pain intensity between the units could be discerned $(p=<0.003)$. A post hoc Scheffe-Test highlighted the difference between the Bernese unit and the units in Zürich $(p=0.028$ and $p=0.003$, respectively).

\section{Discussion}

In this study we revealed some predominant findings. We found that there is a significant difference in the subjective pain intensity assessment of procedural pain between nurses and physicians. Nurses generally rated all the procedures as being more painful. Although the four surveyed NICUs have similar functions to fulfil as tertiary level NICUs and were comparable with respect to basic level of education, the mean score for all procedures shows a significant difference between the hospitals, especially between the units in Switzerland. Gender, age and professional experience do not seem to influence the assessment of pain intensity. Furthermore, in accordance to the cut-off for a pain experience in adult care of $\geq 4$ points on a VAS, we found that the majority $(70 \% / n=19)$ of the routine procedures in a NICU were assessed as painful and $44 \%$ of those $(n=11)$ were classified as very painful with a median pain value of $\geq 6$ points. This meaningful results need to be discussed on their influence in the daily clinical setting. 
The finding that nurses tend to rate procedures as more painful than physicians confirms similar studies done in recent years (Porter et al., 1997; Simons et al., 2003). Thus profession must be considered an influencing factor in pain assessment. The nurses' generally higher classification of pain intensity may be explained by their continuous observation of the neonate, which extends over hours and days. Discrepancies with familiar behaviour patterns of well-being can therefore be identified and, more specifically, might be interpreted as pain. The difference in assessment between physicians and nurses merits exploration in terms of its impact on collaborative decision-making concerning pain management in neonates. Although the application of a validated instrument for neonatal pain assessment offers a possible disentanglement of subjective opinions and is therefore urgently recommended to objectivise pain, it needs to be stated that in spite of all the developments made in the last years to establish valid pain assessment tools many conceptual and measurement issues remain. Thus, the influence of contextual factors on the expression of pain, such as the gestational age and the associated immaturity of the central nervous system, as well as the influence of states of illness and of consciousness has not yet been comprehensively explained.

Professional experience - as detailed analysis shows - had no influence on subjective pain assessment as already confirmed by Hamers et al., (1997). Obviously, experience alone is not enough to optimize the complexity of pain assessment in neonates. It seems more likely that knowledge about pain and special training of professionals would have an influence on its management. As shown by Barnason et al., 1998 and by Rond et al. 2000, special training in pain knowledge was effective in improving pain management in adult acute care situations and increasing patient satisfaction with the applied pain relief methods. The difference delineated between the four participating NICUs deserves more attention. One possible explanation is that in the NICU with the highest mean score, a great deal of attention has been paid to neonatal pain management over the last 10 years. This could have influenced the general rating of the staff. Nevertheless, this remains a hypothetical conclusion, since the training intensity of the professional was not under question in the present study.

The present study is establishing a categorization of pain intensity of routine procedures in a NICU. Of the procedures listed $70 \%(n=19)$ were assessed as painful and $44 \%$ of them $(n=11)$ were classified as very painful with a median pain value of $\geq 6$ points. This high number of procedures categorized as being painful is surprising and could indicate that health care providers of the participating NICUs are aware of the pain intensity of procedures and that they seem not very likely to underestimate them. However, it must be stated that physicians assessed some procedures as not being painful ( $<4$ points on the VAS), while nurses assessed the same procedures with $\geq 4$ points on the VAS and therefore being painful. These major discrepancies concern the procedures "insertion/reinsertion of CPAP" the "extubation" the "tape removal", the "transcutaneous O2 tape removal" and the "insertion of an umbilical line". However, we can not conclude an underestimation of these procedures by physicians, but that they rather have a different perception of pain intensity of the mentioned procedures. Furthermore, it must be emphasized that all these ratings of painfulness of procedures in a neonatal intensive care setting are subjective and therefore speculative.

The result of a general awareness of pain intensity of procedures is in line with the study of Porter et al. (1997), which confirms that there has been a change concerning attitudes to and assessment of pain among health care providers of NICUs over the last decade. An underestimation or misjudgement of pain as described by Saläntera (1999) and Dodd (2003) could not be confirmed by this survey. 
This study further confirms that the three procedures .insertion of thoracic drain“, intubation" and ...umbar punction" are assessed as the most painful manipulations in neonates, a result also described in the study of Simons et al. (2003). However, in the study of Simons et al., 120031 the most painful rated procedures delineated in the present study like "intubation", "lumbar punction", "hladder punction" "removal of a thoracic drain" and "endotracheale suctioning" were tated 1.2 points higher in the assessment of nurses and physicians either (expressed by median). In a study with 120 preterm neonates we found that the procedures "insertion of a thoracic drain" is performed at a frequency of $0.1 \%$ among all the procedures during the first 14 days of life, while "intuhation" is performed more frequently $(0.5 \%)$, and "lumbar punction" is very seldom done $10.01 \%$ ) (Cignacco et al. 2007 manuscript in preparation). The most frequent painful procedures in the mentioned sample were "CPAP prongs insertion and removal" (24\%), "pharyngeal suctioning" (11\%) and "endotracheal suctioning" $(8 \%)$. All three procedures are classified as painful or very painful by the categorization in the present study. As expected, the procedures "diaper change“, "cranial ultrasound" and "x-ray" were classified as .not painful" with a median pain value of $<4$ points in the present study. These procedures make up about $1 / 3$ of all measures $(30 \%)$.

The described pain intensity of procedures needs to be discussed under the consideration that neonates are generally exposed to a high number of interventions, which can include 14 to 26 procedures a day (Simons et al., 2003: Cignacco et al., 2007 manuscript in preparation). Furthermore, neonates of a NICU are exposed to different sources of stress like light, noise and manipulations, which might contribute to a hypersensitivity of the central nervous system. As a consequence, even non-painful procedures can create a neuronal over-stimulation expressed as an increase in pain perception (Stevens et al., 2000; Fitzgerald, 2005). It is also important to remember that few neonates receive pre-emptive analgesia for procedural pain (Simons et al. 2003; Johnston et al. 1997). Taken together, these findings urgently demand exploration with a view to the possible unfavourable consequences for the development of the central nervous system in neonates.

The fact that in the present study the pain intensity of 14 procedures shows a broad range of scores from "no pain" ( $=0$ points) to "unbearable pain" (= 10 points) calls for critical discussion. It might be explained by existing clinical guidelines, which in some of the surveyed NICUs do not permit performing certain procedures without analgesia. This probably had a substantial influence on the subjective pain intensity assessment of some health care providers. Although the study has limitations concerning the purposive sampling which for conclusive testing of the delineated hypotheses should be improved by stratification of the sample (e.g. according to educational training of pain management skills and by selection of procedures for which there is no common sense concerning the need of pre-emptive analgesia by participating hospitals) in conclusion this study gives important insights.

Our findings confirm that most routine procedures in a NICU are considered as painful, stating a general difference of the pain intensity assessment between nurses and physicians. This difference deserves exploration in terms of its impact on collaborative decision-making. It would be of interest for further research to explore if nurses' and physicians' beliefs and perceptions affect their willingness to prevent or to treat pain. The application of a validated instrument for pain assessment for neonates offers a disentanglement of subjective opinions and therefore is urgently recommended to objectivize pain. Furthermore the delineated categorization into three pain dimensions can be used as hasis to define the pain management for the single procedures, where also non-pharmacological as well as pharmacological measures should be considered. 


\section{References}

Alpen MA, Titler MG. Pain management in the critically ill. What do we know and how can we improve? Clin Issues Crit Care Nurs 1994; 5:159-167.

Anand KJS, Whit Hall R, Desai N, Shephard B, Bergqvist L, Young T, Boyle E, Carbajal R, Bhutani V, Moore N, Kronsberg S, Barton B (NEOPAIN Trial Investigators Group). Effects of morphine analgesia in ventilated preterm neonates: Primary outcomes from the NEOPAIN randomized trial. Lancet 2004; 363:1673-82.

Anand KJS and the International Evidence-Based Group for Neonatal pain: consensus statement for the prevention and management of pain in the newborn. Arch Pediatr Adolesc Med $2001 ; 155: 173-180$.

Andrews K, Fitzgerald M. Wound sensitivity as a measure of analgesic effects following surgery in human neonates and infants. Pain 2002; 99:185-95.

Barker DP, Rutter N. Exposure to invasive procedures in neonatal intensive care unit admissions. Arch Dis Child Fetal Neonatal Ed 1995; 72:F47-F48.

Barnason S, Merboth M, Pozehl B, Tietjen M. Utilizing an outcome approach to improve pain management by nurses: A pilot study. Clin Nurse Spec 1998; 12:28-36.

Bartocci M, Bergqvist L, Lagercrantz H, Anand KJS. Pain activates cortical areas in the preterm newborn brain. Pain 2006; 122:109-117.

Benis MM, Suresh GK. Frequency of invasive procedures in very low birth weight (VLBW) infants in the neonatal intensive care unit (NICU (abstract). Pediatrc Res 2001; 49:392A Abstract 2253.

Brockopp DY, Downey E, Powers P, Vanderveer B, Warden S, Ryan P, Saleh U. Nurses' clinical decision-making regarding the management of pain. Int J Nurs Stud 2004;41:631-636.

Brockopp DY, Brockopp G, Warden S, Wilson J, Carpenter J, Vandeveer B. Identification of social and institutional barriers to effective management of pain in acute care institutions. Int $J$ Nurs Stud 1998; 35: 226-232.

Brown S, Timmins F. An exploration of nurses' knowledge of, and attitudes towards, pain recognition and management in neonates. J Neonatal Nurs 2005; 11:65-71.

Buskila D, Neumann L, Zmore E, Feldman M, Bolotin A, Press J. Pain sensitivity in prematurely born adolescents. Arch Pediatr Adolesc Med 2003; 157:1079-82.

Carbajal R, Mucha J, Milagro R, Arias J, Bao V, Rivadeneyra M, Zegarra J, Bazuan C, Cimerman P, Annequin D. Epidemiology of painful procedures and analgesic therapy in neonates in NICUs of a developing country, Peru: Poster presentation, Poster Abstract, 7th International Symposium on Pediatric Pain, Vancouver, June 2006, Pain Res Manage Vol 11 Suppl B, Summer 2006;E29. 
Carbajal R, Lenclen R, Jugie M, Paupe A, Bruce A, Anand KJS. Morphine does not provide adequate analgesia for acute procedural pain among preterm neonates. Pediatrics 2005; 115:1494-1500.

Cignacco E, Hamers J, Stoffel L, Gessler P, Mc Dougall J, Nelle M. Efficacy of non pharmacological interventions in the management of procedural pain in preterm and term neonates. A systematic review. Eur J Pain 2007; 11:139-152.

Corcoran SA. Task complexity and nursing expertise as factors in decision making. Nurs Res 1986; 35:107-112.

Dodd E. Neonatal procedural pain: a survey of nursing staff. Paediatr Nurs 2003;15:18-21.

Duhn LJ, Medves JM: A systematic integrative review of infant pain assessment tools. Adv neonatal Care 2004; 3:126-140.

Fitzgerald M: The development of nociceptive circuits. Nature 2005; 6: 507-20.

Franck LS, Greenberg CS, Stevens B. Pain assessment in infants and children. Acute pain in children. Pediatr Clin North Am 2000; 47:487-512.

Franck LS, Miaskowski C. Measurement of neonatal responses to painful stimuli: A research review. J Pain Symptom Manage 1997; 14:343-378.

Grunau RE, Holsti L, Halev DW, Oberlander T, Weinberg J, Solimano A, Whitfield MF, Fitzgerald C, Yu W. Neonatal procedural pain exposure predicts lower cortisol and behavioural reactivity in preterm infants in the NICU. Pain 2005; 113:293-300.

Grunau R. Early pain in preterm infants: A model of long-term effects. Clin Perinatol 2002; 29: 373-394.

Grunau RE, Oberlander TF, Whitfield MF, Fitzgerald C, Lee SK. Demographic and therapeutic determinants of pain reactivity in very low birth weight neonates at 32 weeks' postconceptional age. Pediatrics 2001; 107:105-12.

Grunau R, Whithfield MF, Petrie JH. Childrens judgements about pain at age 8-10 years: Do extremely low birthweight $(<1000 \mathrm{~g})$ children differ from full birthweight peers? J Child Psychol Psychiatry 1998; 39:587-594.

Grunau R, Whithfield MF, Petrie, JH, Fryer, EL. Early pain experience, child and family factors as precursors of somatization: a prospective study of extremely premature and fullterm children. Pain 1994; 56:353-359.

Hamers, JPH, van den Hout, MA; Halfens RJG, Abu-Saad HH, Heijltjes AEG. Differences in pain assessment and decisions regarding the administration of analgesic between novices, intermediates and experts in pediatric nursing. Int J Nurs Stud 1997; 34:325-334.

Hamers JPH, Abu-Saad HH, van den Hout MA, Ruud JGH, Kester ADM. The influence of children's vocal expression, age, medical diagnosis and information obtained from parents on nurses' pain assessment and decision regarding interventions. Pain 1996; 65: 53-61.

Hamers, JPH, Abu-Saad HH, Halfens RJG, Schumacher JNM. Factors influencing nurses' pain assessment and interventions in children. J Adv Nurs 1994a; 20:853-860.

Hamers JP, Hujer Abu-Saad H, Halfens RJ. Diagnostic process and decision making in nursing: a literature review. J Prof Nurs 1994b; 10:154-63. 
Hamill-Ruth RJ, Marohn ML. Evaluation of pain in the critically ill patient. J Crit Car 1999; 15:35-54.

Hermann C, Hohmeister J, Demirakca S, Zohsel K, Flor H. Long-term alteration of pain sensitivity in school-aged children with early pain experiences. Pain 2006; 125:278-285.

Hummel P, van Dijk M. Pain assessment current status and challenges. Semin Fetal Neonatal Med $2006 ; 11: 237-45$

Johnston CC, Stevens BJ: Experience in a neonatal intensive care unit affects pain response. Pediatrics 1996; 98:925-30.

Johnston CC: A cross-sectional survey of pain and pharmacological analgesia in Canadian neonatal intensive care units. Clin J Pain 1997; 13:308-312.

Loveman E, Gale A. Factors influencing nurses' inferences about patient pain. Br J Nurs 2000; 9:334-337

Margolius FR, Hudson KA, Michel Y. Beliefs and perceptions about children in pain: a survey. Pediatr Nurs 1995;21:111-115.

Oberlander T, Grunau RE, Whitfield MF, Fitzgerald C, Pitfield S, Saul JP. Biobehavioral pain responses in former extremely low birth weight infants at four months' corrected age. Pediatrics 2000; 105:e6.

Ohlsson A, Taddio A, Jadad AR, Stevens B. Evidence-based decision making, systematic reviews and the Cochrane collaborations: implications for neonatal analgesia. In: Anand $\mathrm{KJ}$, Stevens B, Mc Grath PH, editors. Pain in neonates, vol. 10. Amsterdam: Elsevier 2000. (2nd Revised and enlarged edition).

Pederson C, Matthies D, Mc Donald, S. A survey of paediatric critical care nurses' knowledge of pain management. Am J Crit Care 1997; 6:289-295.

Peters JW, Schouw R, Anand KJ, van Dijk M, Duivendvoorden HJ, Tibboel D: Does neonatal surgery lead to increased pain sensitivity in later childhood? Pain 2005; 114:444-54.

Peters JW, Koot HM, de Boer JB, Passchier J, Bueno-de-Mesquita JM, de Jong FH, Duivendvoorden HJ, Tibboel D. Major surgery within the first 3 months of life and subsequent biobehavioral pain response to immunization at later age: a case comparison study. Pediatrics 2003; 111:129-35.

Pooler-Lunse, C; Price, P. Pain and the critically ill. Can Nurse 1992; 88: 22-25.

Porter FL, Anand KJS. Epidemiology of pain in neonates. Res Clin Forums 1998; 20:9-18.

Porter, FL; Wolf, CM; Gold, J; Lotsoff, D; Miller JP. Pain and pain management in newborn infants: A survey of physicians and nurses. Pediatrics 1997; 100: 626-632.

Rennick JE, Johnston CC, Dougherty G, Platt R, Ritchie JA: Children's psychological responses after critical illness and exposure to invasive technology. J Dev Behav Pediatr 2002; 23:133-44.

Rond de M; Wit de R; Dam van F; Muller M: A pain monitoring program for nurses: effect on the administration of analgesics. Pain 2000; 89:25-38.

Sabrine N, Sinha S. Pain in neonates. Lancet $200011 ; 355: 932-3$.

Saläntera S. Finnish nurses' attitudes to pain in children. J Adv Nurs 1999; 29:727-736.

Shapiro C. Nurses judgements of pain in term and preterm newborns. J Obstet Gynecol Neonatal Nurs $1993 ; 22: 41-47$. 
Simons S, van Dijk M, Anand R, Roothooft D, van Lingen R, Tibboel D. Do we still hurt newborn babies? Arch Pediatr Adolesc Med 2003; 157:1058-1064.

Stevens B, Mc Grath P, Gibbins S, Beyene J, Breau L, Camfield C, Finley A, Franck L, Howlett A. Mc Keever P, O'Brien K, Ohlsson A, Yamada J. Procedural pain in newborns at risk for neurologic impairment. Pain 2003; 105: 27-35.

Stevens B, Franck LS. Assessment and management of pain in neonates. Paediatr Drugs 2001; 3:539-558.

Stevens B, Gibbins S; Franck L: Treatment of pain in the neonatal intensive care unit. Pediatric Clinics of North America 2000; 3:633-650.

Stevens B, Johnston C, Gibbins S. Pain assessment in neonates. In: Anand KJ, Stevens B, Mc Grath PJ, editors. Pain in neonates, vol. 10 Amterdam: Elsevier 2000; pp: 101-34 (2nd and enlarged edition).

Taddio A, Ohlsson $\mathrm{K}$, Ohlsson A. Lidocaine - prilocaine cream for analgesia during circumcision in newborn boys. Cochrane Database Syst Rev 2002:2.

Taddio A, Katz J, Ilersich AL, Loren G. Effect of neonatal circumcision on pain response during subsequent routine vaccination. Lancet 1997; 349:599-603.

Taddio A, Goldbach M, Ipp M, Stevens B, Koren G. Effect of neonatal circumcision on pain responses during vaccination in boys. Lancet 1995; 345:291-2.

Tanner CA, Padrick KP, Westfall UA, Putzier DJ. Diagnostic reasoning strategies of nurses and nursing students. Nurs Res 1987; 36:358-363.

Todd KH, Samaroo N, Hoffman JR. Ethnicity as a risk factor for inadequate emergency department analgesia. J Am Med Assoc 1993; 269:1537-1539.

van Dijk M, Simons S, Tibboel D. Pain assessment in neonates. Paediatr Perinat Drug 2004; 6:97-103.

Walker SM. Management of procedural pain in NICUs remains problematic. PaediatrAnaesth 2005; 15:909-12. 


\section{Chapter 5}

NEONATAL PROCEDURAL PAIN EXPOSURE AND

PAIN MANAGEMENT IN VENTILATED PRETERM

INFANTS DURING THE FIRST 14 DAYS OF LIFE

Cignacco E, Hamers JPH, van Lingen RA, Stoffel L, Büchi S, Müller R, Schütz N, Zimmermann LJI, Nelle M 


\section{Abstract}

Background: Preterm infants admitted to a NICU are exposed to a great number of procedures which are connected with pain. This is especially true for infants requiring mechanical ventilation. Previous studies describe the type and the frequency of procedures and the lack of appropriate pain management in this vulnerable patient population. Very little is known about the systematic assessment of acute pain in the daily clinical routine.
\end{abstract}

Aims: To determine current pain management practices in ventilated infants.

Method: A descriptive-explorative cohort design was used, examining the first 14 days of life of preterm infants requiring mechanical ventilation.

Results: The total number of procedures all the infants underwent was 38,626, indicating a mean of 22.9 general procedures performed per child and day. Overall, $76 \%$ of these procedures are considered to be painful. Manipulation on the CPAP prongs is the most frequently performed procedure. Up to 4 : 7 pain measurements are performed per day. Furthermore, $99 \%$ of the infants received either non. pharmacological and/or pharmacological agents. Of the preterm infants studied, $71 \%$ received orally administered glucose as pre-emptive analgesia. Morphine was the most commonly used pharmacological agent. Preterm infants with a low gestational age $(<28$ weeks) are exposed to the highest number of procedures and are given the lowest amount of pharmacological analgesia.

Conclusions: The number of procedures ventilated preterm infants are exposed to is disconcerting Efforts to minimize the number of invasive procedures and efforts should be made to improw analgesia for the most pain-exposed gestational group. 


\section{$1 \quad$ Introduction}

Pain exposure in a NICU is considered a major source of distress for children and their families (Boyle et al., 2006; Franck et al., 2005; Gale et al., 2004; Padden and Glenn, 1997). The most frequently described painful procedures include endotracheal and naso-pharyngeal suctioning (Benis and Suresh, 2001; Simons et al., 2003) and the heel lance (Barker and Rutter, 1995; Johnston et al., 1997; Carbajal et al., 2006). The removal of adhesive tape and the application of an intravenous cannula are also frequently performed painful procedures (Stevens et al., 2003). The number of such procedures a neonate is exposed to varies from 2 to $14(+/-4)$ per day (Stevens et al., 2003; Simons et al., 2003; Benis and Suresh, 2001; Johnston et al., 1997).

Pain treatment is viewed as inadequate in the context of acute diagnostic and therapeutic procedures in NICUs - in contrast to the postoperative routine medication of opioids (Walker, 2005). Interventions are frequently performed without any pharmacologic or non-pharmacologic analgesia. More than $65 \%$ of the neonates in a NICU did not receive adequate pain therapy and $40 \%$ of the children were not given any analgetic therapy at all (Simons et al., 2003). In 86 neonatal intensive care units, analgesics were found to be used in less than $10 \%$ of the invasive procedures (Sabrine and Sinha, 2000). Even for the insertion of a chest tube, which ranks among the most painful interventions (Cignacco et al., 2006), only $16 \%$ of the patients were administered an analgesic (Sabrine and Sinha, 2000). Neonates at the highest risk of neurological impairment had the greatest number of painful procedures and the least amount of opioids administered during the first day of life (Stevens et al., 2003). Current results suggest that neonates' exposure to pain tends to be exceedingly high during their hospitalisation, while pain relieving methods are not adequately applied. Furthermore, there is a lack of data on how frequently the pain is assessed by a pain measurement tool in the daily clinical setting. Specifications on the use of such a tool are usually restricted to studies of interventions and have no applicability to the daily routine.

The aims of the present study were a) to explore the number of procedures in general and pain exposures of ventilated preterm neonates during the first 14 days of life, b) to describe the amount of pain and pain intensity assessed by a pain assessment tool in the context of routine clinical care, and c) to explore the type and frequency of analgesic (pharmacological and non-pharmacological) use in mechanical ventilated preterm neonates during their first 14 days of life.

We hypothesized a) that the number of painful procedures would be high, $b$ ) that in the clinical routine pain assessment by a validated tool is not performed systematically, c) that preventing analgesia before procedural pain is not done systematically, d) that pharmacological agents are applied restrictively, and e) that infants of lower gestational age are exposed to a higher number of procedures and receive less analgesia than those of higher gestational age. 


\section{Methods}

A retrospective descriptive cohort design analyzing the medical and nursing charts of 120 preterm neonates needing mechanical ventilation was used to document pain management during their first 14 days of life.

\subsection{Sample and settings}

The purposive sample was recruited from two tertiary level NICUs in two different hospitals in Switzerland with 32 (site 1 ) and 19 (site 2 ) beds respectively. The total sample size consisted of 120 $(85$ preterms for site 1 and 35 preterms for site 2). All the neonates were born as preterm neonates in the period from 1.5.2004 through 31.3.2006 and needed mechanical ventilation due to respiratory distress after preterm birth.

\subsection{Inclusion and exclusion criteria}

All preterm neonates who were born between $\geq 240 / 7$ and $370 / 7$ weeks of gestation based on early ultrasound and had been hospitalized in the NICU for at least 14 days, needing intubation and mechanical ventilation in the first 48 hours of life were eligible for the study independently of their health/illness status. Only preterm infants needing a transfer into another clinic during the first 14 days of life were excluded from the analysis.

\subsection{Data management}

\subsubsection{Data collection}

Retrospective data collection from nursing and medical charts was performed covering the first 14 days of life.

\subsubsection{Procedures}

A standardized document listing 27 routine procedures was used to record the number of procedures, the number of documented pain scores and the amount and type of pharmacological and nonpharmacological interventions which were used throughout the first 14 days of life during routine care. The standardized list of procedures was developed on the basis of a literature search, highlighting the number of procedures neonates are exposed to most frequently (Barker and Rutter, 1995; Johnston et al., 1997; Simons et al., 2003). The list was further supplemented by expert opinions in Switzerland (clinical nurse specialists and the medical heads of the neonatological units). A ranking and categorization of the pain intensity of these procedures was described in a previous survey (Cignacco et al.. 2006). The categorization showed that the majority (70\%) of the routine procedures were assessed as painful, as shown by a mean pain value of $\geq 4$ points on a Visual Analogue Scale. About $1 / 3$ of all measures ( $30 \%$ ) were considered not to be painful (e.g. diaper change, cranial sonography, $x$-ray). For the present study all 27 procedures were documented. Calculations of painful procedures were performed additionally, in accordance with the above mentioned categorization of Cignacco et al. (2006).

\subsubsection{Pain assessment}

According to existing clinical guidelines in both sites, pain needs to be measured on a regular daily basis in order to detect a possible pain status of the preterm infant. These measurements need to be done independently of acute painful procedures. The documented pain ratings were scored by using two validated pain scores: the "Bernese Pain Scale for Neonates" (BPSN) (Cignacco et al. 2004) in site 1 and the "Neonatal Infants Pain Scale" (NIPS) (Lawrence et al., 1993) in site 2. The BPSN needs 
to be applied at least once per shift, and more frequently if required. The cut-off score for a painful status of the BPSN is set at $\geq 11$ points. The NIPS should be used four to six hourly, at least once per shift. The cut-off score for a painful status of the NIPS is set at $\geq 2$ points. On the basis of these guidelines, the frequency of use was determined for both instruments. Then, the number of pain values considered to be painful was calculated.

\subsubsection{Pain relieving interventions}

The study focussed on pharmacological pain treatment in general and also investigated the administration of orally administrated glucose, which is considered a pain relieving non pharmacological agent (Stevens et al., 2004). The administration of sucrose is the most frequently studied non-pharmacological intervention for the relief of procedural pain in neonates (Stevens et al., 1997; 1999; Blass et al., 1999; Kaufmann et al., 2002; Gibbins et al., 2002) and has been shown to have a pain relieving effect for acutely painful stimuli (Stevens et al., 2004). Although in both sites other non-pharmacological comforting techniques are part of care, there is a lack of standardisation with high performance variability depending on individual factors of each caring nurse. Furthermore, due to the lack of systematic documentation of these interventions, retrospective data collection would not provide reliable information. Therefore, the present study considers the administration of sucrose/glucose only.

\subsubsection{Data analysis}

The data were entered into an Excel database and then transferred to SPSS statistic program software, version 14.01 for Windows. The assumptions for parametric tests were verified by Q-Q-Plots. Descriptive statistics including variance-analy sis were performed.

\subsubsection{Ethical approval}

The approval for retrospective data collection from existing nursing and medical data was given by the medical director for research of the University of Berne and the ethical board of the Canton of Berne and Zurich, according to the general ethical approval practices for retrospective data.

\section{Results}

During the study period data from the medical and nursing records of 120 preterm neonates were collected (85 from site 1 and 35 from site 2). As shown in table 5-1, the mean gestational age of the study sample was 29.7 weeks. Most of the included preterm infants $(n=49)$ had a low gestational age of between $240 / 7$ and $280 / 7$ weeks (F294.37; $\mathrm{p}=<0.001$ ). The mean ventilation time for the whole cohort was 94.8 hours (SD 122.2) and differed significantly between the gestational groups (F5.415; $p$ $=0.006$ ). 
Table 5-1: Neonatal characteristics of study sample

\begin{tabular}{|c|c|c|c|}
\hline & Mean & SD & $\begin{array}{l}\text { Significance } \\
\text { (p value })^{*}\end{array}$ \\
\hline Mean gestational age & 29.7 & 3.5 & \\
\hline \multicolumn{4}{|l|}{ Gestational group } \\
\hline $\begin{array}{l}\text { Group } 1: 240 / 7 \text { to } 280 / 7 \\
\text { weeks of gestation }(n=49)\end{array}$ & 26.3 & 1.1 & \multirow{3}{*}{$\begin{array}{l}F 294.37 \\
(<0.001)\end{array}$} \\
\hline $\begin{array}{l}\text { Group } 2: 281 / 7 \text { to } 320 / 7 \\
\text { weeks of gestation }(n=37)\end{array}$ & 30.0 & 1.8 & \\
\hline $\begin{array}{l}\text { Group } 3: 321 / 7 \text { to } 370 / 7 \\
\text { weeks of gestation }(n=34)\end{array}$ & 34.2 & 1.4 & \\
\hline Birth weight (g) & 1334.0 & 635.6 & $\begin{array}{l}\text { Fl64.40 } \\
(<0.001)\end{array}$ \\
\hline \multirow[t]{2}{*}{ Intubation time in bours } & 94.8 & 122.28 & $\begin{array}{l}\text { F294.37 } \\
(0.006)\end{array}$ \\
\hline & $\mathbf{N}$ & $\%$ & \\
\hline \multicolumn{4}{|l|}{ Gender } \\
\hline Male & 65 & 46 & \\
\hline Female & 55 & 54 & \\
\hline \multicolumn{4}{|l|}{ Delivery mode } \\
\hline Spontaneous labour & 80 & 67 & \\
\hline C-Section & 40 & 33 & \\
\hline Single birth (number of children) & 101 & 84 & \\
\hline Twin birth (number of children) & 16 & 13 & \\
\hline Triplet birth (number of children) & 3 & 2 & \\
\hline Death/died $\%$ & 13 & 11 & \\
\hline
\end{tabular}

\subsection{Procedural pain exposure during the first 14 days of life}

\subsubsection{Number of painful procedures}

Table 5-2 shows that a total number of $38^{\prime} 626$ procedures were performed on the whole sample during the first 14 days of life. This result indicates a mean of 22.9 general procedures performed per child and day. Preterm infants of the lowest gestational age were exposed to the highest number of general procedures (F29.843; $p=<0.001$ ) (Figure 5-1). The same holds true if one considers the analysis of painful procedures only. Preterm infants with a low gestational age experience the highest rate of painful procedures ( $\mathrm{F} 31.786 ; \mathrm{p}=<0.001)$. The number of painful procedures decreases the higher the gestational age. Each child of the whole cohort was exposed to a mean of 17.3 painful procedures a day. Analyzing the number of non painful procedures only again revealed that the infants of lowest gestational age were exposed to the highest number of interventions (F5.929; $p=0.004$ ) (Table 5-2).

Scrutinizing the number of interventions for each of the first 14 days of life confirmed a decrease in the median of 35 total daily procedures to 16 total daily procedures at day 14 (see Figure $5-2)$. 
NEONATAL PROCEDURAL. PAIN EXPOSURE AND PAIN MANAGEMENT IN

Table 5-2: Number of procedures on study sample during the first 14 days

\begin{tabular}{|c|c|c|c|}
\hline & $\mathbf{N}$ & $\begin{array}{l}\text { Mean } \\
\text { (SD) }\end{array}$ & $\begin{array}{c}\text { Level of } \\
\text { significance F-Test } \\
\text { (p-value) }\end{array}$ \\
\hline Number of total procedures & $38^{\prime} 626$ & & \\
\hline Number of total procedures per child / day & & 22.9 & \\
\hline $\begin{array}{l}\text { Number of total procedures } \\
\text { in gest. group 1 ( } \leq 28 \text { weeks) }\end{array}$ & 203319 & $\begin{array}{c}414.7 \\
(107.6) \\
\end{array}$ & \\
\hline $\begin{array}{l}\text { Number of total procedures } \\
\text { in gest. group } 2 \text { ( } 28 \text { to } 32 \text { weeks) }\end{array}$ & $10^{\prime} 829$ & $\begin{array}{c}292.7 \\
(127.1) \\
\end{array}$ & \\
\hline $\begin{array}{l}\text { Number of total procedures } \\
\text { in gest. group } 3(>32 \text { weeks) }\end{array}$ & 7478 & $\begin{array}{l}219.9 \\
(116.0) \\
\end{array}$ & $\begin{array}{l}\text { F29.843 } \\
(<0.001)\end{array}$ \\
\hline Number of total painful procedures & $29^{\prime} 228$ & & \\
\hline Number of painful procedures per child / day & & 17.3 & \\
\hline $\begin{array}{l}\text { Number of painful procedures } \\
\text { in gest. group } 1 \text { ( } \leq 28 \text { weeks) }\end{array}$ & $16^{\prime} 174$ & $\begin{array}{l}330.1 \\
(97.4) \\
\end{array}$ & \\
\hline $\begin{array}{l}\text { Number of painful procedures } \\
\text { in gest. group } 2 \text { ( } 28 \text { to } 32 \text { weeks) }\end{array}$ & 79913 & $\begin{array}{c}213.9 \\
(115.6) \\
\end{array}$ & \\
\hline $\begin{array}{l}\text { Number of painful procedures } \\
\text { in gest. group } 3 \text { ( }>32 \text { weeks) }\end{array}$ & $5^{\prime} 141$ & $\begin{array}{c}151.2 \\
(100.3) \\
\end{array}$ & $\begin{array}{l}\text { F31.786 } \\
(<0.001) \\
\end{array}$ \\
\hline Number of total non painful procedures & 9'398 & & \\
\hline $\begin{array}{l}\text { Number of total non painful procedures } \\
\text { per child / day }\end{array}$ & & 5.5 & \\
\hline $\begin{array}{l}\text { Number of total non painful procedures } \\
\text { in gest. group } 1 \text { ( } \leq 28 \text { weeks) }\end{array}$ & $4 ' 145$ & $\begin{array}{c}84.6 \\
(17.2) \\
\end{array}$ & \\
\hline $\begin{array}{l}\text { Number of total non painful procedures } \\
\text { in gest. group } 2 \text { ( } 28 \text { to } 32 \text { weeks) }\end{array}$ & $2 ’ 916$ & $\begin{array}{c}78.8 \\
(17.7) \\
\end{array}$ & \\
\hline $\begin{array}{l}\text { Number of total non painful procedures } \\
\text { in gest. group } 3 \text { ( }>32 \text { weeks) }\end{array}$ & $2 ’ 337$ & $\begin{array}{l}68.7 \\
(27.1)\end{array}$ & $\begin{array}{l}\text { F5.929 } \\
(0.004)\end{array}$ \\
\hline
\end{tabular}

All values expressed as mean (standard deviation) or numbers

Figure 5-1: Number of procedures according to gestational group

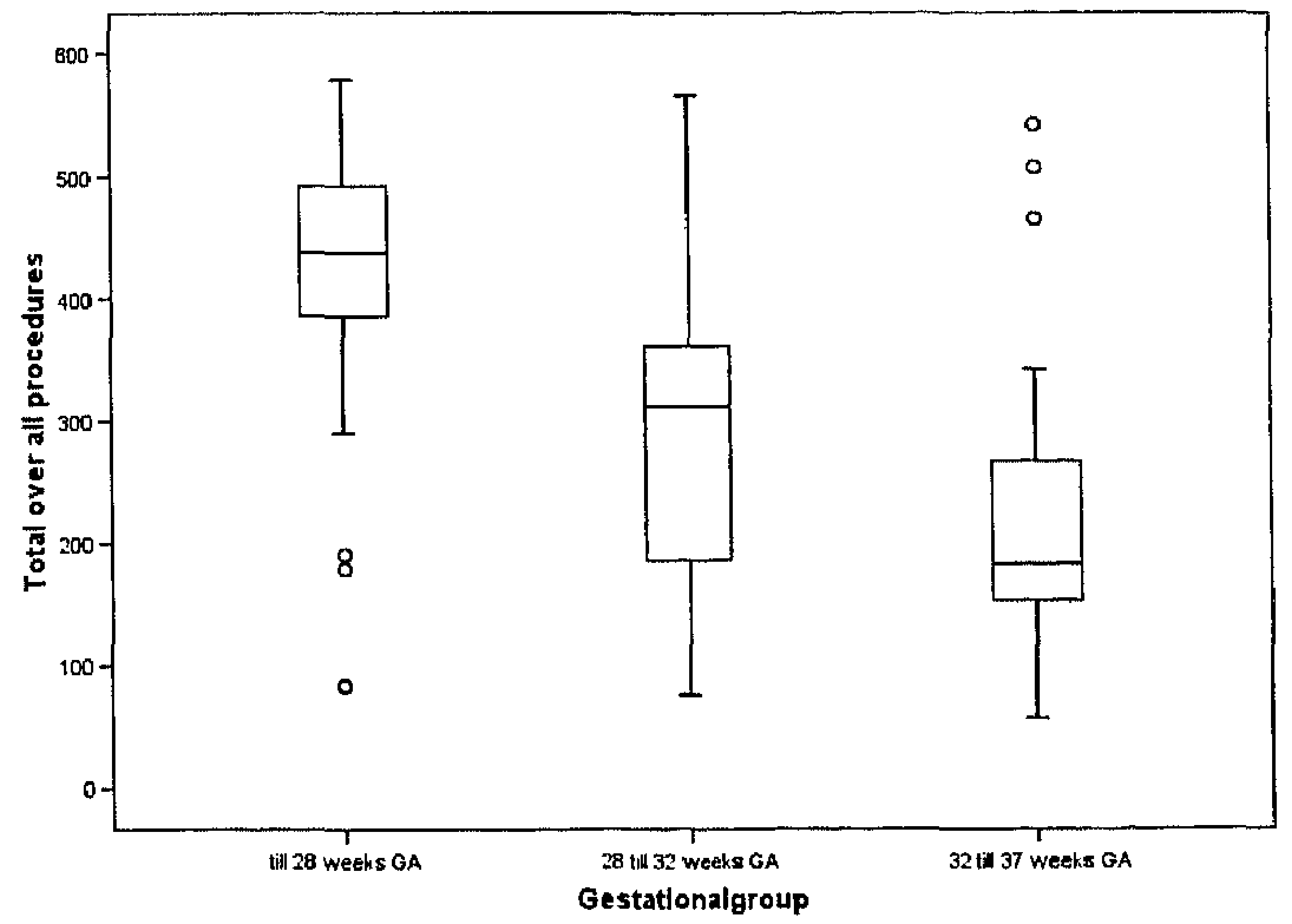

Values: Boxes are interquartile ranges, the midpoints are medians, whiskers are ranges and circles are outliers 
Figure 5-2: Number of procedures by hospitalisation day during the first 14 days of life $(n=120$ preterms and a total of 38,626 procedures)

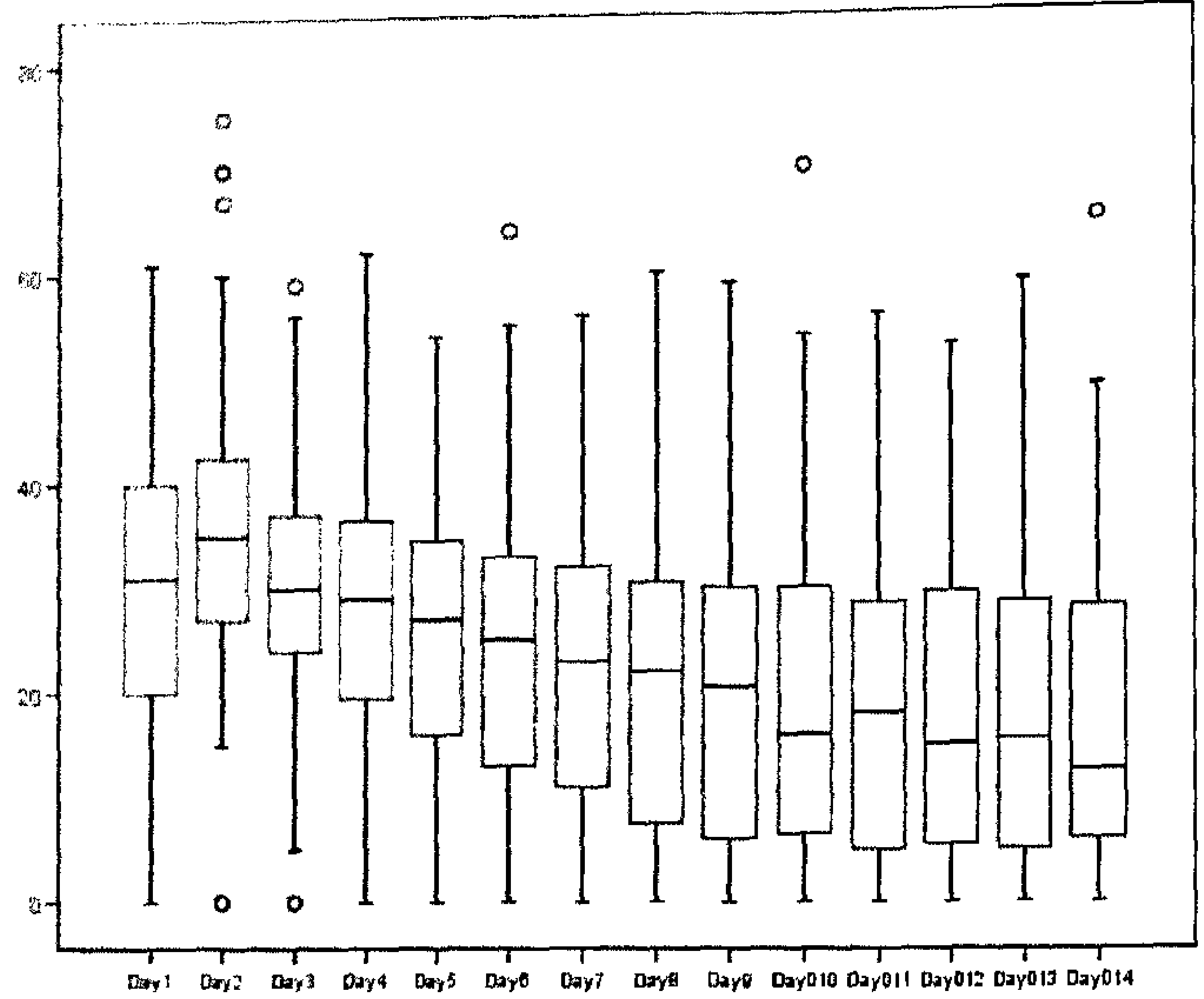

Falues: Boxes are interquartile ranges, the midpoints are medians, whiskers are ranges and circles are outliers

\subsubsection{Type and frequency of procedures}

The most prevalent procedure was the manipulation with CPAP (prongs insertion/reinsertion), which amounted to $24 \%$ of all procedures. This was followed by the procedures of changing diaper (18\%), naso-pharyngeal suctioning (11\%), transcutaneous $\mathrm{O}_{2}$ tape removal (9\%), and endotracheal suctioning $(8 \%)$ (see Table 5-3). At 5\% the heel lance procedure appears in seventh place. Lumbar puncture was rarely performed and appears in the lowest rank with $0.01 \%$ (see Table 5-3). 
Table 5-3: Procedures performed in 120 preterm neonates ranked by mean

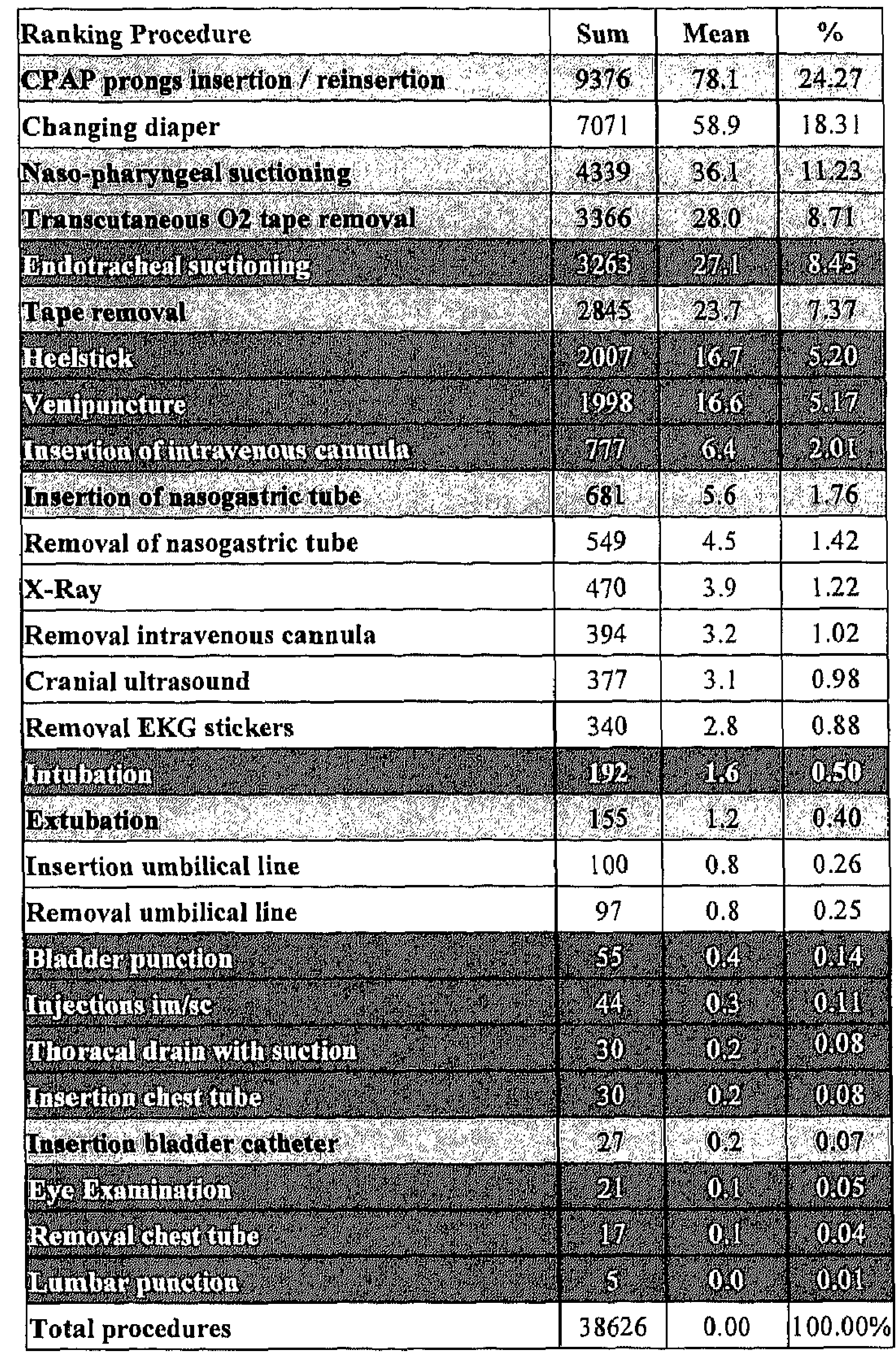

Legend:

Pain intensity of procedures (Cignacco et al., 2006)

Procedures assessed... 3.

\section{ras painful}

...not being painful

\subsection{Pain management}

\subsubsection{Pain assessment in the clinical routine using a validated tool}

With the BPSN a total of 4,820 measurements were performed on 85 infants during the first 14 days of their life, resulting in an average of 4 measurements per day/child. All infants were subjected to at least one pain assessment per day. Of all results determined with the BPSN, 94\% were not rated as painful in the whole cohort. Only $6 \%$ of all measurements were considered painful at $\geq 11$ points. When assessments were categorized according to gestational group, there were a significantly higher number of measurements performed on infants with the lowest gestational age (mean 65.2; SD 24.9; F5.573; $p=0.005$ ). When differentiating between scores rated as painful or not painful we again found significantly more BPSN scores in the non painful range $(<11$ points) in the group of infants with the lowest gestational age ( $F 7.042 ; p=0.002)$. 
With the NIPS a total of 3,510 measurements were performed on 35 infants during the first 14 days of their life, resulting in an average of 7.1 measurements per day/child. Again, pain was assessed for each child at least once per day. Of all results determined with the NIPS, $83 \%$ were not rated as painful. Only $16 \%$ of all values were considered painful with $\geq 2$ points. When assessments were categorized according to gestational group, the results are similar to the measurements by BPSN: a significantly higher number of measurements were performed on infants with the lowest gestational age (mean 181.1; SD 68.7; F6.039; $\mathrm{p}=0.006$ ). When differentiating between scores rated as painful or not painful, significantly more NIPS scores in the non painful range $(<2$ points) in the group of infants with the lowest gestational age again $(F 7.937 ; p=0.002)$ were found.

\subsubsection{Non-pharmacological and pharmacological analgesia}

Of all the preterm infants, $99 \%$ had one or more analgesic treatments. Only one infant of the cohort was not given any analgesic during the first 14 days of life. Of the preterm neonates, $71 \%$ received preemptive analgesia with glucose before a painful procedure, but only $9 \%$ of them were given orally administered glucose before a procedure every day. As a pharmacological agent an intermittent bolus of morphine was administrated with the highest frequency (66\%). Morphine was followed by pethidin (25\%) and fentanyl (16\%). Regarding the amount of all pharmacological agents given to the whole sample during the first two weeks, there is a significant difference between gestational groups. Preterm infants at the lowest gestational age had the smallest amount of analgesics (F8.349; $p=<0.001$ ) (Table 5-4).

Table 5-4: Total administered pharmacological agents during the first 14 days of life

\begin{tabular}{lrrr}
\hline $\begin{array}{l}\text { Total pharmacological agents in } \\
\mathbf{1 4} \text { days in } \mathbf{m g}\end{array}$ & Mean & SD & Level of significance \\
\hline Gestational group up to 28 weeks $(\mathbf{n}=\mathbf{4 9})$ & 6.5 & 12.5 & \\
\hline Gestational group $\mathbf{2 8}$ to $\mathbf{3 2}$ weeks $(\mathbf{n}=\mathbf{3 7})$ & 45.5 & 104.4 & \\
\hline Gestational group $\mathbf{3 2}$ to $\mathbf{3 7}$ weeks $(\mathbf{n}=\mathbf{3 4})$ & 138.9 & 252.7 & \\
\hline & & & F8.308; $\mathrm{p}=<0.001$ \\
\hline
\end{tabular}

\section{Discussion}

The principal finding of this study is that almost 39,000 procedures, of which $75 \%$ are considered as painful, were performed on a group of 120 infants over the first 14 days of life. The study confirms also that pain assessment using a validated tool is performed systematically in daily practice in preterm infants and that analgesia was given to $99 \%$ of all neonates under investigation.

The mean frequency of 22.9 general procedures and 17.3 painful procedures, per infant per day, is higher than has been described in previous research. With a median of 16 procedures on day 14 a higher number of procedures than described in other studies (Johnston et al., 1997; Benis and Suresh, 2001; Stevens et al., 2003; Simons et al., 2003) was found. In interpreting the data, it should be considered that the highest frequency was documented for the procedure manipulation on CPAP (prongs insertion/reinsertion), which is hardly described as a procedure in other studies. A further explanation for the high number could be that other procedures, such as the insertion and removal of a nasogastric tube and the removal of tapes, have probably not been evaluated in the same systematic way as in the present study. As in the study of Simons et al. (2003) failed procedures (i.e. number of attempts) were part of the analysis also. This could have led to the clearly higher number of 
procedures in comparison with other studies. Furthermore, the lower mean of gestational age (29.7 weeks) of the whole sample compared with 32 weeks of gestation in the study samples of Johnston et al., (1997) and Simons et al., (2003) could be an explanation for the higher number of procedures in this study.

As expected, infants with the lowest gestational age (24 to 28 weeks of gestation) were subjected to the greatest number of painful procedures during their first 14 days of life. It is known that these infants are at high risk for neurological impairment. This higher pain exposure can be explained by the general immaturity of these infants requiring a higher degree of intensive care interventions as underlined by the significantly longer ventilation time also confirmed by this study. But it should also be considered that these infants may suffer more pain than other neonates due to a misconception in the assessment of their pain by care givers (Walco et al., 1994).

Manipulation on the CPAP prongs (insertion/reinsertion) was the most prevalent procedure, with a frequency of $24 \%$ among the 27 documented procedures. It should be mentioned that in the sites participating in this study removal and insertion of CPAP prongs is a standard procedure after each change of position for the neonate and is needed for naso-pharyngeal suctioning. The second most frequent painful procedure in the ranking was naso-pharyngeal suctioning, followed by transcutaneous 02 tape removal. Endotracheal suctioning and heel lance, which are usually considered as procedures with the highest frequency in other studies (Simons et al., 2003; Benis and Suresh, 2001; Johnston et al., 1997; Barker and Rutter, 1995; Carbajal et al., 2006), only ranked in places 5 and 7 , respectively, in the present study.

It is encouraging that for both sites the two tools BPSN and NIPS are used with a mean frequency of between 4.05 and 7.1 times per day/child. Because of their limited energy reserves infants of low gestational age cannot sustain the ability to express pain via behavioural and physiological patterns (Anand 1997). Therefore, this group of patients runs a high risk that a painful state will be underestimated (Axelin et al., 2006; Johnston et al., 1997; Walco et al., 1994; Shapiro 1993). It is therefore particularly commendable that pain assessment was performed most frequently in preterm infants of low gestational age in the present study. Most of the measurements performed at both sites showed a "non painful" state. The frequency of a "non-painful" state as a measurement outcome might appear to contradict the high amount of pain exposure described in the cohort of this study. It should however be noted that the ability to express pain can be influenced by the general immaturity of preterm infants, particularly if they are ventilated, since facial expression is reduced due to respiration devices. This phenomenon is underlined by the result of this study, which shows the highest number of non-painful scores described in the group of infants with the lowest gestational age.

We found that $71 \%$ of the preterm infants received glucose as a preventive intervention on a daily basis before a procedure. Although this is a higher amount of pain prevention than described in earlier studies (Simons et al., 2003; Johnston, 1997) this result clearly indicates that despite the growing body of literature on the efficacy of sucrose as an analgesic, nurses do not standardly administer it before painful procedures, as only $9 \%$ of all infants receiving glucose received it every day. In the group of pharmacological agents an intermittent bolus of morphine is the most commonly used analgesic (66\%). The fact that only one child had no analgesia at all indicates more appropriate pain management than reported in previous studies (Simons et al., 2003, Sabrine and Sinha, 2000; Johnston et al., 1997), where the absence of non-pharmacological and pharmacological analgesia was much more common. 
In conclusion the present study confirms that iatrogenic pain is a serious problem particularly in preterm infants of low gestational age. Further we found that pain assessment is an integrative part of the daily clinical routine in the participating sites of this study, especially in preterm infants, who run a high risk of pain underestimation. Almost all infants received either non-pharmacological preventive analgesia before a procedure or were given an intermittent dose of morphine as a pain relieving intervention. However, some critical points in pain management were also discerned in this study: a) Infants with the highest level of pain exposure received the lowest amount of pharmacological analgesics. b) Despite the daily procedural exposure undergone by each of the infants, only a minority received pre-emptive glucose every day.

As several studies in human and animal neonates show, repeated and sustained pain can have direct and long-term consequences on neurological and behaviour-oriented development (Anand, 1997; Bhutta et al., 2001, Gagnon, 1999; Grunau et al., 2005; 2002; 2001; 1998; 1994; Oberlander et al., 2000; Peters et al., 2005, Ren et al., 2004; Ruda et. al., 2000; Taddio and Katz, 2005).These results need further discussion to improve the situation in the clinical setting by reducing the exposure to pain and improving pain relieving interventions for the most preterm infants. 


\section{References}

Anand KJS. Long-term effects of pain in neonates and infants. In: Jensen TS, Turner JA, WiesenfeldHalling Z, eds. Proceedings of the 8th World Congress on Pain. Seattle, WA: IASP Press 1997; pp:881-92.

Axelin A, Salanterä S, Lehtonen L. Facilitated tucking by parents in pain management of preterm infants - a randomized crossover trial. Early Hum Dev 2006; 82:241-47.

Barker DP, Rutter N. Exposure to invasive procedures in neonatal intensive care unit admissions. Arch Dis Child Fetal Neonatal Ed 1995; 72:F47-8.

Bhutta AT, Rovnaghi C, Simpson PM, Gosset JM, Scalzo FM, Anand KJS. Interactions of inflammatory pain and morphine in infant rats: Long-term behavioral effects. Physiol Behav $2001 ; 73: 51-8$.

Blass EM, Watt LB. Suckling- and sucrose-induced analgesia in human newborns. Pain 1999; $83: 611-23$.

Benis MM, Suresh GK. Frequency of invasive procedures in very low birth weight (VLBW) infants in the neonatal intensive care unit (NICU) (abstract). Pediatr Res 2001; 49:392A.

Boyle EM, Freer Y, Mae Wong C, McIntosh N, Anand KJS: Assessment of persistent pain or distress and adequacy of analgesia in preterm ventilated infants. Pain 2006; 124:87-91.

Carbajal R, Mucha J, Milagro R, Arias J, Bao V, Rivadeneyra M, Zegarra, J, Bazan C, Cimerman P, Annequin D.: Epidemiology of painful procedures and analgesic therapy in neonates in NICUs of a developing country, Peru: Poster presentation, Poster Abstract, 7th International Symposium on Pediatric Pain, Vancouver, June 2006, Pain Res Manage Vol 11 Suppl B, Summer 2006; E29.

Cignacco E, Hamers J, Stoffel L, Schütz N, van Lingen R, Zimmermann L, Nelle M: Differences in the assessment of the intensity of procedural pain in NICUs. Poster Abstract, 7th International Symposium on Pediatric Pain, Vancouver, June 2006, Pain Res Manage Vol 11 Suppl B Summer 2006; 41B.

Cignacco E, Müller R, Hamers JPH, Gessler P. Pain assessment in the neonate using the Bernese Pain Scale for Neonates. Early Hum Dev 2004; 78:125-31.

Franck LS, Cox S, Allen A, Winter I. Parent's view about infant pain in neonatal care. Clin J Pain $2005 ; 21: 133-9$.

Gale G, Franck LS, Kools S, Lynch M. Parents perception of their infant's pain experience in the NICU. Int J Nurs Stud 2004; 41:51-8. 
Gibbins S, Stevens B. Hodnett E, Pinelli J, Ohlsson A. Darlington G. Efficacy and safety of sucrose for procedural pain relief in preterm and term neonates. Nurs Res 2002; $51: 375-81$.

Gagnon R. Leung A, Macnab A. Variations in regional cerebral blood volume in neonates associated with nursery care events. Am J Perinatol 1999; 16:7-11.

Grunau RE, Holsti L, Haley DW, Oberlander T, Weinberg $\mathbf{J}$, Solimano A, Whitffield MF, Fitzgerald C. Yu W. Neonatal procedural pain exposure predicts lower cortisol and behavioral reactivity in preterm infants in the NICU. Pain 2005; 113:293-300.

Grunau R.: Early pain in preterm infants. A model of long-term effects. Clin Perinatol 2002; 29:373-94

Grunau R, Oberlander TF, Whitfield MF, Fitzgerald C, Lee SK. Demographic and therapeutic determinants of pain reactivity in very low birth weight neonates at 32 weeks' postconceptional age. Pediatr 2001; 107:105-12.

Grunau R. Whifield MF, Petrie JH. Children's judgements about pain at age 8-10 years. Do extremely low birthweight $(<1000 \mathrm{~g})$ children differ from full birthweight peers? J Child Psychol Psychiatr 1998; 39:587-94.

Grunau R, Whitfield MF, Petrie JH, Fryer EL. Early pain experience, child and family factors as precursors of somatization: A prospective study of extremely premature and fullterm children. Pain 1994: 56:353-9.

Johnston CC, Collinge JM, Henderson SJ, Anand KJ. A cross-sectional survey of pain and pharmacological analgesia in Canadian neonatal intensive care units. Clin J Pain 1997; $13: 308-12$

Kaufmann GE, Cimo S, Miller LW, Blass EM. An evaluation of the effects of sucrose on neonatal pain with 2 commonly used circumcision methods. Am J Obstet Gynecol 2002; 186:564-8.

Lawrence J, Alcock D, McGrath P, Kay J, Mac Murray SB, Dulberg C: The development of a tool to assess neonatal pain. Neonatal Netw 1993; 15:59-66.

Oberlander TF, Grunau R, Whitfield M, Fitzgerald C, Pitfield S, Saul JP. Biobehavioral pain responses in former extremely low birth weight infants at four months' corrected age. Pediatr 2000; 105:e6.

Padden T, Glenn S. Maternal experiences of preterm birth and neonatal intensive care. J Reprod Infant Psychol 1997; 15:121-39.

Peters JW, Schouw R, Anand KJS, van Dijk M, Duivenvoorden HJ, Tibboel D. Does neonatal surgery lead to increased pain sensitivity in later childhood? Pain 2005; 114:444-54.

Ren K, Anseloni V, Zou SP, Wade EB, Novikova SI, Ennis M, Traub RJ, Gold MS, Dubner R, Lidow MS. Characterisation of basal and re-inflammation-associated long-term alteration in pain responsivity following short-lasting neonatal local inflammatory insult. Pain 2004; 110:588-96.

Ruda MA, Qing-Dong L, Hohmann AG, Peng YB, Tachibana T. Altered nociceptive neuronal circuits after neonatal peripheral inflammation. Science $2000 ; 289: 628-30$.

Sabrine N, Sinha S. Pain in neonates. Lancet 2000; 355:932-3.

Shapiro C. Nurses judgements of pain in term and preterm newborns. JOGNN 1993;22:41-7. 
Simons SH, van Dijk M, Anand KS, Roofthooft D, van Lingen RA, Tibboel D. Do we still hurt newborn babies? A prospective study of procedural pain and analgesia in neonates. Arch Pediatr Adolesc Med 2003; 157:1058-64.

Stevens B, Yamada $J$, Ohisson A. Sucrose analgesia in newborn infants undergoing painful procedures. Cochrane Database Syst Rev 2004; 3:CD001069.

Stevens B, McGrath P, Gibbins S, Beyene J, Breau L, Camfield C, Finley A, Franck L, Howlett A, McKeever $\mathrm{P}$, O'Brien $\mathrm{K}$, Ohlsson A, Yamada J. Procedural pain in newborns at risk for neurologic impairment. Pain 2003; 105:27-35.

Stevens B, Johnston C, Franck L, Petryshen P, Jack A, Forster G. The efficacy of developmentally sensitive interventions and sucrose for relieving procedural pain in very low birth weight neonates. Nurs Res 1999; 48:35-43.

Stevens B, Taddio A, Ohlsson A, Einarson T. The efficacy of sucrose for relieving procedural pain in neonates - a systematic review and meta-analysis. Acta Paediatr 1997; 86:837-42.

Taddio A, Katz J. The effects of early pain experience in neonates on pain responses in infancy and childhood. Paediatr Drugs 2005; 7:245-57.

Walco GA, Cassidy RC, Schechter NL. Pain, hurt and harm. The ethics of pain control in infants and children. N Engl J Med 1994; 32:19-33.

Walker SM. Management of procedural pain in NICUs remains problematic. Paediatr Anaesth 2005; 15:909-12. 


\section{CHAPTER 6}

PAIN RELIEF IN VENTILATED PRETERMS

DURING ENDOTRACHEAL SUCTIONING.

A RANDOMIZED CONTROLLED TRIAL

Cignacco E, Hamers JPH, van Lingen RA, Zimmermann LJI, Müller R, Gessler P, Nelle M

Submitted 2007 


\section{Abstract}

Background: In Switzerland approximately $8 \%-9 \%$ of infants are born prematurely. Some of them need mechanical ventilation and undergo endotracheal suctioning (ETS). ETS is one of the most frequently performed interventions and is linked to stress and pain, but its treatment is controversial. In Switzerland there is a lack of standardization in pain relief for ETS.

Aims: To test the hypothesis that an intermittent dose of morphine reduces pain during ETS and that subsequent multisensorial stimulation, as a non-pharmacological comforting intervention, helps infants to recover from experienced pain.

Method: A randomized placebo-controlled trial in two tertiary NICUs with a sample of 30 mechanically ventilated preterm infants was conducted.

Results: Morphine did not lead to any pain relief from ETS as measured by three pain scales. Nor did the comforting intervention of multisensorial stimulation show any effect. Repeated-measure analysis of variance for the within- and between groups comparison showed no statistical significance.

Conclusions: The administration of morphine for pain relief in ventilated preterm neonates during ETS remains questionable and the use of multisensorial stimulation as a comforting intervention after painful stimulus cannot be recommended. The validity-testing of the instruments for this patient population should undergo a systematic validation trajectory. Future research should focus on options among non-pharmacological interventions for relieving pain during ETS. 


\section{Introduction}

In Switzerland approximately $8 \%$ of the preterm infants are born prematurely and $3 \%$ out of them require mechanical ventilation with a mean intubation time of 6.75 days (Swiss Minimal Neonatal Data Set, 2004). As part of their intensive care these infants undergo endotracheal suctioning (ETS), one of the most commonly performed nursing procedures while infants are being ventilated (Simons et al., 2003, Benis and Suresh, 2001, Cignacco et al., 2007 manuscript in preparation). ETS is associated with stress and pain and its use is therefore a matter of ongoing discussion. A related problem is that there is insufficient evidence to recommend routine use of opioids in ventilated newborns (Bellù et al., 2005). Although opioids and especially morphine are used in neonates for the treatment of procedural and postoperative pain and pain during mechanical ventilation, concerns exist about potential side effects such as urinary retention, constipation and necrotising enterocolitis (Anand et al., 1999; Saarenmaa et al., 1999; Orsini et al., 1996). Furthermore, preemptive morphine infusions, additional morphine, and lower gestational age are associated with hypotension among preterm neonates (Hall et al., 2005). Due to the possible side effects, reluctance to use opioids (Johnston, 1997) and their underutilization in NICUs (Franck 2002; Franck and Miaskowski 1998; Anand, 1998) might be explained.

The results of the NEOPAIN randomised trial of morphine analgesia in ventilated preterm neonates showed that morphine use did not alter the risk of severe intraventricular haemorrhage (IVH), cystic periventricular leukomalacia or death within 28 days (Anand et al., 2004, Hallstrom, 2003). In a subsequent analysis, the authors concluded that the use of morphine prolonged the duration of mechanical ventilation. Similar results are shown by Simons et al. (2003a), who describe a decreased incidence of IVH $(23 \%$ vs. $40 \%, p=0.04)$ in the group receiving morphine. However, morphine had no protective effect on poor neurologic outcome as defined by severe IVH (grade 3 and 4) or death.

The efficacy of morphine in pain relief is also questionable. Continuous morphine infusion was found to have no apparent analgesic effect in some studies (Carbajal et al., 2005; Simons et al., 2003a) while Anand et al. (2004) found that pain scores were reduced slightly. In contrast, a metaanalysis carried out by Anand and Hall (2006) showed significantly lower pain scores in the morphine group. It is therefore recommended that opioid analgesia should be limited to the treatment of severe or repetitive pain in preterm neonates or clinical situations in which it provides short-term clinical benefit (Anand et al., 2004).

Non-pharmacological pain relieving interventions are also increasingly discussed (Cignacco et al., 2007). Multisensorial stimulation which addresses the neonate on a number of different sensory levels (auditory, orogustatory, tactile), has been described as pain relieving for heel-prick (Bellieni et. al., 2001). Facilitated tucking as a further non-pharmacological intervention might add to diminishing the pain/stress from ETS (Ward-Larson, 2004). 
In contrast to the studies just mentioned, which were testing a continuous administration of morphine, the aim of the present study was to determine the effects of an intermittent dose of morphine on pain resulting from ETS and further to investigate the effect of multisensorial stimulation (MSS) after pain exposure. The number of routine procedures the infants were exposed to was also of interest.

We hypothesized that pain could be reduced by administering an intravenous dose of $0.1 \mathrm{mg} / \mathrm{kg}$ of morphine (primary endpoint) and that MSS would help to recover from a painful stimulus particularly in the group receiving a placebo (secondary endpoint).

\section{Methods}

\subsection{Design and setting}

A prospective multicenter randomized controlled and blinded study design was used. The sample was recruited from two tertiary level NICUs in Switzerland with 32 (site 1) and 19 (site 2) beds respectively and included 30 preterm infants who required mechanical ventilation and who were ventilated for over 13 hours. The sample was divided into two groups (morphine vs. placebo) covering all the neonates who were born in the period from 1st May 2004 to 30th April 2006.

\subsection{Sample, inclusion and exclusion criteria}

All preterm neonates who were $\geq 24$ to 37 weeks postmenstrual age based on early ultrasound, who were admitted to the NICU and who were intubated and mechanically ventilated were eligible for inclusion. The data analysis for the effect of morphine and the effect of multisensorial stimulation included the first 5 days of mechanical ventilation. Data on morbidity included the whole hospitalization period until discharge or until transmission to another hospital. Eligibility for study inclusion was validated by neonatologists and a clinical nurse specialist in the first 24 hours after birth. The following criteria for exclusion were set: Preterm infants a) with diagnosed IVH grade III and IV, b) suffering from any condition involving partial or total loss of sensitivity, c) who had been given morphine intravenously up to 10 hours before the study started, d) with an APGAR score $<3$ after 5 minutes or with a cord blood $\mathrm{pH}$ of $<7.00$ ), e) whose mothers were drug addicts, $f$ ) who were ventilated after surgery. The original sample size $(n=100)$ was based on the ability to detect a difference of $1 / 2 \sigma$ in the mean pain score in the two groups measured by three pain assessment tools. The random sampling calculations were based on al level of significance of $5 \%$ and a quality level of $80 \%$ using the NCSS trial and PASS 2000 program.

\subsection{Study Procedures}

\subsubsection{Inclusion and investigation procedure}

If an infant was eligible the primary investigator or the study nurse was asked to obtain final informed consent from the parents. Whenever possible, preterm infants were included in the study from the first day of intubation on. In order to identify IVH, a cranial ultrasound was carried out by a physician in the first 24 hours of life.

\subsubsection{Randomization procedure}

As shown in figure 6-1 preterm infants were selected at random for the type of treatment they were to receive. This selection was made on the basis of a computer list relating to the medication to be given (morphine or a placebo) as well as the comforting technique to be used after suctioning (multisensorial stimulation or standard technique). A sealed opaque envelope contained each infant's randomisation 
number. The primary investigator or the study nurse opened the envelope and assigned the child according to its number to one of the treatment groups. The medication was prepared in the correct dose and numbered correspondingly by the hospital pharmacy. In the case of assignment to the morphine group, a dose of $0.1 \mathrm{mg} / \mathrm{kg}$ was set for this study. Neither the nurse taking care of the infant nor the prescribing doctor knew which type of medication was given.

The interval between treatments depended on the need for suctioning in the individual infant and was decided by the nurse in charge. Owing to the long half-life of morphine in preterm infants an interval of 6 hours was set for repeating medication during ETS. If it was necessary to suction the infant sooner, the medication was either modified accordingly $(0.05 \mathrm{mg} / \mathrm{kg})$ or not given at all. Additional open-label morphine was allowed if infants were considered to be in pain, as verified by a pain score.

Figure 6-1: Diagram of randomization and investigation

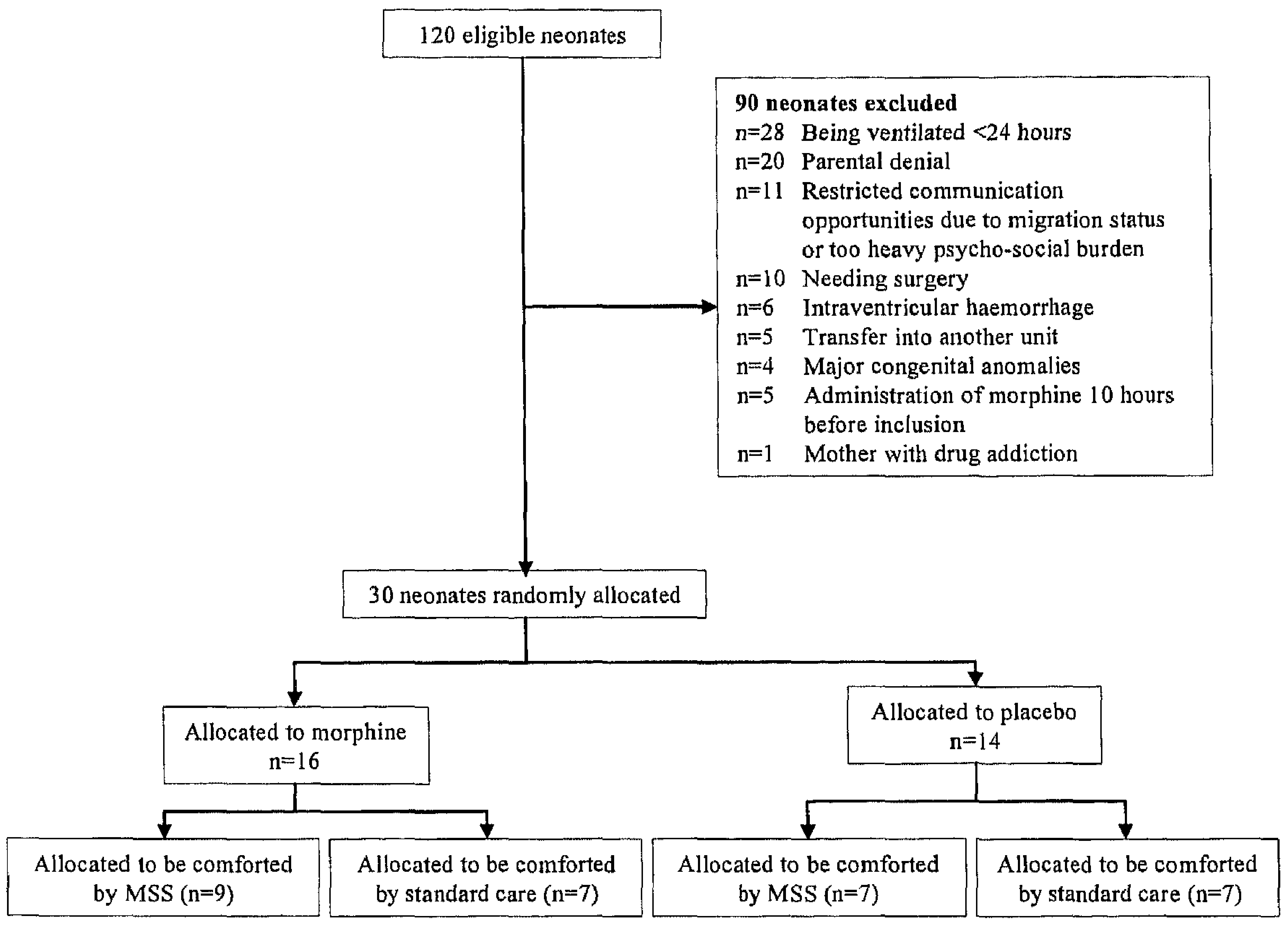




\subsubsection{Intervention procedure}

Routine ETS was carried out by qualified and trained nurses, who administered the i.v. medication 5 minutes before the ETS. After the suctioning, the infant was comforted by the same nurse for 2 to 3 minutes either by randomized multisensorial stimulation (MSS) or by using a standard method (holding the child in the incubator). A second qualified and trained nurse on duty performed the scoring, using all three pain assessment tools (see section 2.4.1). The scoring nurse did not observe the comforting intervention, but was called for the assessment immediately after the comforting was finished by the nurse caring for the child.

\subsection{Data collection}

Background demographic data were collected from nursing and medical charts. A standardized document listing 27 routine procedures was used to record the number of painful procedures throughout the first 14 days. The standardized list of procedures was developed on the basis of a literature search, highlighting the most common painful procedures neonates are exposed to (Barker and Rutter, 1995; Johnston et al., 1997; Simons et al., 2003b). Expert opinion was also consulted in compiling the list.

\subsubsection{Pain measurements}

There is no gold standard for measurements of pain in ventilated preterm infants. In the present study the "Bernese Pain Scale for Neonates" (BPSN) (Cignacco et al., 2004), the "Premature Infant Pain Profile (PIPP) (Ballantyne et al., 1999) and the "Visual Analogue Scale" (VAS) (Price et al., 1994) were used simultaneously. The BPSN and the PIPP are both multidimensional tools used to objectivate acute pain and demonstrating satisfying psychometric properties among preterm and term neonates in validation studies. The BPSN measures 9 indicators, two of which are observed on the monitor (heart rate and oxygen saturation) and seven clinically (grimacing, body movements, crying, skin colour, sleeping patterns, respiration, and consolation). Validation of the BPSN tool showed construct validity with a differentiation between painful and non-painful procedures $(F=41.27 ; p=<$ $0.0001)$, inter-rater reliability coefficients of $r=0.86-0.97$ and intrarater reliability of $(r=0.98-$ 0.99). In the BPSN-scaling a score of $\leq 11$ is considered to be non-painful. The PIPP measures gestational age, behavioural state, heart rate, oxygen saturation, and 3 facial reactions (brow bulge, eye squeeze, and nasolabial furrow). Validation of the PIPP score showed construct validity with an ability to differentiate painful from non-painful procedures or baseline events $(p=0.0001)$, inter-rater reliability coefficients of 0.93 to 0.96 , and intra-rater reliability coefficients for individual events of 0.94 to 0.98 . The cut-off score for a painful state of the PIPP is set at $\geq 12$ points. The VAS is recommended as a tool for assessing pain in clinical studies. The cut-off of a painful state of the VAS is set at $\geq 4$ points. In the present study it was used to compare objective and subjective assessment of pain by the rating nurse. Pain is assessed at four intervals: (T0) At the baseline before administration of study medication; (T1) after administration of an analgesic, 5 minutes before ETS; (T2) during ETS; (T3) 2-3 minutes after comforting interventions (multisensorial stimulation or holding the child). Measurements were made up to the 5th day of intubation at the latest.

\subsection{Statistics}

The data were analysed descriptively and exploratively using statistical values (mean, standard deviation) and the hypotheses were examined using variance analysis (univariate analysis and the general linear model). The within-subjects factor were the pain scores of the BPSN, PIPP, VAS at T0, $\mathrm{T} 1, \mathrm{~T} 2, \mathrm{~T} 3$; the between-subjects factor was the treatment group (placebo versus morphine). Mauchly's test of sphericity was verified before interpretation of results. Nominal variables were 
compared with Chi tests of Fischer's exact tests (for contingency tables with small cell frequency). If the data were not distributed normally, non-parametric procedures were used. In the comparison of MSS and standard comforting it was expected that the infants in the placebo group would be comforted more quickly through MSS. This was verified using exploratory statistics. No power analysis was done in this respect. All data were entered into an SPSS-File (Version 14). The assumptions for parametric tests were verified by Q-Q-Plots.

\section{Ethical considerations}

In the two participating hospitals the clinical routine of analgesia for ETS intervention is characterised by heterogeneity. While at one site no pre-emptive analgesia is given at all, the other site administers Pethidine (Meperidine). The administration of Pethidine (Meperidine) is not recommended (Anand et al., 2001) because of its potential to cause central nervous system irritability and convulsion due to accumulation of the drug and its metabolite (Pokela et al., 1992; Saneto et al., 1996) The "no treatment" as part of standard care at one site and the use of a potentially harmful agent at the other, as well as the lack of evidence for the pain relieving effect of morphine led the author group to agree that the trial with a placebo group was ethically acceptable according to international consensus (World Medical Association's Declaration of Helsinki, revised 2000). In order to ensure that each infant received at least some pain relief even in the placebo-group, each preterm infant enrolled in the study was given $0.1 \mathrm{ml} / \mathrm{kg}$ of $30 \%$ glucose orally in addition to the morphine or placebo. Glucose, which has provided sufficient evidence for pain relief (Stevens et al., 2004) was given. Glucose is not a strong analgesic but simply reduces sensitivity to pain. The glucose was given to the infant orally in addition to the study medication.

The study was approved by all local ethics committees (two in the Canton of Bern; main ethical board and sub-commission for paediatrics and two in the Canton Zürich; main ethical board and sub-commission for paediatrics) according to national and local regulations. Written informed parental consent was obtained according to local rules.

\subsection{Problems of patient recruitment during this study}

As already encountered in a study of Ballard et al. (2004), we were confronted with the problem that a full understanding of the study aim was difficult for parents to acquire and required several conversations with the researcher team, before consent was given. However, it is an ethical principle in research that parents fully understand the research intention and aims. Furthermore, the fact that migrants make up $45 \%$ of the hospital population, some of them with refugee status and lacking any knowledge of the local language, meant that adequate information policies were not always possible. For the present study we had a refusal rate of $22 \%$; furthermore, $12 \%$ of the parents of the preterm infants born in the period mentioned were not approached at all because of restricted communication opportunities due to migrant status or to too heavy a psychosocial burden.

\section{$4 \quad$ Results}

\subsection{Background demographic and clinical characteristics of the study sample}

During the study period from 1st May 2004 to 30th April 2006120 infants needed mechanical ventilation and 30 infants were enrolled in this study (Figure 6-1). There were no differences in perinatal characteristics between the morphine and placebo groups (Table 6-1). Mean ventilation time duration and therefore mean time for intermittent administration of morphine was 86.0 hours for the 
morphine group and 65.2 for the placebo group ( $\mathrm{F} 0.459 ; \mathrm{p}=0.53)$. Open-label morphine was administered to 6 infants in the morphine group and 6 infants in the placebo group with a mean dose of $0.18 \mathrm{mg} / \mathrm{kg}$ (SD 0.4) in the placebo group and $0.05 \mathrm{mg} / \mathrm{kg}$ (SD 0.09) in the morphine group $(\mathrm{F} 1.383 ; \mathrm{p}=0.25)$.

The number of procedures during the time the infants were ventilated was 3'082 for the whole sample. The mean number of procedures for the placebo group was 89.57 procedures $(+109.45)$ compared with $114.25(+111.77)$ in the morphine group (F0.371; $p=0.54)$. During the first 14 days of life 10'638 procedures occurred for all 30 preterm infants, showing no difference between the study groups ( $F 0.215 ; p=0.64)$. According to this result each preterm infant was on average exposed to 354.6 procedures in the first two weeks of life or 25.3 procedures per day.

Table 6-1: Background demographic and clinical characteristics

\begin{tabular}{|c|c|c|c|c|c|}
\hline & \multicolumn{2}{|c|}{$\begin{array}{l}\text { Morphine } \\
(n=16)\end{array}$} & \multicolumn{2}{|c|}{$\begin{array}{c}\text { Placebo } \\
(n=14)\end{array}$} & \multirow[t]{2}{*}{$\begin{array}{c}\text { Level of } \\
\text { significance } \\
\text { (p value) }\end{array}$} \\
\hline & $N$ & $\%$ & $\mathbf{N}$ & $\%$ & \\
\hline \multicolumn{6}{|l|}{ Gender } \\
\hline Male & 10 & 37.5 & 11 & 78.6 & \\
\hline Female & 6 & 62.5 & 3 & 21.4 & \\
\hline Total pro study group & 16 & $100.0 \%$ & 14 & $100 \%$ & \\
\hline Gestation from $24-28$ weeks & 9 & 56.3 & 8 & 57.1 & \\
\hline Gestation from $28-32$ weeks & 5 & 31.3 & 3 & 21.4 & \\
\hline \multirow[t]{2}{*}{ Gestation from $32-37$ weeks } & 2 & 12.5 & 3 & 21.4 & \\
\hline & Mean & SD & Mean & SD & \\
\hline Gestational age & 28.1 & 3.0 & 28.0 & 3.9 & $F 0.006(0.940)$ \\
\hline Birth weight (g) & $1^{\prime} 113.4$ & 562.4 & $1 \times 110.2$ & 703.5 & $\mathrm{~F} 0.000(0.989)$ \\
\hline Apgar 1 minute & 4.3 & 1.9 & 4.5 & 2.5 & F0.023 (0.881) \\
\hline Apgar 5 minute & 6.6 & 2.1 & 6.7 & 2.1 & $F 0.053(0.820)$ \\
\hline Ventilation time in hours & 86.0 & 79.8 & 65.2 & 87.5 & F0.459 (0.503) \\
\hline $\begin{array}{l}\text { Amount of suctioning } \\
\text { procedures during study time }\end{array}$ & 13.7 & 8.9 & 11.2 & 12.2 & F0.381 (0.542) \\
\hline $\begin{array}{l}\text { Amount of procedures during } \\
\text { intubation time }\end{array}$ & 114.2 & 111.7 & 89.5 & 109.4 & $\mathrm{~F} 0.371(0.547)$ \\
\hline $\begin{array}{l}\text { Amount of procedures during } \\
\text { the first } 14 \text { days of life }\end{array}$ & 356.4 & 127.4 & 377.9 & 121.2 & F0.251 (0.646) \\
\hline Weight at discharge & $2 ' 207.3$ & 835.2 & $2 \cdot 306.5$ & 858.3 & $F 0.096(0.759)$ \\
\hline \multirow[t]{2}{*}{$\begin{array}{l}\text { Head circumference at } \\
\text { discharge }\end{array}$} & 33.9 & 7.0 & 33,3 & 3.0 & F0.094 (0.762) \\
\hline & $\mathbf{N}$ & $\%$ & $\mathbf{N}$ & $\%$ & \\
\hline $\begin{array}{l}\text { Patients receiving additional } \\
\text { open label morphine }\end{array}$ & 6 & 38 & 6 & 43 & N.A. \\
\hline $\begin{array}{l}\text { Patients receiving } \\
\text { multisensorial stimulation }\end{array}$ & 9 & 56 & 7 & 50 & N.A. \\
\hline $\begin{array}{l}\text { Patients receiving standard } \\
\text { comfort technique }\end{array}$ & 7 & 43 & 7 & 50 & N.A. \\
\hline
\end{tabular}

All values expressed as means (standard deviation) or amoumts (\%);

N.A: No statistical testing applicable 
PAIN RELIEF IN VENTILATED PRETERMS DURING ENDOTRACHEAL SUCTIONING. A RANDOMIZED CONTROLLED TRIAL

\subsection{Effect of morphine}

Mean pain scores for both groups are shown in table 6-2. Overall, we found that pain scores did not significantly differ between the two groups. Because of the known possible lack of behavioural reactions in preterm infants, a calculation was made including only the physiological indicators measured by the BPSN (mean of the increase in heart rate and mean of the decrease in oxygen saturation) to verify whether physiological changes could indicate a reaction to pain independently from behavioural indicators. Table 6-2a shows that there are no statistically significant differences in the mean pain score as measured by heart rate and oxygen saturation between the two groups. Table 63 shows the results of the repeated-measure analysis of variance for the within- and between groups comparisons of pain scores using the BPSN, the PIPP and the VAS. Mean pain scores induced by endotracheal suctioning (pain at TO - T3) show a statistical difference for the total scores of BPSN (F20.358; $\mathrm{p}=<0.001$ ), for the PIPP (F11.519; $\mathrm{p}=<0.001)$ and for the VAS (F17.74; $\mathrm{p}=<0.001$ ) over time (see also figure 6-2a-6-2c). The within-groups analysis of the interaction between the time factor and the treatment group detected no statistical significance either for the BPSN (F1.060; $\mathrm{p}=$ 0.359 ), the PIPP (F0.092; $p=0.932$ ) or for the VAS (F1.099; $p=0.347$ ). Further, the same analysis for the BPSN with physiological parameters only showed no statistical difference, either for the mean pain scores over time $(F 0.847 ; \mathrm{p}=0.457)$ or for the interaction of time and treatment group (F0.002; $p$ $=0.969)$ (see Table 6-3a).

Table 6-2: Pain scores induced by endotracheal suctioning performed before any intervention (T0), after i.v. administration of study medication (T1), during endotracheal suctioning (T2) and after comforting technique (T3)

\begin{tabular}{|c|c|c|c|c|c|}
\hline & \multicolumn{2}{|c|}{$\begin{array}{l}\text { Morphine } \\
(\mathrm{n}=16)\end{array}$} & \multicolumn{2}{|c|}{$\begin{array}{c}\text { Placebo } \\
(n=14)\end{array}$} & \multirow[t]{2}{*}{$\begin{array}{l}\text { Level of } \\
\text { significance } \\
\text { (p value) }\end{array}$} \\
\hline & Mean & SD & Mean & SD & \\
\hline \multicolumn{6}{|l|}{$\begin{array}{r}\text { Bernese Pain Scale for } \\
\text { Neonates (BPSN) }\end{array}$} \\
\hline T0 & 3.5 & 2.6 & 4.4 & 2.2 & F0.012(0.914) \\
\hline T1 & 3.6 & 2.8 & 3.0 & 1.5 & F0.484 (0.492) \\
\hline $\mathrm{T} 2$ & 6.6 & 2.5 & 7.6 & 2.9 & F0.907 (0.349) \\
\hline $\mathrm{T3}$ & 3.2 & 2.3 & 4.3 & 4.2 & $\mathrm{~F} 0.821(0.373)$ \\
\hline \multicolumn{6}{|l|}{$\begin{array}{l}\text { Premature Infants } \\
\text { Pain Profile (PIPP) }\end{array}$} \\
\hline To & 5.4 & 1.8 & 5.0 & 1.5 & F0.581(0.452) \\
\hline $\mathrm{T} 1$ & 5.4 & 0.9 & 4.8 & 1.2 & $F 2.047(0.164)$ \\
\hline $\mathrm{T} 2$ & 6.8 & 1.5 & 6.6 & 2.0 & $\mathrm{~F} 0.116(0.736)$ \\
\hline T3 & 4.8 & 1.8 & 4.5 & 2.4 & F0.188 (0.668) \\
\hline \multicolumn{6}{|l|}{$\begin{array}{r}\text { Visual Analogue Scale } \\
\text { (VAS) }\end{array}$} \\
\hline To & 16.7 & 16.9 & 14.9 & 11.9 & $\mathrm{~F} 0.110(0.742)$ \\
\hline $\mathrm{T} 1$ & 15.4 & 11.8 & 11.9 & 8.3 & F0.856 (0.363) \\
\hline $\mathrm{T} 2$ & 28.9 & 15.0 & 33.0 & 16.3 & F0.502 (0.484) \\
\hline $\mathrm{T3}$ & 9.5 & 6.4 & 14.8 & 19.9 & $F 1.010(0.323)$ \\
\hline
\end{tabular}


Table 6-2a: Mean of total physiological pain scores only of the BPSN

\begin{tabular}{|c|c|c|c|c|c|}
\hline & \multicolumn{2}{|c|}{$\begin{array}{l}\text { Morphine } \\
(n=16)\end{array}$} & \multicolumn{2}{|c|}{$\begin{array}{c}\text { Placebo } \\
(n=14)\end{array}$} & \multirow[t]{2}{*}{$\begin{array}{c}\text { Level of } \\
\text { significance } \\
\text { (p value) }\end{array}$} \\
\hline & Mean & SD & Mean & SD & \\
\hline \multicolumn{6}{|l|}{$\begin{array}{r}\text { Bernese Pajn Scale for } \\
\text { Neonates (BPSN) }\end{array}$} \\
\hline TO & 0.2 & 0.3 & 0.2 & 0.4 & F0.000 (0.988) \\
\hline $\mathrm{T} 1$ & 0.1 & 0.3 & 0.1 & 0.3 & $\mathrm{~F} 0.010(0.920)$ \\
\hline $\mathrm{T} 2$ & 0.9 & 0.8 & 1.2 & 0.7 & F1.485(0.234) \\
\hline T3 & 0.5 & 0.7 & 0.4 & 0.5 & F0.148 (0.704) \\
\hline
\end{tabular}

Table 6-3: Results of the Repeated-Measures Analysis of Variance for Within- and Between-Groups Factors Comparing Scores during ETS (T0 - T3)

\begin{tabular}{lrrrr}
\hline Source & $\begin{array}{r}\text { Sum of } \\
\text { squares }\end{array}$ & DF & F & P \\
\hline BPSN- Within group & & & & \\
\hline Time (T0, T1, T2,T3) & 293.4 & 2 & 20.35 & 0.00 \\
Interaction of time and treatment group & 15.2 & 2 & 1.06 & 0.36 \\
Error-time & 403.5 & 62 & & \\
BPSN- Between group & 3.6 & 1 & 0.22 & 0.64 \\
\hline Error & 445.7 & 28 & & \\
\hline PIPP-Within group & & & & \\
\hline Time (T0, T1, T2,T3) & 70.1 & 2 & 11.51 & 0.00 \\
Interaction of time and treatment group & 0.6 & 2 & 0.09 & 0.93 \\
Error-time & 170.5 & 64 & & \\
PIPP- Between group & 4.9 & 1 & 0.82 & 0.37 \\
\hline Error & 169.8 & 28 & & \\
\hline VAS-Within group & \multicolumn{3}{c}{} & \\
\hline Time (T0, T1, T2,T3) & 6746.1 & 2 & 17.74 & 0.00 \\
Interaction of time and treatment group & 418 & 2 & 1.09 & 0.35 \\
Error-time & 10647.7 & 66 & & \\
\hline VAS- Between group & $\mathbf{3 0 . 6}$ & $\mathbf{1}$ & $\mathbf{0 . 0 7 7}$ & $\mathbf{0 . 7 8}$ \\
\hline Error & 11191.6 & 28 & & \\
\hline
\end{tabular}

Table 6-3a: Results of the Repeated-Measures Analysis of Variance for Within- and Between-Groups Factors Comparing BPSN physiological scores only during ETS (T0 - T3)

\begin{tabular}{lcccc}
\multicolumn{1}{c}{ Source } & $\begin{array}{c}\text { Sum of } \\
\text { squares }\end{array}$ & DF & F & P \\
\hline BPSN within-group & & & & \\
\hline Time (T0, T1, T2,T3) & 0.8 & 3 & 0.847 & 0.46 \\
Interaction of time and treatment group & 0.0 & 1 & 0.002 & 0.97 \\
Error-time & 9.5 & 25 & & \\
\hline BPSN- Between group & $\mathbf{0 . 1}$ & $\mathbf{1}$ & $\mathbf{0 . 3 4 5}$ & $\mathbf{0 . 5 6}$ \\
\hline
\end{tabular}


PAIN RELIEF IN VENTILATED PRETERMS DURING ENDOTRACHEAL SUCTIONING.

Figure 6-2a: Overall mean measurements with BPSN during T0 - T3

Overall mean of measurements with BPSN

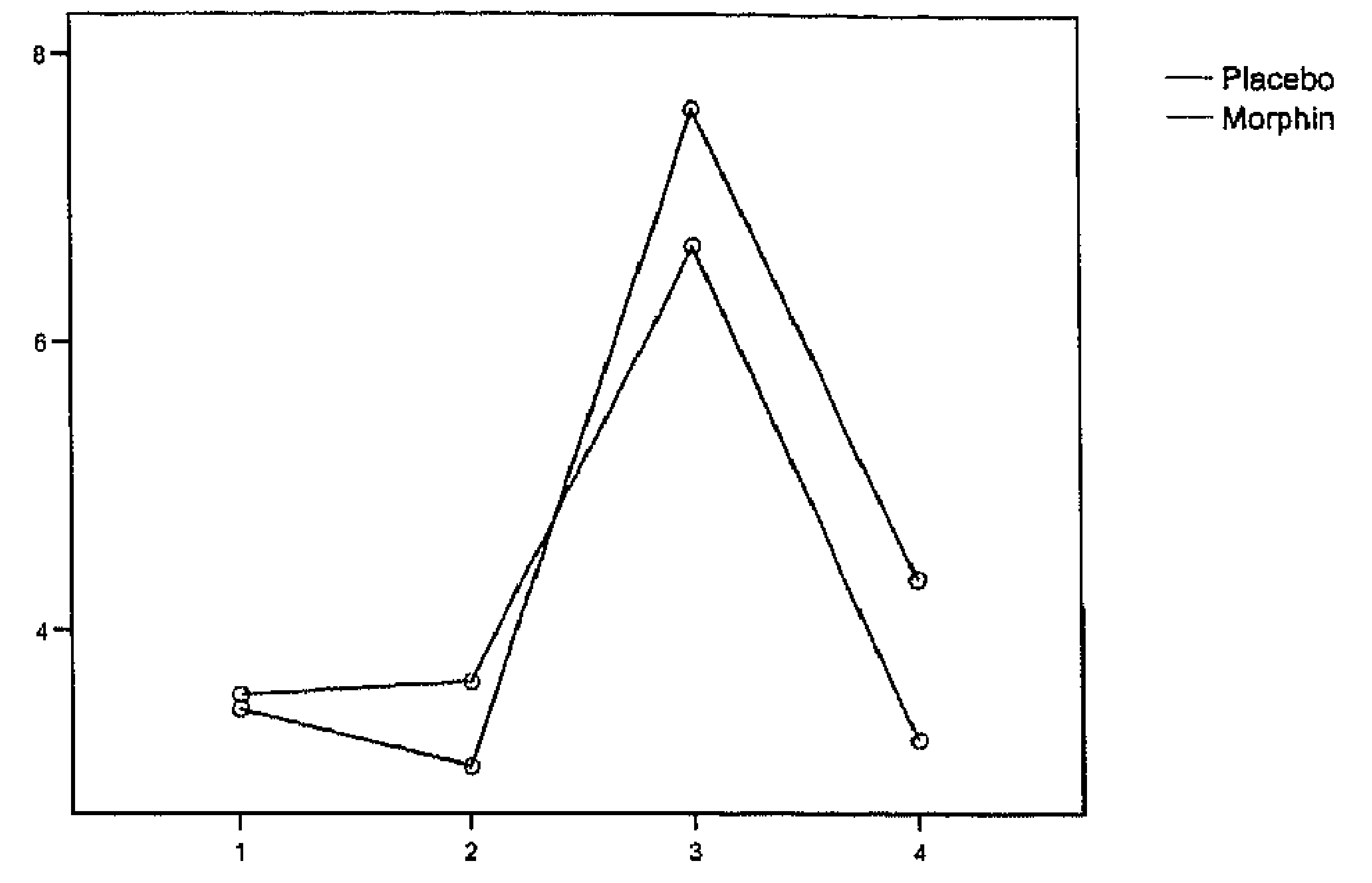

Figure 6-2b: Overall mean measurements with PIPP during T0 - T3

Overall mean of measurements with PIPP

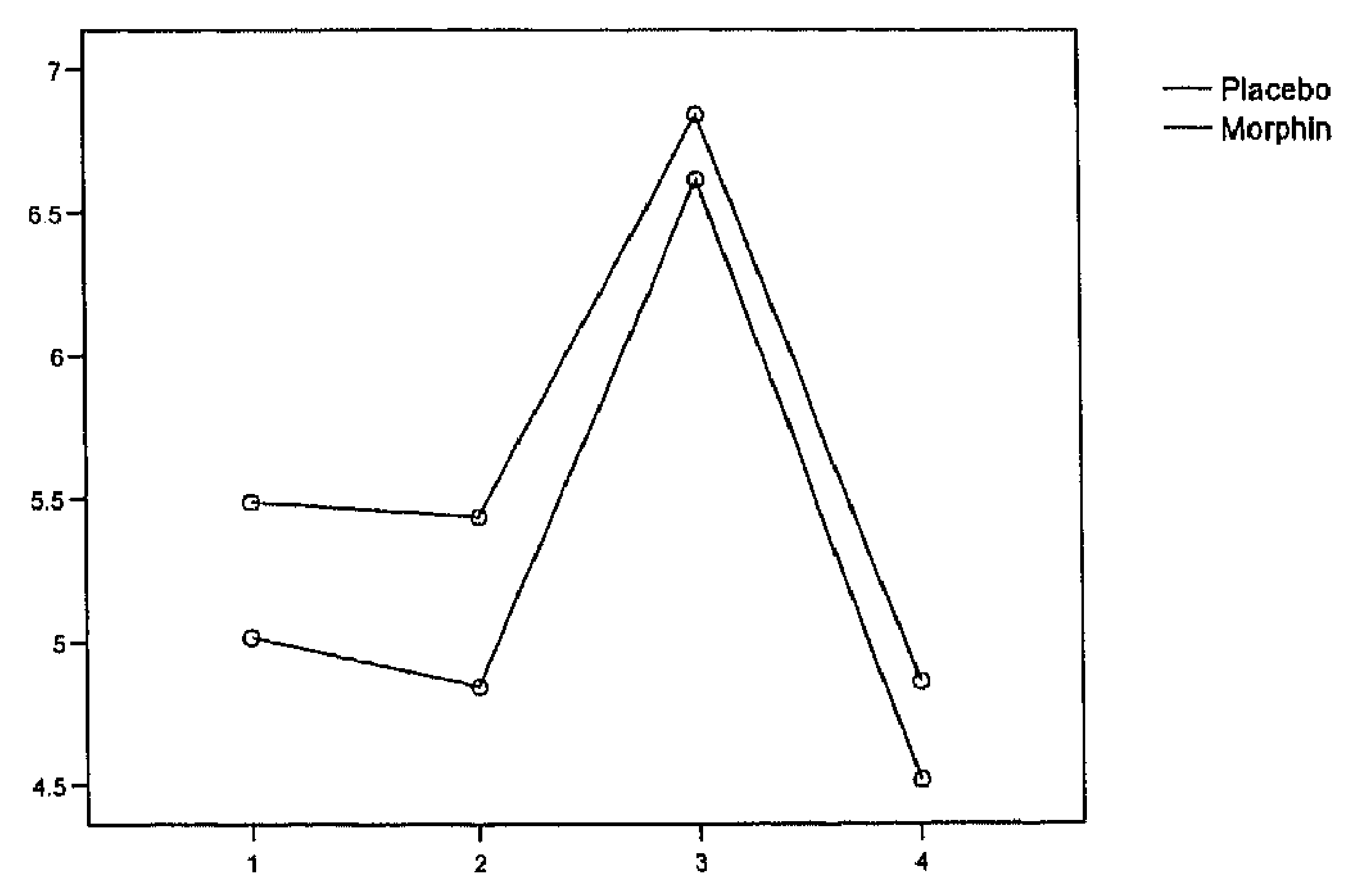


Figure 6-2c: Overall mean measurements with VAS during T0 - T3

Overall mean of measurements with VAS

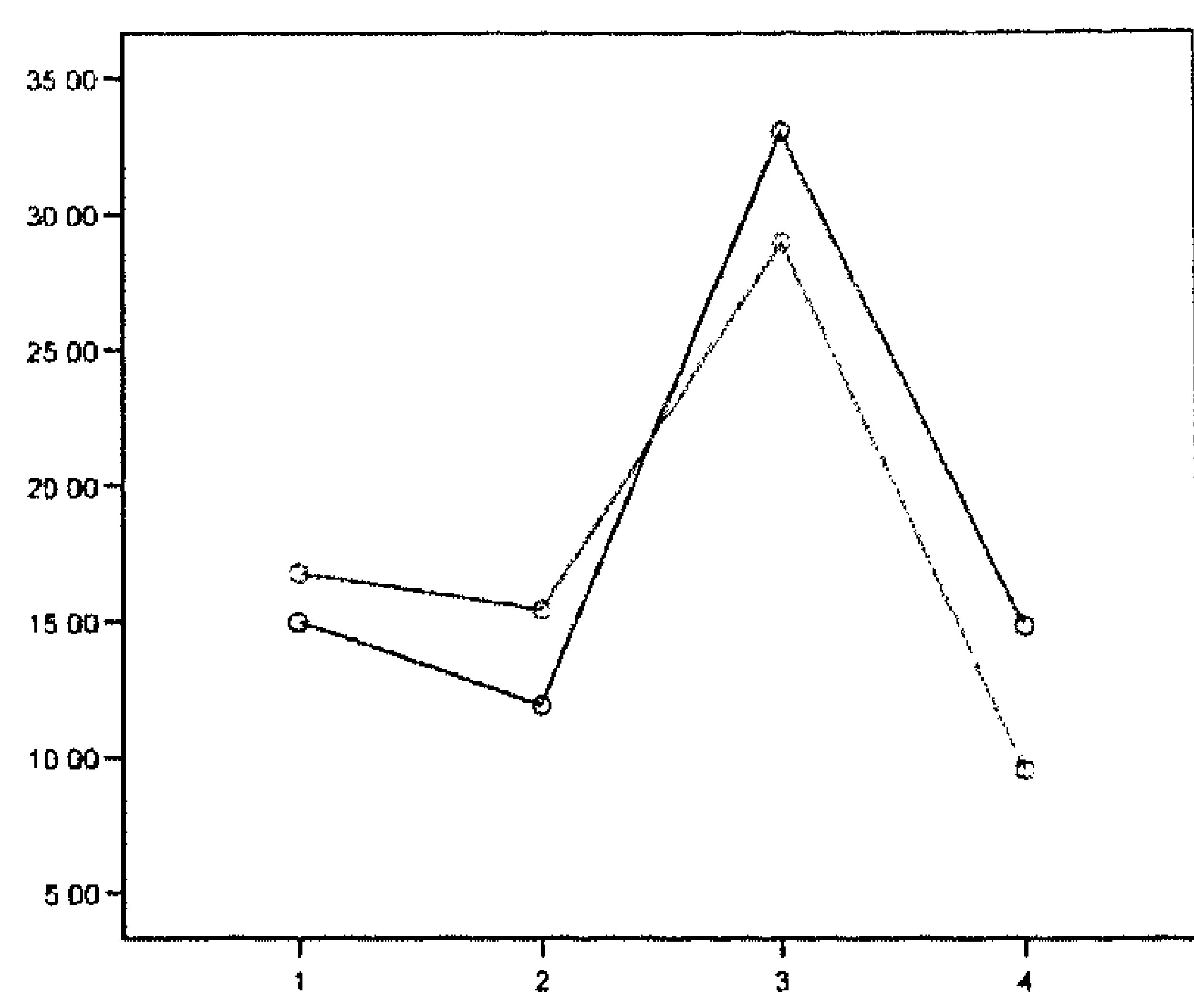

\subsection{Effect of multisensorial stimulation (MSS)}

As a comforting intervention after a painful stimulus, multisensorial stimulation was performed directly after endotracheal suctioning. Table 6-4 shows that no statistical effect could be detected in the comparison of MSS and standard comforting interventions as measured by all assessment tools. The mean pain score for MSS in the placebo group did not differ significantly from that of the standard comforting intervention. Although the pain measurements revealed no statistical significance, it is noteworthy that the mean pain score in the group of children receiving MSS as a comforting technique was higher than that of children receiving standard care, independently of the group they were assigned to.

Table 6-4: Comparison of the two comfort techniques

\begin{tabular}{llllrrl}
\hline Pain Score & Medication & N & Comfort & Mean & SD & Level of significance \\
\hline BPSN & & & & & & \\
\hline & Placebo & 7 & Standard & 3.6 & 3.8 & \\
& & 7 & MSS & 5.0 & 4.9 & \\
& \multirow{2}{*}{ Morphine } & 7 & Standard & 2.0 & 1.3 & Medication * comfort \\
& & 9 & MSS & 4.1 & 2.6 & F $0.067 ; \mathrm{p}=0.798$ \\
\hline PIPP & & & & & & \\
\hline & Placebo & 7 & Standard & 4.4 & 2.6 & \\
& & 7 & MSS & 4.6 & 2.5 & \\
& \multirow{3}{*}{ Morphine } & 7 & Standard & 3.8 & 1.9 & Medication * comfort \\
& & 9 & MSS & 5.6 & 1.4 & F 0.969; $\mathrm{p}=0.334$ \\
\hline VAS & & & & & & \\
\hline & Placebo & 7 & Standard & 13.0 & 15.8 & \\
& & 7 & MSS & 16.6 & 24.6 & \\
& \multirow{2}{*}{ Morphine } & 7 & Standard & 8.6 & 5.6 & Medication * comfort \\
& & 9 & MSS & 10.2 & 7.2 & F 0.035; $\mathrm{p}=0.853$ \\
\hline
\end{tabular}


PAIN RELIEF IN VENTILATED PRETERMS DURING ENDOTRACHEAL SUCTIONING.

\subsection{Incidence of morbidity and mortality}

Table 6-5 lists the incidences of morbidity and mortality for the two groups. Because of the small sample size the prevalence of any occurring morbidity is rather limited. With exception of the "inhibition of respiratory drive" statistical testing was not applicable. For the ventilation period there is a trend towards increased morbidity in the placebo group. For the period from extubation until discharge, there is a trend towards higher urinary retention, a higher constipation rate and higher gastric retention in the morphine group than in the placebo group. Overall, 5 infants died during the first 30 days of life ( 3 in the placebo group and 2 in the morphine group) and 1 child was diagnosed with an IVH grade 3.

Table 6-5: Morbidity and mortality

\begin{tabular}{|c|c|c|c|c|c|}
\hline & \multicolumn{2}{|c|}{$\begin{array}{c}\text { Morphine } \\
(\mathrm{n}=16)\end{array}$} & \multicolumn{2}{|c|}{$\begin{array}{c}\text { Placebo } \\
(n=14)\end{array}$} & \multirow[t]{2}{*}{$\begin{array}{c}\text { Level of } \\
\text { significance ( } p \text { value) }\end{array}$} \\
\hline & $\mathbf{N}$ & $\%$ & $\mathbf{N}$ & $\%$ & \\
\hline \multicolumn{6}{|l|}{ Morbidity during intubation time } \\
\hline Inhibition of respiratory drive & 4 & 25 & 1 & 7 & N.A. \\
\hline Urinary retention & 1 & 6 & 2 & 14 & N.A. \\
\hline Constipation (no bowel function for $>48$ hours) & 4 & 25 & 4 & 57 & N.A. \\
\hline Arterial hypotension & 6 & 37 & 6 & 42 & N.A. \\
\hline \multicolumn{6}{|c|}{ Morbidity till discharge or till transfer into another hospital } \\
\hline Inhibition of respiratory drive & 11 & 68 & 11 & 78 & 0.68 (Fisher Exact Test) \\
\hline Urinary retention & 2 & 12 & 0 & 0 & N.A. \\
\hline Arterial hypotension & 2 & 12 & 3 & 21 & N.A. \\
\hline Constipation (no bowel function for 48 hours) & 6 & 37 & 1 & 7 & N.A. \\
\hline Gastric retention & 7 & 43 & 4 & 28 & N.A. \\
\hline Chronic lung disease & 3 & 18 & 2 & 14 & N.A. \\
\hline Necrotising enterocolitis & 1 & 6 & 1 & 7 & N.A. \\
\hline Regurgitation & 4 & 25. & 4 & 28 & N.A. \\
\hline Sepsis & 2 & 12 & 1 & 7 & N.A. \\
\hline Intraventricular haemorrhage Grade 3 and 4 & 1 & 6 & 0 & 0 & N.A. \\
\hline Respiratory Distress Syndrom (RDS) & 3 & 18 & 2 & 14 & N.A. \\
\hline Persistent Ductus Arteriousus (PDA) & 6 & 37 & 5 & 35 & N.A. \\
\hline Pneumonia & 1 & 6 & 4 & 28 & N.A. \\
\hline Death during the first 30 days of life & 2 & 12 & 3 & 21 & N.A. \\
\hline
\end{tabular}

All values expressed as numbers and amounts (\%); N.A.: Statistical lesting not applicable

\section{Discussion}

Morphine did not reveal any analgesic effect for pain induced by ETS among ventilated preterm neonates, as measured with three pain scales. These results confirm earlier findings of similar studies (Simons et al., 2003a; Anand, 2004; Carbajal et al., 2005; van Dijk, 2002). Furthermore, the comforting intervention of multisensorial stimulation did not result in any difference in the mean pain score compared to the standard comforting intervention, which had been expected especially for the placebo group. In contrast to the findings of Anand et al. (2004) we could not show any statistical difference in the ventilation time between the two groups. However, the morphine group showed a tendency towards difference, with a higher mean intubation time of almost 20 hours. According to the 
clinical judgement of nurses and physicians open-label morphine was administered if the infant wats assessed as being in pain (either by objective measurements or by clinical observations of restlessness). The use of open-label morphine was slightly higher in the placebo group $(43 \% \mathrm{vs} .38 \%$.

\subsection{Possible explanations for the inefficacy of morphine}

The lack of analgesic effect requires discussion regarding aspects of hormonal responses and possitly jeopardized behavioural responses in neonates after birth. Taking into consideration that the children were enrolled within 24 hours of their birth, the low pain scores may be explained by the release of endorphines during the birth process (Simons et al., 2003), which might provide a protective effect against noxious stimuli. However, reports of B-endorphine changes over hours indicate a decrease 2 hours after the stress of birth or intubation (Pokela, 1993: Ruth et al., 1986). For this sample of children, who were included 6-10 hours after intubation, the explanation of a protective endorphine level is not convincing. The immaturity of opioid receptors (Kart et al., 1997: Rahman et al., 1998: Kinney et al., 1990) among preterm neonates and the decreased production of morphine-6-glucuronide and increased production of morphine-3-glucuronide (de Wildt et al.. 1949) might be another explanation for the lack of effectiveness of morphine. It should furthermore be considered that besides the immaturity of opioid receptors and the general organic immaturity of preterm infants. the lack of behavioural patterns in these children due to extreme stress needs to be taken into account. As postulated by Als (1982; Als et al., 1986; 1994), preterm infants in NICUs become disorganized under the extreme stress of preterm birth and the following intensive care treatment. As a consequence, they are not able to respond coherently to noxious stimuli, due to exhaustion resulting from extreme stress.

Further, it is a matter of discussion whether the pain experienced during ETS is severe enough to generally warrant the use of morphine (Anand et al., 2004). This raises the question of whether, for this short-term acute noxious stimulus, non-pharmacological interventions like "facilitated tucking" might not be a more valuable approach for pain relief (Axelin et al., 2006, Ward-Larson et al., 2004). "Facilitated tucking", a specific procedure designed to hold the child in a flexed position, alleviated behavioural pain among the preterm infants under investigation in both studies and as such deserves further assessment.

In connection with further investigations, particularly of non-pharmacological treatments, one critical point remains to be discussed. This is the blinding of pain raters, which is a very difficult requirement to fulfil in studies measuring the effect of non-pharmacological interventions, since the child needs to be observed during the pain relieving procedures. Therefore the positive pain relieving effect of a non-pharmacological intervention should be critically discussed with a special view to the non blinded raters and their subjective influence on the pain assessment through observing the procedures performed, which might have biased the results. The presumed intensity of ErS has recently been studied by a survey of 400 health care providers (Cignacco et al., 2006). According to the results of the subjective pain intensity assessment, ETS appears to be one of the most painful procedures of routine care in a NICU. This has been confirmed in studies with adults, where the suctioning procedure is associated with pain and anxiety (Jeitziner and Schwendimann, 2006). There is no plausible reason why this should be different in ventilated preterm neonates. Therefore the issue of the intensity of pain experienced during suctioning in preterm infants remains inconclusive and needs to be investigated further.

One concern about the lack of pain responses of ventilated preterm infants are the psychometric properties of the instruments used in this study, which are in need of critical reconsideration. Measuring the effect of morphine on the pain experienced by preterm infants 
generally remains difficult because of the lack of a gold standard for assessing neonatal pain. As stated in the Cochrane review of Bellù et al. (2005) one major problem regarding the primary outcomes of pain relief is the difference in measuring pain in the different studies analyzed. When subgroup analysis was performed to account for the issue of pain measurement it yielded different results, indicating problems in measuring pain. So far, the validity of the BPSN and PIPP relies on preterm neonates not needing mechanical ventilation only. As the BPSN was validated by good concurrent validity with the PIPP by Cignacco et al. (2004) and the PIPP itself was recently used for several studies regarding the efficacy of morphine, and was described as a reliable tool for this patient population as well, the research team of the present study decided that the BPSN might also be a valid tool. However, the mean difference of the BPSN was minus 0.95 (7.62 points vs. 6.67) for the morphine group during ETS (T2), a result with no statistical significance. As a difference of one point has no clinical implications, this result is not considered to be of clinical importance. The PIPP even showed a higher mean pain score for the measurement during endotracheal suctioning in the morphine group than in the placebo group (6.61 vs. 6.84). Nurses participating in this study had considerable difficulties in assessing pain with the PIPP score, which mainly focusses on the infant's facial expressions. The measurement of facial expression however, was very often jeopardized by the tapes fixing the tube and by the general immaturity of the very low birth weight children $(<1500 \mathrm{~g})$, resulting in less facial action. To achieve a valid and reliable pain measurement, we recommend further validity testing of the BPSN and PIPP for use in this particularly vulnerable patient population.

\subsection{Lack of efficacy of multisensorial stimulation as a non-pharmacological intervention}

In the present study multisensorial stimulation (MSS), performed as described by Bellieni et al. (2001) did not show any pain relieving effect. Although the subgroups for the comparison between multisensorial stimulation and standard comforting intervention were too small to generalize findings, the results show that none of the instruments showed a significant difference between the groups for this intervention. This contrasts with the findings of Bellieni et al. (2001), whose study showed positive results in a sample of 17 non ventilated preterm neonates with $<35$ weeks gestation. It is however notable that we found even higher mean pain scores in preterm infants comforted by MSS than comforted by standard care, even in the placebo group. These empirical data are in line with the clinical experiences during the study: According to several feedbacks of trained nurses who performed MSS in this study they observed the infants mainly being over stimulated by this intervention by the different levels of stimuli (auditory, orogustatory, olfactory and tactile) they had to cope with.

\subsection{Number of procedures}

During the first 14 days of life 10,638 procedures occurred for all the 30 preterm infants, showing no difference between the study groups (F0.215; $\mathrm{p}=0.646$ ). According to this result each preterm infant was on average exposed to 354.6 procedures in the first two weeks of life or 25.3 procedures per day, a higher exposure to painful procedures than previously reported (Johnston et al., 1997, Benis and Suresh, 2001, Stevens et al., 2003, Simons et al., 2003, Carbajal et al., 2006). This difference in pain exposure might be due to discrepancies in the listing of routine procedures and the inconsistent consideration of failed procedures between studies.

No conclusive statements can be made regarding the incidence of morbidity and mortality in either group since the sample size for each event is too small.

Finally, a major methodological constraint needs to be discussed for the present study: a small sample size critically affects the validity of the findings. The small sample size of the present study 
clearly affects its statistical power (a post hoc power analysis revealed that the power of the study is 0.152 , this in accordance with the mean and SD of the BPSN during endotracheal suctioning, with alpha set at 0.05 and a sample size of $n=30$, based on a one-way ANOVA). Although the study period lasted almost 2 years, only 30 children could be included in the study. Small sample sizes are a crucial problem for research projects in the NICU setting, due to the vulnerability of the study sample and the general recruitment problems mentioned above (see section 3.1). It was not possible to extend the study period because of practical and financial constraints which the research group had to cope with. However, we believe that the issues addressed in this study concerning the questionable psychometric properties of the instruments and the reasons for a lack of pain response clearly come through despite the small sample size. These important issues need to be discussed critically for further investigation of pain management in ventilated preterm infants.

\section{Conclusions}

The use of morphine for pain relief during ETS and the use of multisensorial stimulation as a comforting method for very low birth weight children $\left(<1^{\prime} 500 \mathrm{~g}\right)$ who are being mechanically ventilated cannot be recommended. Future research should focus on options among nonpharmacological interventions for relieving pain during ETS, and at the same time ensure as well as possible a blinding of the raters and a standardization of the procedure under investigation. Measuring the effect of morphine on the pain experienced by preterm neonates remains a challenge. 


\section{References}

Als H, Lawhon G, Duffy FH, McAnulty GB, Gibes-Grossmann R, Blickman JG. Individualized developmental care for very low birth weight preterm infants: medical and neurofunctional effect. JAMA 1994; 272:853-8.

Als $\mathrm{H}$, Lawhon G, Brown E, Gibes R, Duffy FH, Mc Anulty G, Blickman JG. Individualized behavioural and environmental care for the very low birth weight preterm infant at high risk for bronchopulmonary dysplasia: neonatal intensive care unit and developmental outcome. Pediatr 1986; 78:1 123-32.

Als H. Toward a synactive theory of development: Promise for the assessment of infants individuality. Inf Ment Health Jl 1982; 3:229-43.

Anand KJS, Hall RW. Pharmacological therapy for analgesia and sedation in the newborn. Arch Dis Child Fetal Neonatal Ed 2006; 91;448-53.

Anand KJ, Hall RW, Desai N, Shephard B, Bergqvist LL, Young TE, et al. for the NEOPAIN Trial Investigators Group. Effects of morphine analgesia in ventilated preterm neonates: primary outcomes from the NEOPAIN randomised trial. Lancet 2004; 363:1673-82.

Anand KJS and the International Evidence-Based Group for Neonatal Pain: Consensus statement for the prevention and management of pain in the newborn. Arch Pediatr Adolesc Med 2001;155:173-80.

Anand KJS, McIntosh N, Lagercrantz H, Pelause E, Young TH, Vasa R. Analgesia and sedation in preterm neonates who require ventilatory support. Arch Pediatr Adolesc Med 1999; 153:331-8.

Anand KJ. Clinical importance of pain and stress in preterm neonates. Biology of the Neonate 1998; 73:1-9.

Axelin A, Salanterä S, Lehtonen L. Facilitated tucking by parents' in pain management of preterm infants - a randomized crossover trial. Early HumDev 2006; 82:241-7.

Ballantyne M, Stevens B, Mc Allister M, Dionne K, Jack A. Validation of the Premature Infant Pain Profile in the clinical setting. Clin J Pain 1999; 15:297-303.

Ballard HO, Shook LA, Desai NS, Anand KJS. Neonatal research and the validity of informed consent obtained in the perinatal period. J Perinatol 2004; 24:409-15.

Barker DP, Rutter N. Exposure to invasive procedures in neonatal intensive care unit admissions. Arch Dis Child Fetal Neonatal Ed 1995; 72; F47-8.

Barr RG. Reflections on measuring pain in infants: the problem of dissociations in responsive systems and "honest signaling". Arch Dis Child Fet Neon Ed 1998; 79:F152-6. 
Bellieni CV, Buoncore G, Nenci A, Franci N, Cordelli DM, Bagnoli F. Sensorial saturation: an effective analgesic tool for heel-prick in preterm infants. Biol Neon 2001;80:15-8.

Bellù $\mathrm{R}$, de Waal KA, Zanini R. Opioid for neonates receiving mechanical ventilation. Cochrane Database of Systematic Reviews 2005, Issue 1 CD004212. Review.

Benis MM, Suresh GK. Frequency of invasive procedures in very low birth weight (VLBW) infants in the neonatale intensive care unit (NICU) (abstract). Pediatr Res. 2001; 49:392A.

Carbajal R, Mucha J, Milagro R, Arias J, Bao V, Rivadeneyra M, Zegarra, J, Bazan C, Cimerman P, Annequin D.: Epidemiology of painful procedures and analgesic therapy in neonates in NICUs of a developing country, Peru. (abstract) Pain Res Manag 2006; 11:E29.

Carbajal R, Lenclen R, Jugie M, Paupe A, Barton b, Anand KJS. Morphine does not provide adequate analgesia for acute procedural pain among preterm neonates. Pediatr 2005; 115:1494-500.

Cignacco E, Hamers JPH, Stoffel L, van Lingen R, Gessler P, Mc Dougall F, Nelle M. Efficacy of non-pharmacological interventions for procedural pain in preterm and term neonates. A systematic literature review. Eur J Pain 2007; 11:139-52.

Cignacco E, Hamers J, Stoffel L, Schütz N, van Lingen R, Zimmermann L, Nelle M: Differences in the assessment of the intensity of procedural pain in NICUs. (abstract). Pain Res Manag 2006; $11: 41 \mathrm{~B}$.

Cignacco E, Gessler P, Müller R, Hamers JPH. Pain assessment in the neonate using the Bernese Pain Scale for Neonates. Early Hum Dev 2004; 2:125-31.

De Wildt SN, Kearns GL, Leeder JS, van den Anker JN. Glucuronidation in humans. Pharmacogenetic and developmental aspects. Clin Pharmacokinet 1999; 36:439-52.

Franck LS. Some pain, some gain:reflections on the past two decades of neonatal pain research and treatment. Neon Netw 2002; 21:37-41.

Franck LS, Miaskowski C. The use of intravenous opioids to provide analgesia in critically ill, premature neonates: a research critique. Journal of Pain and Symptom Management 1998. 15:41-69.

Hall RW, Kronsberg SS, Barton BA, Kaiser JR, Anand KJS for the NEOPAIN Trial Investigator Group: Morphine, hypotension, and adverse outcome among preterm neonates: Who's blame? Secondary results from the NEOPAIN trial. Pediatr 2005; 115:1351-1359.

Hallstrom M, Koivisto AM, Janas $M$, Tammela $O$ : Frequency of and risk factors for necrotizing enterocolitis in infants born before 33 weeks of gestation. Acta Paediatr 2003; 92:111-113.

Jeitziner MM, Schwendimann R. Identification of pain in the case of patients under sedation and artificial ventilation: A systematic literature review. Pflege 2006; 19:335-44.

Johnston CC, Collinge JM, Henderson SJ, Anand KJ. A cross-sectional survey of pain and pharmacological analgesia in Canadian neonatal intensive care units. Clin J Pain. 1997; 13:308-12.

Kinney HC Ottoson CK, White WF. Three-dimensional distribution of 3H-nalaxone binding to opiate receptors in the human fetal and infants brainstem. J Comp Neurol 1990, 291:55-78.

Orsini AJ, Leef $\mathrm{KH}$, Costarino A: Routine use of fentanyl infusions for pain and stress reduction in infants with respiratory distress syndrome. J Pediatr 1996; 129:140-5. 
Pokela ML. Effect of opioid-induced analgesia on beta-endorphin, cortisol and glucose responses in neonates with cardiorespiratory problems. Biology of the Neonates 1993, 64:360-367.

Pokela ML, Olkkola KT, Koivisto M, Ryhanen P. Pharmacokinetics and pharmacodynamics of intravenous meperidine in neonates and infants. Clin Pharmacol Ther 1992; 52: 342-9.

Price DD, Bush FM, Long S, Harkins SW. A comparison of pain measurement characteristics of mechanical visual analogue and simple numerical rating scales. Pain 1994; 56:217-26.

Rahman W, Dashwood MR, Fitzgerald M, Aynsley-Green A, Dickenson AH. Postnatal development of multiple opioid receptors in the spinal cord and development of spinal morphine analgesia. Brain Res Dev Brain Res 1998, 108:239-254.

Ruth V, Pohjavuori M, Rovamo L, Salminen K, Laatikainen T. Plasam B-endorphin in the perinatal asphyxia and respiratory difficulties in newborn infants. Pediatric Research, 1986, 20:577-580.

Saneto RP, Fitch JA, Cohen BH. Acute neurotoxicity of meperidin in an infant. Pediatr Neurol 1996; $14: 339-41$.

Saarenmaa E, Huttunen P, Leppäluoto J, Meretoja O, Fellmann V. Advantages of fentanyl over morphine in analgesia for ventilated newborn infants after birth: A randomized trial. J Pediatr $1999 ; 34: 144-50$.

Simons SHP, van Dijk $M$, van Lingen $R A$, Roofthooft $D$, Duivenvoorden $H J$, Jongeneel $N$, Bunkers C, Smink E, Anand KJS, van den Anker JN, Tibboel D. Routine morphine infusion in preterm newborns who received ventilatory support: A randomized controlled trial. JAMA 2003a; $290 ; 2419-27$

Simons SH, van Dijk M, Anand KS, Roofthooft D, van Lingen RA, Tibboel D. Do we still hurt newborn babies? A prospective study of procedural pain and anaigesia in neonates. Arch Pediatr Adolesc Med 2003b; 157:1058-64.

Stevens B, Yamada J, Ohlsson A. Sucrose analgesia in newborn infants undergoing painful procedures. Cochrane Database Syst Rev 2004; 3:CD001069.

Stevens B, McGrath P, Gibbins S, Beyene J, Breau L, Camfield C, Finley A, Franck L, Howlett A, McKeever P, O'Brien K, Ohlsson A, Yamada J.. Procedural pain in newborns at risk for neurologic impairment. Pain 2003; 105:27-35.

Stevens B, Johnston CC. Physiologic response of premature infants to a painful stimulus. Nurs Res $1994 ; 43: 261-331$.

Swiss Minimal Neonatal Data Set (MNDS), 2004 (www.neonet.ch/en02_Neonatal_Network/aimes.asp)

Van Dijk M, Bouwmeester NJ, Duivenvoorden HJ, Koot HM, Tibboel D, Passchier J, de Boer JB. Efficacy of continuous versus intermittent morphine administration after major surgery in 0-3-years-old infants; a double-blind randomized controlled trial. Pain 2002; 98:305-13.

Ward-Larson C, Horn R, Gosnell F. The efficacy of facilitated tucking for relieving procedural pain of endotracheal suctioning in very low birthweight infants. Am J Matern Child Nurs 2004; 29:151-6. 


\section{CHAPTER 7}

THE EFFICACY OF NON-PHARMACOLOGICAL

INTERVENTIONS FOR PAIN TREATMENT IN

PRETERM AND TERM NEONATES.

A SYSTEMATIC REVIEW

Cignacco E, Hamers JPH, Stoffel L, van Lingen RA, Gessler P, Mc Dougall J, Nelle M

Published in European Journal of Pain, 2007; 11:39-152.

Reprinted with the copyright permission from the European Federation of Chapters of the International Association for the Study of Pain 


\section{Abstract}

Background: Neonates in a neonatal intensive care unit are exposed to a high number of painful procedures. Since repeated and sustained pain can have consequences for the neurological and behaviour-oriented development of the newborn. the greatest attention needs to be paid to systematic pain management in neonatology. Non-pharmacological treatment methods are being increasingly discussed with regard to pain prevention and relief either alone or in combination with pharmacological treatment.

Aims: To identify effective non-pharmacological interventions with regard to procedural pain in neonates.

Methods: A literature search was conducted via the MedLine, CINAHL, Cochrane Library databases and complemented by a handsearch. The literature search covered the period from 1984 to 2004. Data were extracted according to pre-defined criteria by two independent reviewers and methodological quality was assessed.

Results: 13 randomised controlled studies and two meta-analyses were taken into consideration with regard to the question of current nursing practice of non-pharmacological pain management methods. The selected interventions were "non-nutritive sucking", "music", "swaddling", "positioning", "olfactory and multisensorial stimulation", "kangaroo care" and "maternal touch". There is evidence that the methods of "non-nutritive sucking", "swaddling" and "facilitated tucking" do have a painalleviating effect on neonates.

Conclusions: Some of the non-pharmacological interventions have an evident favourable effect on pulse rate, respiration and oxygen saturation, on the reduction of motor activity, and on the excitation states after invasive measures. However, unambiguous evidence of this still remains to be presented. Further research should emphasise the use of validated pain assessment instruments for the evaluation of the pain-alleviating effect of non-pharmacological interventions. 


\begin{abstract}
Background: Neonates in a neonatal intensive care unit are exposed to a high number of painful procedures. Since repeated and sustained pain can have consequences for the neurological and behaviour-oriented development of the newborn, the greatest attention needs to be paid to systematic pain management in neonatology. Non-pharmacological treatment methods are being increasingly discussed with regard to pain prevention and relief either alone or in combination with pharmacological treatment.
\end{abstract}

Aims: To identify effective non-pharmacological interventions with regard to procedural pain in neonates.

Methods: A literature search was conducted via the MedLine, CINAHL, Cochrane Library databases and complemented by a handsearch. The literature search covered the period from 1984 to 2004. Data were extracted according to pre-defined criteria by two independent reviewers and methodological quality was assessed.

Results: 13 randomised controlled studies and two meta-analyses were taken into consideration with regard to the question of current nursing practice of non-pharmacological pain management methods. The selected interventions were "non-nutritive sucking", "music", "swaddling", "positioning", "olfactory and multisensorial stimulation", "kangaroo care" and "maternal touch". There is evidence that the methods of "non-nutritive sucking", "swaddling" and "facilitated tucking" do have a painalleviating effect on neonates.

Conclusions: Some of the non-pharmacological interventions have an evident favourable effect on pulse rate, respiration and oxygen saturation, on the reduction of motor activity, and on the excitation states after invasive measures. However, unambiguous evidence of this still remains to be presented. Further research should emphasise the use of validated pain assessment instruments for the evaluation of the pain-alleviating effect of non-pharmacological interventions. 


\section{Introduction}

\subsection{Problem statement}

Intensive care treatment of preterm and sick term infants in the neonatology unit entails a period of hospitalisation which may last from several weeks to several months. These children are exposed to an environment characterised by highly variable, sometimes excessive stimulation (light, noise and activity related to monitors and respirators as well as medical emergencies), lack of diurnal variation and frequently changing caregivers. Furthermore, neonatal intensive care involves a high number of diagnostic and therapeutic procedures which are associated with pain for the neonates concerned. Stevens et al. (1999), for example, described an average of 134 painful procedures within the first two weeks of life for each of 124 preterm neonates with a gestational age of 27-31 weeks. One preterm infant even underwent 766 invasive procedures in the course of the entire hospitalisation period (Porter et al., 1998). Among 151 neonates, an average of $14+/-4$ painful interventions was recorded during the first 14 days of life within a period of 24 hours (Simons et al., 2003). In a study covering 54 neonates, more than 3000 painful interventions were documented during their entire hospitalisation period, of which $74 \%$ involved preterm infants under 31 weeks gestation (Barker and Rutter, 1995). Most of the painful interventions included capillary blood sampling by heel stick, followed by endotracheal suctioning. Preliminary intermediate results from a study in Switzerland involving a random sample of the vulnerable group of intubated preterm neonates during their first 14 days of life showed a total number of 4,092 interventions among 11 children alone, $65 \%$ of these interventions being related to intubated preterm infants below 28 weeks gestation. According to this study, every preterm infant experiences an average of 372 interventions within the first 14 days of their life (Cignacco et al., 2005, manuscript in preparation). These studies are restricted to the description of brief acute pain stimuli. The fact that neonates in an intensive care unit are also subjected to chronic pain (e.g. in the case of illnesses and abnormalities) and post-operative pain must not be disregarded.

The number of painful and distressing events (light, noise, manipulations) can influence the metabolic rate by increasing the demand for oxygen (Ambuel et al., 1992) and be the cause for cerebral oxygenation disturbances (Gagnon, 1999). As a number of studies show, repeated and sustained pain can have direct and long-term consequences on the neurological and behaviour-oriented development of the neonate (Anand and Carr, 1989; Grunau et al., 1994, 1998; Gagnon, 1999; Oberlander et al., 2000; Anand, 2000; Grunau et al., 2001; Grunau, 2002; Peters et al., 2005). Data from animal models confirmed that prolonged exposure to pain is harmful to development. It affects the normal development of the nociceptive neural circuits and leads to an altered development of the pain system, characterised by lowered pain thresholds during later infancy (Anand et al., 1999; Ruda et al., 2000; Bhutta et al., 2001) and both hypoalgesia after puberty and hyperalgesia in adulthood (Ren et al., 2004). Therefore, strategies for stress reduction, such as the concept of developmental care (Sizun et al., 2002; Als et al., 1996), and systematic pain management are central issues in neonatal intensive care to promote the wellbeing and unimpeded development of the neonate. In particular, the 
use of non-pharmacological interventions is of great importance, since they are based on nurses' clinical assessment of pain and can be carried out by nursing staff without instructions by physicians. However, pain management in a neonatal intensive care unit (NICU) remains an interdisciplinary task.

\subsection{Pain assessment instruments for neonates}

A precondition for an adequate pain treatment procedure is the accurate assessment of the pain. Recently, a growing number of reliable and valid measurement tools for neonates have been developed. In the clinical setting, the validated instruments "Bernese Pain Scale for Neonates" (Cignacco et al., 2004), the "Premature Infant Pain Profile" (Ballantyne et al., 1999) and the "Comfort Scale" (Ambuel, 1992; van Dijk, 2000) are widely used. However, in spite of these developments, many conceptual and measurement issues remain. Thus, the influence of contextual factors on the expression of pain, such as the gestational age and the associated immaturity of the central nervous system, as well as the influence of states of illness and of consciousness (for example, in the case of sedation during mechanical ventilation) has not yet been comprehensively explained. No instruments have been definitively validated with regard to these influences. Although the use of multidimensional instruments is recommended for pain assessment in neonates (Mc Grath et al., 1985; Abu-Saad et al., 1990; 1998; Cignacco, 2001), there are reports of either no correlation or low correlation $(r=0.3)$ between physiological and behavioural outcomes of pain (Steven and Johnston, 1994; Johnston et al, 1995; Barr, 1998). According to these studies, using measures which combine the interpretation of behavioural and physiological responses into a single score for assessing the efficacy of painalleviating interventions may not reveal the individual effects on each of the two systems. Such dissociations suggest that physiological systems are only loosely coupled to behavioural responsive systems (Barr, 1998). This renders any evaluation of the effectiveness of interventions difficult, which particularly applies to the evaluation of the efficacy of non-pharmacological interventions. According to some studies, there was only a reduction in behavioural indicators, not in physiological ones (Johnston et al., 2003; Field and Goldson, 1984). The use of multidimensional instruments is therefore under discussion. The validation study of the Bernese Pain Scale for Neonates yielded contrary results. The study proved a good correlation (Cronbach's Alpha $r=0.80$ ) between two physiological indicators (heart rate and oxygen saturation) and seven behavioural indicators (Cignacco et al., 2004). Consequently, the "Bernese Pain Scale for Neonates" also appears to be a valid pain assessment instrument in the evaluation of non-pharmacological interventions with a more marked effect on behavioural indicators. With regard to the dissociation described between physiological and behavioural indicators of individual pain assessment instruments, further validation studies are necessary.

\subsection{Interventions in pain management}

Up to $80 \%-90 \%$ of the medications which are used among sick preterm and term neonates in an intensive care unit are either not approved for the illness concerned (off-label use), or are administered in a form other than that officially approved (unlicensed use) (Conroy, 1999; Roth, 2004). As a rule, their use is based on clinical guidelines. The reticence in systematic application for routine short interventions can be justified with a view to their long-term effects and possible side-effects (Anand et al., 2004). By contrast, non-pharmacological methods are suitable to counteract procedural pain because of their short-term efficacy and good tolerance, and are therefore increasingly being recommended for pain prevention and pain management. In order to achieve optimum efficacy, both pharmacological and non-pharmacological interventions additionally require a reduction of external stimuli, such as loud noise and bright light (Franck and Lawhon, 1998; Stevens et al., 2000). The initiation of non-pharmacological treatment is recommended for mild pain (American and Canadian 
Academy of Pediatrics, 2000; Anand and the International Evidence-Based Group for Neonatal Pain, 2001). Although the immature pain system in preterm infants predisposes them to greater clinical and behavioural sequelae (Anand, 2000), there has been little progress in the provision of effective procedural pain management (Anand, 2001; Anand and Selankio, 1996; Stevens, 1996).

The administration of sucrose has been the most frequently studied non-pharmacological intervention for the relief of procedural pain in neonates (Stevens et al., 1997; Blass et al., 1999; Kaufmann et al., 2001; Gibbins et al., 2002). The effects of sucrose are thought to be mediated by endogenous opioid pathways activated by sweet taste, and endure after sucrose is orally administered. There is evidence that the combination of sucrose and "non-nutritive sucking" is the most efficacious intervention for single heel stick (Stevens et al., 2004). However, there was some inconsistency as to the concentration of sucrose at which it was effective, and therefore the optimum concentration to be used in preterm and/or term infants has not yet been identified. There is still little evidence with regard to the long-term effect of sucrose. In a study by Johnston et al. (2002), the analgesic effect of sucrose even after several administrations has been confirmed. In the case of prolonged administration of sucrose, however, the authors describe a possible risk of impaired neurological development at the corrected age of 40 weeks gestation in preterms of less than 31 weeks gestation. Studies regarding the real long term effects i.e. neurological outcome at one year and beyond are not available.

Although there are other non-pharmacological methods for pain relief currently in use in the neonatal setting, there is a paucity of data about their efficacy. This stresses the need for further research into the efficacy and safety of non-pharmacological management of pain in preterm infants.

\subsection{Mechanism of non-pharmacological pain interventions}

Non-pharmacological pain intervention is a prophylactic and complementary approach to reduce pain (Franck and Lawhon, 1998). It is assumed that non-pharmacological interventions activate the gate control mechanism (Meizack and Wall, 1965). Some of them lead to an endogenous endorphine dispersal, which contributes to the modulation of the pain pulse at the level of the spinal cord, and have the effect of relieving pain. These interventions can also activate the attention of neonates, distract them from the pain, and thus modify the pain (Bellieni et al., 2001). It is postulated that they reduce the pain by pre-empting hypersensitivity (Stevens et al., 2000). However, it is likely that further multiple parallel physiological analgetic systems are involved. Effective coping strategies, such as "maternal touch", "non-nutritive sucking" and "kangaroo care" (Johnston et al., 2003), may elicit activation of neuropeptides systems, such as cholecystokinin. Cholecystokinin is an opioid-modulating substance that promotes stressor adaptability and can achieve an analgetic effect through the potentiation of opioid activity (Hebb et al., 2005). Furthermore, infants are particularly responsive to olfactory cues emanating from their mothers' nipple regions (Porter and Winberg, 1999). Familiar odours may also stimulate the release of cholecystokinin.

\subsection{Objective of the literature overview}

The aim of this systematic literature review is to gain insight into the efficacy of non-pharmacological interventions in pain management for preterm and term neonates in a neonatal intensive care setting. The selected interventions, such as "non-nutritive sucking", "music", "swaddling", "positioning", "olfactory and multisensorial stimulation", "kangaroo care" and "maternal touch", are all part of current nursing practice. As the use of sucrose has been reviewed recently (Stevens et al., 2004) in a Cochrane review and judged to have a high level of evidence, we choose not to investigate this intervention again. 


\section{Methods}

In lire with the reseatch otiective a systematic search was conducted via the MedLine, CINAHL and

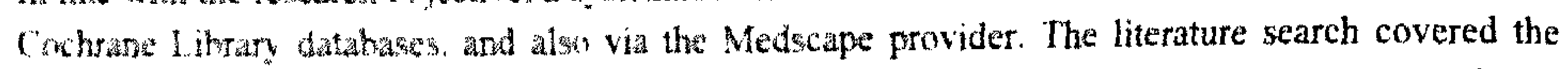
perwd from 1924 to 2004 , frowing on randomised controlled intervention studies and meta-analyses. Since non-phamacolegical interventions are a central issue for the nursing profession. two MESH headings were entered ("Intant, Newborn" and "Neonatal Nursing"). working in combination with the followny search terms: "pain management", "neonatal pain and comfort", "neonatal pain and nursing intervention". "neonatal pain and nonnutritive sucking". "neonatal pain and sensory stimulation", "neonatal pain and musices." "neonatal pain and facilitated tucking" AND "positioning", "neonatal pain and kangaroo" "pain prevention and neonate". Studies which exclusively examined the administration of sucrose were rot included in this review since the effect of sucrose alone has been extensively studied hefore and there is sufficient evidence available regarding its efficacy. After examining 89 abstracts. 30) stulies wete analy sed in greater detail on the basis of established inclusion criteria (Table 7-1). Furthermote, a handsearch was carried out in the Bern University Library which also included the reference lists of all tocated articles. The search attempted to identify all relevant studies in English. German. French and ltalian. In total, 13 studies and two meta-analyses were taken into consideration with regard to the question of non-pharmacological pain management methods among neonates.

\section{Table 7-1: Inclusion criteria}

Randomised controlled trials or meta-analy sis

German. French, Italian and English articles

Articles on non-pharmacological interventions, which are part of current nursing practice (Music, kangaroo-care, facilitated tucking, swaddling, nonnutritive sucking, olfactorial and multisensorial stimulation, positioning,).

Articles in which interventions before, during and after a painful stimulus were studied.

Articles which included preterm and term infants hospitalised in a neonatal intensive care unit up to 44 weeks gestational age

Studies with ventilated and not ventilated preterm and term neonates.

\subsection{Quality examination of the studies selected}

The quality examination of randomised controlled trials (RCT's) includes a consensus statement prepared by an expert survey (Verhagen et al., 1998). In this context, criteria are determined which allow for qualitative statements regarding RCT's. Accordingly, important quality features of the randomisation process are the explicit determination of inclusion and exclusion criteria, the comparability of patients, double-blinding (both examiner and patient) and the intention-to-treat analysis. In this present study, with the exception of double-blinding, which is not applicable within the framework of trials involving neonates, all of these features were taken into account for the quality examination. The use of pain assessment instruments was also examined. To appraise the quality, a numeric scale of $1-10$ was used, 10 representing the best score. The appraisal was shared between two authors. The independent appraisal achieved a correlation of Kappa $r=0.613$ (see Table 7-2). The evidence presented by the studies was assigned on the basis of an existing and generally 
acknowledged classification (Gray, 1997). The studies selected do exhibit weaknesses with respect to some criteria, which does not allow for authoritative statements with regard to the efficacy of nonpharmacological interventions. These deficiencies are taken into consideration and explained in the results and discussion sections.

\section{Results}

\subsection{Features of the studies}

The studies taken into consideration (Table 7-2) differ with respect to the variables examined (physiological and/or behaviour-oriented parameters), the patients (ventilated and non-ventilated neonates) and the methods of the non-pharmacological interventions. "Swaddling" of the neonates and "positioning", as well as "non-nutritive sucking", are described as the most frequently applied methods for pain relief. Eleven studies examined the routine intervention "heel stick" and one study (WardLarson et al., 2004) focused on the relief of pain during endotracheal suctioning. The two metaanalyses (Prasopkittikun and Tilokskulchai, 2003; Shiao et al., 1997) were likewise restricted to the heel stick. The pain response was determined with different assessment instruments, which were described in the main as valid and reliable.

Table 7-2: The efficacy of non-pharmacological interventions on behavioural and physiological indicators

\section{Legend:}

Preterm Newborn (PN)

Term Newborn (TN)

Postnatal Age (PA)

Gestational Age (GA)

Intermediate Care (IMC)

Intensive Care (IC)

Neonatal Intensive Care Unit (NICU)

Heart Rate (HR); Respiratory Rate (RR)

Transcutaneous Oxygen Saturation (tcpAO2)

Oxygen Saturation ( $\mathrm{SaO} 2)$

Non-nutritive Sucking (NNS)

Randomised Controlled Trial (RCT)

Premature Infant Pain Profile (PIPP)

Neonatal Infant Pain Scale (NIPS)

Neonatal Facial Coding System (NFCS)

Echelle de Douleur et d'Incomfort (EDIN)

+ : low efficacy

++ : moderate efficacy

+++ high efficacy 


\begin{tabular}{|c|c|c|c|}
\hline $\begin{array}{l}0 \\
\end{array}$ & $\ddagger$ & $\ddagger$ & 寿 \\
\hline 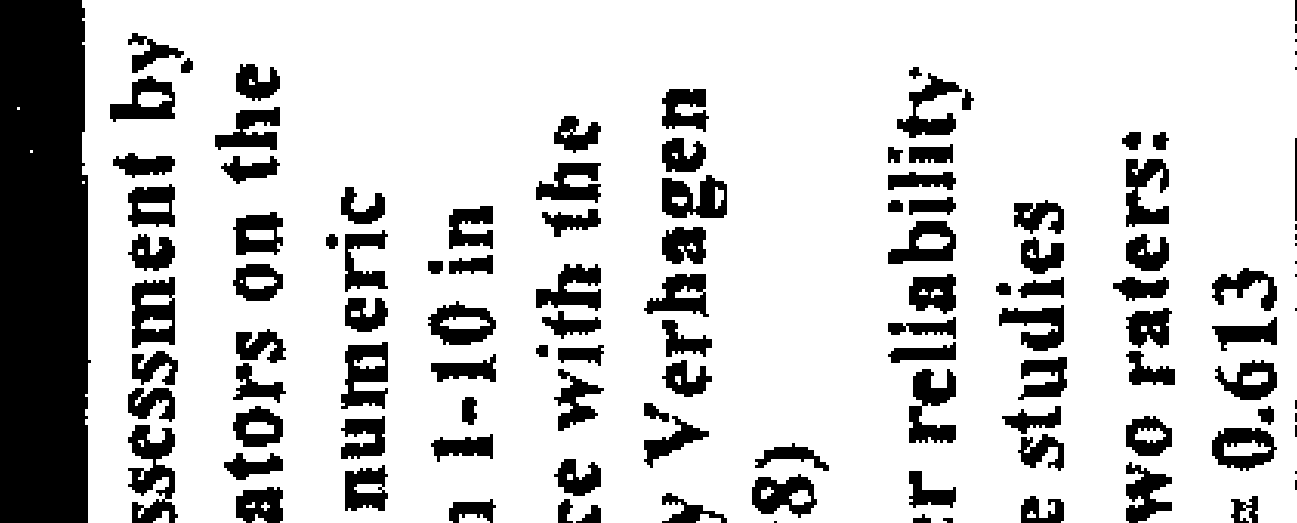 & - & 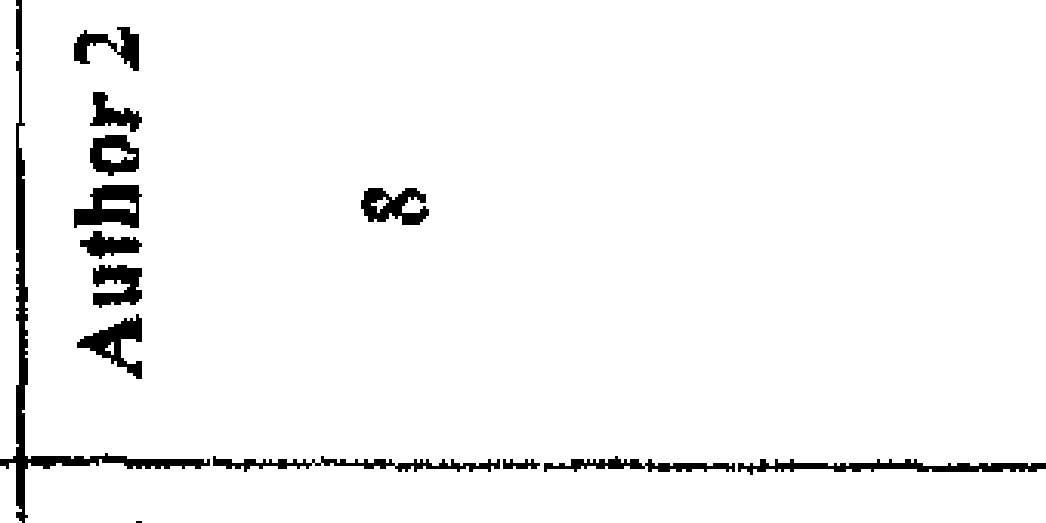 & 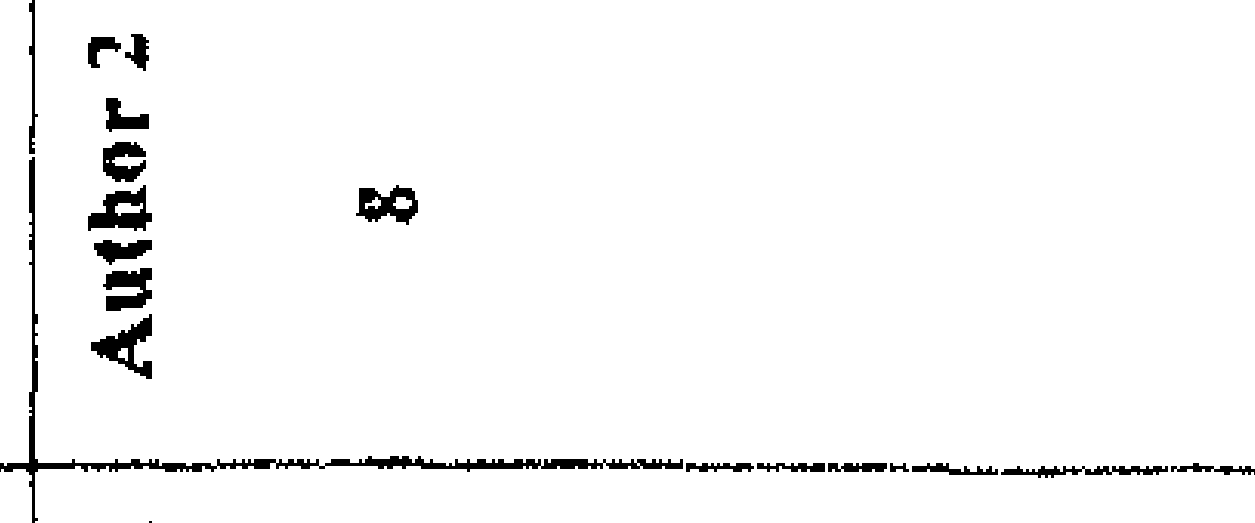 \\
\hline 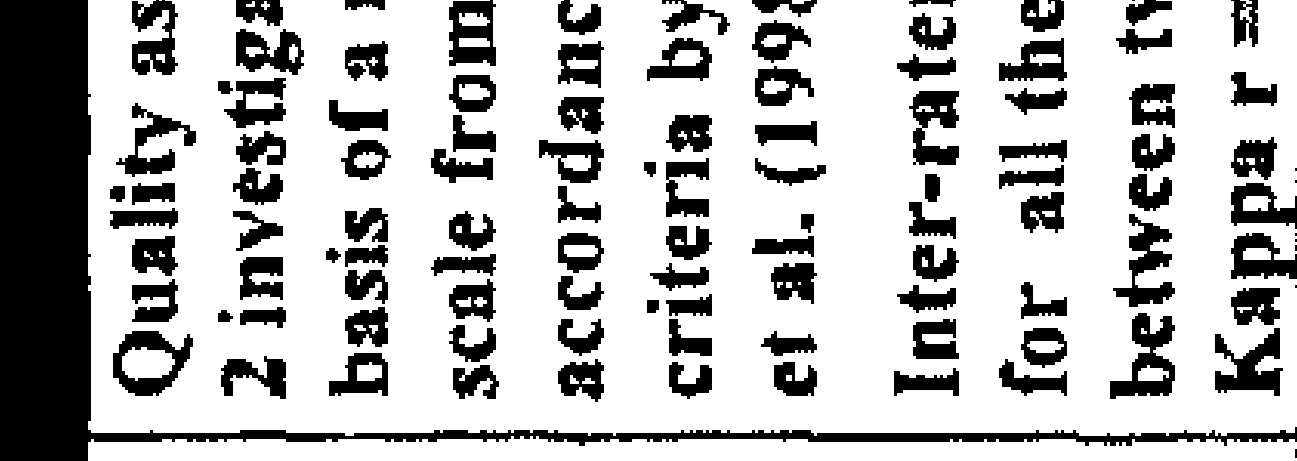 & 咅。 & 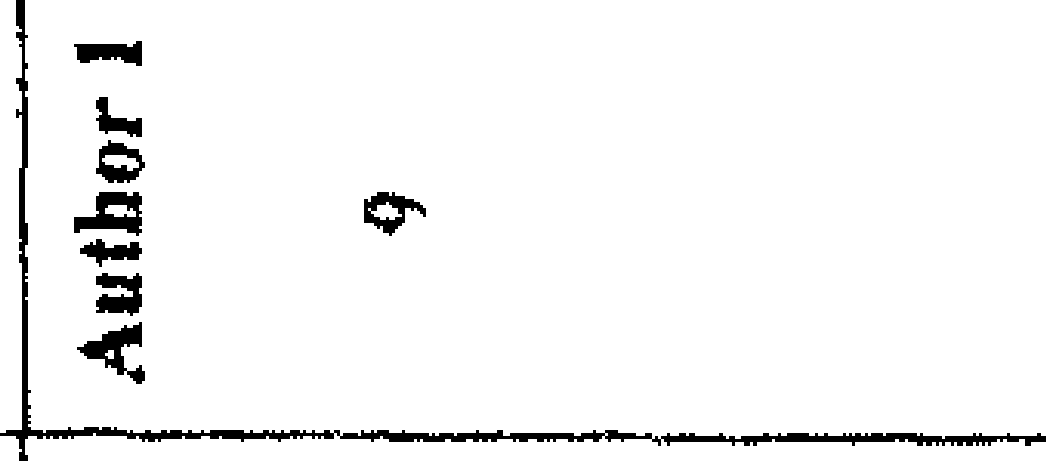 & \\
\hline & 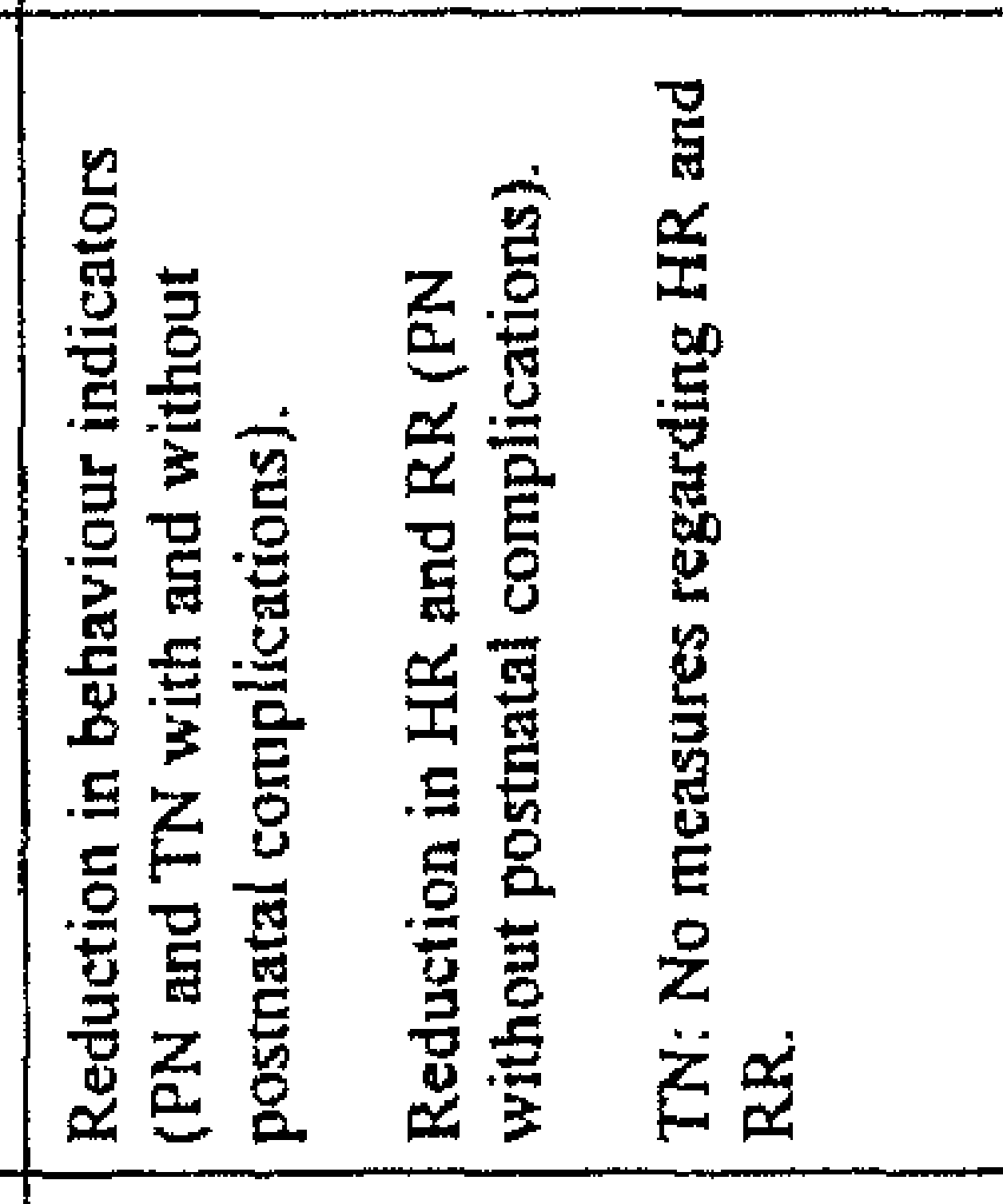 & 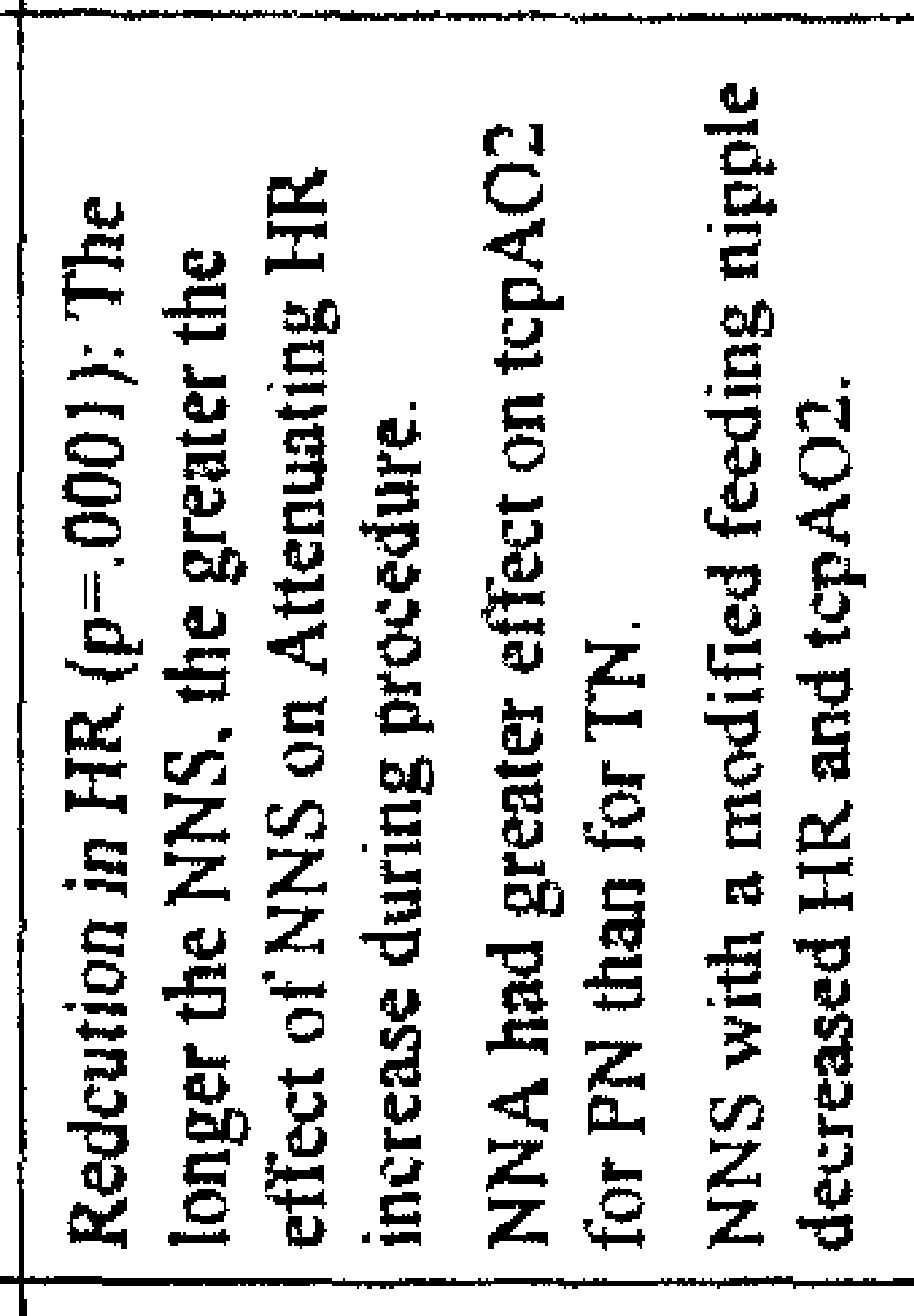 & 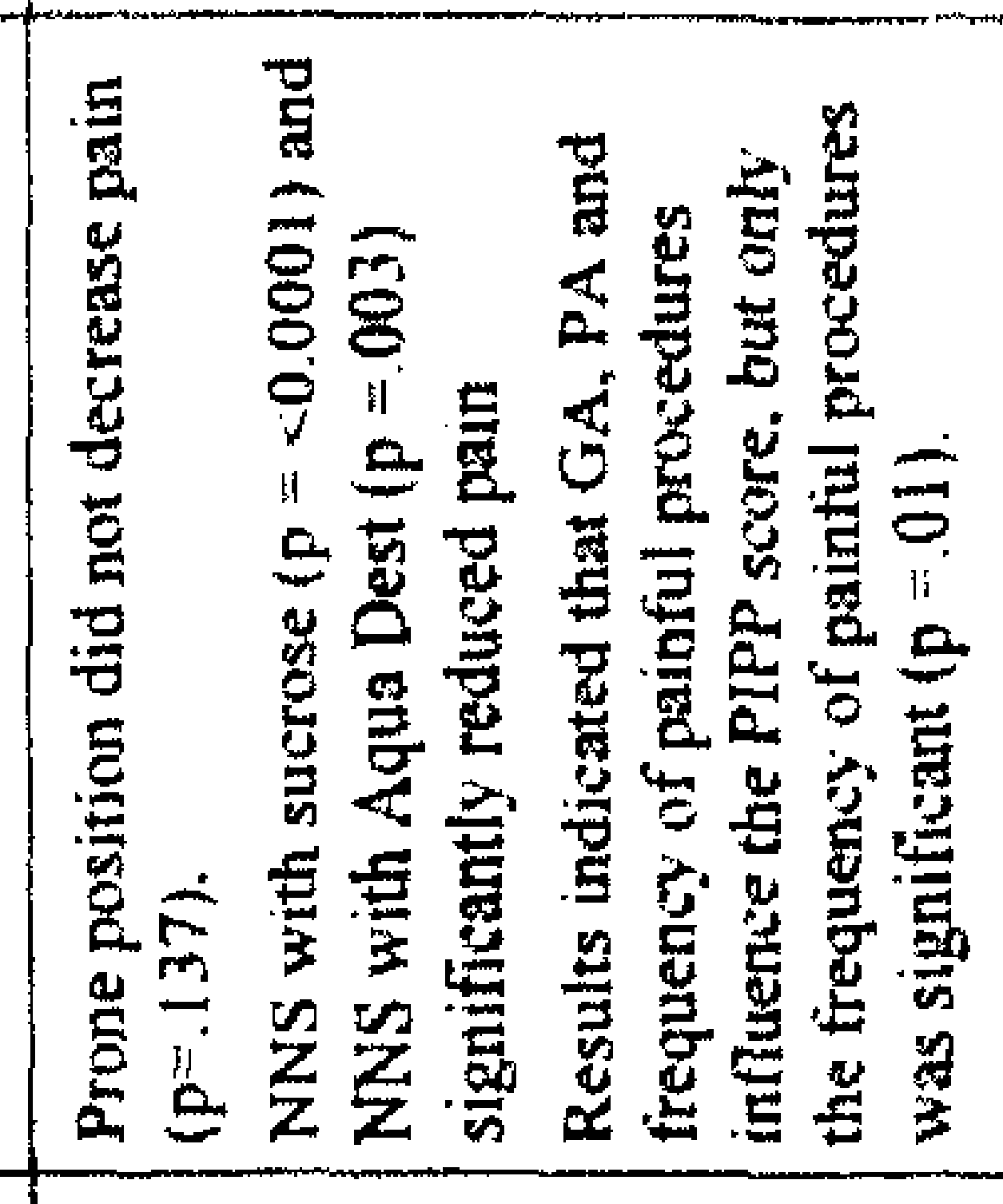 \\
\hline & 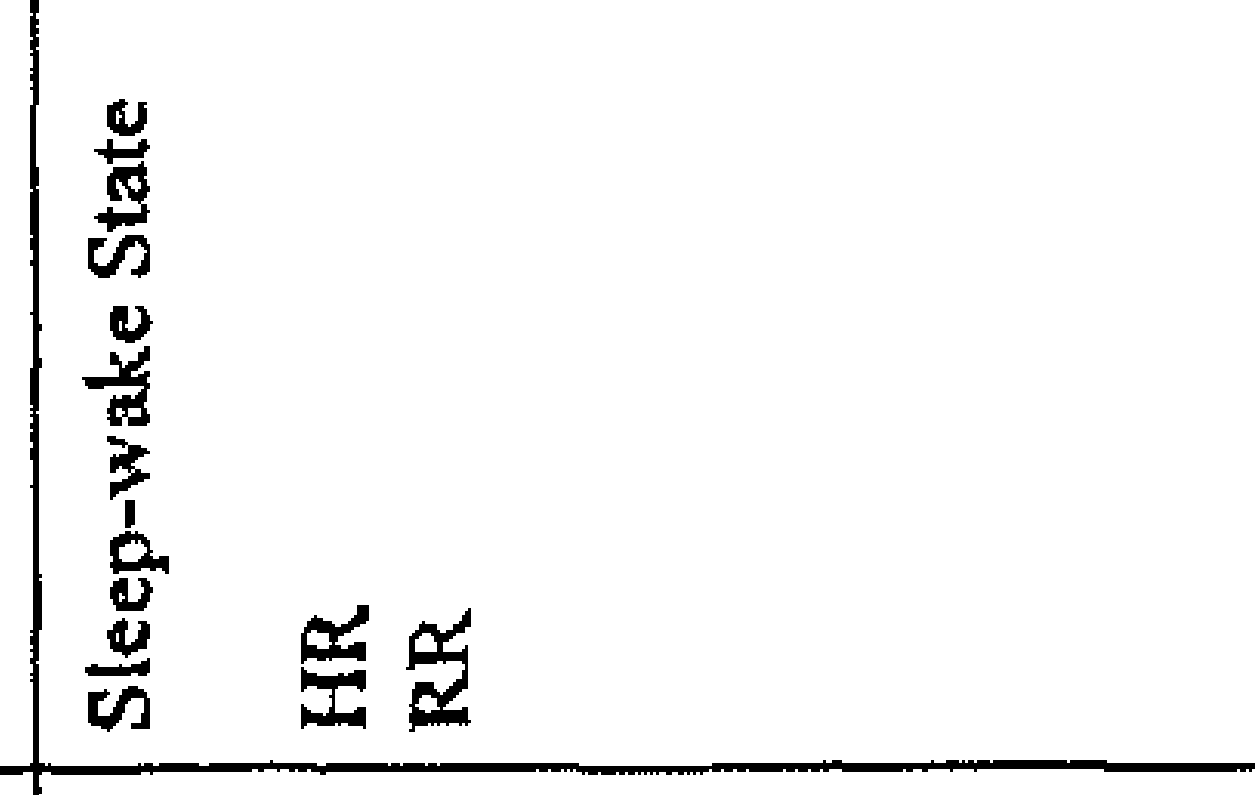 & 象总 & 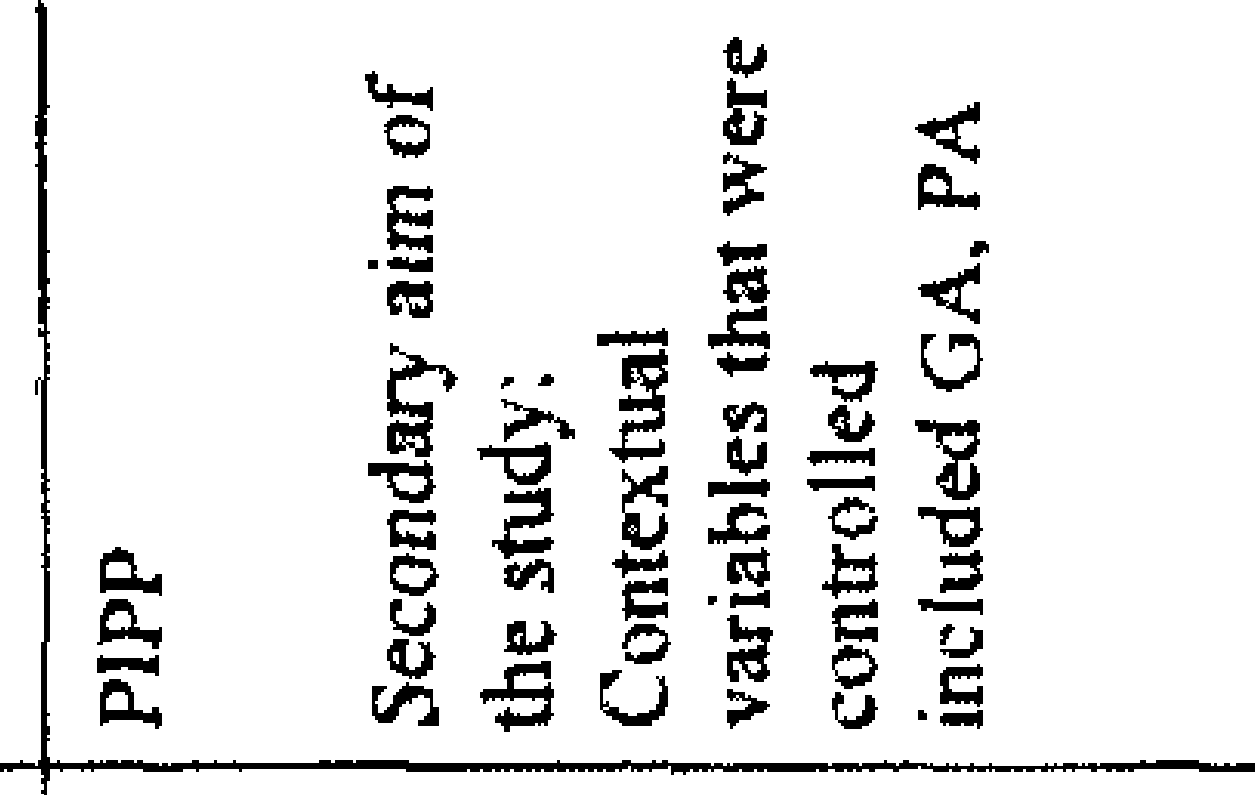 \\
\hline & 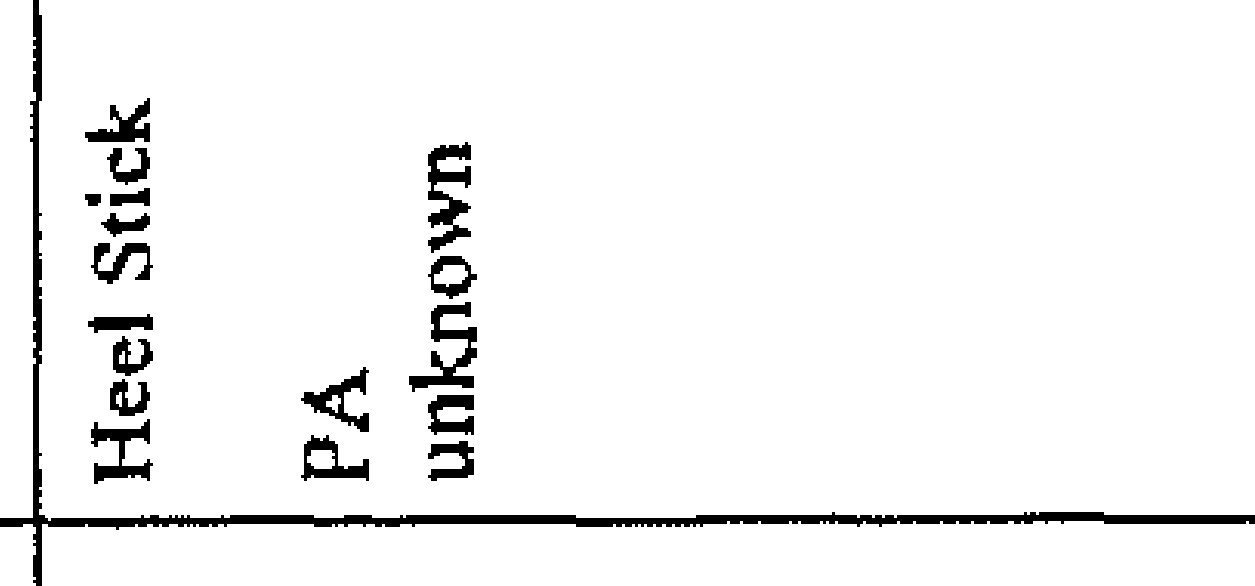 & 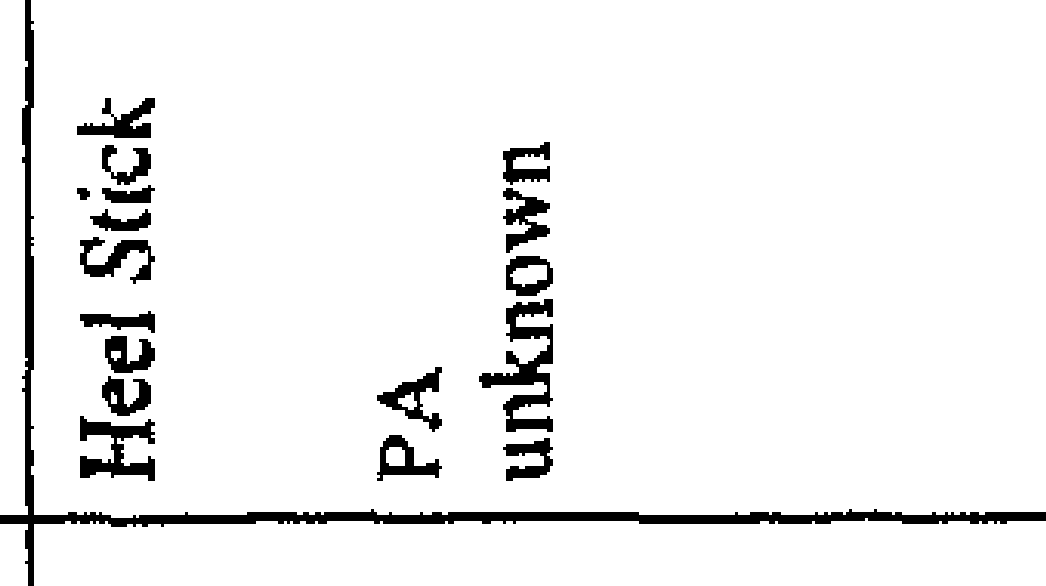 & 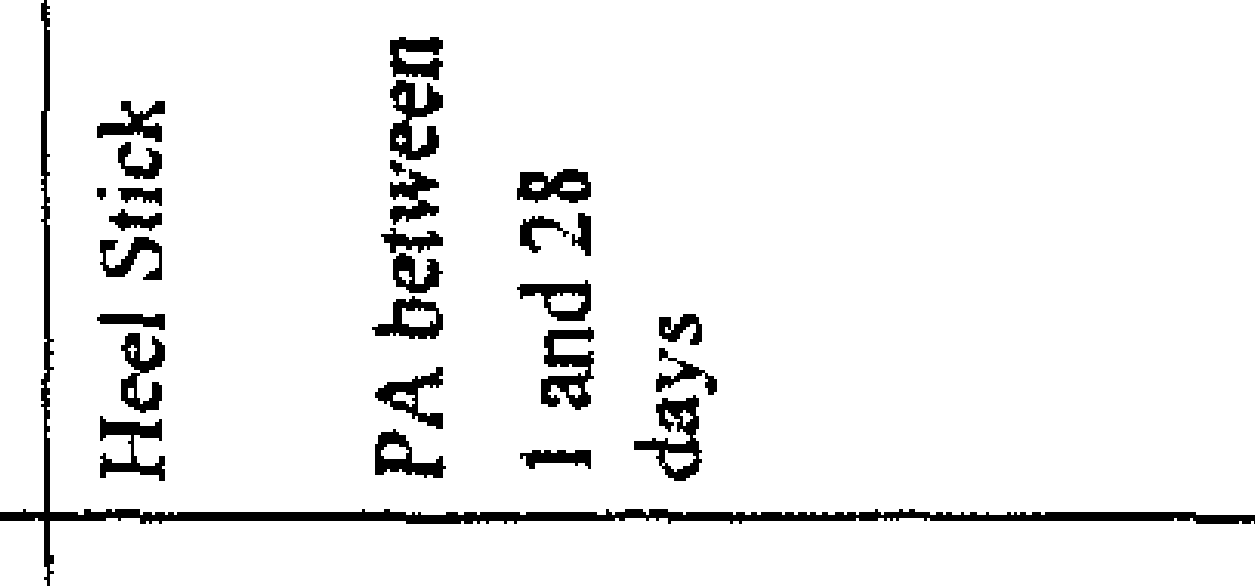 \\
\hline & 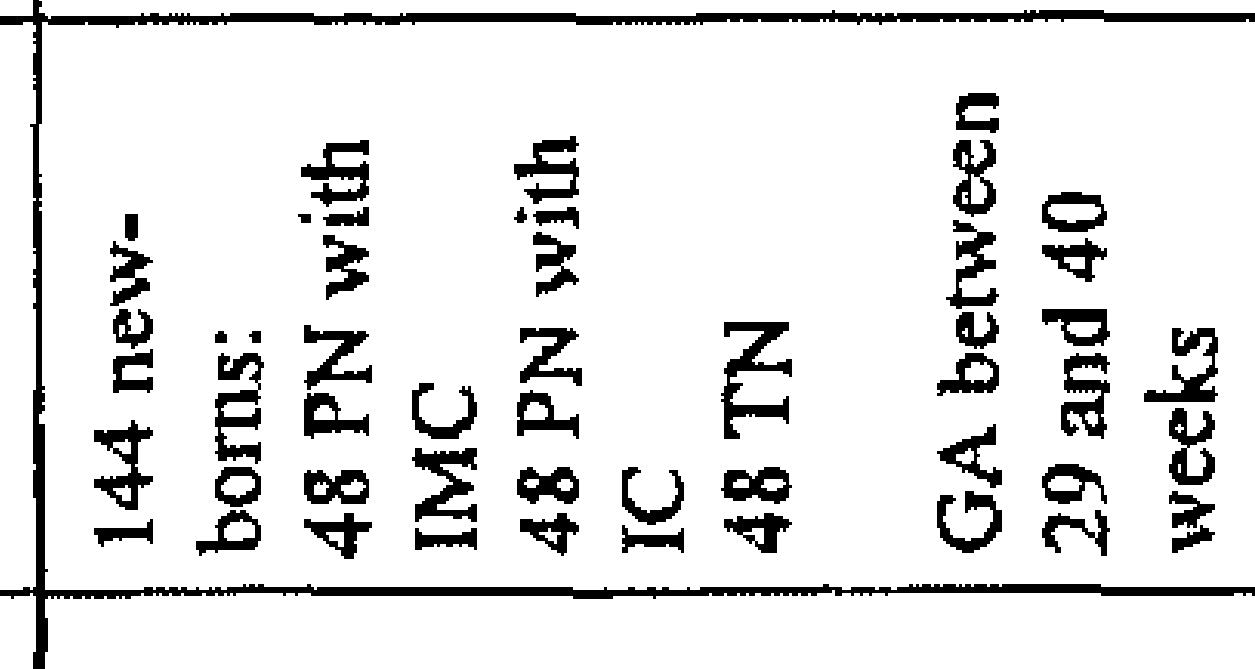 & žㅡㄹ & 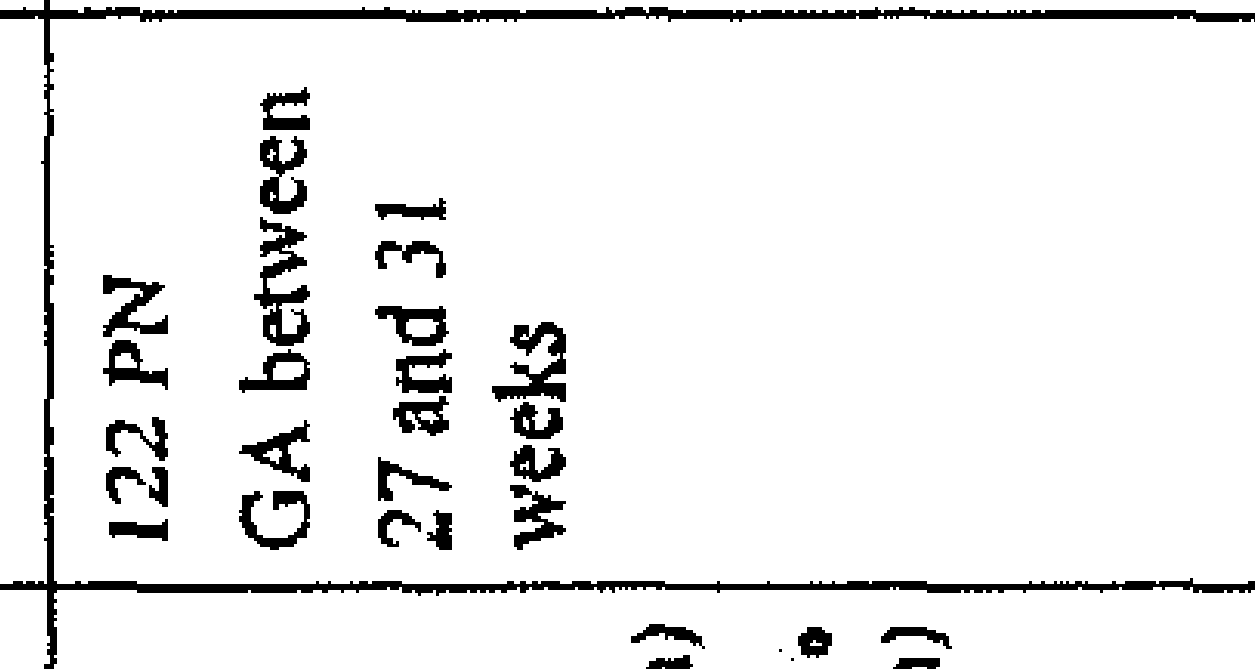 \\
\hline & 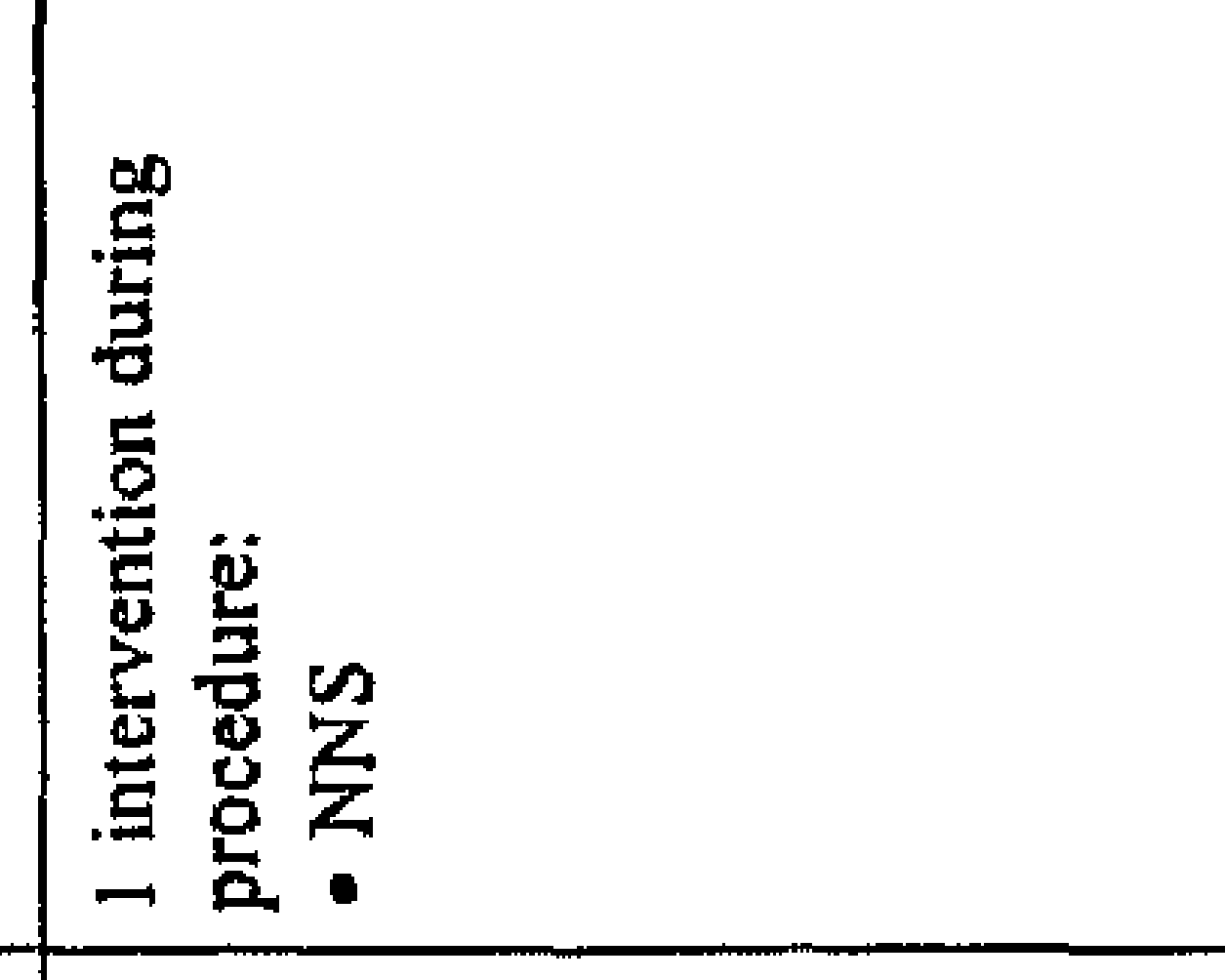 & 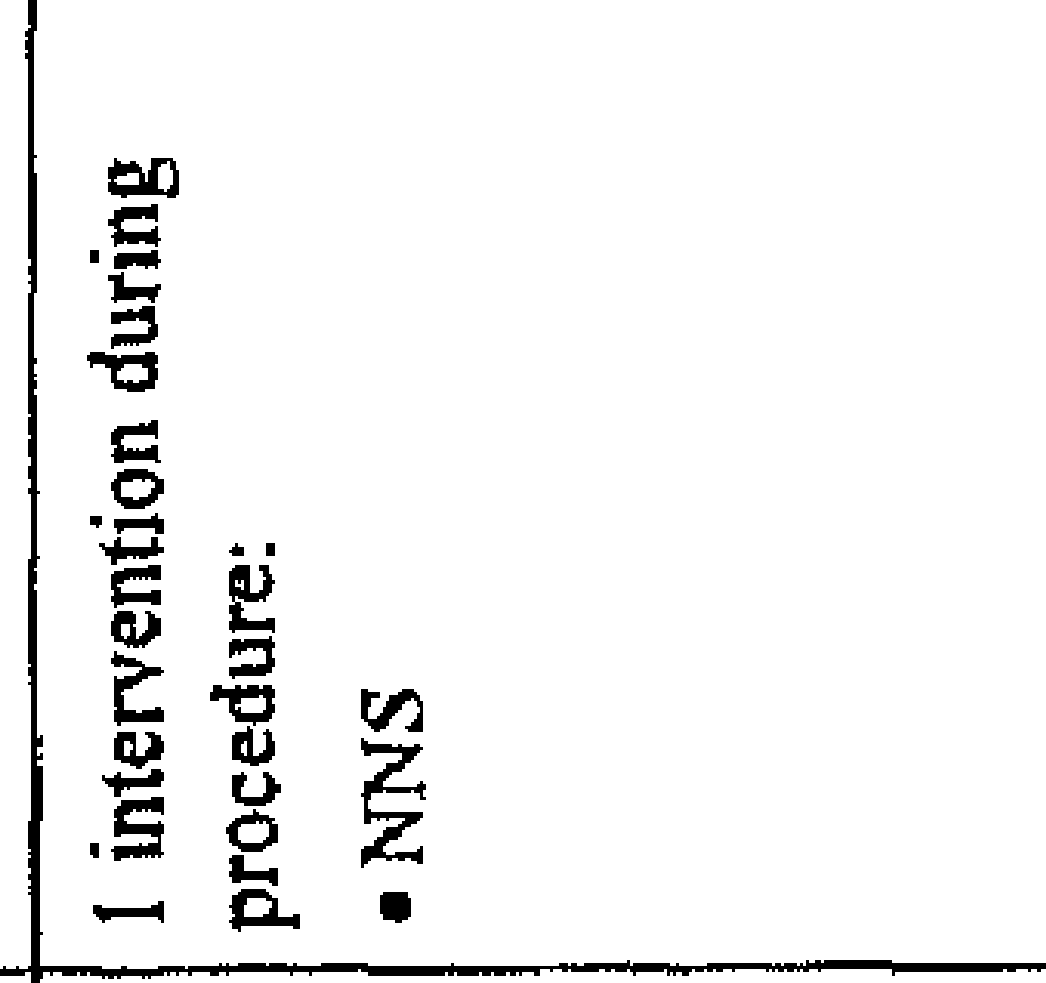 & 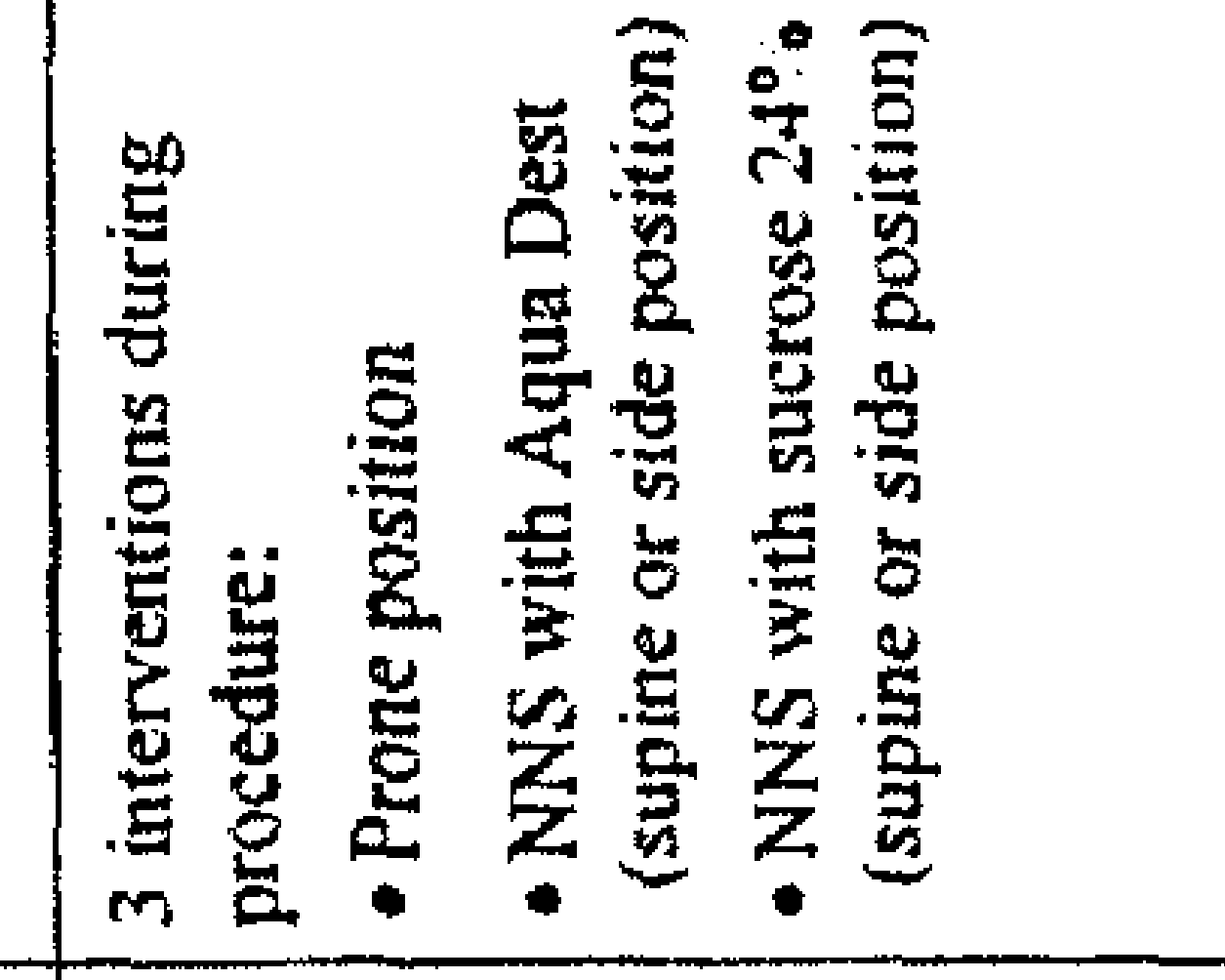 \\
\hline 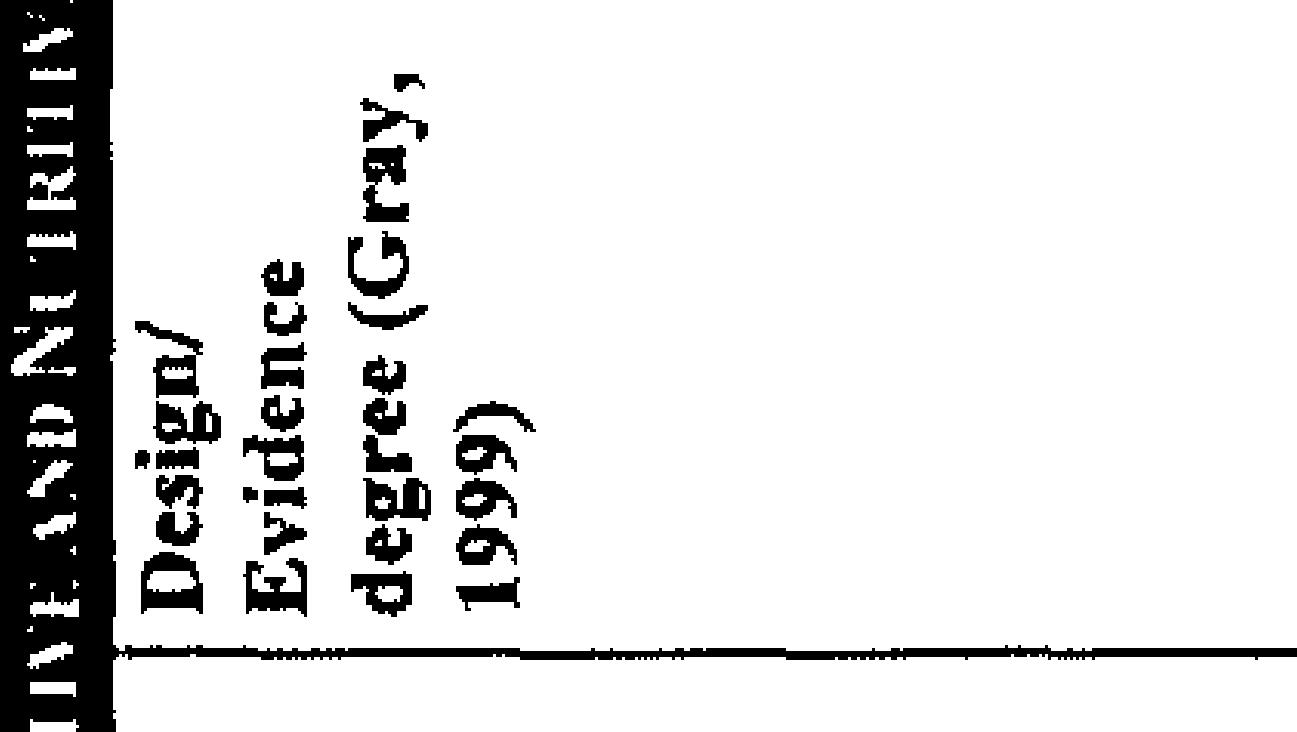 & 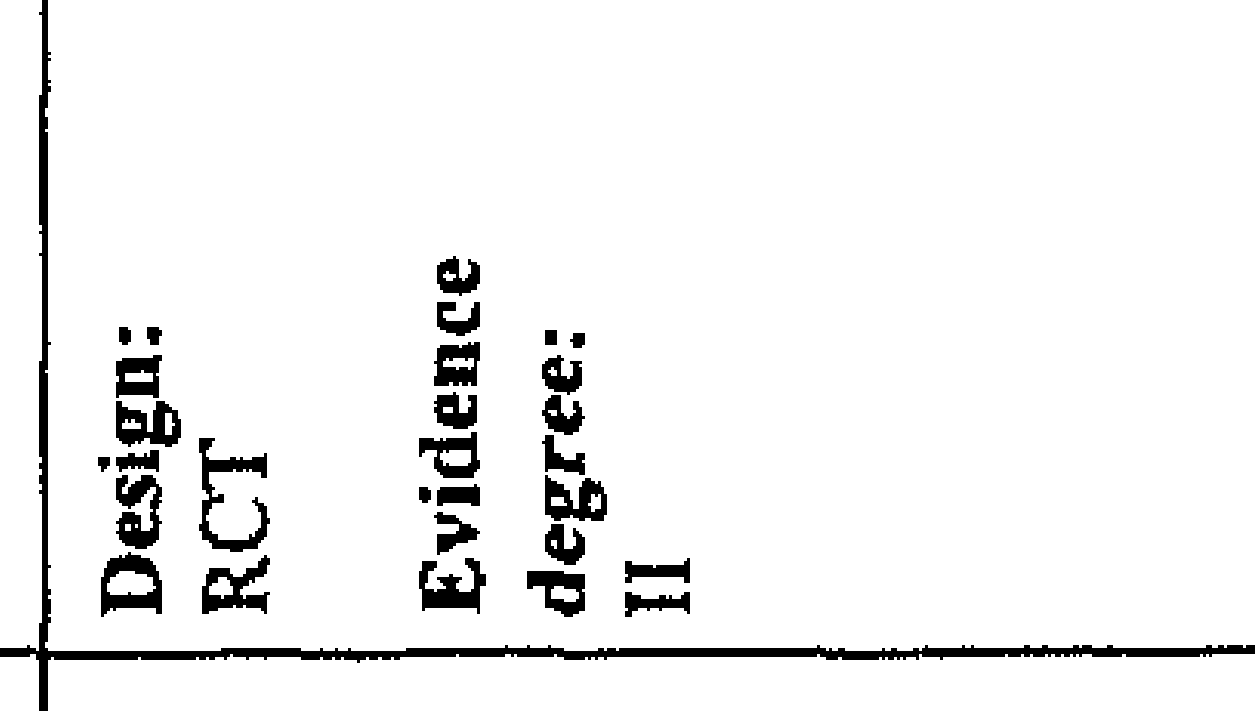 & 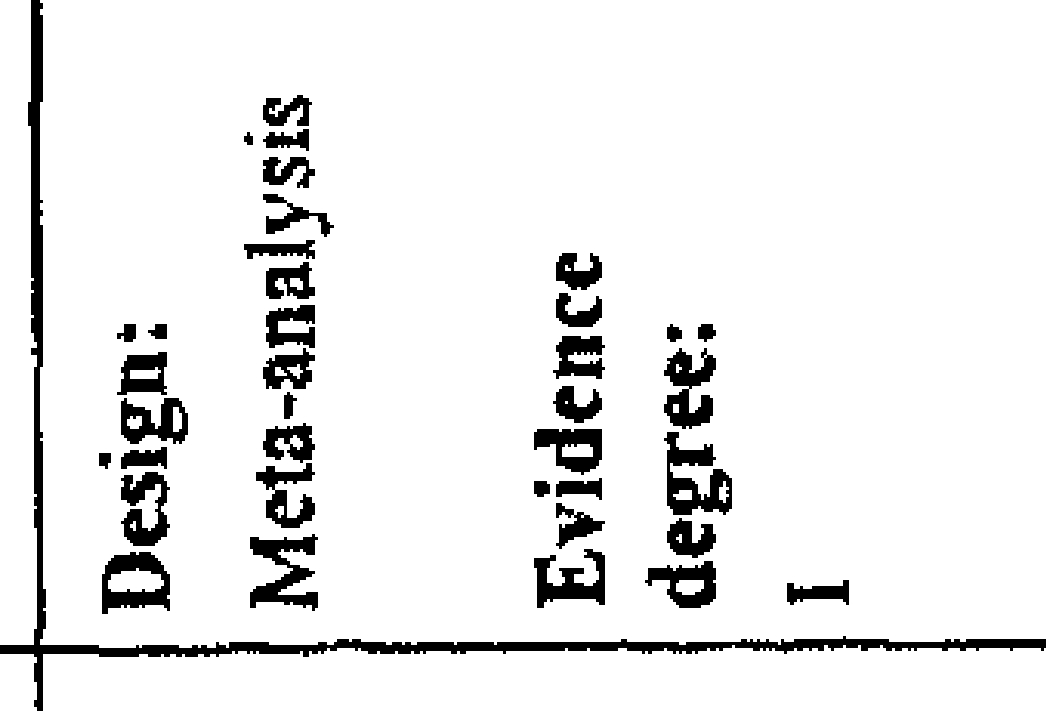 & 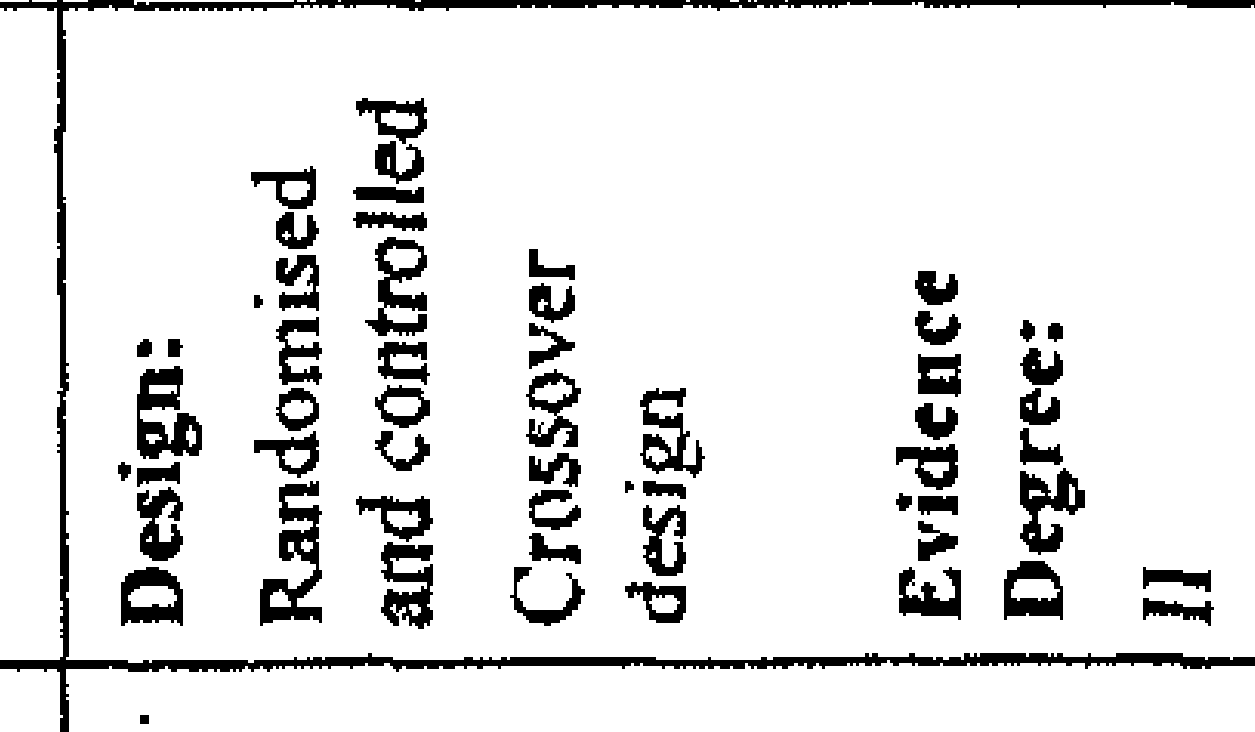 \\
\hline & 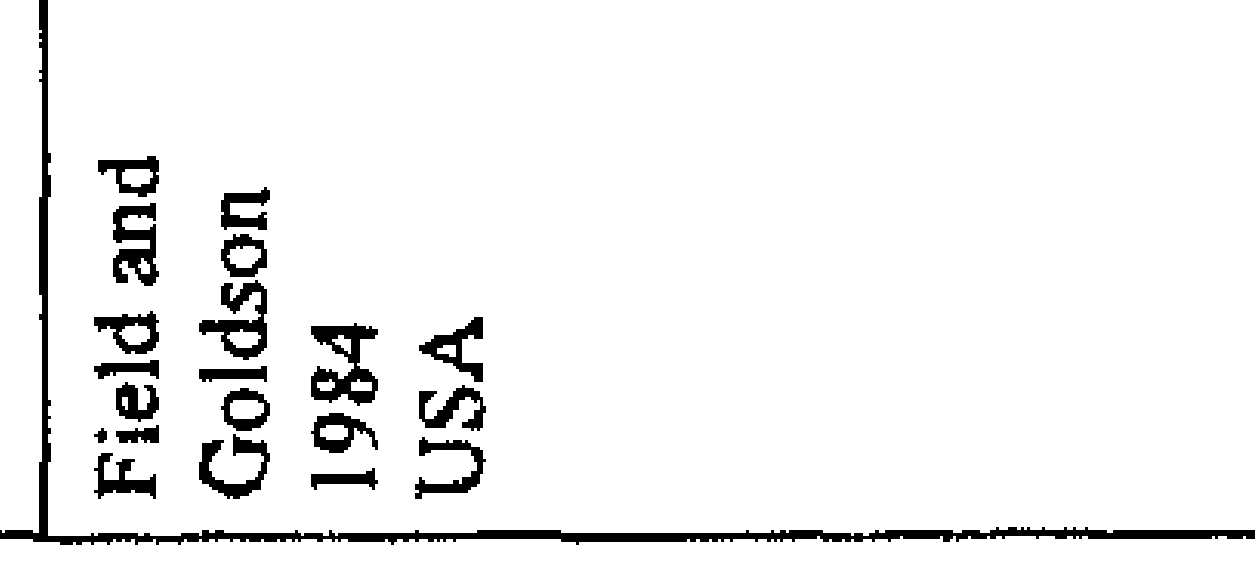 & 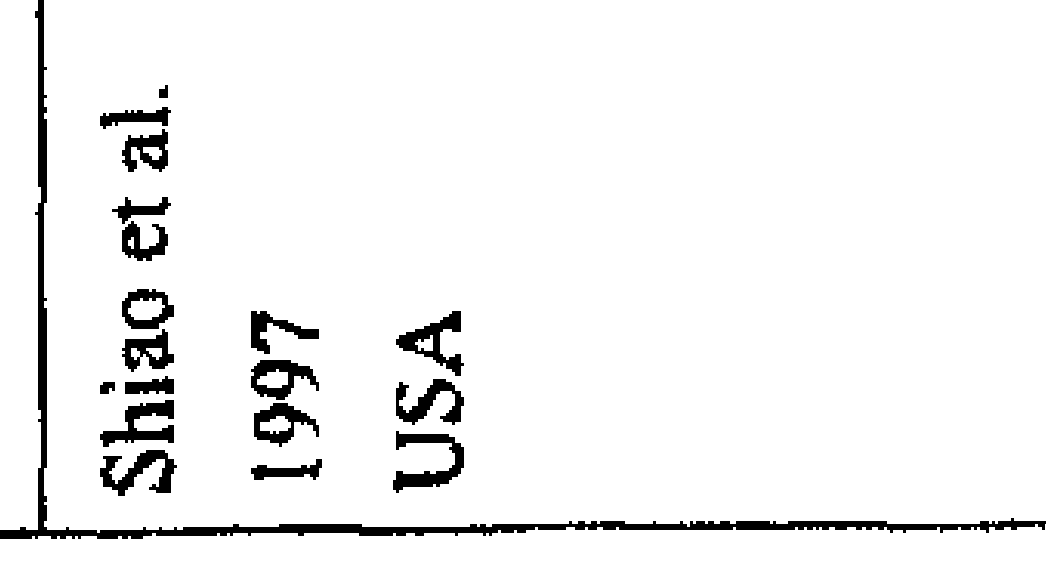 & 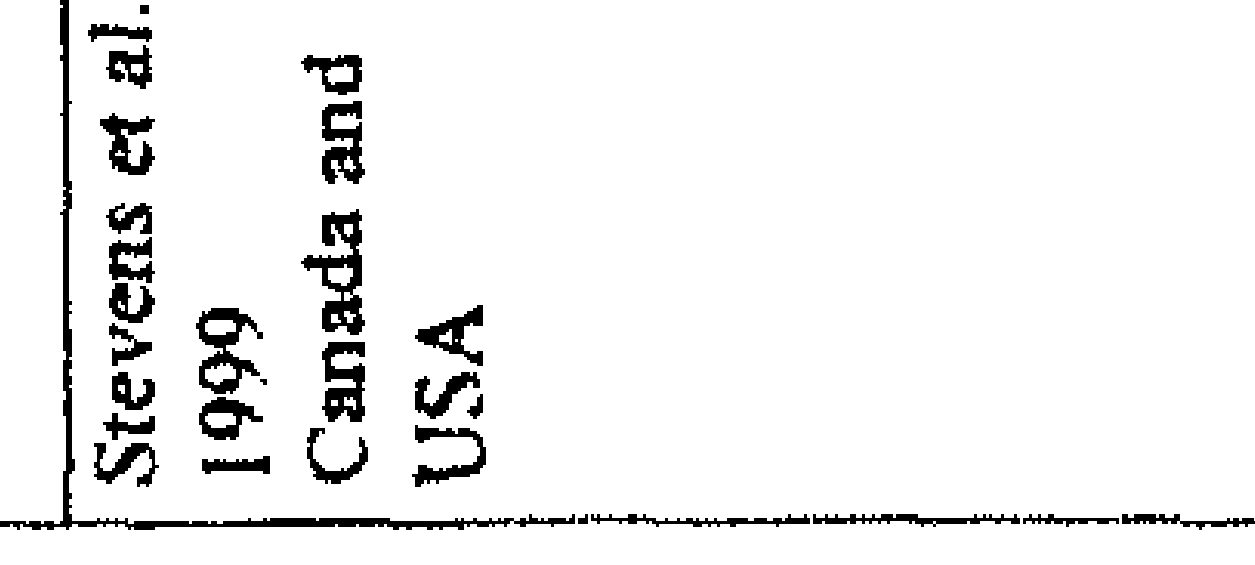 \\
\hline
\end{tabular}




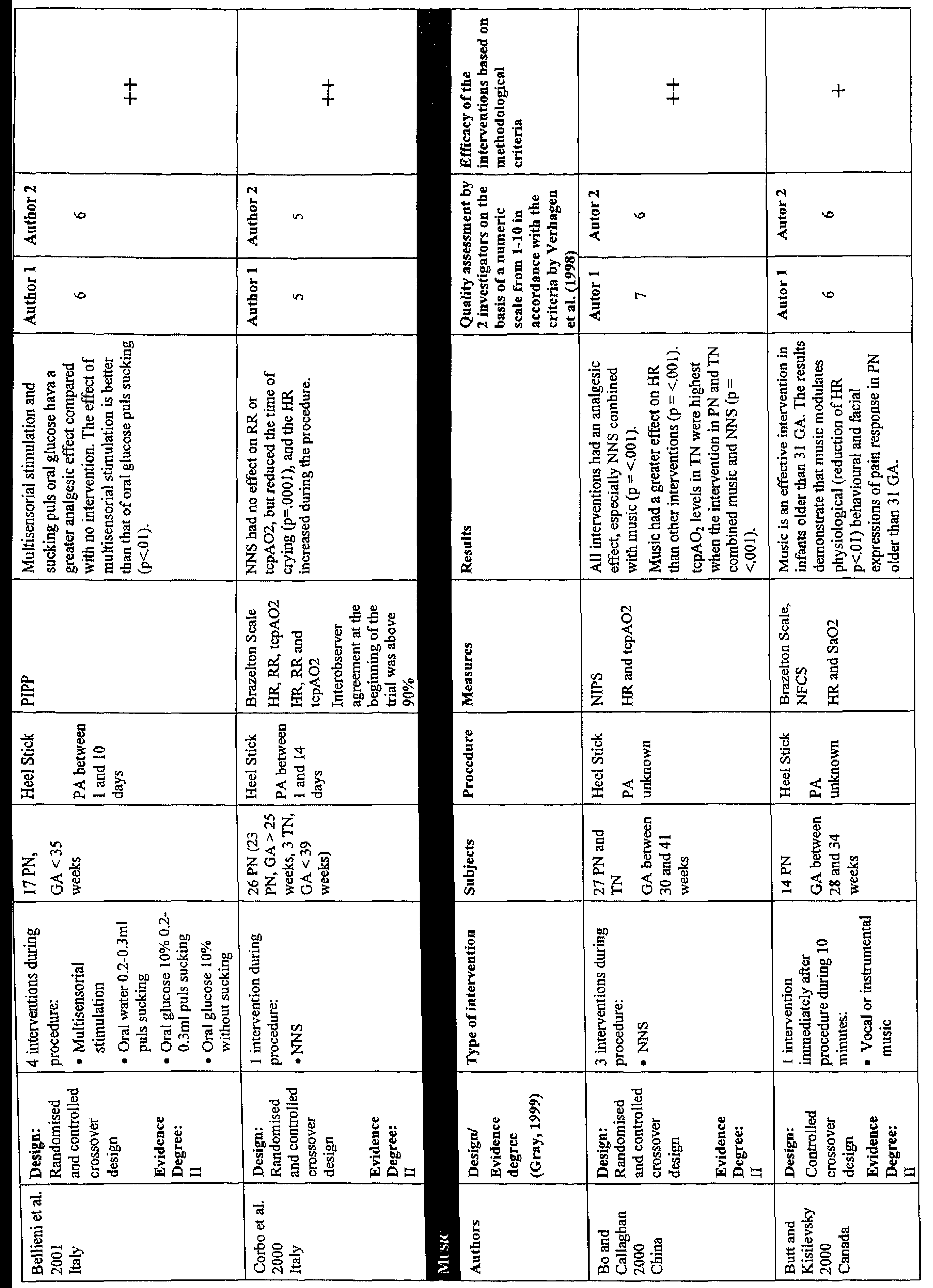




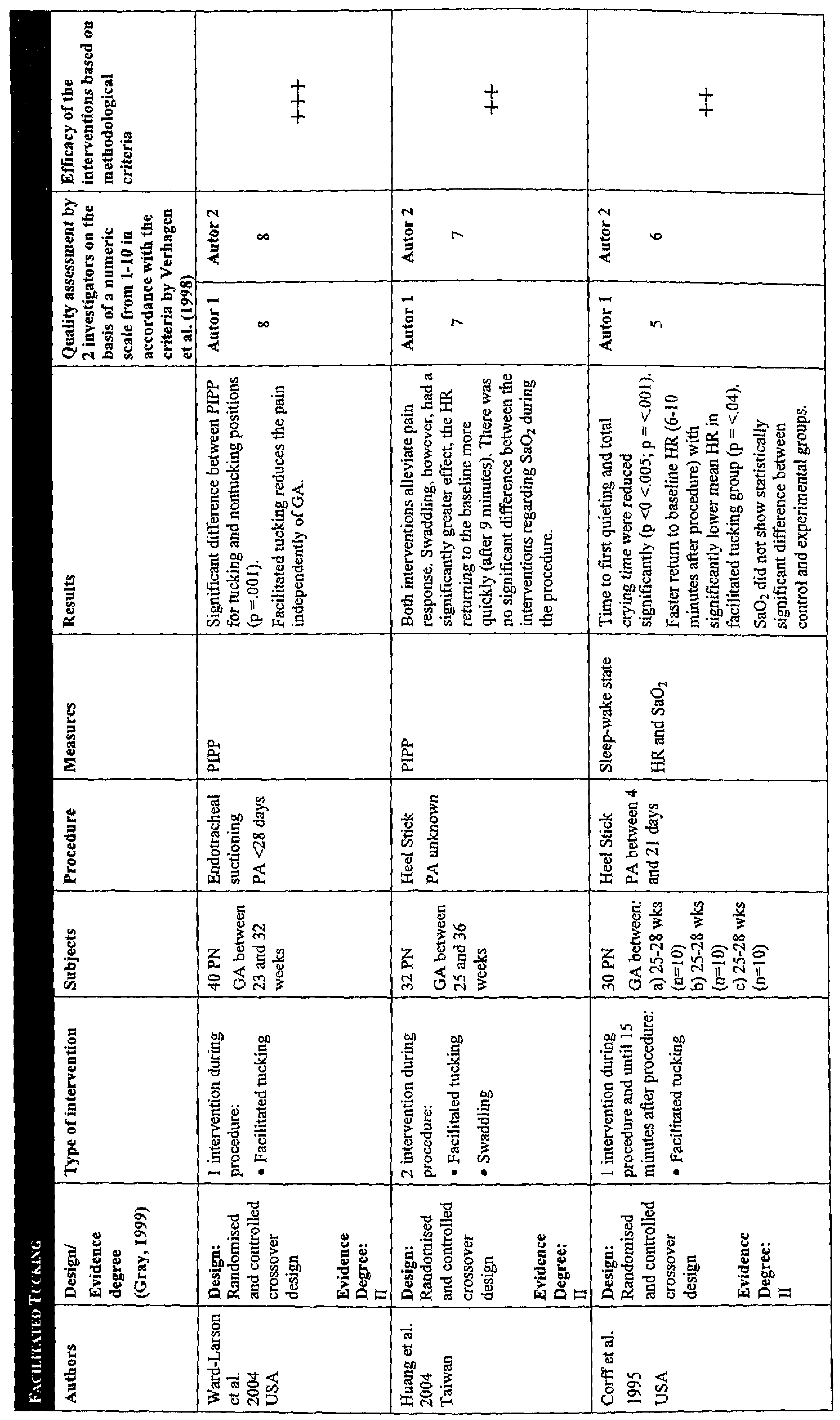




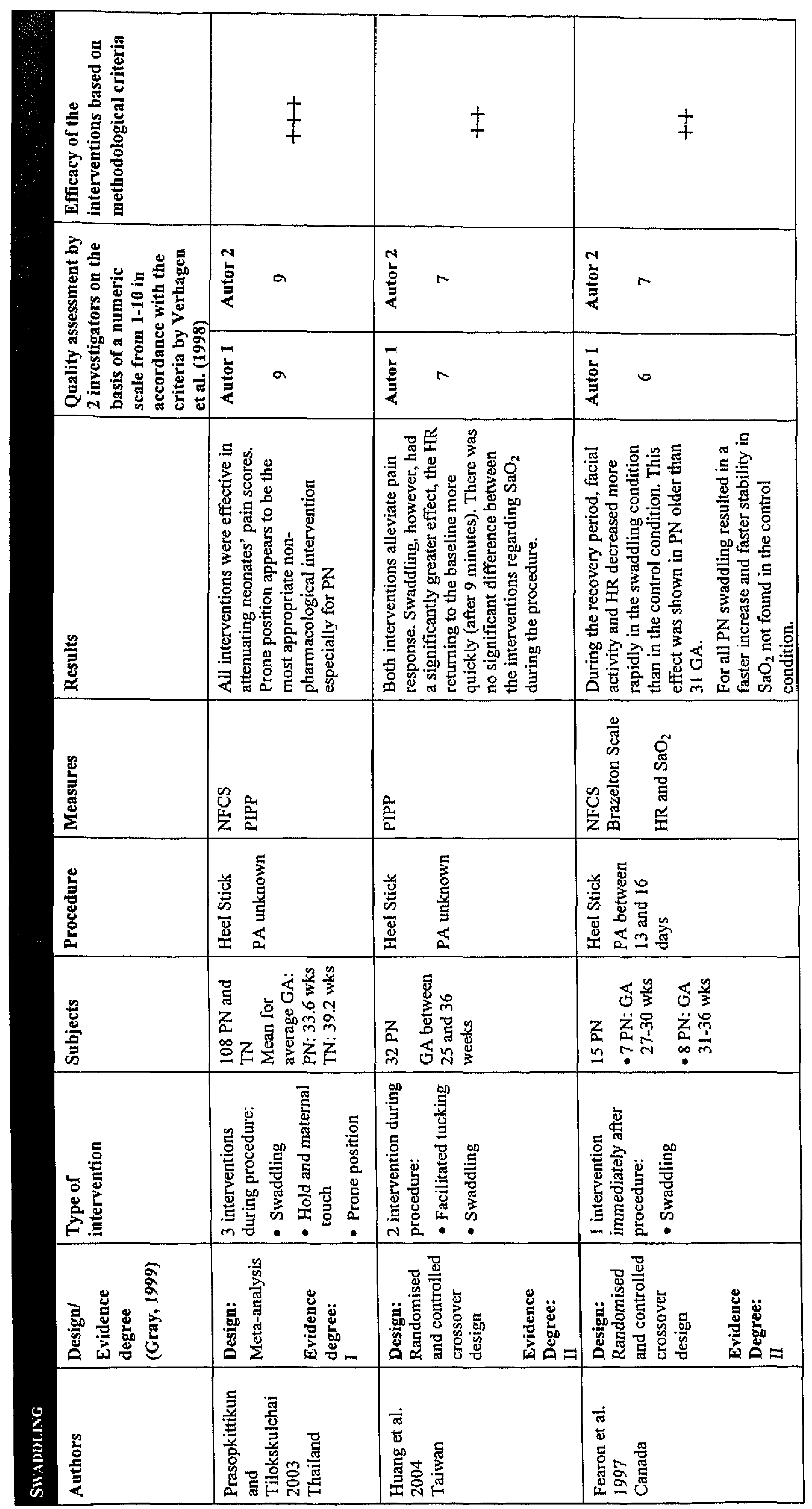




\begin{tabular}{|c|c|c|c|}
\hline 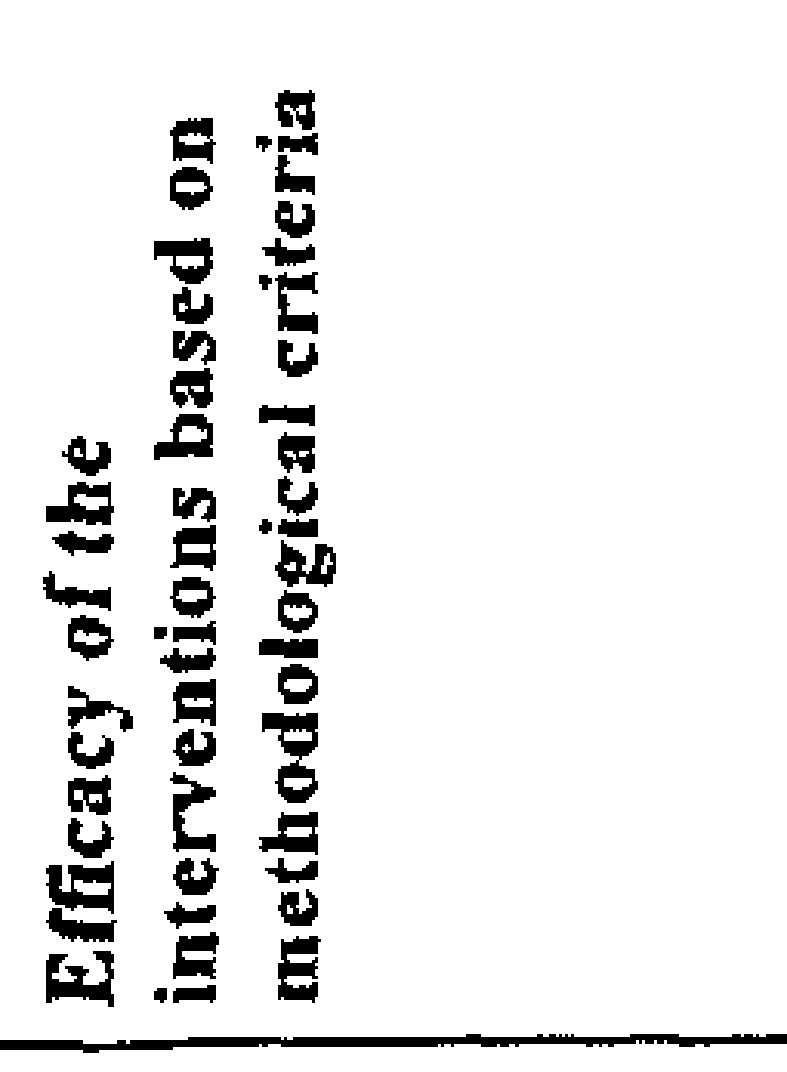 & + & $\neq$ & + \\
\hline \multirow{2}{*}{ 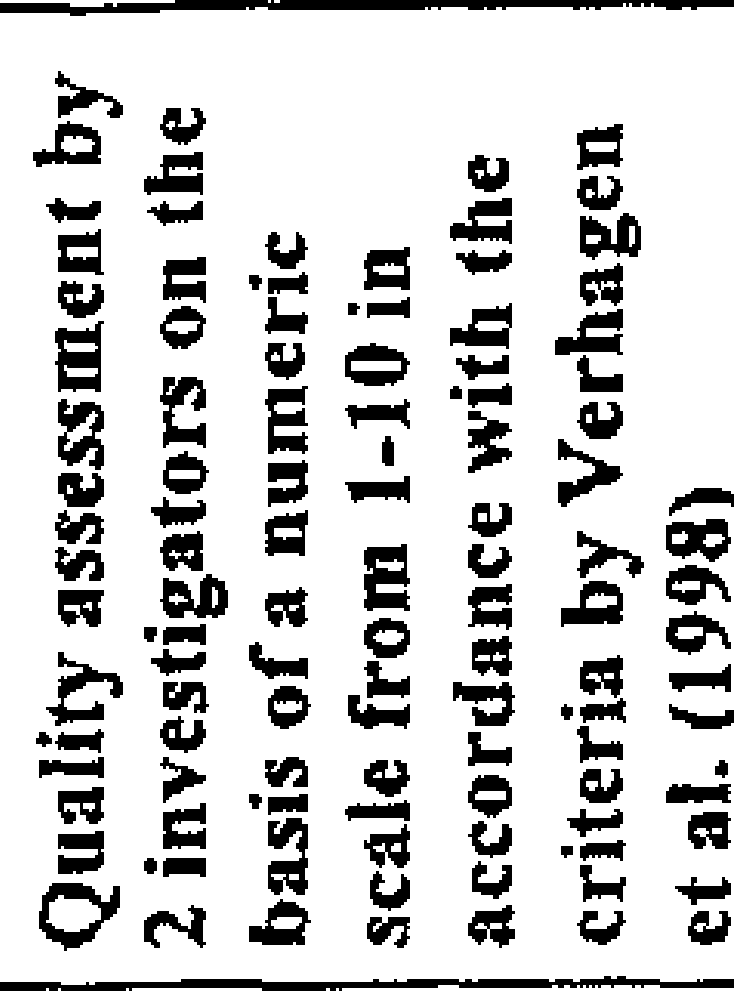 } & $\mid \begin{array}{ll}N & \\
\frac{5}{2} & \infty\end{array}$ & 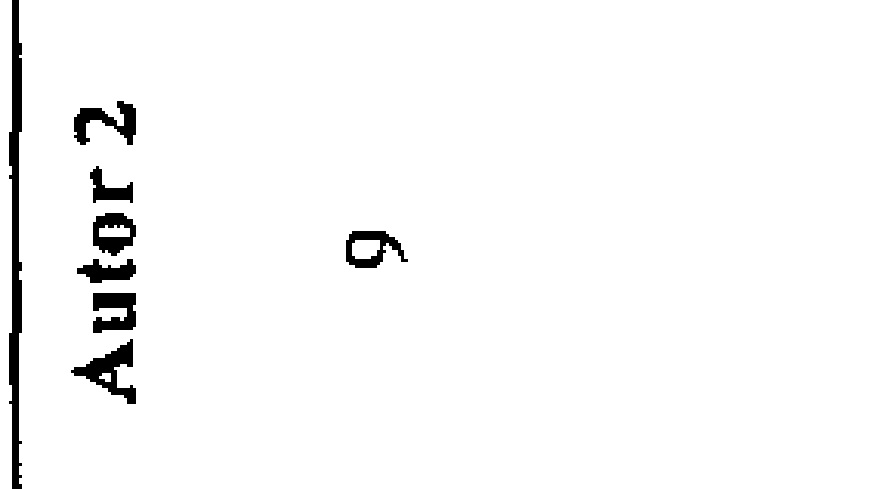 & 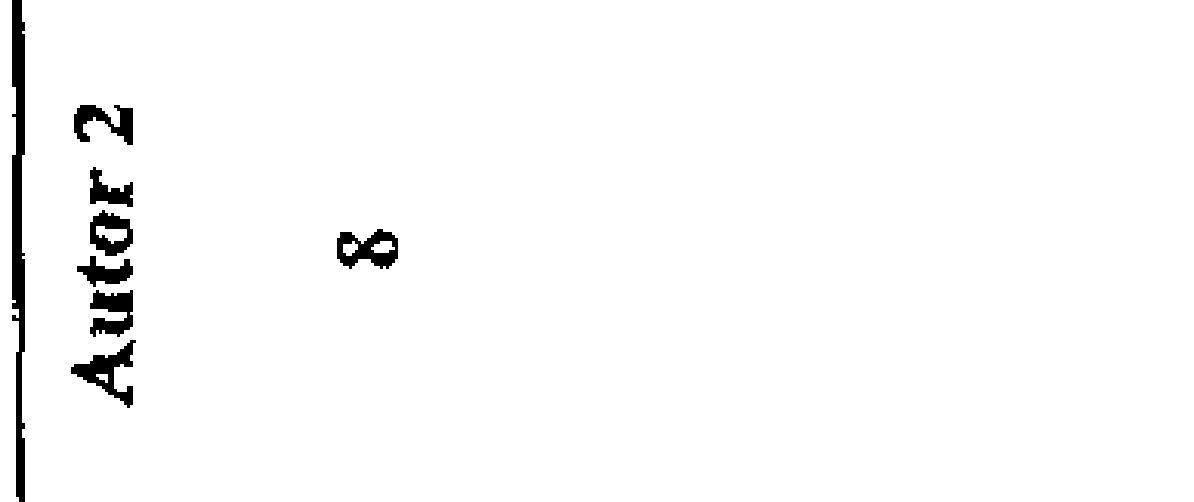 \\
\hline & 竞 & $\begin{array}{ll}\overrightarrow{5} & a \\
\end{array}$ & \begin{tabular}{ll}
\multirow{8}{*}{} & $\infty$ \\
\end{tabular} \\
\hline 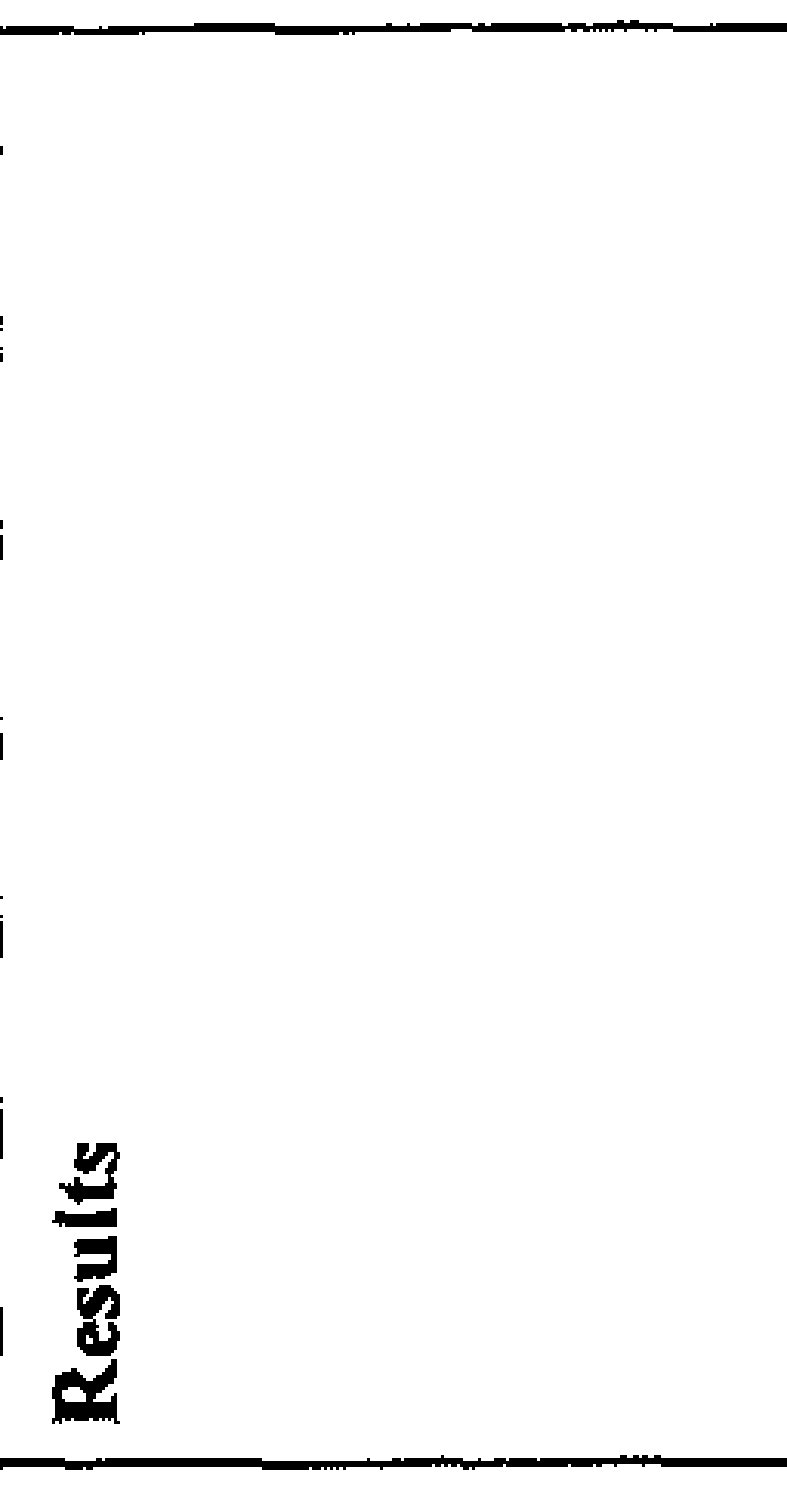 & 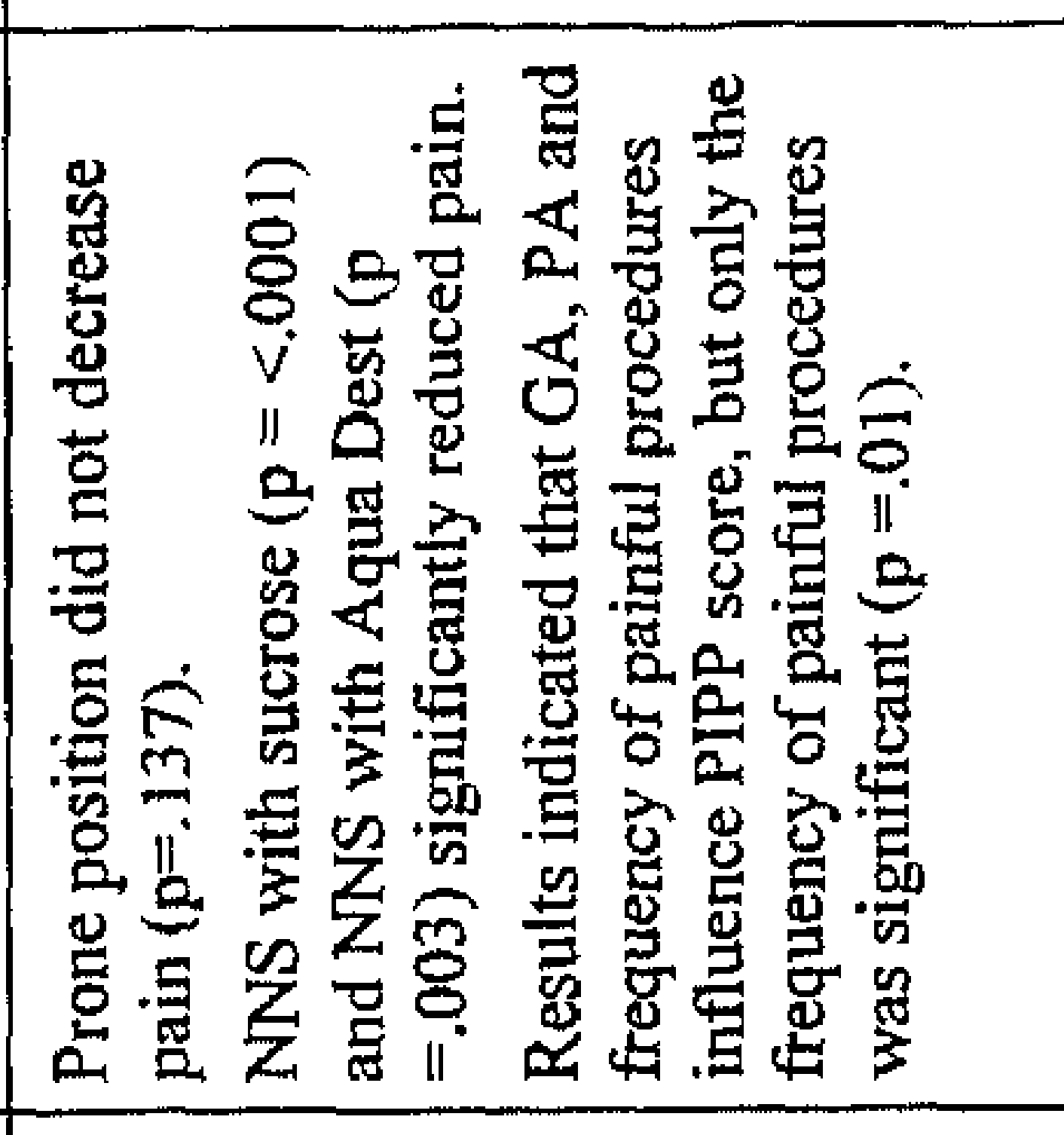 & 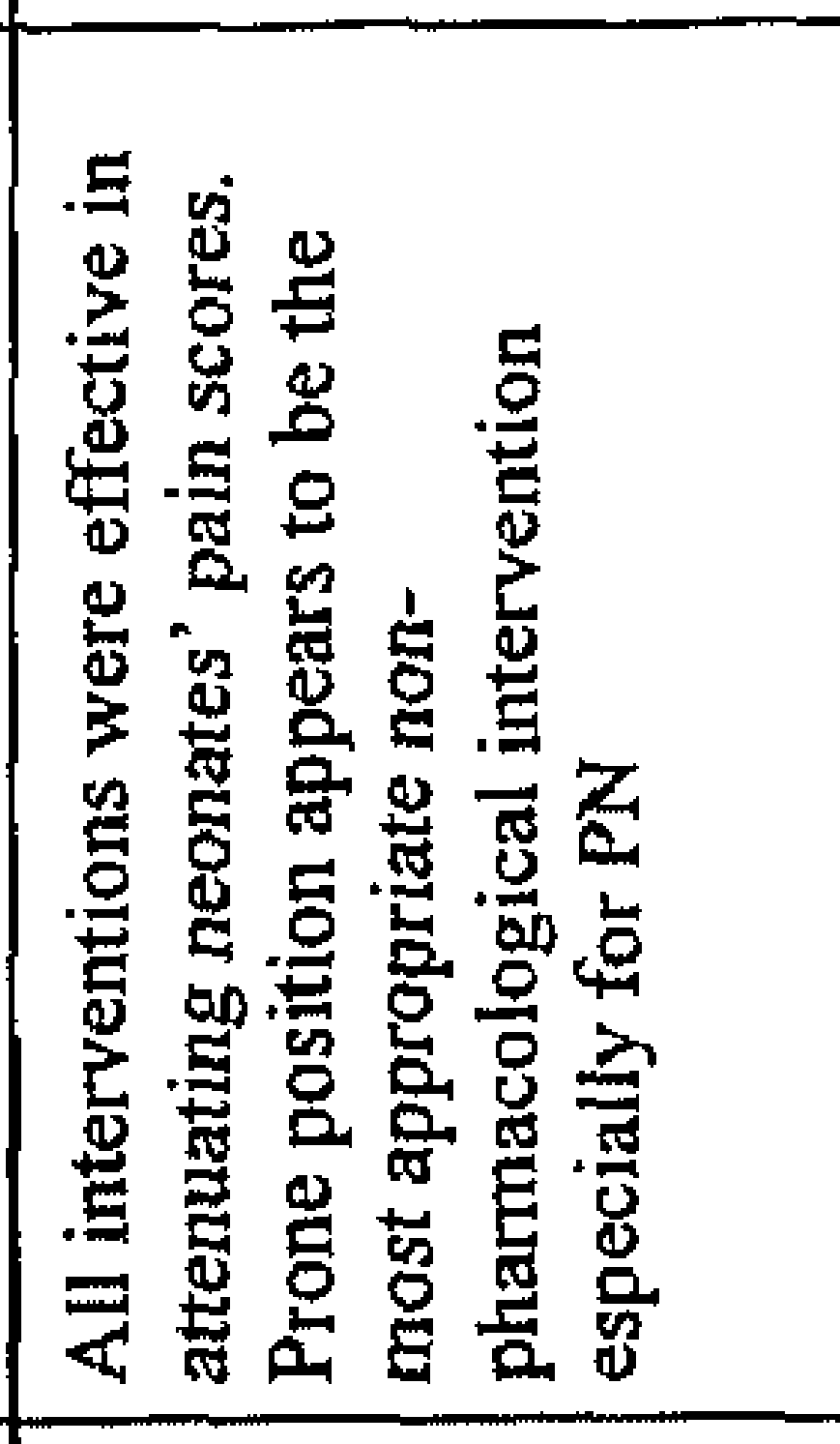 & 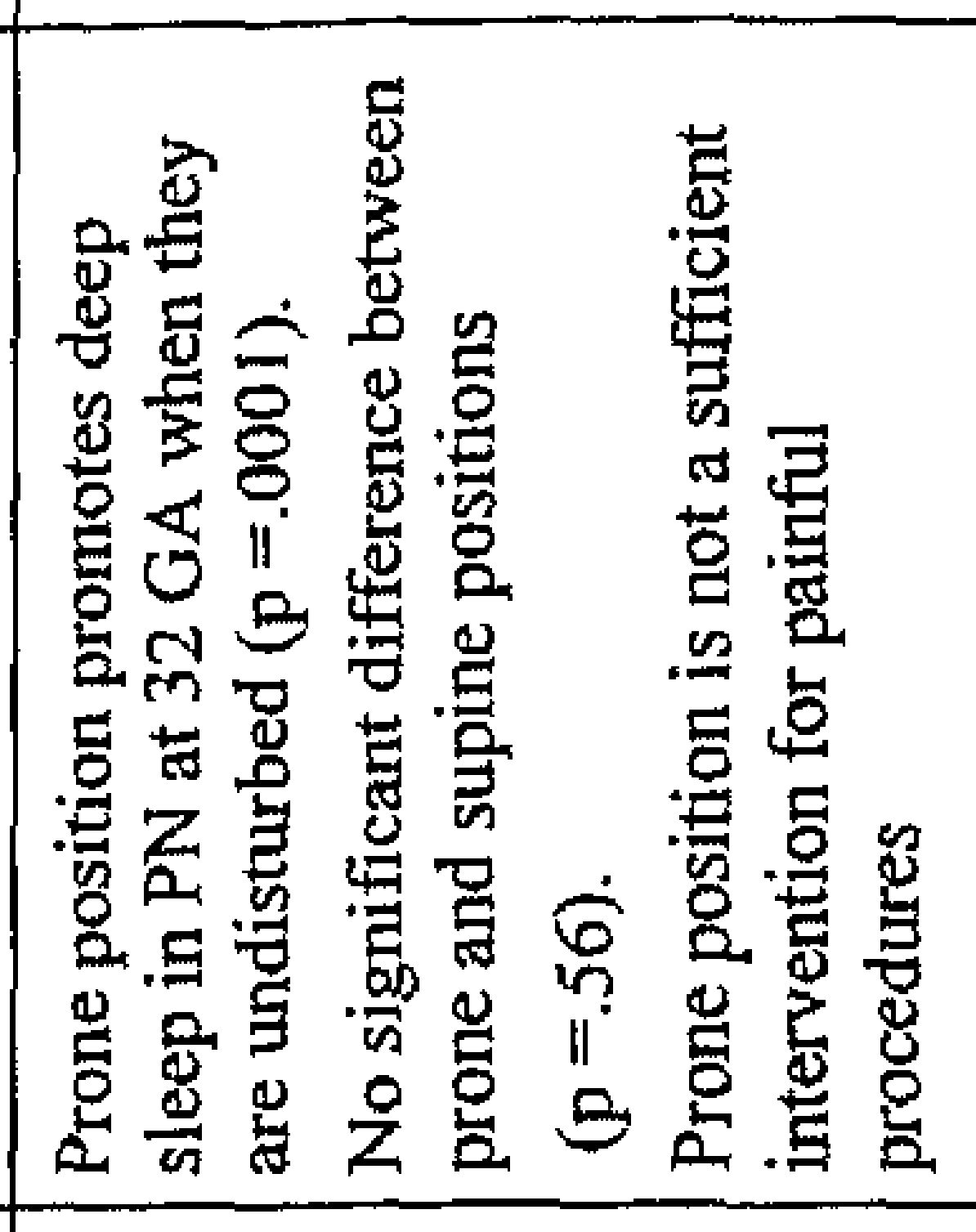 \\
\hline 亭 & 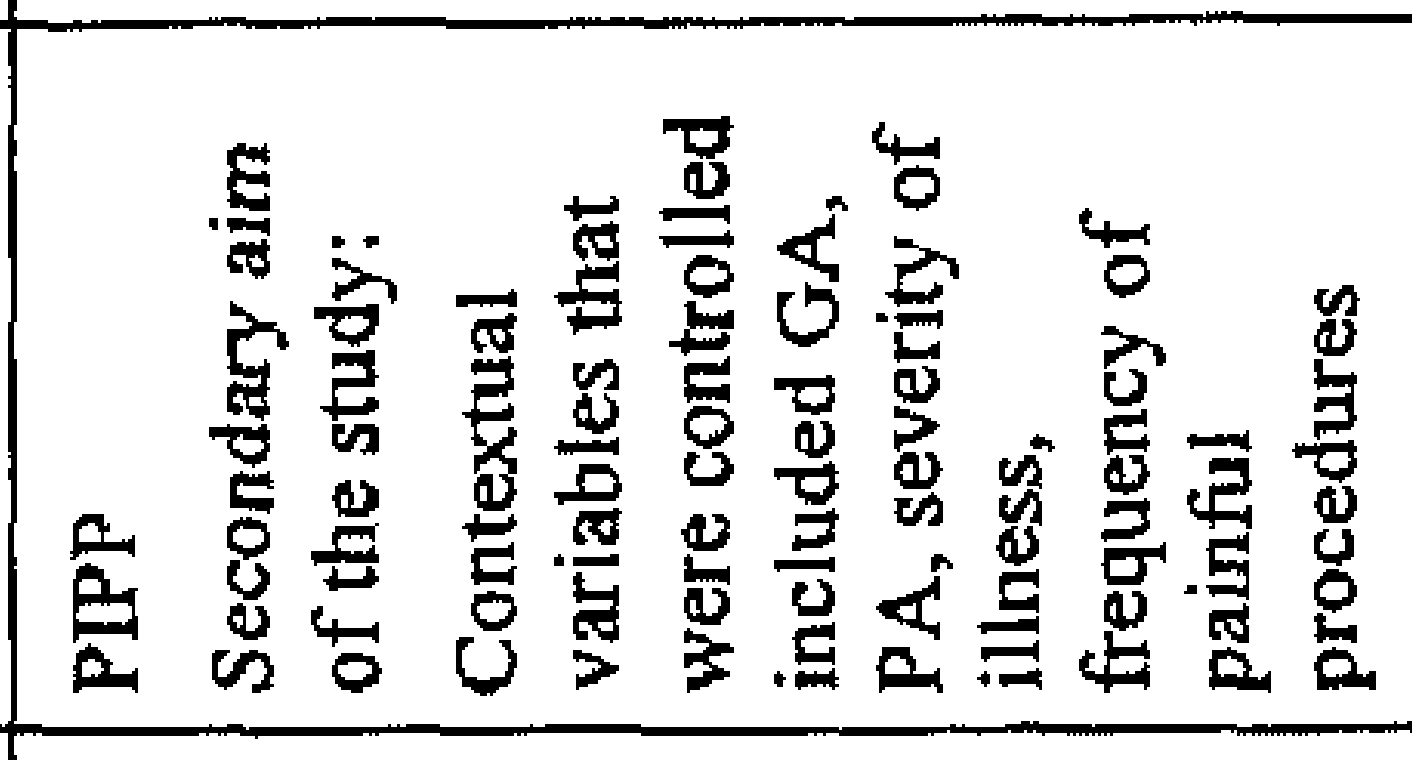 & 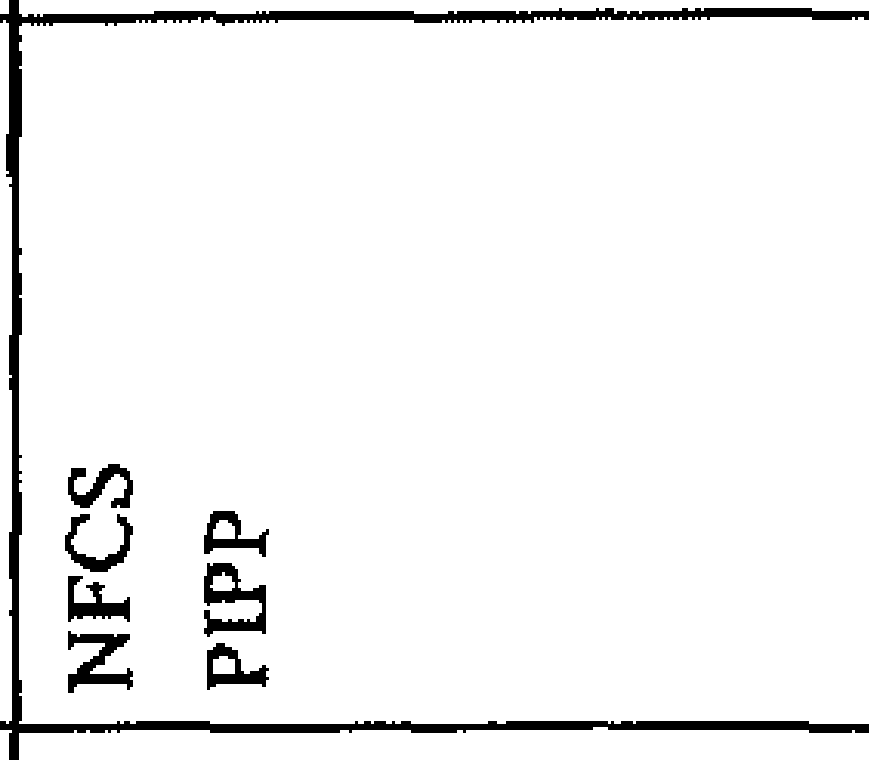 & 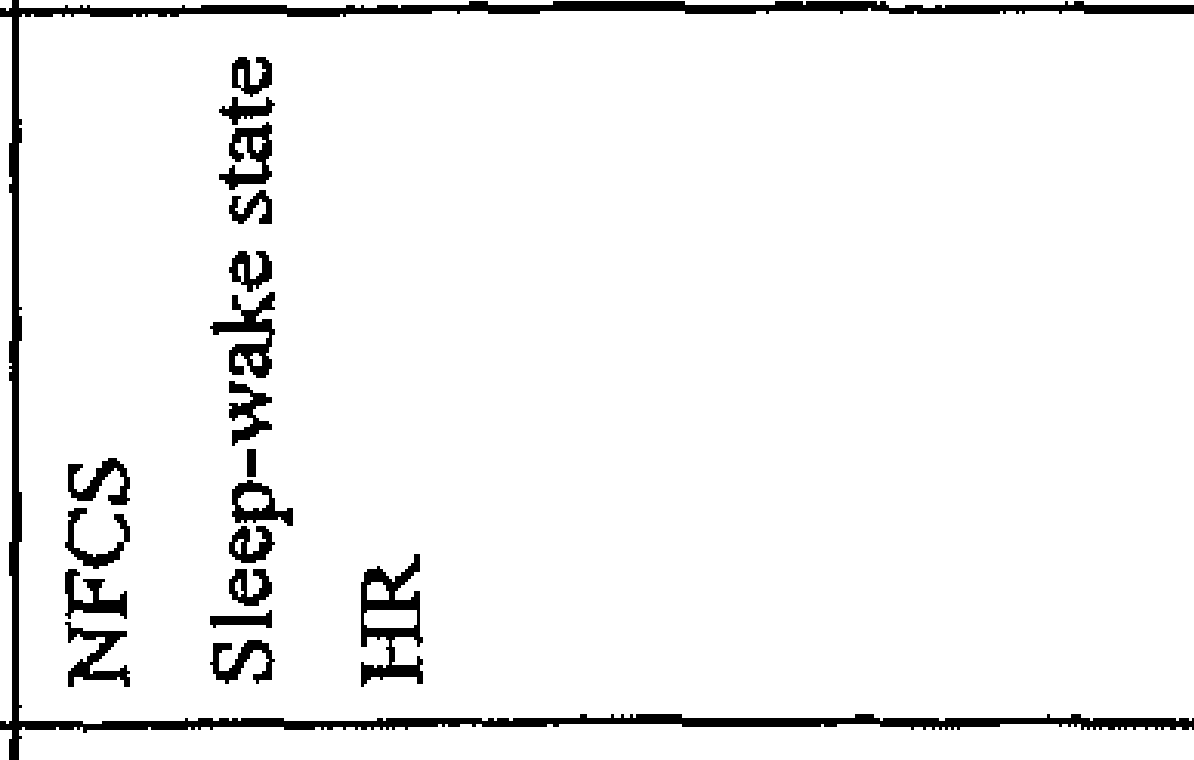 \\
\hline 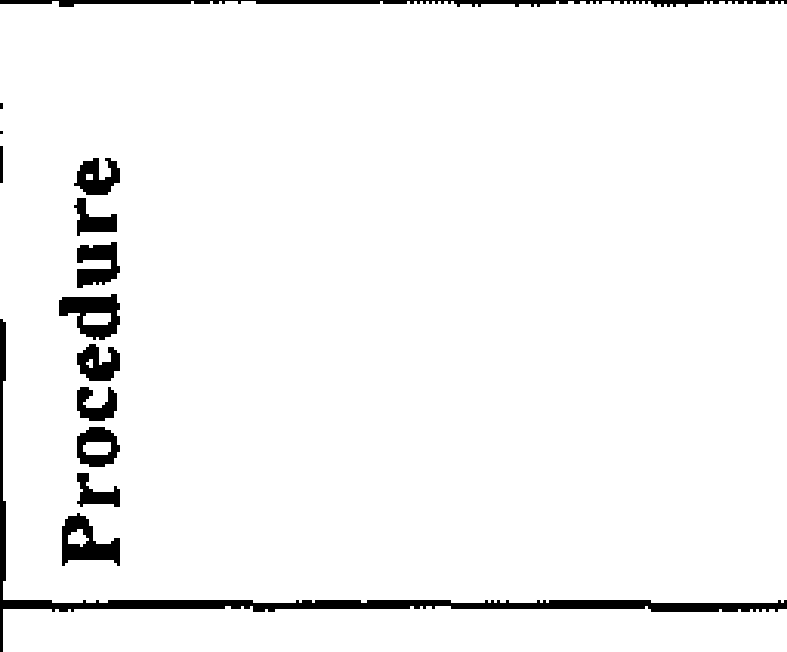 & 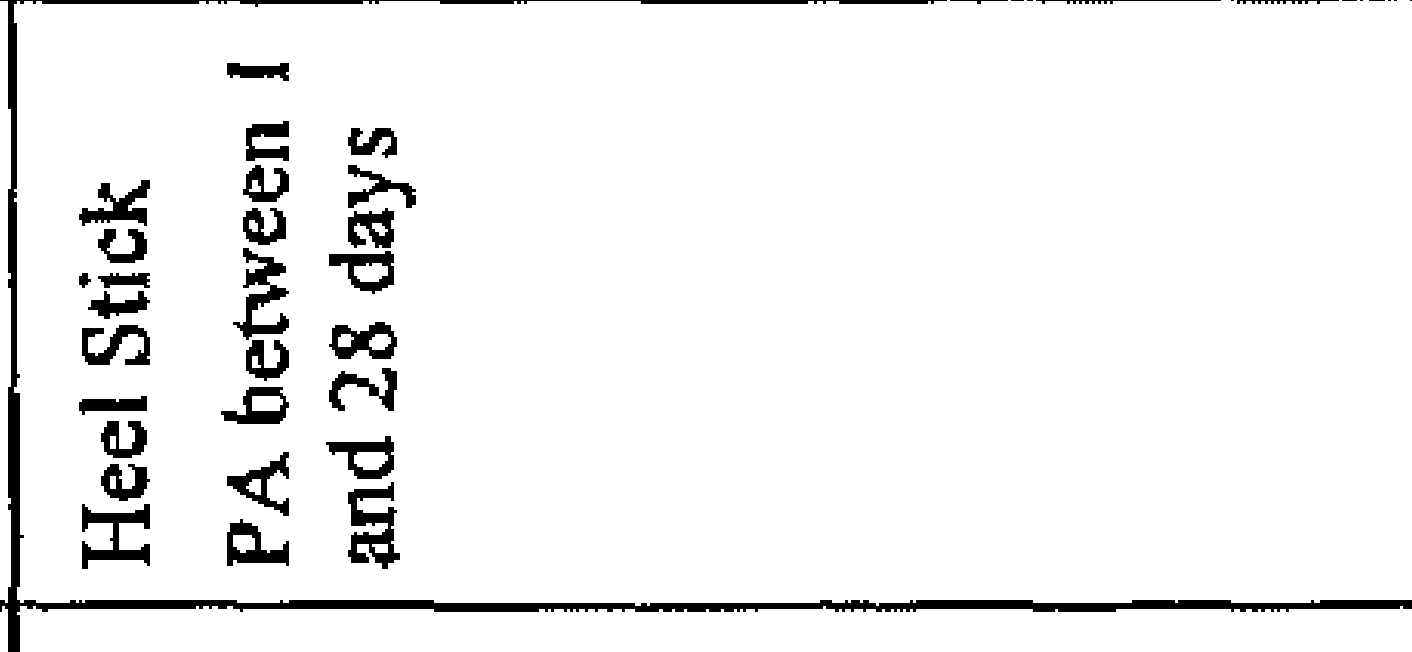 & 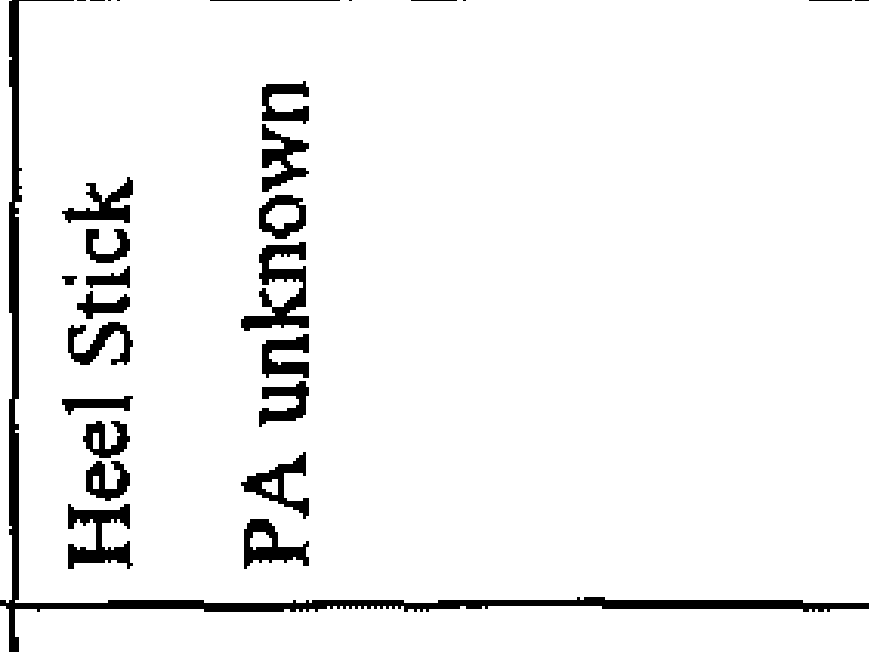 & 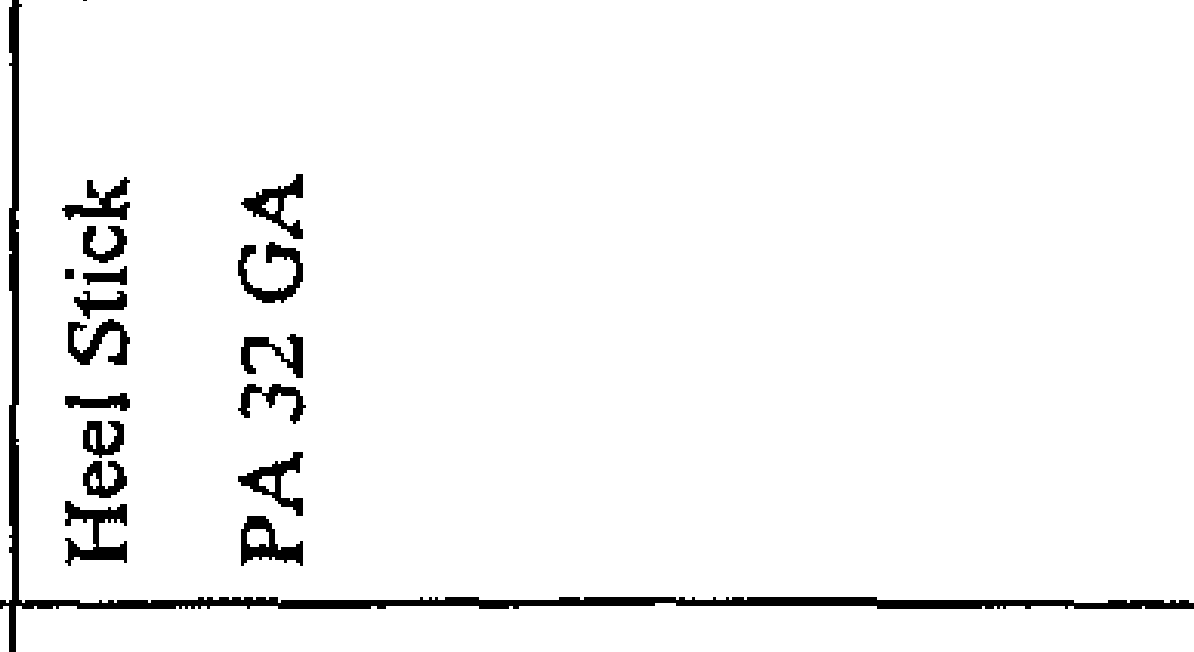 \\
\hline 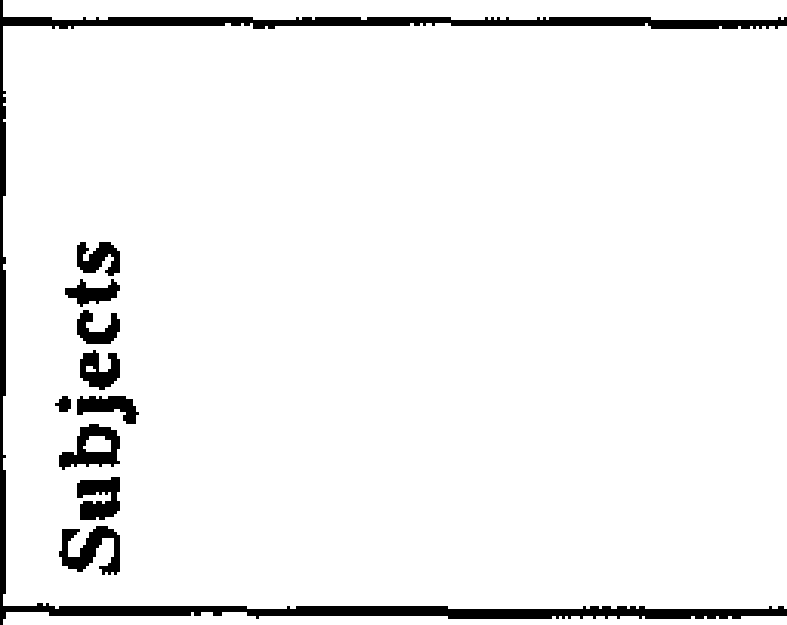 & 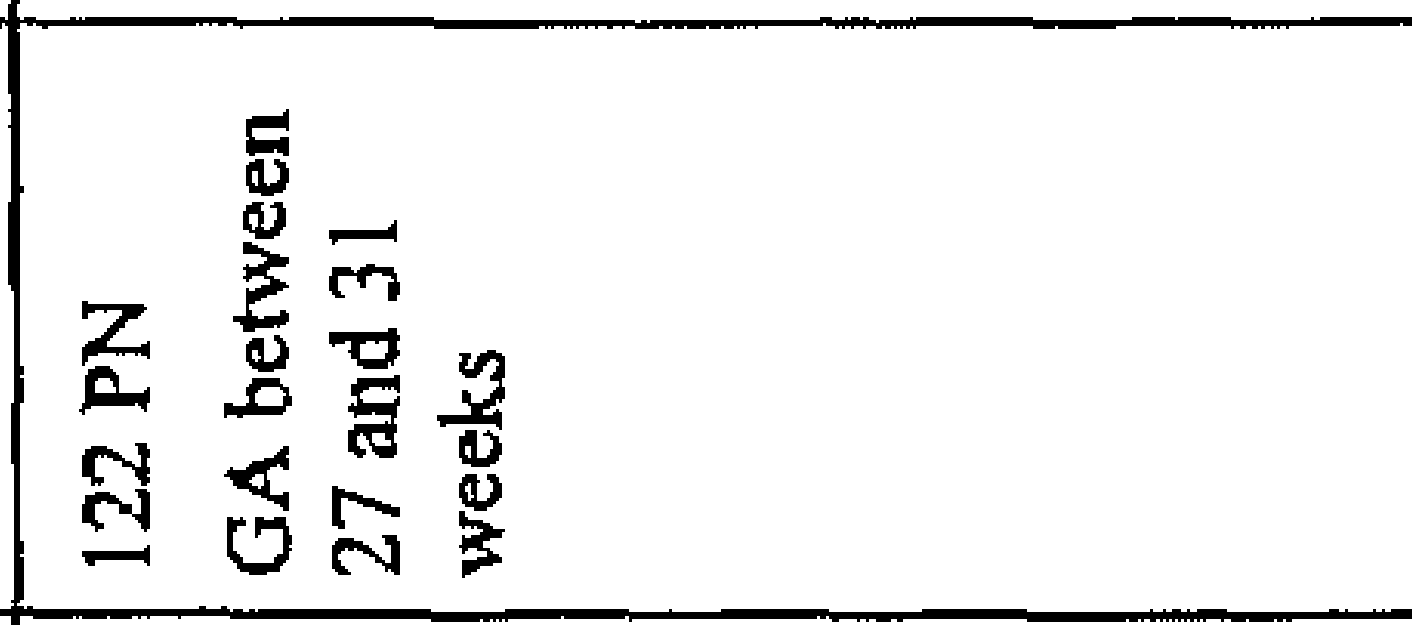 & 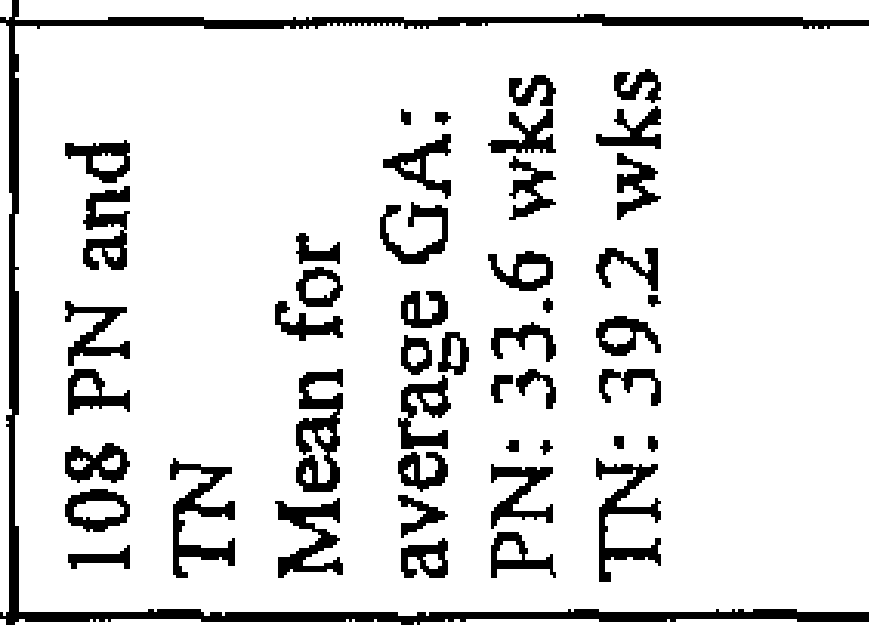 & 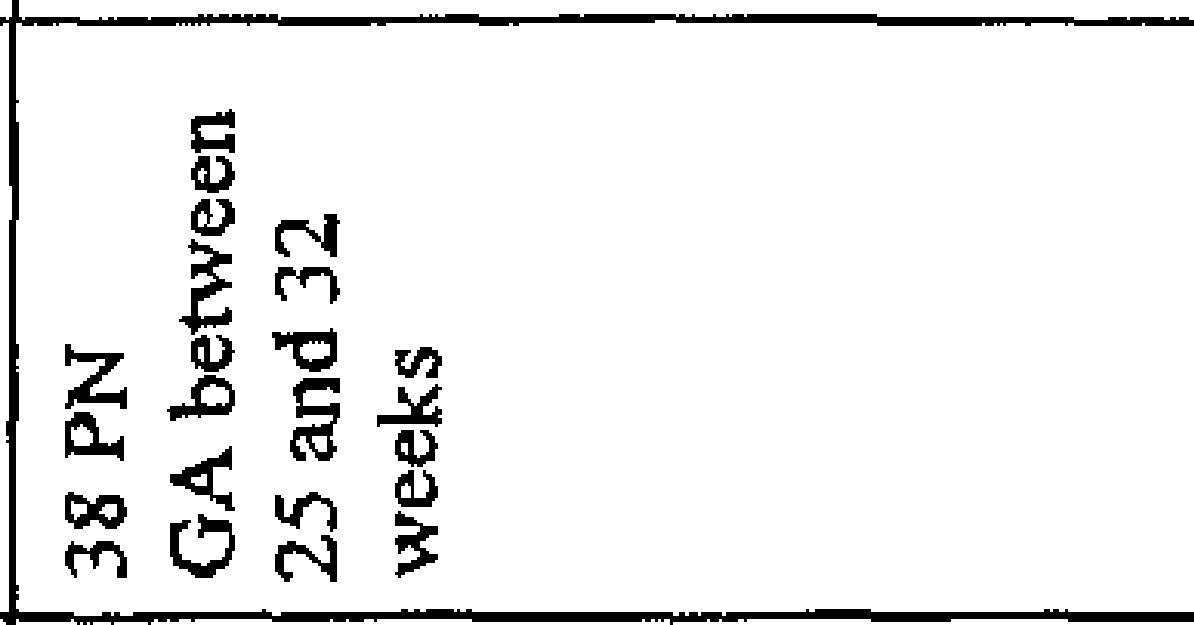 \\
\hline 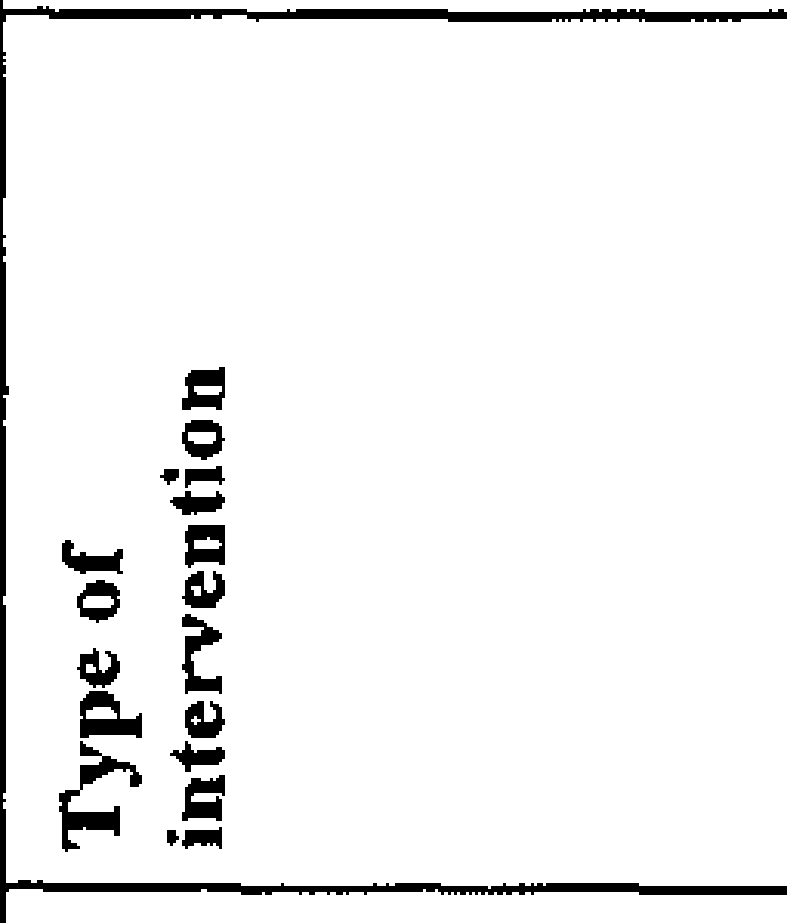 & 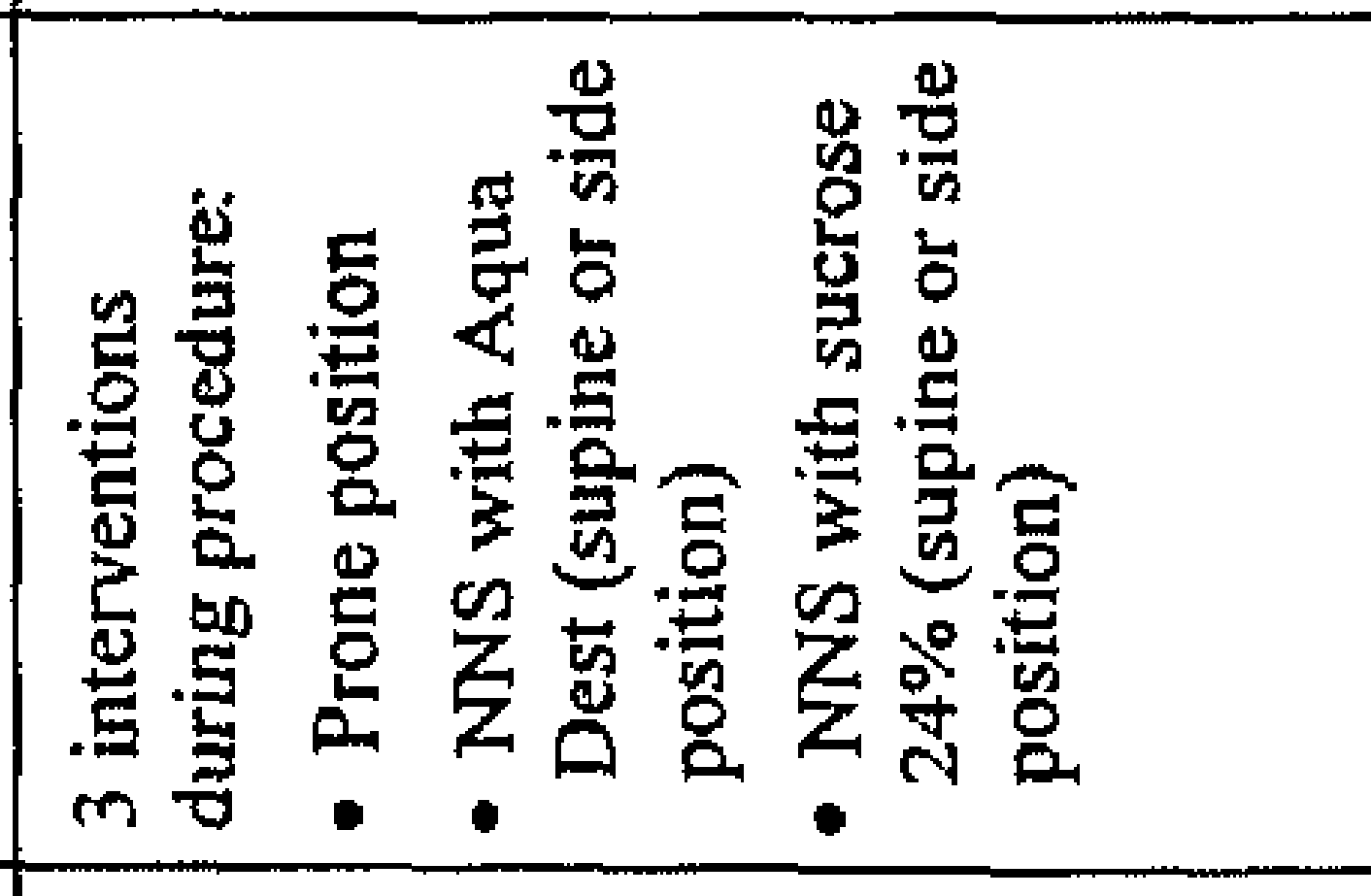 & 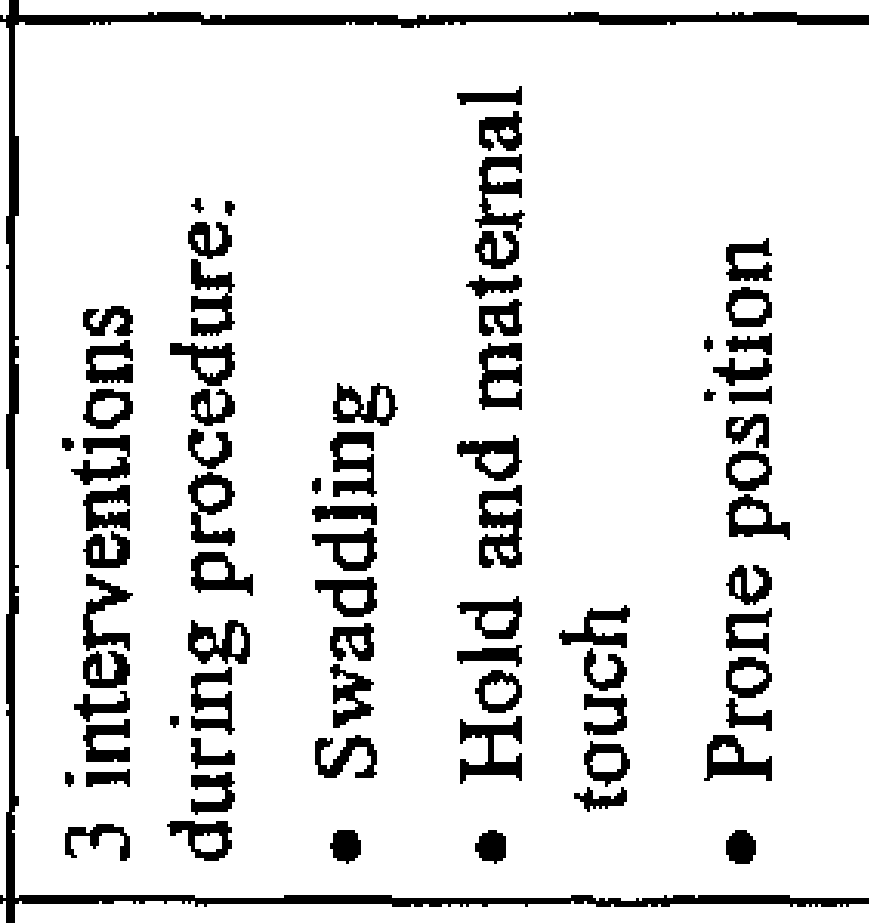 & 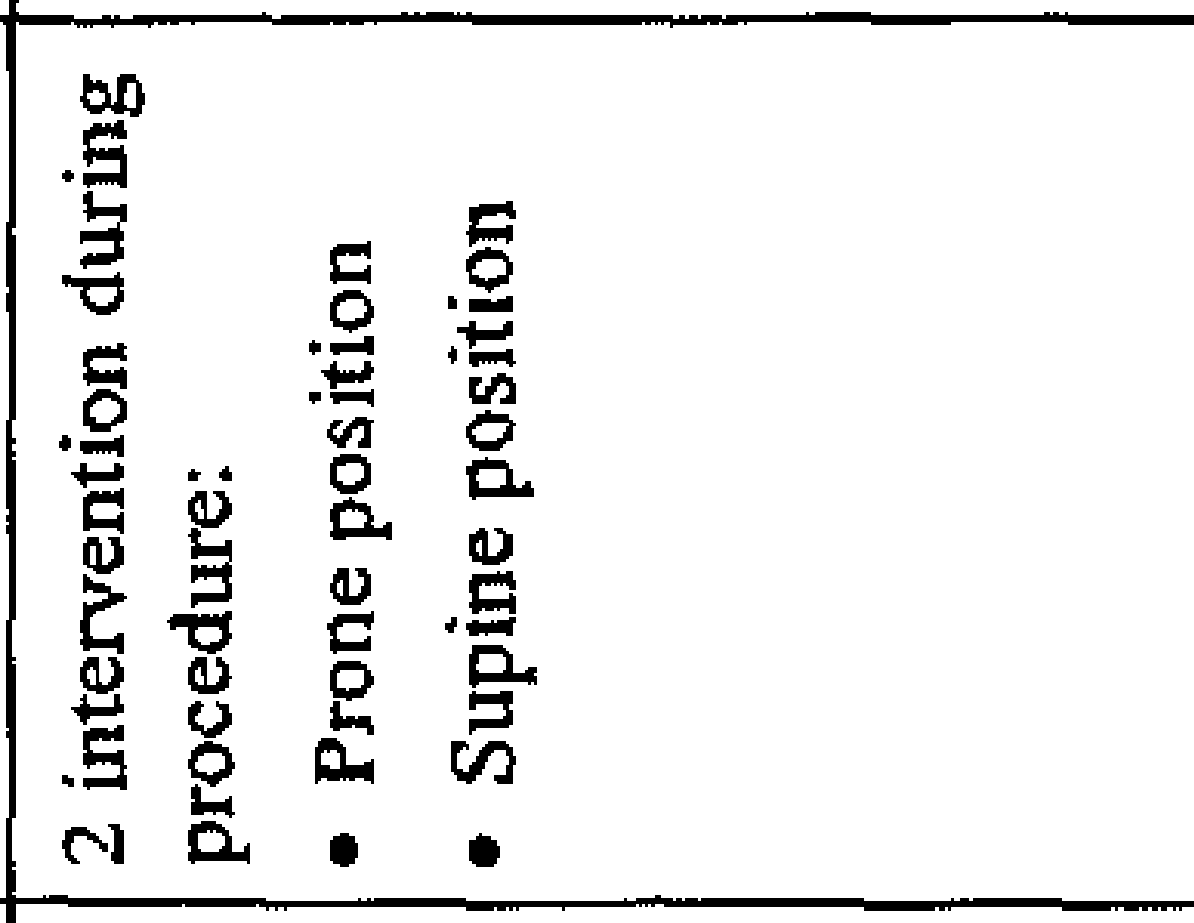 \\
\hline 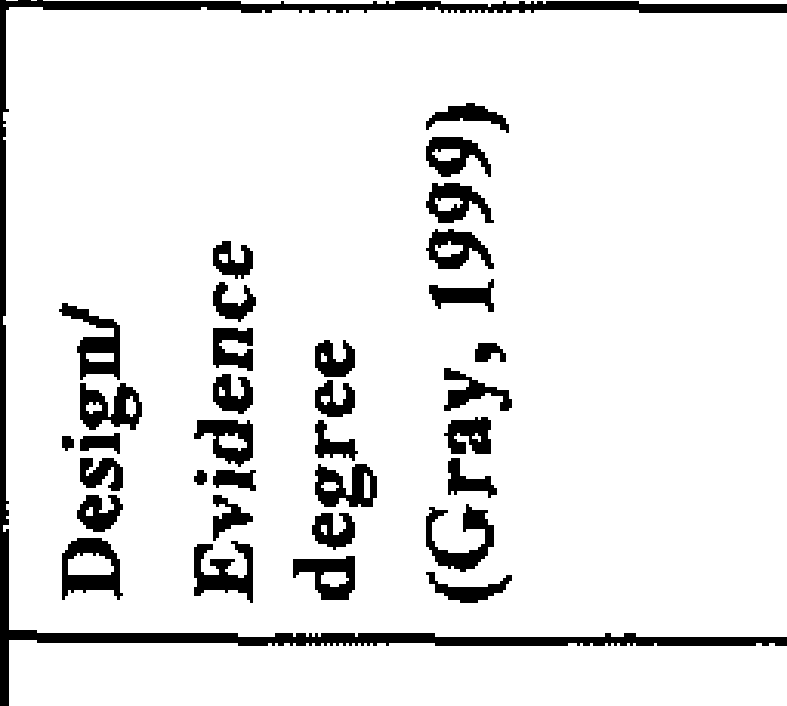 & 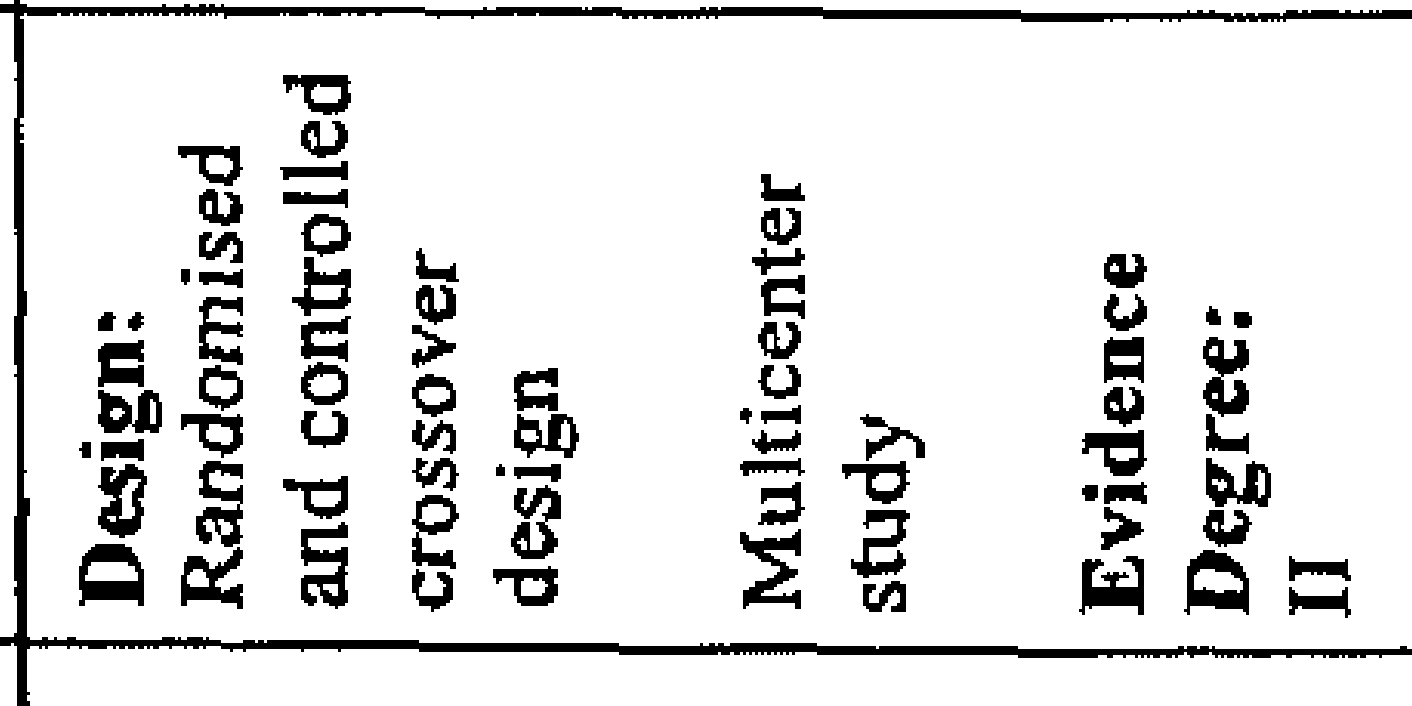 & 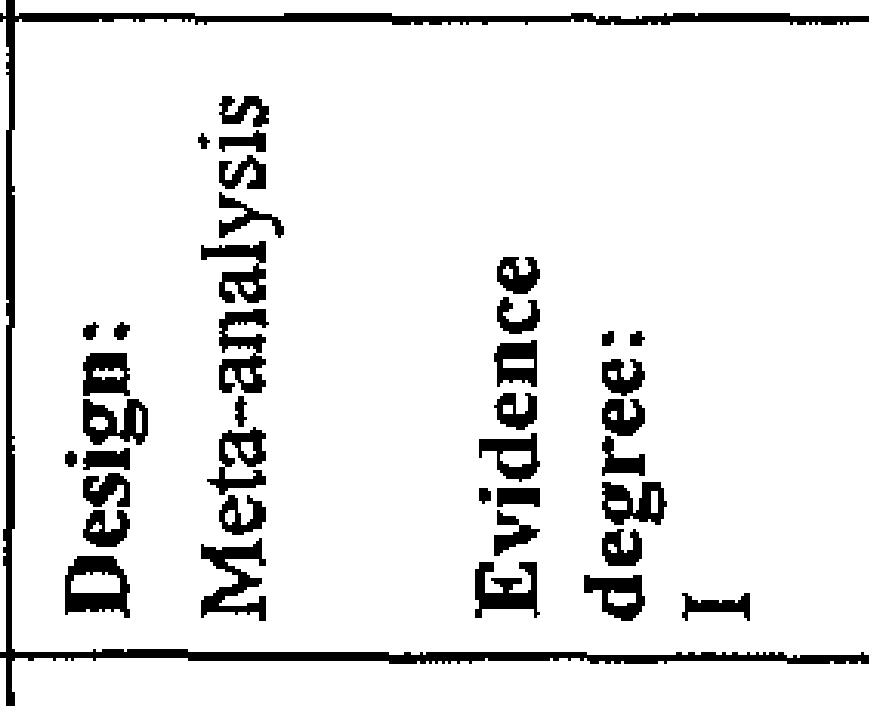 & 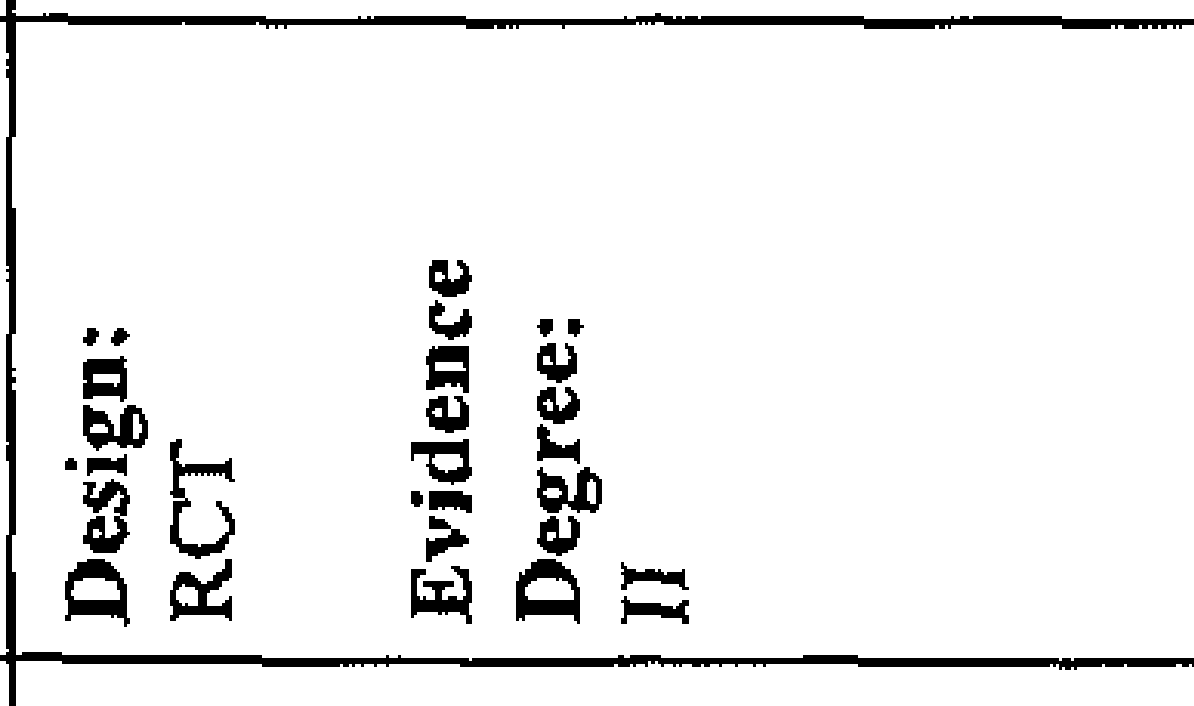 \\
\hline 量 & 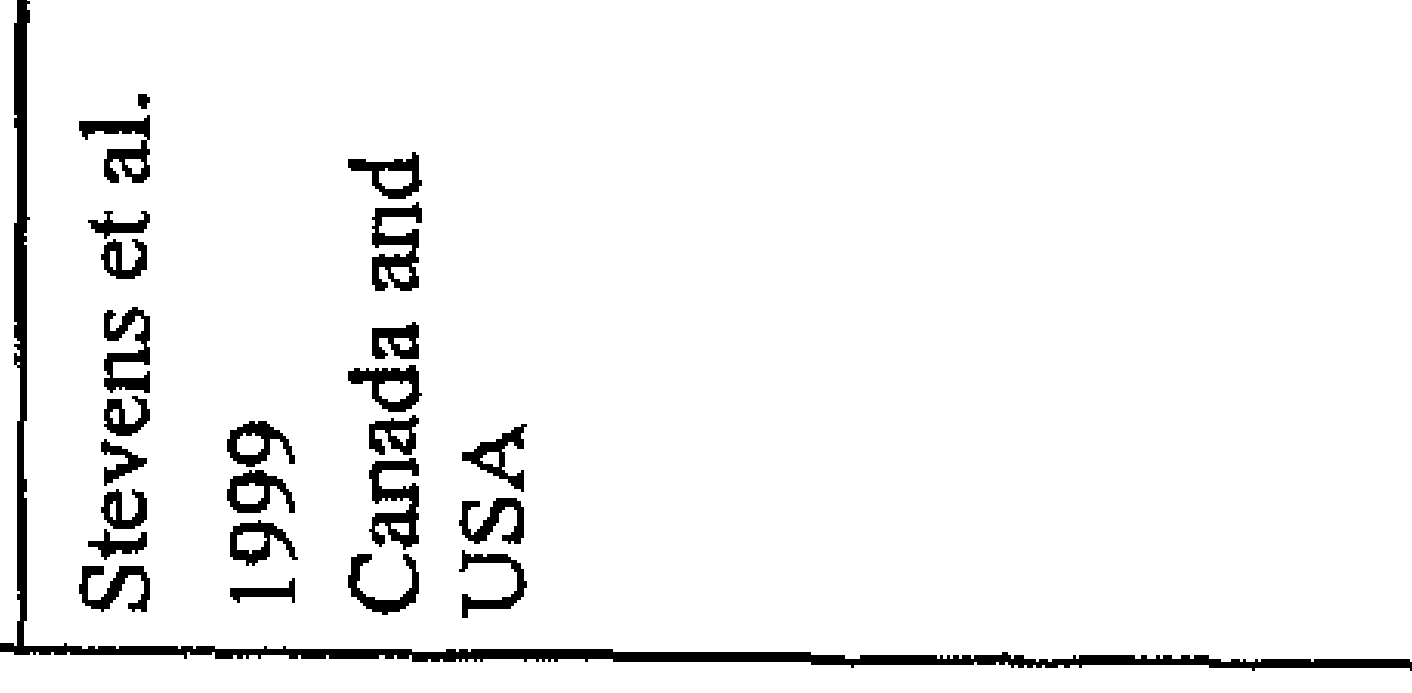 & 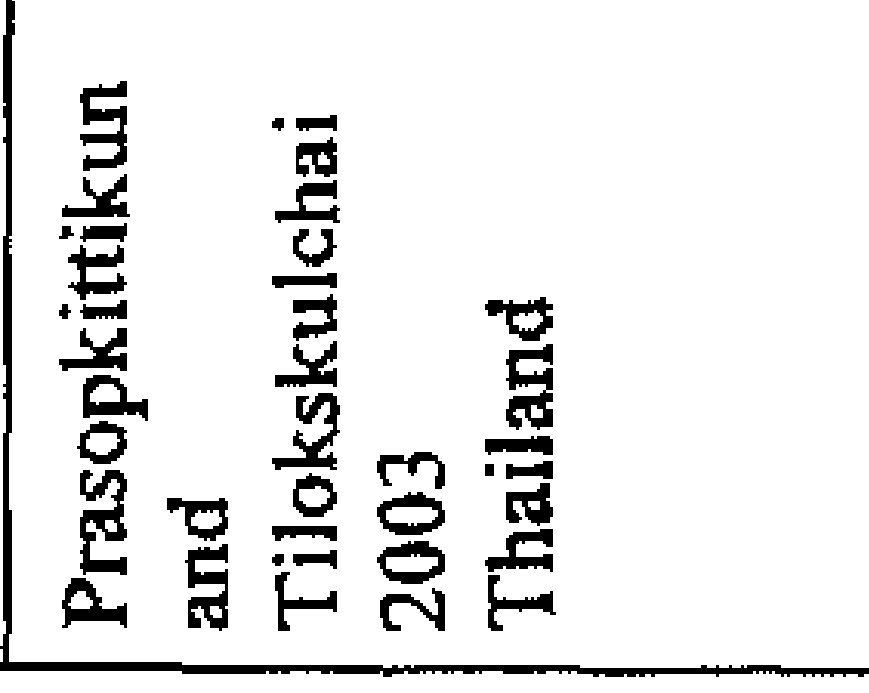 & 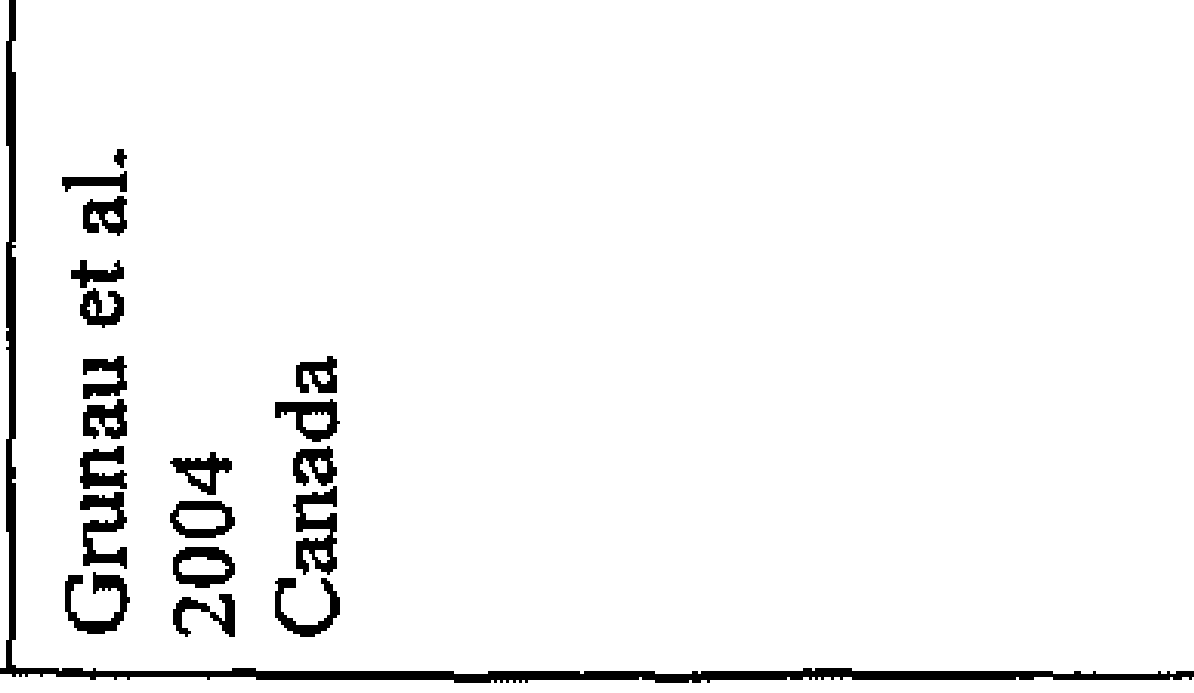 \\
\hline
\end{tabular}




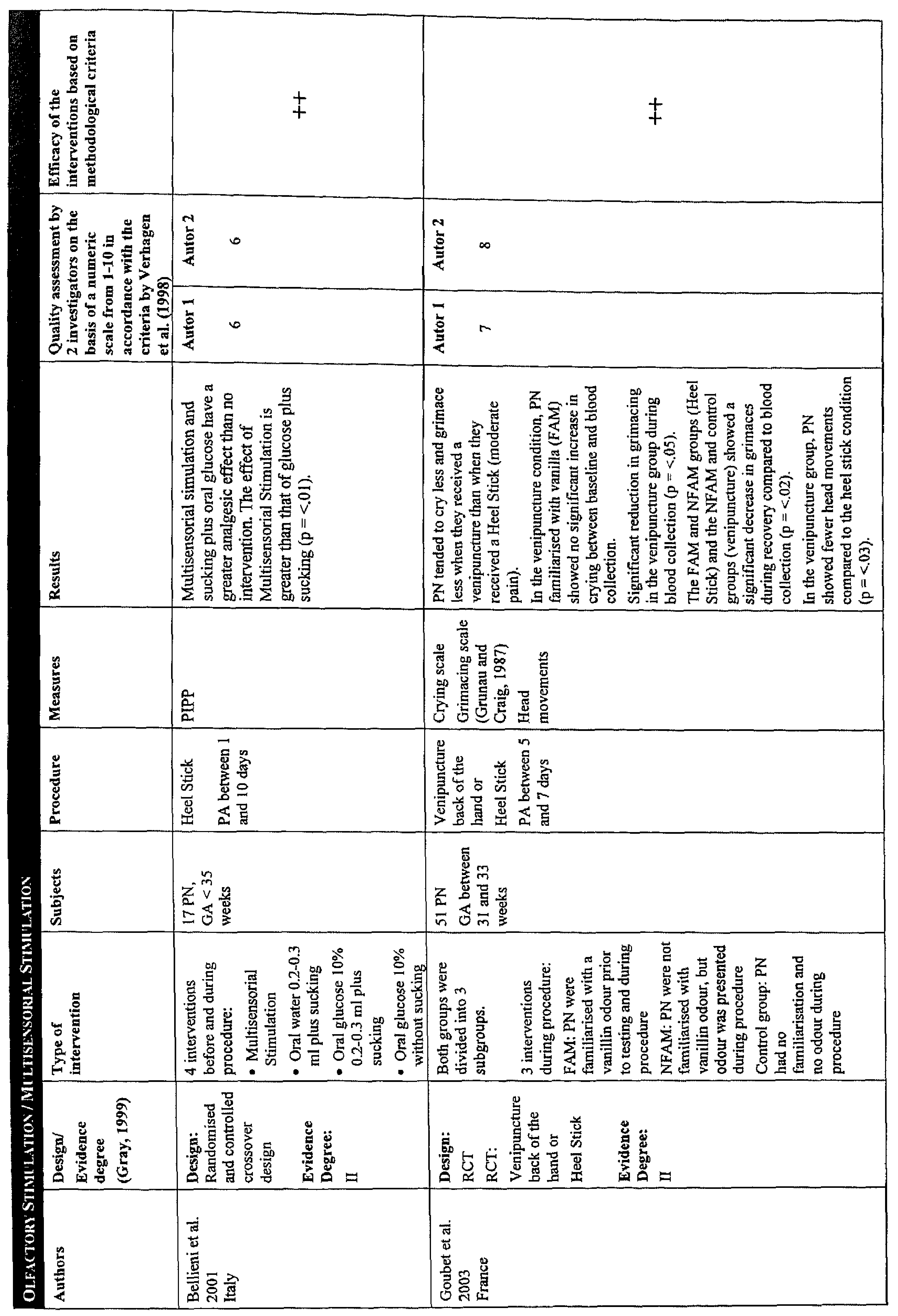




\begin{tabular}{|c|c|c|}
\hline 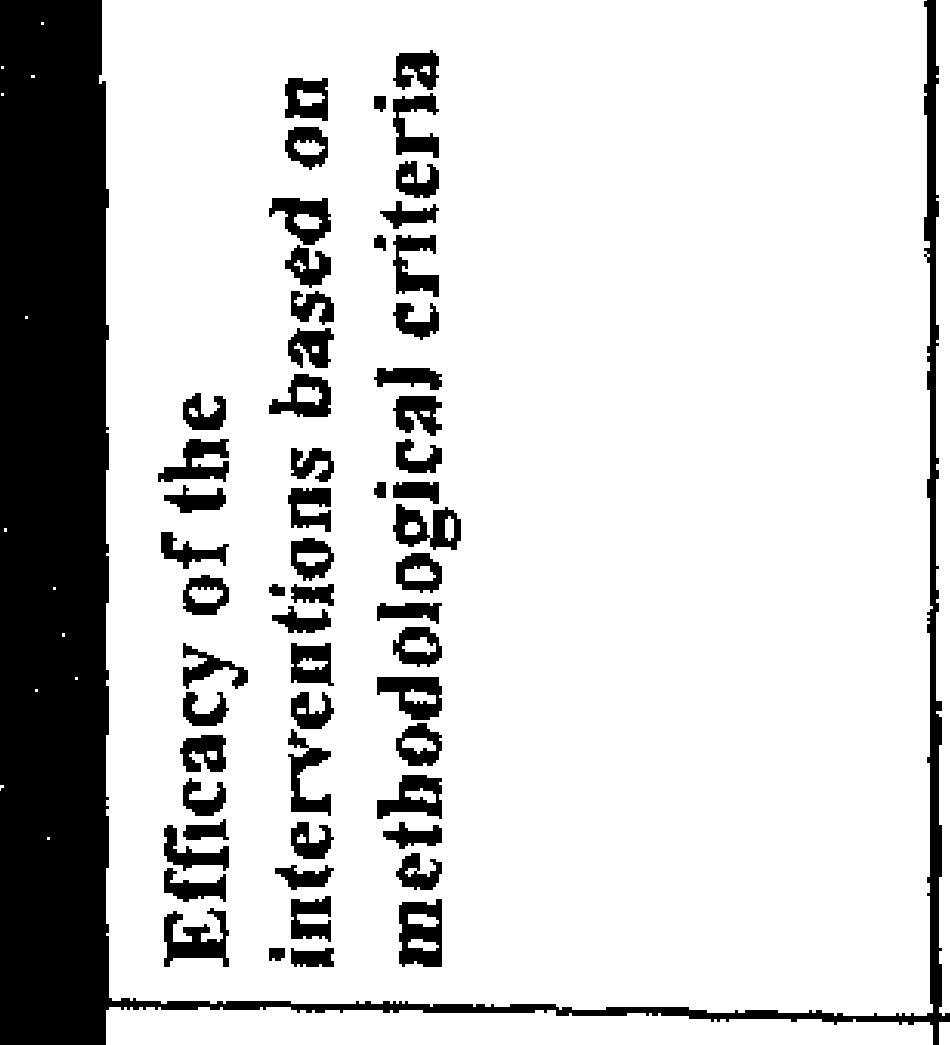 & $\ddagger$ & $\ddagger$ \\
\hline 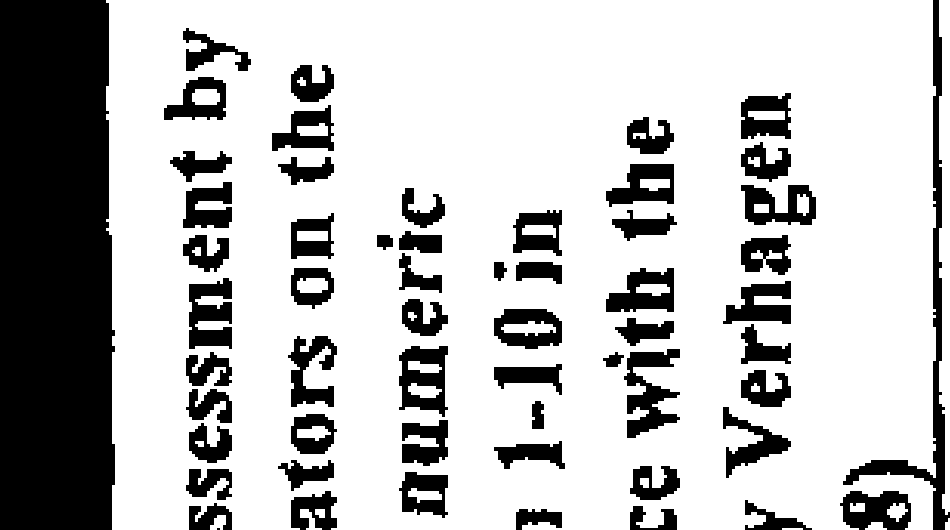 & $\stackrel{N}{5}$ & 点 \\
\hline 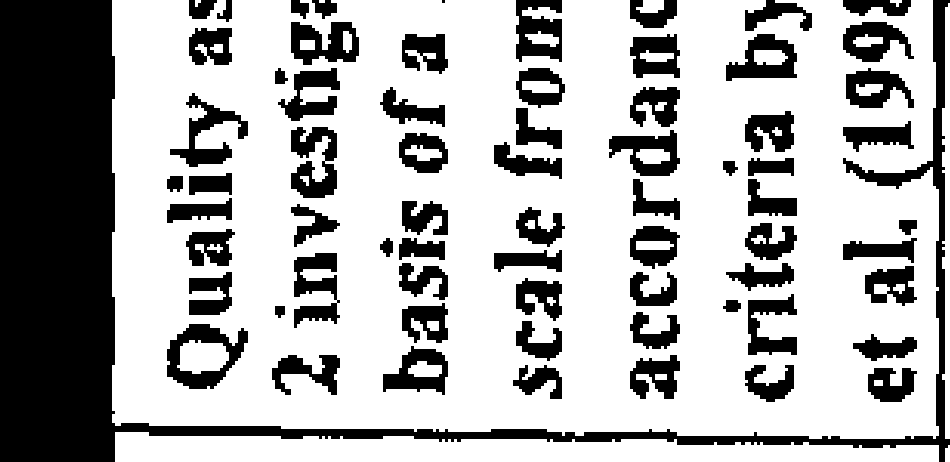 & 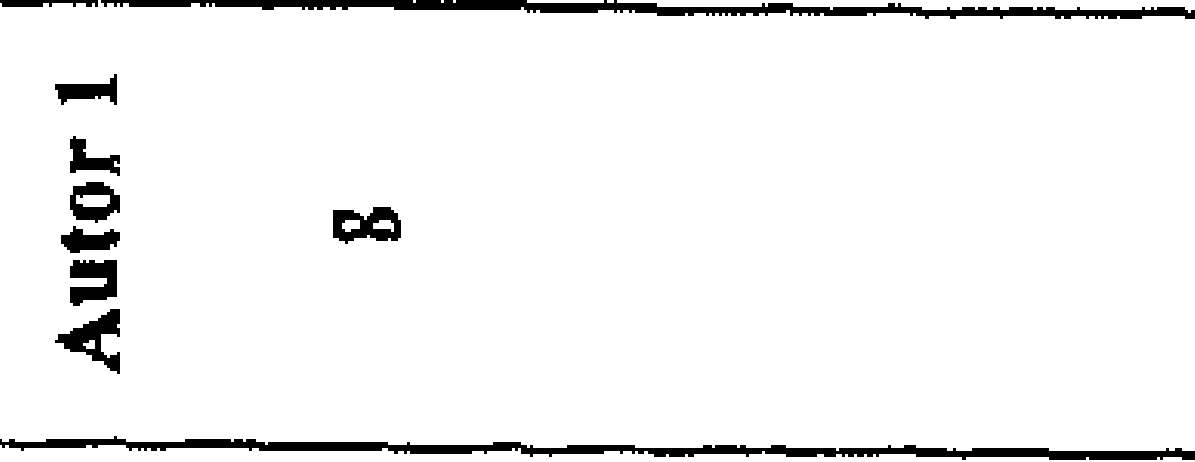 & a \\
\hline 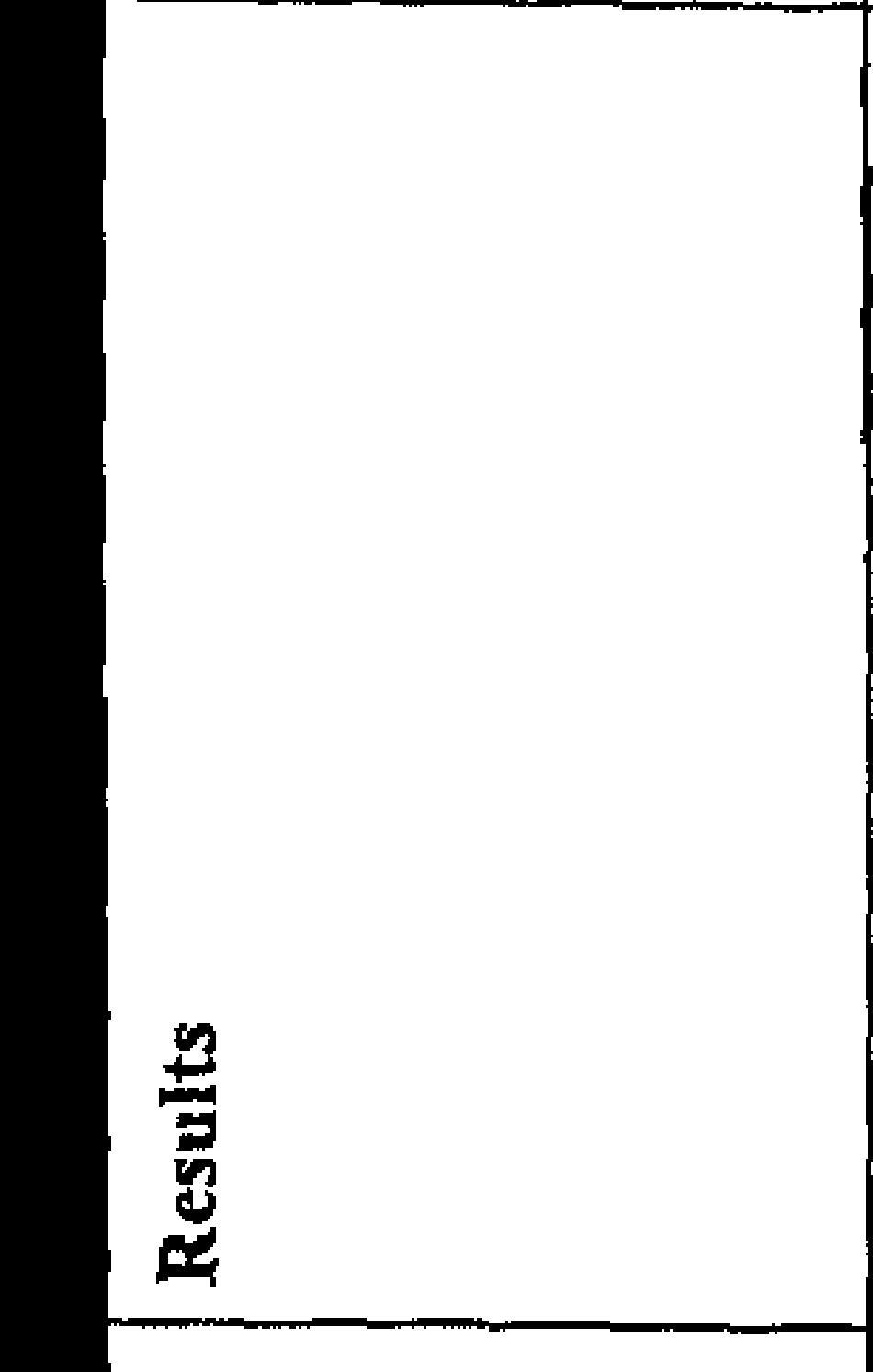 & 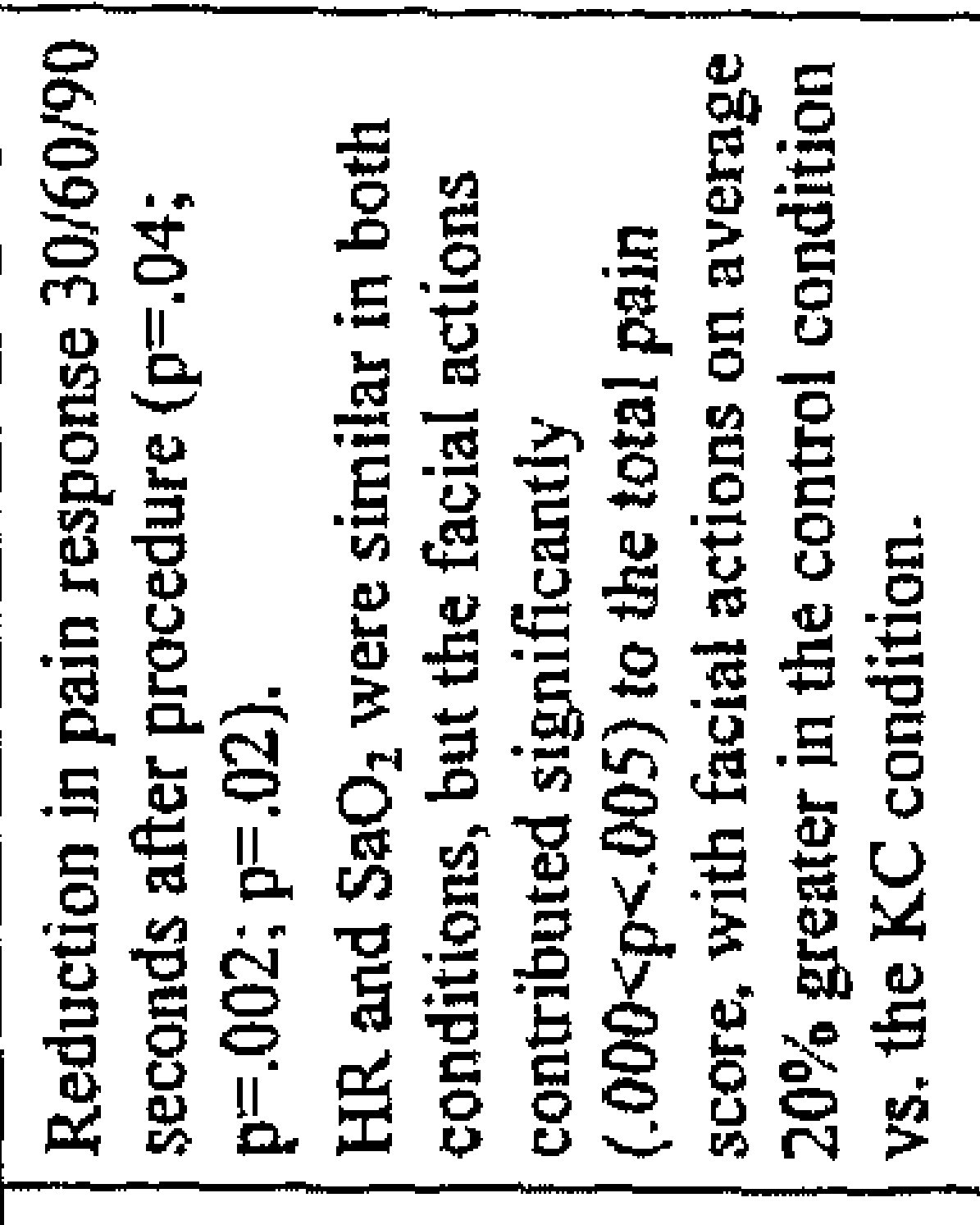 & 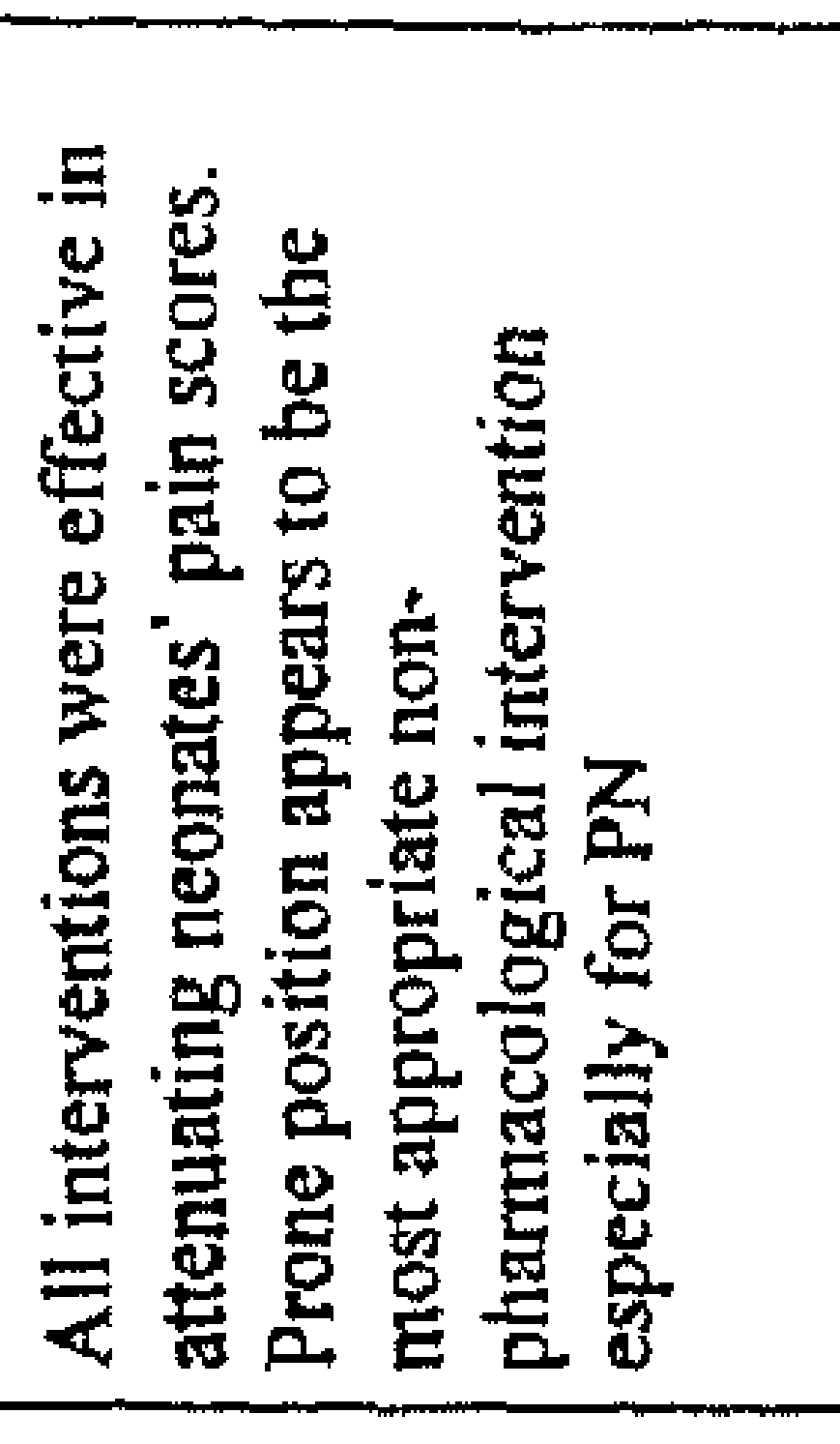 \\
\hline 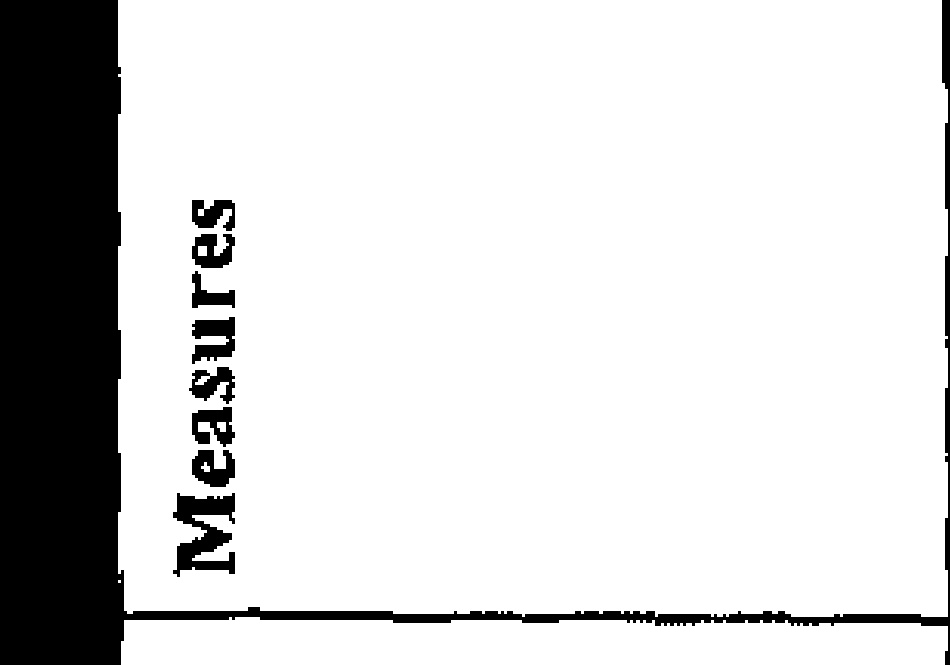 & 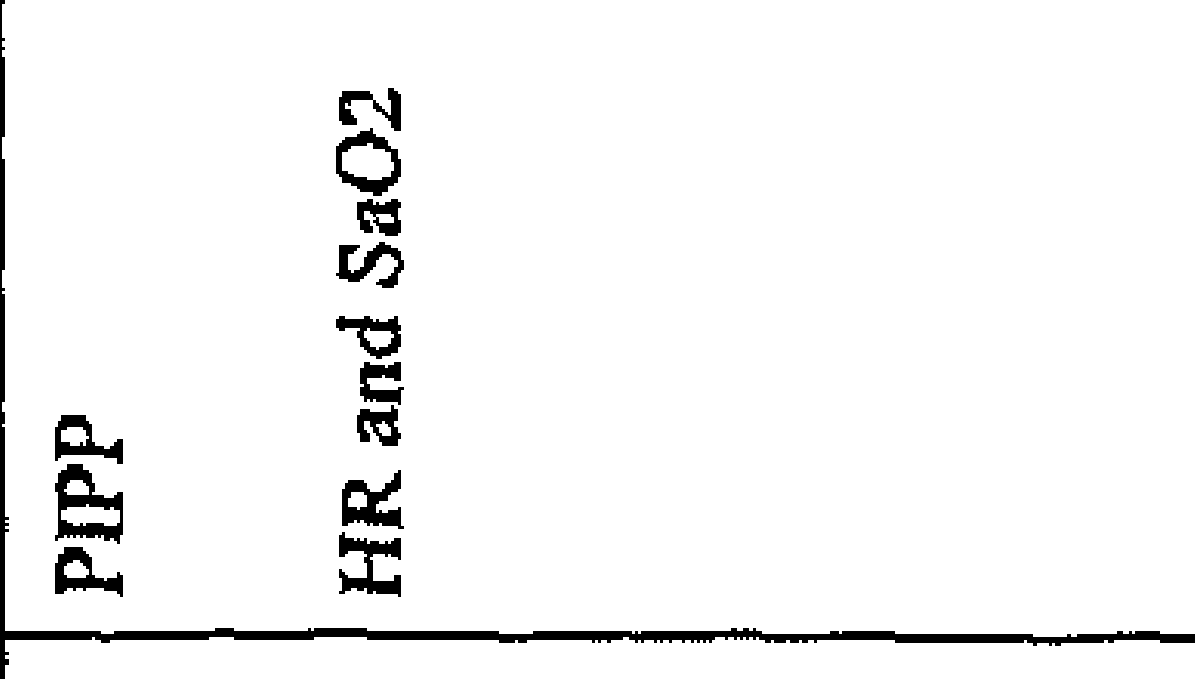 & 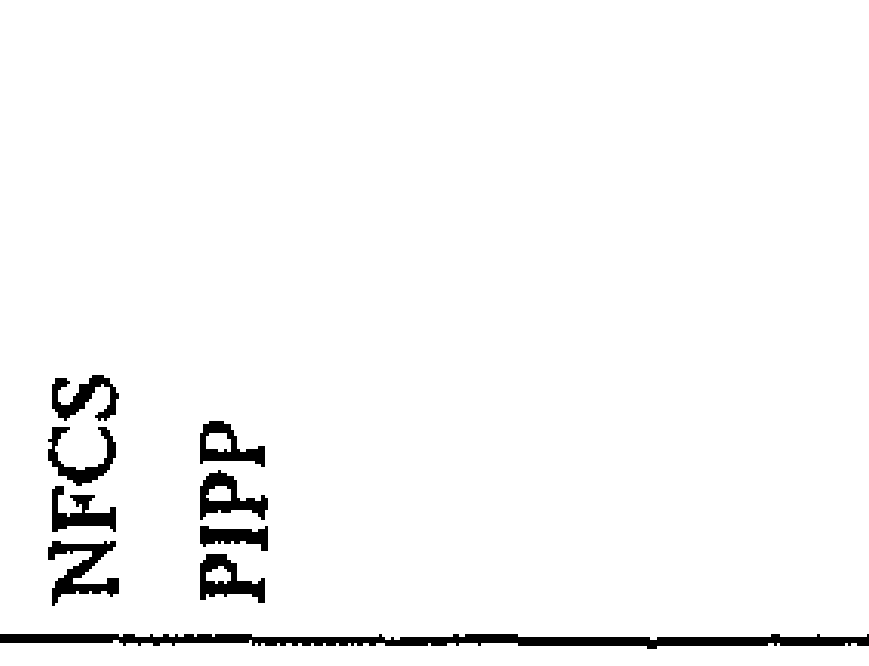 \\
\hline 产 & 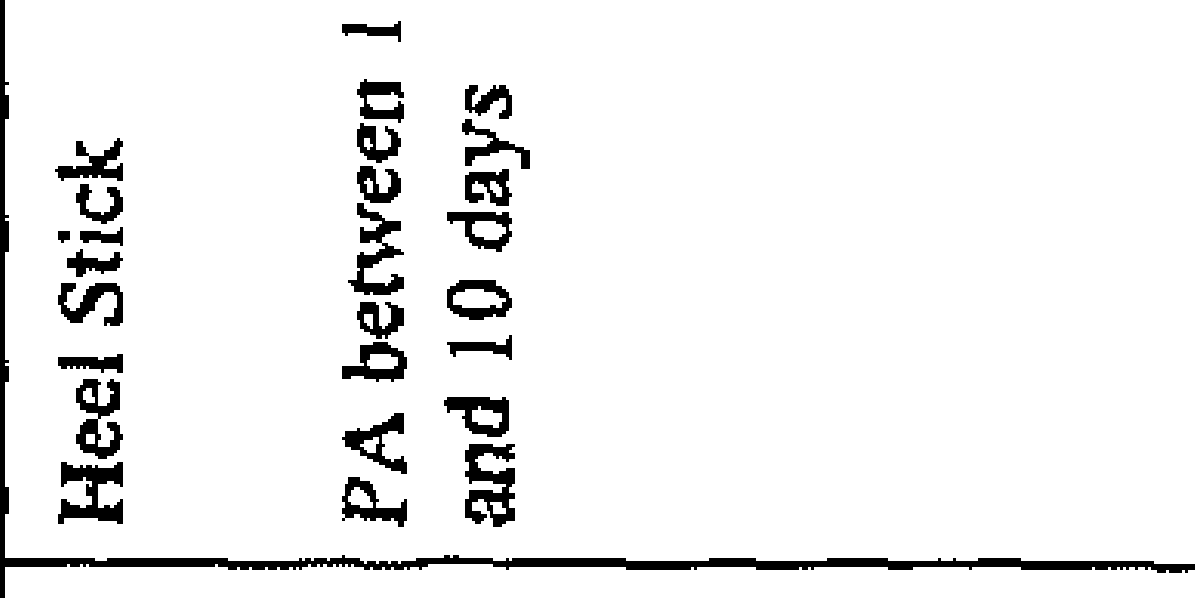 & 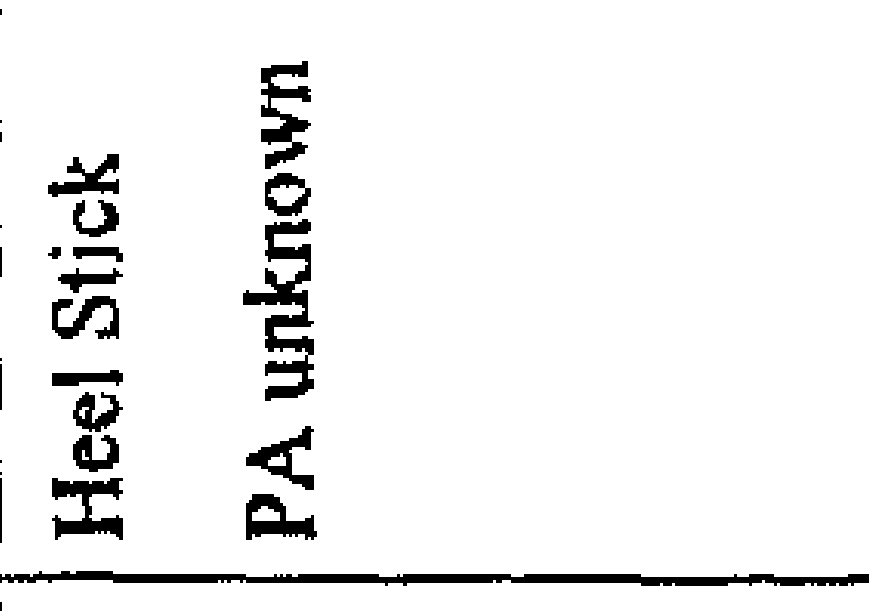 \\
\hline 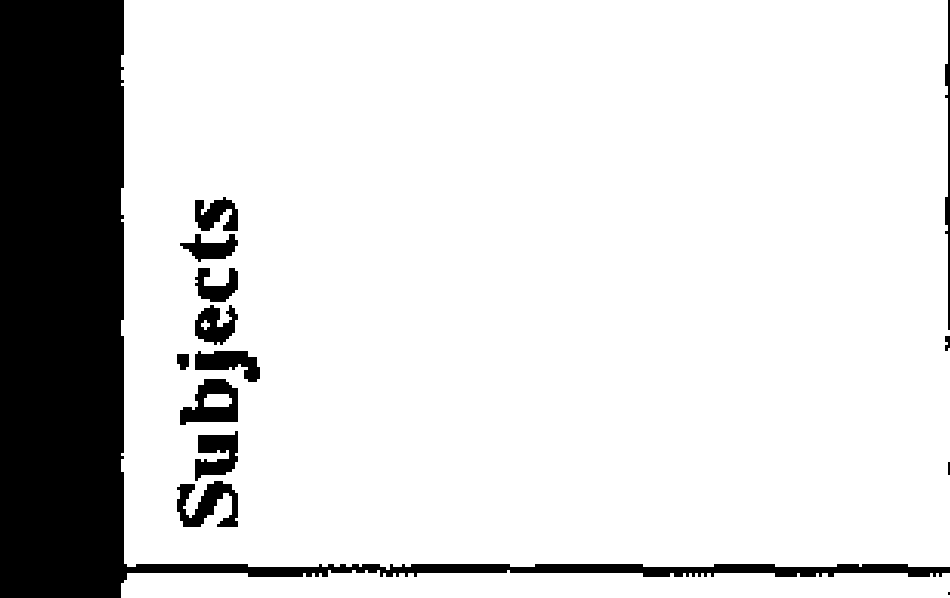 & 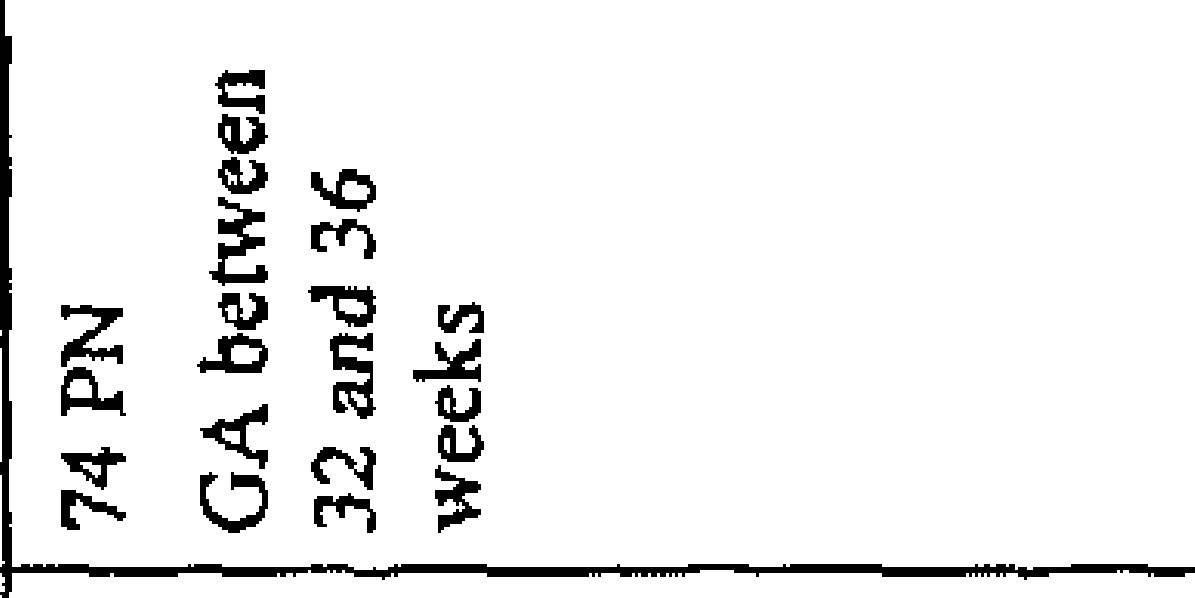 & 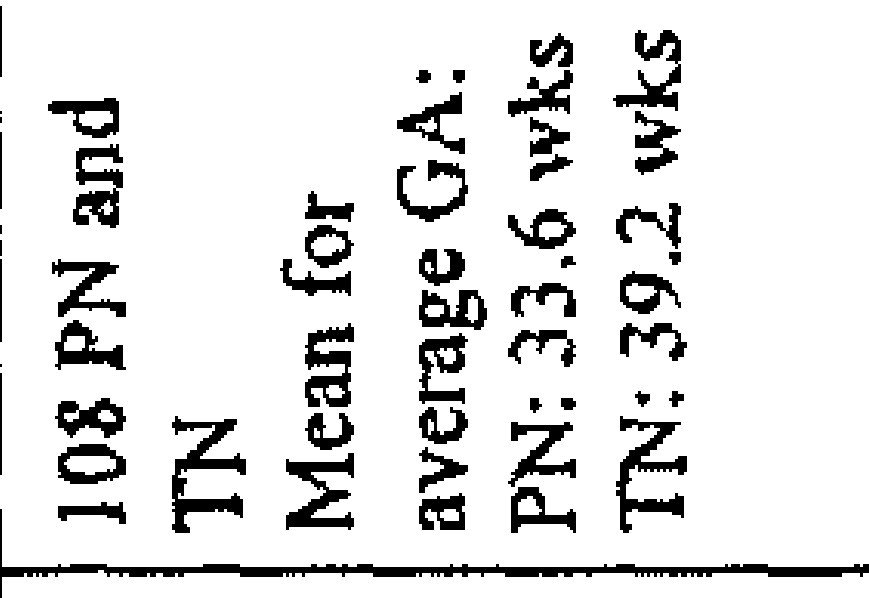 \\
\hline 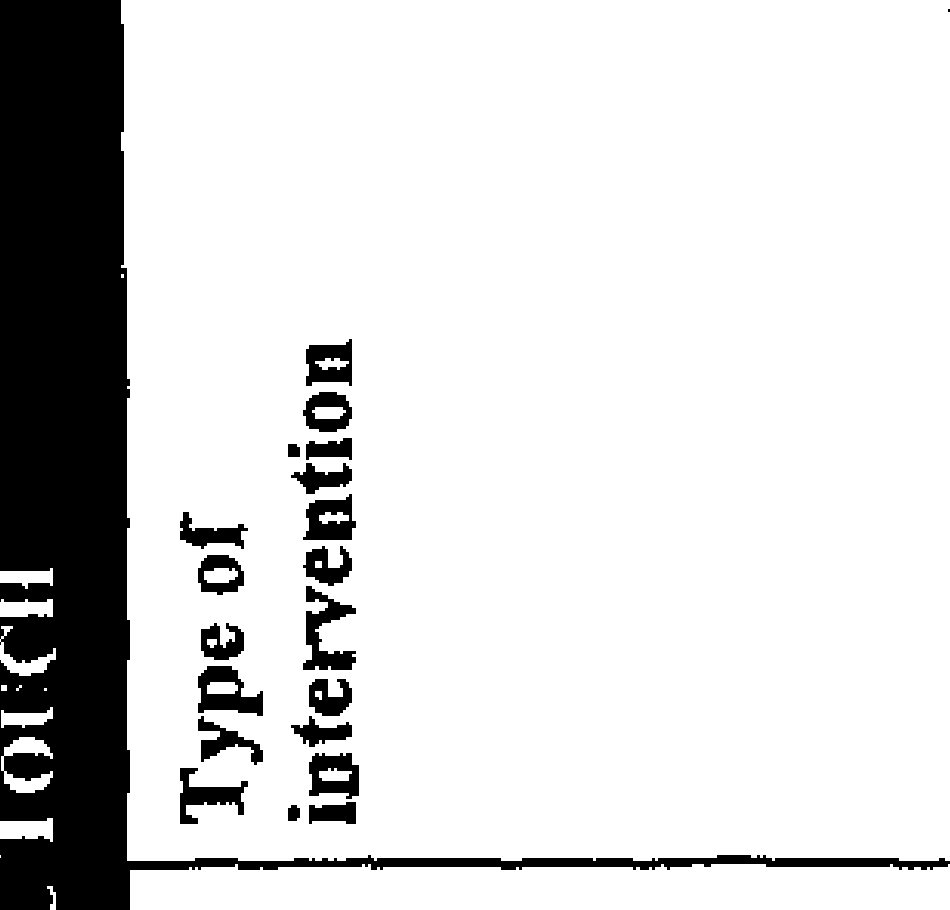 & 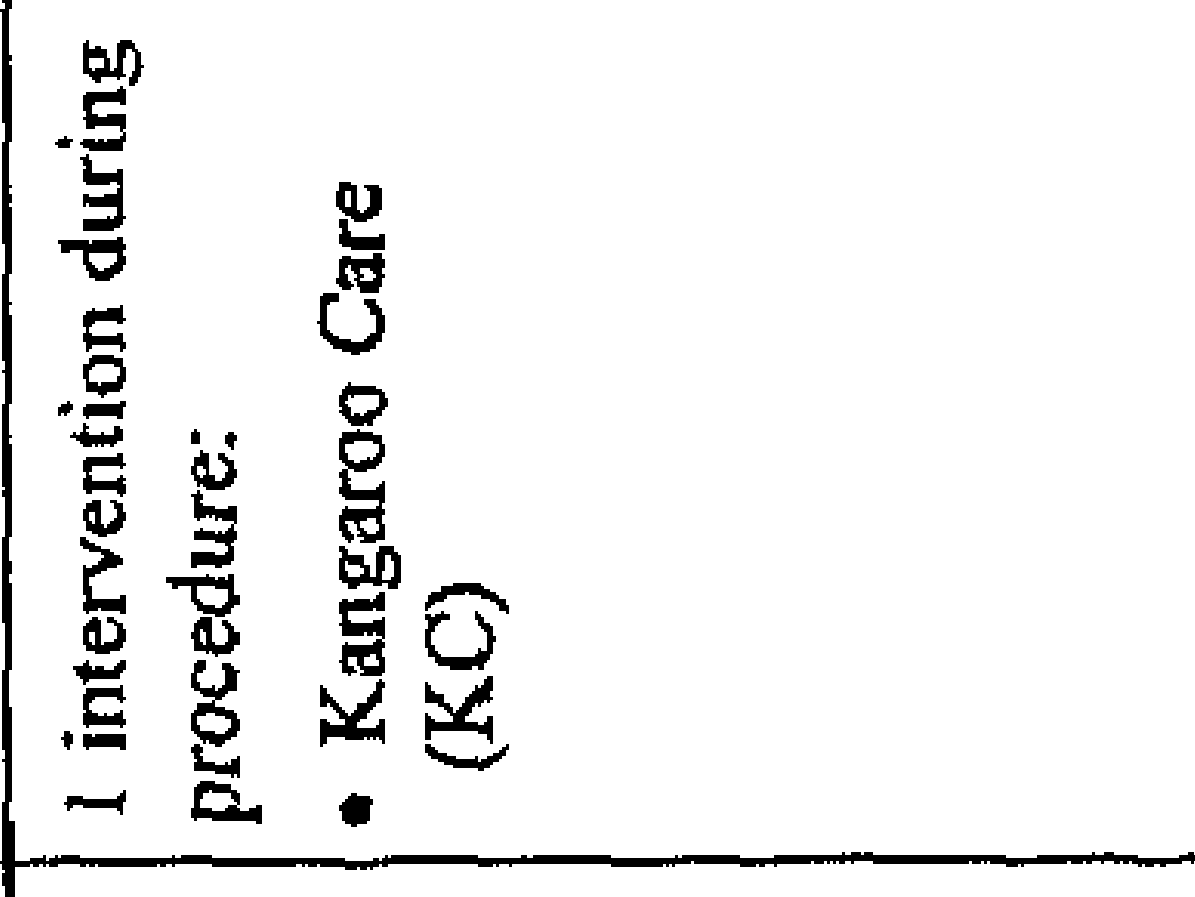 & 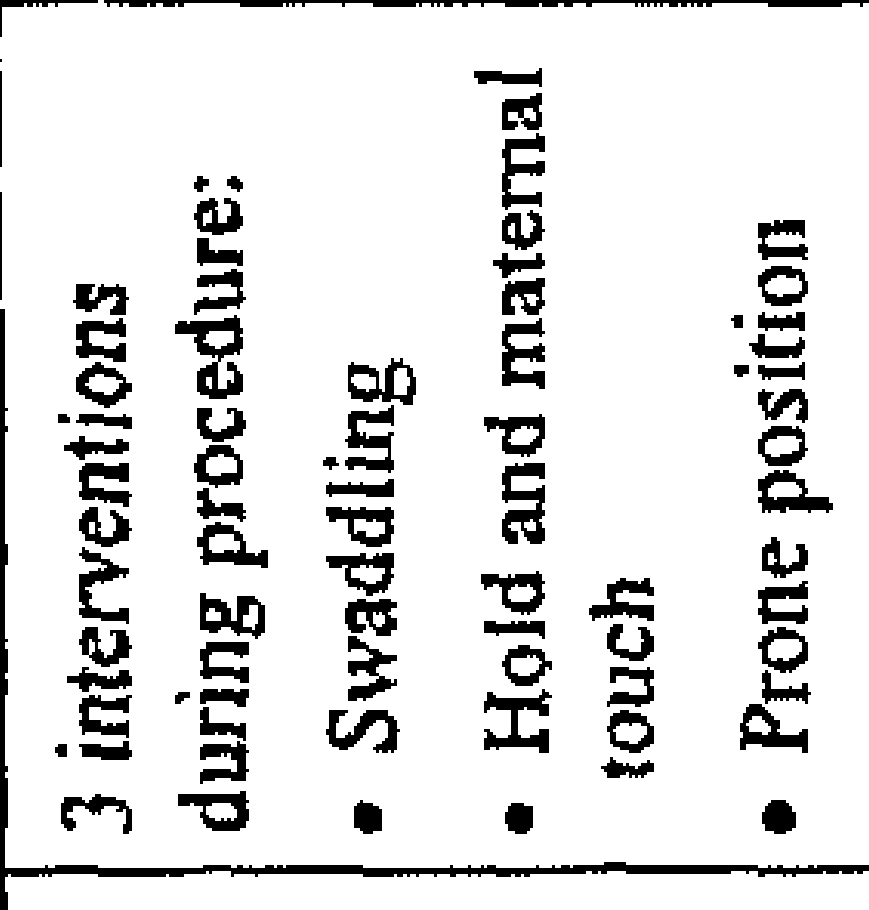 \\
\hline 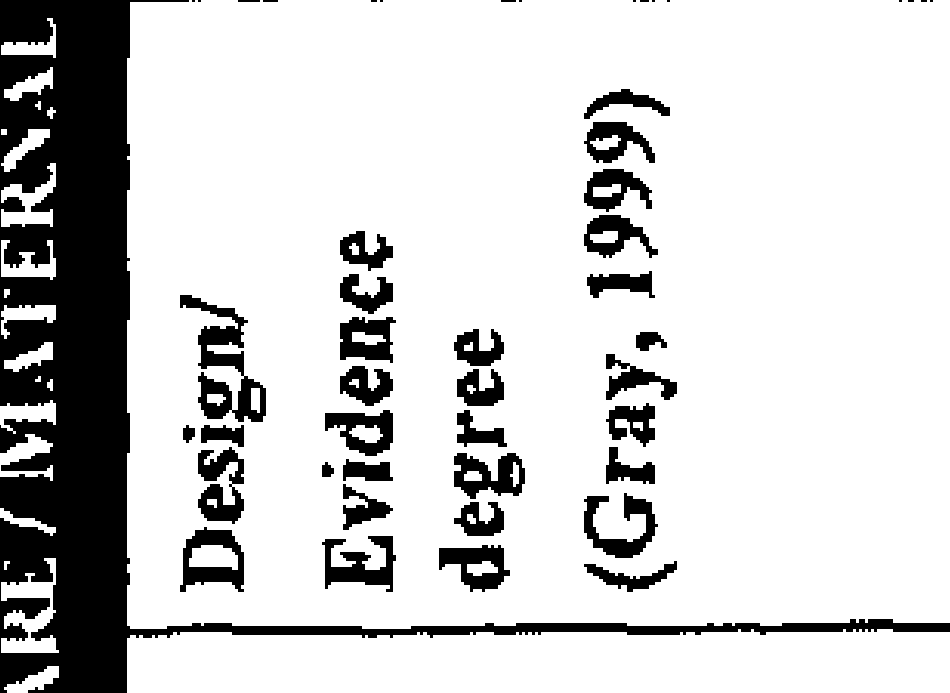 & 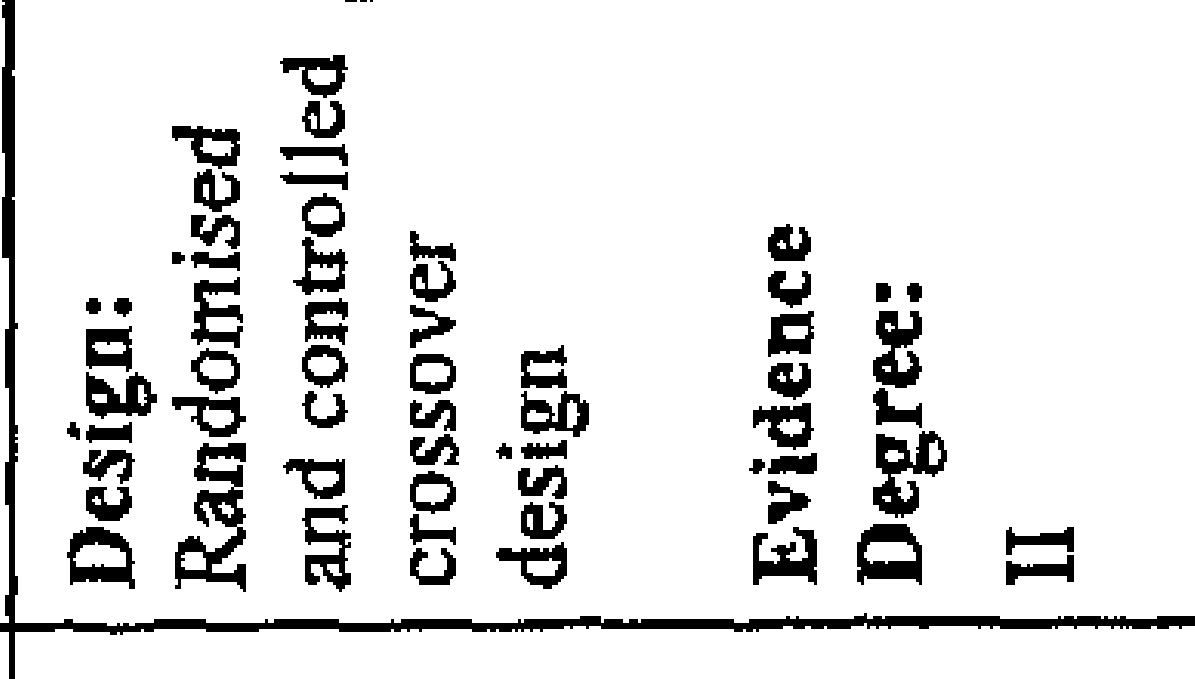 & 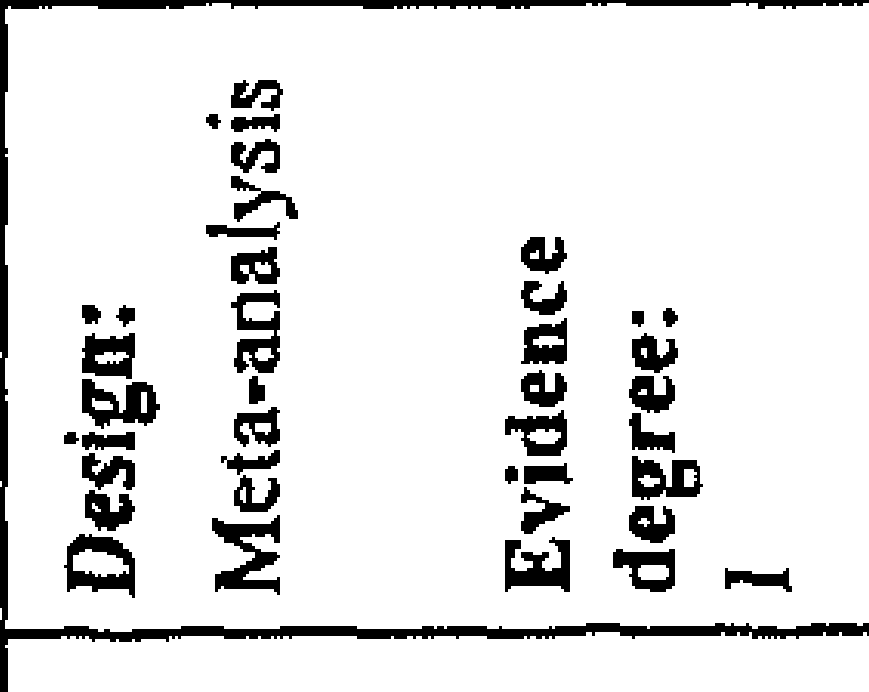 \\
\hline 管 & 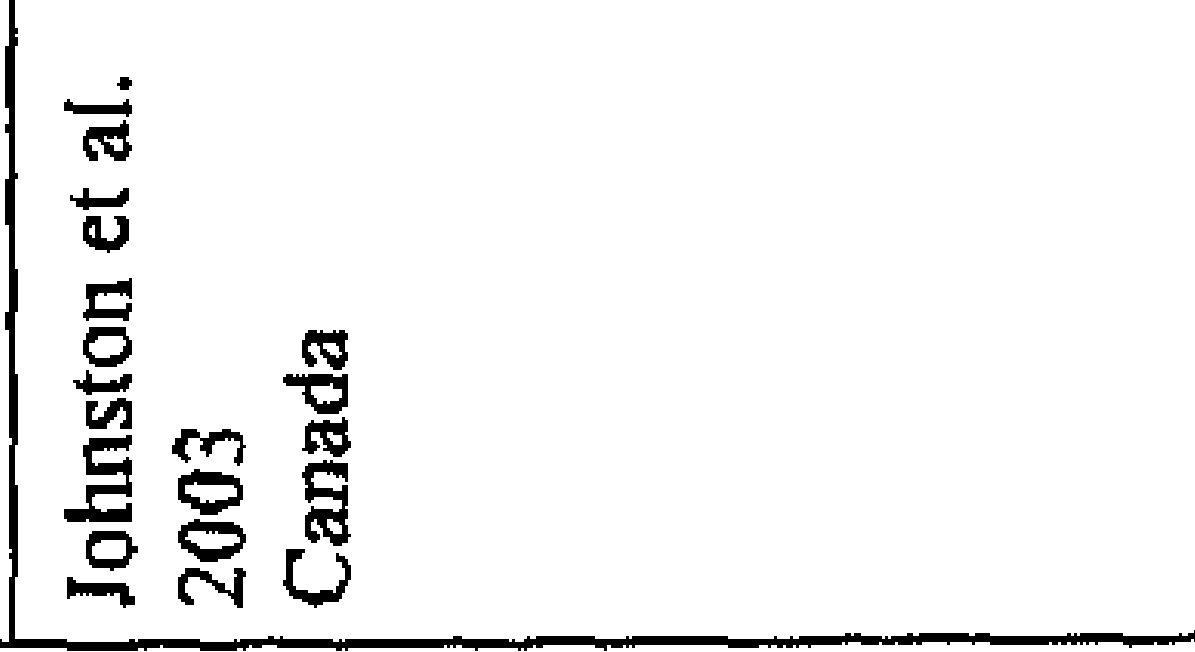 & 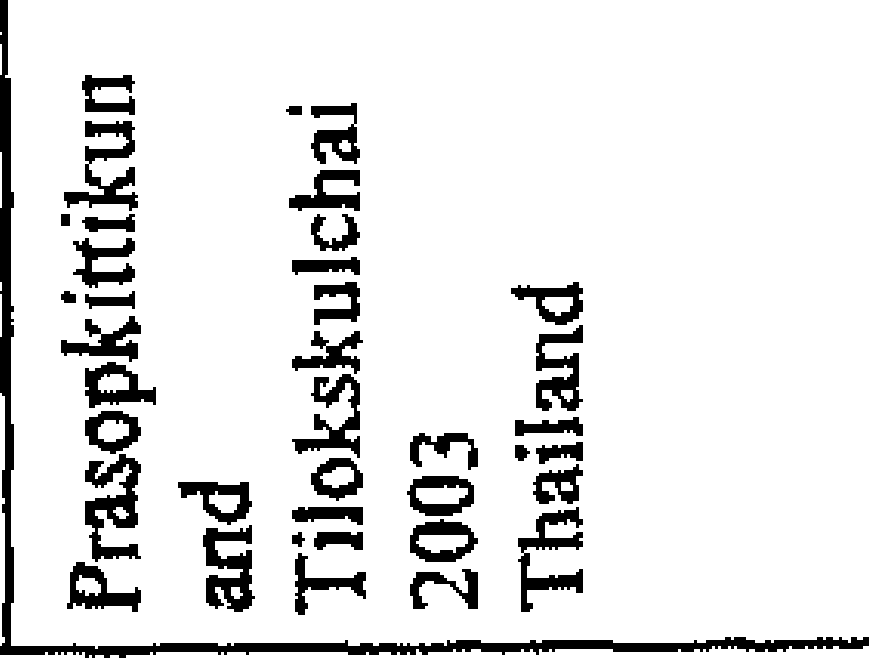 \\
\hline
\end{tabular}


THE EFFICACY OF NON-PHARMACOLOGICAL INTERVENTIONS

\subsection{Efficacy of non-pharmacological interventions}

\subsubsection{Non-nutritive and nutritive sucking}

"Non-nutritive sucking" refers to the placement of a pacifier in an infant's mouth to promote sucking behaviour without breast or formula milk to provide nutrition. As table 7-2 shows, the intervention "non-nutritive sucking" achieves a moderate effect on the behaviour of preterm and term neonates, regardless of neonatal complications (Field and Goldson, 1984; Corbo et al., 2000). As a result of "non-nutritive sucking" they become calmer and more attentive, and a reduction in crying was observed (Field and Goldson, 1984; Corbo et al., 2000). "Non-nutritive sucking" on a pacifier or a cotton wool stick also resulted in a significant reduction in the pulse rate (Field and Goldson, 1984; Shiao et al., 1997; Corbo et al., 2000) and seems to be highly effective. Interestingly, this effect was not demonstrated among neonates with neonatal complications (Field and Goldson, 1984). It was not possible to provide conclusive proof of an effect on transcutaneous partial oxygen saturation or the respiratory rate (Shiao et al., 1997; Corbo et al., 2000). One meta-analysis confirmed that the type of pacifier (shape, material) and the duration of sucking influence the physiological pain indicators (Shiao et al., 1997). Sucking on a pacifier or a cotton wool stick which had been sprinkled with distilled water, glucose $10 \%$, or sucrose $24 \%$ resulted in a reduction in pain response. A statistically significant reduction in pain response was achieved by sucking on a pacifier with distilled water (Stevens et al., 1999; Bellieni et al., 2001). However, with regard to pain relief, sucking on a pacifier with glucose $10 \%$ was more effective than sucking on a pacifier with distilled water (Bellieni et al., 2001). This difference could not be observed between distilled water and sucrose $24 \%$. Both interventions seem to be highly effective (Stevens et al., 1999).

\subsubsection{Music}

A number of studies examined the effects of different forms of music: music with intrauterine sounds, instrumental music or acapella singing (Bo and Callaghan, 2000; Butt and Kisilevsky, 2000). Regardless of the type of music, a positive effect on the pain response was invariably recorded, such as the regulation and reduction of the pulse rate, a more rapid reversion of physiological parameters to the initial values, a rise in oxygen saturation and a reduction in the excitation state. "Music" decreased the pain response particularly when combined with non-nutritive sucking in a sample of neonates from 30 to 41 weeks gestation as shown by the "Neonatal Infant Pain Scale" (Bo and Callaghan, 2000).

Butt and Kisilevsky (2000), however, could not identify an effect of instrumental music and a cappella singing on the pulse rate of preterm infants below 31 weeks gestation. Facial relaxation was also delayed in this group. Evidence of a pain-relieving effect achieved by instrumental music and a cappella singing was only confirmed in preterm infants older than 31 weeks gestation, which was measured by the "Neonatal Facial Coding System". This study, however, is restricted in its analytical value because of the small randomised sample size (14 neonates). The authors of both studies are in agreement that "music" should not be provided for longer than 15 minutes per intervention due to the risk of sensory overload.

\subsubsection{Facilitated tucking}

"Facilitated tucking" (see picture 1) was tested in three studies with randomised samples of 30 to 40 preterm infants (Corff et al., 1995; Ward-Larson et al., 2004; Huang et al., 2004). The authors describe facilitated tucking as an effective pain-relieving intervention. "Facilitated tucking" leads to a significant reduction in the pulse rate. Time to first quieting and total crying time were reduced significantly in comparison to the control group (see table 7-2) (Corff et al., 1995). With regard to oxygen saturation, however, this intervention showed no effect (Corff et al., 1995; Huang et al., 2004). 


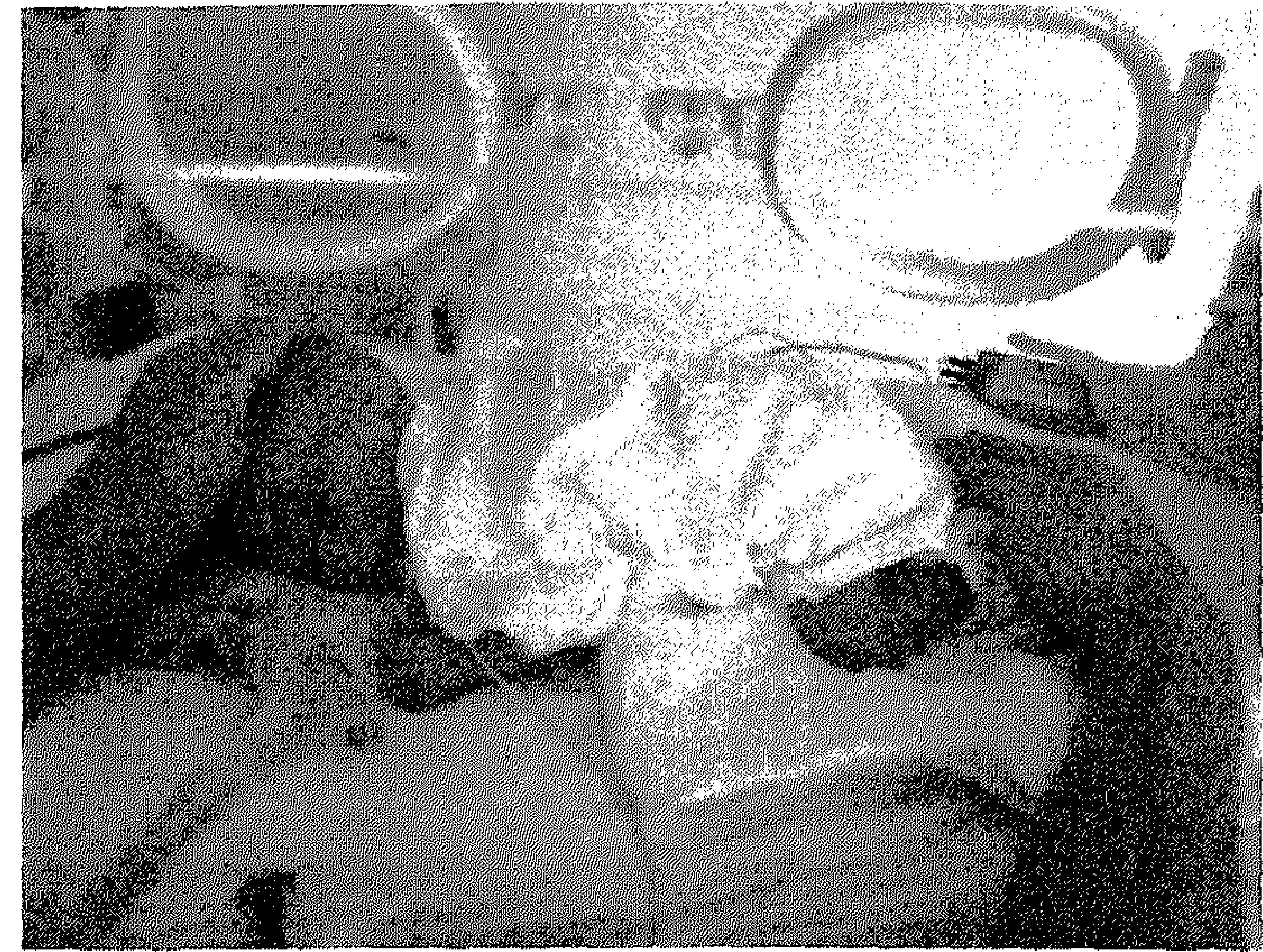

Figure 7-1: Facilitated tucking (Source: Neonatology, Inselspital Bern, Switzerland)

It is important to mention, that Corff et al.. 1995 did not use an objective measurement tool, but based the assessment on heart rate, oxygen saturation and sleep/wake state. The other two studies used the "Premature Infant Pain Profile" as an outcome measure of pain. Among a group of 40 intubated and ventilated preterm neonates between 23 and 32 weeks gestation, "facilitated tucking" during endotracheal suctioning achieved significant pain relief (Ward-Larson et al., 2004).

\subsubsection{Swaddling}

"Swaddling" involves wrapping the neonates in a fabric cloth (see picture 2). Among 15 preterm infants aged above 31 weeks gestation, it was found that "swaddling" after a painful intervention was associated with a clear reduction in the pulse rate (Fearon et al., 1997). Among preterm infants under 31 weeks gestation, by contrast, no effect could be demonstrated with this intervention. A contradictory result was obtained by Huang et al. (2004), who found in their study of 32 preterm infants that "swaddling" was even effective, as measured by the "Premature Infant Pain Profile", for infants younger than 31 weeks (Ballantyne et al., 1999). Likewise, "swaddling" is described as having an effect on oxygen saturation for all age groups (Fearon et al., 1997). During the recovery phase, the preterm neonates demonstrated a significantly faster increase in oxygen saturation, and in the process attained stability more rapidly than the control group. Again, however, a contrary result was obtained by Huang et al. (2004): neither during nor after the intervention was any significant effect on oxygen saturation recorded. The behaviour-oriented indicators, such as facial mimicry, body movement and crying, were attenuated as a result of "swaddling" (Fearon et al., 1997; Huang et al., 2004) although, in the former study, this effect could only be demonstrated in neonates older than 31 weeks gestation. In a meta-analysis with a random sample of 108 term and preterm neonates, a pain-relieving effect was also recorded, the effect being maintained, interestingly, for a longer time among term infants (up to 4 minutes). Among preterm infants, the effect was also present but lasted for a significantly shorter time (Prasopkittikun and Tilokskulchai, 2003). 


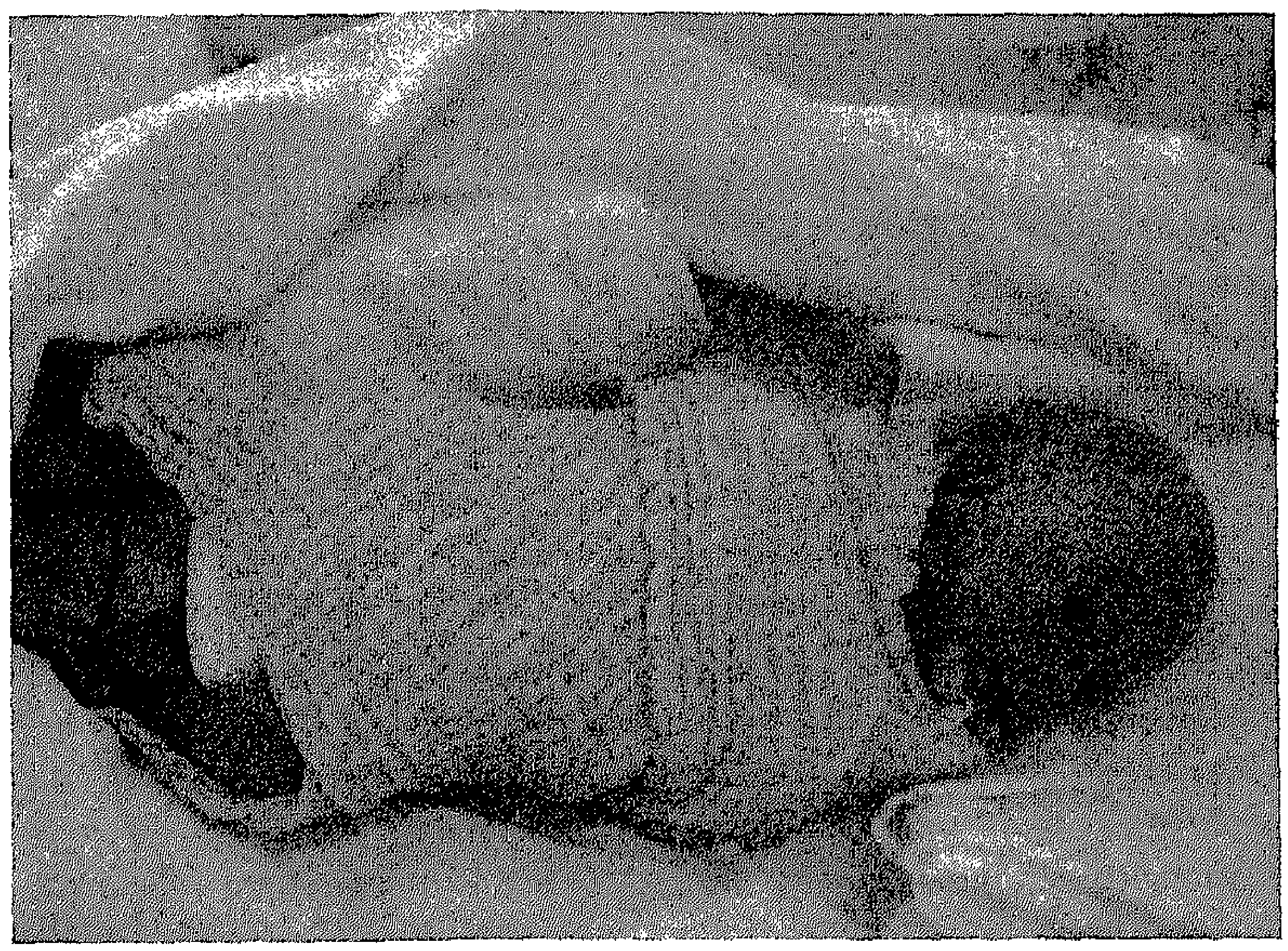

Figure 7-2: Swaddling (Source: Neonatology, Inselspital Bern, Switzerland)

\subsubsection{Positioning}

Laying the neonate in a prone position is a frequent measure in everyday practice as it is expected that the counter-pressure of the mattress will relieve the pain being experienced. Furthermore it promotes better breathing and a decrease of oxygen needed. In a meta-analysis, the non-pharmacological interventions of "swaddling", "maternal skin contact" and "positioning" were found to have a moderate (mean effect size $0.53,95 \% \mathrm{CI}=0.27-0.80$ ) to large (mean effect size $0.79,95 \% \mathrm{CI}=0.27$ 0.80) effect as methods of pain relief (Prasopkittikun and Tilokskulchai, 2003). The findings suggest that the moderate to large effect of "positioning" continued throughout the poststick period. In contrast the effects of "swaddling" (in both fullterm and preterm neonates) and of "maternal holding and touching" tended to decrease over time. Grunau et al. (2004) were unable to confirm the effect of the prone position. It was, however, observed that during the measurement of the baseline before the painful intervention, the prone position was an indication of deeper sleep in preterm neonates than in the control group. Likewise in a further study with 122 very preterm infants was concluded that the prone position did not have a pain-relieving effect (Stevens et al., 1999). The evidence for the effect of "positioning" remains inconclusive.

\subsubsection{Olfactory and multisensorial stimulation}

In accordance with study results which showed a stress-relieving effect of the smell of breast milk, Goubet et al. (2003) tested the hypothesis that a familiar odour might be effective in relieving distress associated with painful stimuli in preterm infants. They tested the pain-relieving effect of a familiar vanillin aroma among preterm neonates while sampling capillary blood or while taking venous blood. In both groups, three interventions were tested: one group was familiarised with a vanillin odour prior to testing and was presented with it during the procedure; the second group was not familiarised with vanillin but was presented with it during the procedure; the third group was neither familiarised nor presented with an odour at all. In the group familiarised with the vanillin aroma, pain relief was 
demonstrated by a significant reduction in facial mimicry and crying, but only while taking venous blood. While drawing capillary blood, no effect was observed. This indicates that the olfactory intervention is probably only effective in cases of slight to moderate pain. The authors concluded that presenting a purely "attentional distracter" like an unfamiliar odour did not relieve the pain in newborns. Only when the odour presented was an "experiential distracter" could a pain-relieving effect be achieved. They qualified the familiar odour as "experiential" because its effect rested on a prior memory of the encounter with the odour in the incubator. Similar results were obtained by the testing of "multisensorial stimulation" (Bellieni et al., 2001). "Multisensorial stimulation" addresses the neonate on a number of different sensory levels: tactile, auditory, olfactory and orogustatory. The neonate is calmed during, and in particular after, a painful stimulus in a tactile manner by massaging his/her back and face. A few drops of a pleasant-smelling oil are spread onto the hand used for this (orogustatory level). During the massage, the child is also spoken to gently (auditory level). Furthermore, the infant is provided with a cotton wool stick which has been sprinkled with glucose $10 \%$ so that he/she can suck on it (olfactory level). In a study of 17 preterm neonates, the authors were able to describe this intervention as being significantly more pain-relieving than when using distilled water and standard nursing. In particular, this intervention had a positive effect on crying. with the multisensorially-stimulated preterms not expressing any crying reaction. However, Bellieni et al. (2001) specify that the assessment of the intervention of "multisensorial stimulation" was not blinded. which is to be criticised as a clear bias and calls into question the efficacy of this non-pharmacological intervention as described.

\subsubsection{Kangaroo care and maternal touch}

"Kangaroo care" involves the neonate being taken out of the incubator and laid on the bare skin of the mother or father. The neonate is covered with towels so that there is no loss of body temperature. A study of 74 preterm neonates older than 32 weeks gestation confirmed that "kangaroo care" produces a reduction in pain response, using the "Premature Infant Pain Profile" as a validated pain assessment tool (Johnston et al., 2003). The "kangaroo care" intervention showed a significant reduction in pain response in comparison with the controls at 30,60 and 90 seconds after the painful procedure. Heart rate and oxygen saturation were similar in both groups, but the facial activity as an indicator of pain being experienced was on average $20 \%$ more marked in the control group. One meta-analysis (Prasopkittikun and Tilokskulchai, 2003) described the greatest pain-relieving effect occurring with "matemal calming" rather than with "swaddling" and "positioning", but the effect dropped off more rapidly in comparison with the other two interventions, where it was sustained over 4-5 minutes. Pain relief was only described for term neonates; preterm neonates had not been taken into consideration in the studies covered by the meta-analysis. There are no results at all for preterm neonates below the gestational age of 32 weeks.

\section{Discussion}

The present systematic literature review provides evidence that non-pharmacological interventions do have a pain-relieving effect among preterm and term neonates. The results indicate that nonpharmacological methods mitigate both physiological and behaviour-oriented reactions. In particular, "non-nutritive sucking", "swaddling" and "facilitated tucking" seem to have an evident pain-relieving effect. A considerable limitation concerning the verification of efficacy is the fact that all the nonpharmacological measures discussed were tested exclusively with one-off painful procedural interventions. Neonates in a neonatal intensive care unit are subjected to a large number of painful 
THE EFFICACY OF NON-PHARMACOLOGICAL INTER VENTJONS

stimuli, but it remains unclear whether the non-pharmacological methods described also have a beneficial effect on any possible long-term consequences of prolonged exposure to pain. Unfortunately, there are no studies available on this subject.

The influence of contextual factors (gestational age, state of illness, state of consciousness) is still a matter of controversy. Butt and Kisilevsky (2000) and Fearon et al. (1997) were able to determine the pain-relieving effect of music and swaddling exclusively among neonates of more than 31 weeks gestation. For preterm neonates younger than 31 weeks, these interventions for pain relief only had an effect on oxygen saturation but not on the behaviour of the neonates. Both studies are limited in their analytical value because of their small sample sizes ( 14 and 15 neonates, respectively). Prasopkittikun and Tilokskulchai (2003) found a rapid recovery phase in swaddled preterm and term neonates, the preterm neonates being older than 31 weeks gestation. The pain-relieving effect was, however, observed to last longer among term neonates than among preterm infants. Both "olfactory and multisensorial stimulation" achieve pain relief regardless of the infants' gestational age. Bellieni et al. (2001) describe significant pain relief after exposure to pain. These results must be interpreted with caution, however, due to the methodological deficits. In addition, the neonates' state of health is described as an influencing variable; the non-pharmacological intervention of "non-nutritive sucking" achieved an effect among healthy preterm neonates only, not among sick neonates (Field and Goldson, 1984). For the latter group, changes were only shown in their behaviour (facial mimicry, body language), but not in pulse rate, respiration or oxygen saturation. Stevens et al. (1999) were unable, however, to demonstrate any difference in pain expression either among extremely preterm neonates or among sick preterm infants in comparison with healthy and older ones. Sucking on a pacifier with distilled water or with glucose $10 \%$ attained a pain-relieving effect in all the neonates in this study. By analysing 10 studies ( $n=281$ ), Shiao et al. (1997) were able to confirm a significant effect of "nonnutritive sucking" in all the preterm and term neonates examined.

Among the highly vulnerable group of intubated preterm neonates with a restricted state of consciousness caused by sedatives, "facilitated tucking" achieved a perceptible pain-relieving effect with regard to endotracheal suctioning (Ward-Larson et al., 2004). This is to be emphasised, in particular, since endotracheal suctioning represents the second most frequent painful intervention, following capillary blood sampling. The question also arises in this context, however, as to whether the neonates' behaviour-oriented expression of pain is influenced by sedatives. This is not critically discussed in the study.

\subsection{Methodological constraints}

There are a number of methodological deficiencies to be taken into account in the interpretation of the results. For example, four of the studies analysed did not use a validated pain assessment instrument for preterm and term neonates (Field and Goldson, 1984; Corff et al., 1995, 1997; Corbo et al., 2000; Goubet et al., 2003). In these studies, the calming of the preterm neonates was examined only on the basis of pulse rate and oxygen saturation. These parameters may give an indication of a possible state of pain, but they are regarded in isolation from other pain indicators, such as facial mimicry, body movements or crying; the studies are therefore unreliable in their conclusion regarding pain. In addition, precise data are missing as to how the blinding in respect of the pain assessment was carried out. A number of studies indicate that video recordings were made, which were then manipulated in such a way that the intervention could not be identified, while other studies provide no details regarding this. Bellieni et al. (2001) specify that the assessment of the intervention of "multisensorial stimulation" was not blinded, which is to be criticised as a clear bias and calls into question the 
efficacy of this non-pharmacological intervention as described. In 10 studies the sample size was very small, with less than 50 neonates, which undoubtedly affects the power to detect the effects of the interventions under study. It is expressly to be pointed out, that the vulnerability of preterm neonates is one of the crucial factors which undoubtedly hinders the inclusion in randomised trials. A further critical issue is the lack of standardization of non-pharmacological interventions. The handling can be subjected to many individual factors of health care providers, which not only hampers comparison but complicates controlling and testing these interventions in RCT's.

The investigation methods follow a randomised controlled procedure and correspond in the majority of cases to an evidence degree II (Gray, 1997). This high quality of the evidence is, however, prejudiced by the criticism already voiced. To support the evidence in favour of non-pharmacological interventions, care would have to be taken in future investigations to ensure the use of validated instruments and consistent blinding.

\section{Conclusion}

This present study supports the view that the non-pharmacological nursing interventions described are to some degree beneficial to neonates who undergo painful procedures. Contextual factors, such as the gestational age or the neonates' state of health, do not yet allow for any conclusive answers with regard to the efficacy of non-pharmacological interventions. It remains an open question as to which non-pharmacological measures relieve pain in the vulnerable group of sick and ventilated preterms. Further studies need to be conducted in this respect, in order to promote the wellbeing of these preterm neonates and to allow them to experience normal cognitive and motor development.

It needs to be emphasized, however, that non-pharmacological interventions cannot replace pharmacological treatment in cases of severe and chronic pain. Future research projects should address the question of whether non-pharmacological interventions are an effective measure in pain relief among the vulnerable group of ventilated or severely sick preterm and term neonates suffering from chronic pain. 


\section{References}

Abu-Saad HH. Toward development of an instrument to assess pain in children: Dutch study.

Advances in Pain Research and Therapy, Pediatric Pain. New York: Raven Press 1990; pp:101-106.

Abu-Saad HH, Bours GJJW, Stevens B, Hamers JPH. Assessment of pain in the neonate. Semin Perinatol 1998; 22:402-16.

Als H, Duff F, McAnulty G. Effectiveness of individualized neurodevelopmental care in the newborn intensive care unit (NICU). Acta Paediatr Suppl 1996; 416:21-30.

Ambuel B, Hamlett K, Marx C, Blumer J. Assessing distress in pediatric intensive care environments: the Comfort Scale. J Pediatr Psychol 1992; 17:95109.

American and Canadian Academy of Pediatrics. Prevention and management of pain and stress in the neonate. Pediatrics 2000; 15:454-61.

Anand KJS, Carr D. The neuroanatomy, neurophysiology, and neurochemistry of pain, stress and analgesia in newborn and children. Pediatr Clin North Am 1989; 36:795-822.

Anand KJS, Selankio JD. SOPAIN study group. Routine analgesia practices in 109 neonatal intensive care units (NICUs) \{abstract\}. Pediatr Res 1996; 39:192A.

Anand KJS, Coskun V, Thrivikraman KV, Nemeroff CB, Plotsky PM. Long-term behavioral effects of repetitive pain in neonatal rat pups. Physiol Behav 1999; 66:627-37.

Anand KJS. Effects of perinatal pain and stress. Prog Brain Res 2000;122:117-29.

Anand KJS, International evidence-based group for neonatal pain. Consensus statement for the prevention and management of pain in the newborn. Arch Pediatr Adolesc Med 2001; $155: 173-80$

Anand KJS, Whit Hall R, Desai N, Shephard B, Bergqvist L, Young T, Boyle E, Carbajal R, Bhutani V, Moore N, Kronsberg S, Barton B (NEOPAIN Trial Investigators Group). Effects of morphine analgesia in ventilated preterm neonates: Primary outcomes from the NEOPAIN randomized trial. Lancet 2004; 363:1673-82.

Ballantyne M, Stevens B, McAllister M, Dionne K, Jack A. Validation of the premature infant pain profile in the clinical setting. Clin J Pain 1999; 15:297-303.

Barker DP, Rutter N. Exposure to invasive procedures in neonatal intensive care unit admissions. Arch Dis Child Fet Neon Ed 1995; 72:F47-8.

Barr RG. Reflections on measuring pain in infants: The problem of dissociations in responsive systems and "honest signaling". Arch Dis Child Fet Neon Ed 1998; 79:F152-6.

Bellieni CV, Buonocore G, Nenci A, Franci N, Cordelli DM, Bagnoli F. Sensorial saturation: An effective analgesic tool for heel-prick in preterm infants. Biol Neon $2001 ; 80: 15-8$. 
Bhutta AT, Rovnaghi C, Simpson PM, Gosset JM, Scalzo FM, Anand KJS. Interactions of inflammatory pain and morphine in infant rats: Long-term behavioral effects. Physiol Behav 2001; 73:51-8.

Blass EM, Watt LB. Suckling- and sucrose-induced analgesia in human newborns. Pain 1999; $83: 611-23$.

Bo LK, Callaghan P. Soothing pain-elicited distress in Chinese neonates. Pediatrics 2000;105:e49.

Butt M, Kisilevsky S. Music modulates behaviour of premature infants following heel lance. Can J Nurs Res $2000 ; 31: 17-39$.

Cignacco E. Schmerzerfassung bei Neugeborenen. Eine Literaturübersicht. Pflege 2001; 14:171-81.

Cignacco E, Müller R, Hamers JPH, Gessler P. Pain assessment in the neonate using the Bernese Pain Scale for Neonates. Early Hum Dev 2004; 78:125-31.

Conroy S, McIntyre J, Choonara I. Unlicensed and off label drug use in neonates. Arch Dis Child Fetal Neon Ed 1999; 80:F142-5.

Corbo MG, Mansi G, Stagni A, Romano A, Van den Heuvel J, Capasso L, Raffio T, Zoccali S, Paludetto R. Nonnutritive sucking during heelstick procedures decreases behavioral distress in the newborn infant. Biol Neon 2000; 77:162-7.

Corff K, Seideman R, Venkataraman S, Lutes L, Yates B. Facilitated tucking: A nonpharmacologic comfort measure for pain in preterm neonates. JOGNN 1995; 24(2):143-7.

Fearon I, Kisilevsky B, Hains S, Muir D, Tranmer J. Swaddling after heel lance: Age specific effects on behavioral recovery in preterm infants. Dev Behav Pediatr 1997; 18:222-2.

Field T, Goldson E. Pacifying effects of nonnutritive sucking on term and preterm neonates during heelstick procedures. Pediatrics 1984; 74:1012-5.

Franck LS, Lawhon G. Environmental and behavioral strategies to prevent and manage neonatal pain. Semin Perinatol 1998; 22:434-43.

Gagnon R, Leung A, Macnab A. Variations in regional cerebral blood volume in neonates associated with nursery care events. Am J Perinatol 1999; 16:7-11.

Gibbins S, Stevens B, Hodnett E, Pinelli J, Ohlsson A, Darlington G. Efficacy and safety of sucrose for procedural pain relief in preterm and term neonates. Nurs Res 2002; 51:375-81.

Goubet N, Rattaz C, Pierrat V, Bullinger A, Lequien P. Olfactory experience mediates response to pain in preterm newborns. Dev Psychobiol 2003; 42:171-80.

Gray JAM. Evidence-based Healthcare. How to Make Health Policy and Management Decisions. Edinburgh: Churchill Livingstone 1997; p:61.

Grunau R, Whitfield MF, Petrie JH, Fryer EL. Early pain experience, child and family factors as precursors of somatization: A prospective study of extremely premature and fullterm children. Pain 1994; 56:353-9.

Grunau R, Whitfield MF, Petrie JH. Children's judgements about pain at age 8-10 years: Do extremely low birthweight $(<1000 \mathrm{~g})$ children differ from full birthweight peers? $\mathrm{J}$ Child Psychol Psychiatry 1998; 39:587-94. 
THE EFFICACY OF NON-PHARMACOLOGICAL INTERVENTIONS

Grunau R, Oberlander TF, Whitfield MF, Fitzgerald C, Lee SK. Demographic and therapeutic determinants of pain reactivity in very low birth weight neonates at 32 weeks' postconceptional age. Pediatrics 2001; 107:105-12.

Grunau R. Early pain in preterm infants: A model of long-term effects. Clin Perinatol 2002; 29:373-94.

Grunau R, Linhares M, Holsti L, Oberlander T, Whitfield MF. Does prone or supine position influence pain response in preterm infants at 32 weeks gestational age? Clin J Pain 2004; 20:76-82.

Hebb AL, Poulin JF, Roach SP, Zacharko RM, Drolet G. Cholecystokinin and endogenous opioid peptides: Interactive influence on pain, cognition, and emotion. Prog Neuropsychopharmacol Biol Psychiatry 2005; 29:1225-38.

Huang CM, Tung WS, Kuo LL, Chang YJ. Comparison of pain responses of premature infants to the heelstick between containment and swaddling. Nurs Res 2004; 12:31-40.

Johnston CC, Filion F, Snider L, Majnemer A, Limperopoulos C, Walker C, Veilleux A, Pelause E, Cake H, Stone S, Sherrard A, Boyer K. Routine sucrose analgesia during the first week of life in neonates younger than 31 weeks' postconceptional age. Pediatrics 2002; 110:523-8.

Johnston CC, Stevens B, Pinelli J, Gibbins S, Filion F, Jack A, Steele S, Boyer K, Veilleux A. Kangaroo care is effective in diminishing pain response in preterm neonates. Arch Pediatr Adolesc Med 2003; 157:1084-88.

Kaufmann GE, Cimo S, Miller LW, Blass EM. An evaluation of the effects of sucrose on neonatal pain with 2 commonly used circumcision methods. Am J Obstet Gynecol 2002; 186:564-8.

McGrath PA, de Veber LL, Hearn MT. Multidimensional pain assessment in children. Advances in Pain Research and Therapy. New York: Raven Press 1985; pp:387-92.

Melzack R, Wall PD. Pain mechanism: A new theory. Science 1965; 150(699):971-9.

Oberlander TF, Grunau R, Whitfield M, Fitzgerald C, Pitfield S, Saul JP. Biobehavioral pain responses in former extremely low birth weight infants at four months' corrected age. Pediatrics 2000; 105(1):e6.

Peters JW, Schouw R, Anand KJS, van Dijk M, Duivenvoorden HJ, Tibboel D. Does neonatal surgery lead to increased pain sensitivity in later childhood? Pain 2005; 114:444-54.

Porter FL, Wolf CM, Miller JP. The effect of handling and immobilization on the response to acute pain in newborn infants. Pediatrics 1998; 102(6):1383-89.

Porter RH, Winberg J. Unique salience of maternal breast odors for newborn infants. Neurosci Biobehav Rev 1999; 23(3):439-49.

Prasopkittikun T, Tilokskulchai F. Management of pain from heel stick in neonates. An analysis of research conducted in Thailand. J Perinat Neonat Nurs 2003; 7:304-12.

Ren K, Anseloni V, Zou SP, Wade EB, Novikova SI, Ennis M, Traub RJ, Gold MS, Dubner R, Lidow MS. Characterisation of basal and re-inflammation-associated long-term alteration in pain responsivity following short-lasting neonatal local inflammatory insult. Pain 2004; 110:588-596.

Roth B. Medikamenteneinsatz bei Neugeborenen: Klinische Studien belegen die Wirksamkeit und erhöhen die Sicherheit. Written notification by the Federal Ministry of Education and Research, Berlin, dated 10 February 2004. 
Ruda MA, Qing-Dong L, Hohmann AG, Peng YB, Tachibana T. Altered nociceptive neuronalcircuits after neonatal peripheral inflammation. Science 2000; 289:628-30.

Shiao SY, Chang YJ, Lannon H, Yarandia H. Meta-analysis of the effects of nonnutritive sucking on heart rate and peripheral oxygenation: Research from the past 30 years. Issues Compr Pediatr Nurs 1997; 20:11-24.

Simons S, van Dijk M, Anand S, Roofthooft D, van Lingen R, Tibboel D. Do we still hur newborn babies? Arch Pediatr Adolesc Med 2003; 157:1058-64.

Sizun J, Ansquer H, Browne J, Tordjman S, Morin JF. Developmental care decreases physiologic and behavioral pain expression in preterm neonates. J Pain 2002; 3:446-50.

Stevens B, Johnston CC. Physiologic response of premature infants to a painful stimulus. Nurs Res $1994 ; 43: 261-31$.

Stevens B. Pain management in newborns: How far have we progressed in research and practice? Birth 1996; 23:229-35.

Stevens B, Taddio A, Ohlsson A, Einarson T. The efficacy of sucrose for relieving procedural pain in neonates - a systematic review and meta-analysis. Acta Paediatr 1997; 86:837-42.

Stevens B, Johnston C, Franck L, Petryshen P, Jack A, Foster G. The efficacy of developmentally sensitive interventions and sucrose for relieving procedural pain in very low birth weight neonates. Nurs Res 1999; 48:35-43.

Stevens B, Gibbins S, Franck L. Treatment of pain in the neonatal intensive care unit. Pediatr Clin North Am 2000; 3(47):633-650.

Stevens B, Yamada J, Ohlsson A. Sucrose analgesia in newborn infants undergoing painful procedures. Cochrane Database Syst Rev 2004; 3:CD001069.

Van Dijk M, de Boer J, Koot H, Tibboel D, Passchier J, Duivenvoorden $H$. The reliability and validity of the COMFORT scale as a postoperative pain instrument in 0 to 3 -year-old infants. Pain $2000 ; 84: 367-77$.

Verhagen AP, de Vet HCW, de Bie RA, Kessels AGH, Boers M, Bouter LM. Knipschild PG. The Delphi List: A criteria list for quality assessment of randomized clinical trials for conducting systematic reviews developed by Delphi Consensus. J Clin Epidemiol 1998; 51(12):1235-41.

Ward-Larson C, Horn R, Gosnell F. The efficacy of facilitated tucking for relieving procedural pain of endotracheal suctioning in very low birthweight infants. Am J Matern Child Nurs 2004; 29:151-6. 


\section{Chapter 8}

GENERAL DISCUSSION AND FUTURE DIRECTIONS 


\section{Introduction}

„(..) The pain experience of neonates concerning mechanical impulse is generally considered lower than it is in reality. (...) For many years I have been examining preterm infants every day, but I could never be persuaded of a lower or even missing pain experience of these infants, provided that the infants were in good general condition. They could by no means be operated without anaesthesia, each blood withdrawal as it often happens during an examination already leads to a vigorous expression of reluctance.(...)."

(Peiper, 1930)

It was Albrecht Peiper, a paediatrician from Berlin, who in the first half of the last century made several observations on preterm infants and started to doubt the prevailing paradigm of pain insensitivity of neonates. But he neither met with any response from his colleagues, nor from psychologists. Fact is that the paradigm of pain insensitivity of neonate and preterm infants prevailed until far beyond the middle of the last century. Only the incidences around Jeffrey Lawson (Harrison, 1987) represented a change in the acknowledgment of the newborns' sensitivity of pain. At the end of the 1980s, procedural pain in newborns was seized as a significant stressor (Anand and Craig, 1989).

Consequently an impressive increase of knowledge about neonatal pain and possible shortand long-term consequences was taking place and more and more interest emerged from a rapidly expanding body of evidence. Neurophysiologic basic research found that newborns might be particularly sensitive to the effects of pain because of their rapidly growing central nervous system and their potential to permanently alter neuronal development and organisation (Coskun and Anand, 2000 ). Nowadays, pain in term and preterm neonates is definitely considered functional (Fitzgerald, 2005 ) and their response to pain is viewed as a complex experience involving not only transduction of noxious stimuli, but also cognitive and emotional processing in the brain (Bartocci et al., 2006). Furthermore, effective mechanisms of hyperalgesia and allodynia also exist in neonates (Fitzgerald et al., 1989; Andrews and Fitzgerald, 1994; Andrews et al., 2002; Taddio et al., 2002).

Beside these fundamental discoveries in neurophysiology, several efforts have been made in research on neonatal pain management: In the last decades, pain assessment tools have been developed and validated (Hummel and van Dijk, 2006; Duhn and Medves, 2004; van Dijk et al., 2004; Stevens and Franck, 2001; Franck et al., 2000; Stevens et al., 2000; Franck and Miaskowski 1997) underlying factors of subjective pain assessment delineated (Porter et al., 1997; Simons et al., 2003; Stevens et al., 200), pain relieving interventions of pharmacological and non-pharmacological nature have systematically been tested, efforts to explore long-term consequences of early pain exposure are actually under investigation, consensus statements of neonatal pain experts are regularly updated 
(Anand 2001; American Academy of Paediatrics, 2000; 2006), and a chapter on children's pits actually an integrative part of the International Association of the Study of Pain (2005). In this one might consider the issue to be sufficiently explored and well developed with established eviderat to enhance an accurate pain management in neonates, especially for preterm neonates hospitalized $x$ NICU.

According to Stevens (2002, personal communication), however, questions of inaccurac pain management in the clinical setting and in the nursing routine particularly remain, due to following factors:

- Still existent, long time out-dated doctrines of qualified personnel

- Fear of side effects of pharmacological interventions

- Deficits in the educational training of qualified personnel

- Non-use of validated instruments for pain measurement

- Lack of guidelines and nursing standards regarding pain treatment in the respective clinical setting

- The absence of a person adopting the role of primary carer for the newborn

- The gap between nursing science and nursing practice

- The adverseness of nurses to theoretical driven innovations

Saläntera (1999) confirmed the nurses' knowledge in the paediatric field to be inconsiste with current research. $13 \%$ of the surveyed nurses believed that children were able to tolerate pas better than adults. They also assumed that vocal infants were more likely to be perceived as being is pain whereas quiet children were not felt to be in pain. Jacob and Puntillo (1999) showed that evert though a procedure was assessed as painful according to the nurses' judgement, the nurses failed $1 \mathrm{co}$ apply pain relieving interventions. Considering these findings, efforts need to be made to improw clinical practice where a systematic approach to pain management for the vulnerable preterm and terrat neonates is concerned. In the clinical setting working with algorhytms should therefore be imperativ But it is not only the existing lack of knowledge impeding the medical and nursing profession perform appropriate action. It is the effective transfer of knowledge into clinical practice which poses a problem. Since nurses are in close contact to the infant and its parents over a long period of times. they acquire a highly influential role in the NICU environment. They find themselves in a unique position to performe accurate pain management according to evidence. Pain assessment, norspharmacological pain relieving interventions and the evaluation of care are central issues nurses have to focus on when caring for a neonate.

However, accurate pain management demands an interdisciplinary approach involving nurse $s$. physicians, psychologists and researchers from different disciplinary fields. Interdisciplinarity itself $\mathbf{i}$ a difficult task to fulfil and requests a high level of knowledge, communication skills and the ability c critical thinking. The nurses' awareness of a leadership position in changing clinical practice guides by a high level of knowledge and evidence to improve outcomes of neonates is very often dampeneci by a behaviour dominated by adaptation to existing traditions and shyness in exposing themselves through their own opinion (Käppeli, 2006). In order to improve clinical outcomes, the development the leadership role of nursing and the professional interdisciplinary collaboration with the medical profession is one of the major challenges for the next couple of years.

It is thus remarkable that already in 1995 a multidisciplinary team of the Division at Neonatology of the University Hospital Inselspital in Berne (Switzerland) started to investigate issue of pain assessment in the neonate. This research had originated in recurrent problems between nurse 
and physicians concerning an objective judgement of the pain status of newborns hospitalised in a NICU. One of the first achievements was the project of developing a pain assessment tool. As a consequence, questions on pain management were raised and became part of a whole complex of research issues integrated in the present thesis e.g. how pain in neonates is measured and what kind of pain assessment tools are in use already? What are the psychometric properties of the "Bernese Pain Scale of Neonates"? What factors are influencing subjective pain assessment in the clinical setting? What is the number of procedural pain exposure in preterm infants needing mechanical ventilation and what kind of non-pharmacological interventions are effective for prevention and treatment of pain? Furthermore we investigated the question whether morphine and multisensorial stimulation were accurate options for pain relief during and after endotracheal suctioning.

The results of our studies reveal major conclusions as follows:

- Measuring pain in neonates in a clinical setting is a complex task and must consider different parameters like behavioural and physicological indicators. Most of the instruments were developed for research purposes and their clinical applicability and utility is lacking. Furthermore, the existing multidimensional instruments are validated for acute pain only. The development of tools for the assessment of chronic pain in conditions of severe illness or for cognitive impaired neonates should be emphasized.

- In a first validation trajectory the BPSN was established as valid and reliable tool for pain assessment in preterm and term neoates. Neverthelsess in the context of the study with mechanical ventilated preterm infants psychometric issues of the instrument arised. The validity-testing of the instrument for this patient population should undergo a systematic validation trajectory.

- The majority of routine procedures in a NICU are considered to be painful by health care providers. Health care providers seem to be very sensitive to pain intensitiy of procedures and the underestimation of procedural pain could not be confirmed. Nurses generally rate almost all procedures as more painful than do physicians. This difference in assessment deserves exploration in terms of its impact on collaborative decisionmaking in neonate's pain management.

- In comparison to former similar studies we confirmed a disconcerting high number of daily procedures each preterm infant was exposed to the first 14 days of life. Generally, almost all the studied infants received either non-pharmacological or pharmacological agents for pain relief. Furthermore, in the clinical setting a systematic assessment of acute pain was performed regularly during the day. However, we could find that preterm infants of low gestational age who are at the highest risk for neurological impairment have the highest procedural pain exposure and the lowest amount of pharmacological analgesia.

- The use of morphine for pain relief during endotracheal suctioning and the use of multisensorial stimulation as comforting techniques after a painful stimulus were not effective. The administration of morphine for pain relief in ventilated preterm neonates during endotracheal suctioning remains questionable. However, there are no better analgesic therapies to date. As an alternative, future research should focus on options in non-pharmacological interventions for relieving pain during endotracheal suctioning. 
- Some of the non-pharmacological interventions like "non-nutritive sucking", "swaddling" and "faciliated tucking" have an evident favourable effect on pulse rate, respiration and oxygen saturation, on the reduction of motor activity, and on the excitation states after invasive measures. However, unambiguous evidence of this still remains to be presented. However, the effect was only tested for one-off painful acute procedure. The effect of non-pharmacological interventions for long-term pain exposure as it is characterized in NICUs has not been established yet.

\subsection{Issues regarding pain assessment in neonates}

The accurate assessment of pain in newborns is essential for an accurate interpretation of responses noxious stimuli, especially in regard to the high vuinerability of preterm or sick neonates of a NIC? A precondition for a sufficient pain management is the adequate appraisal of pain with valid and reliable pain assessment tools that have been proved to be clinically applicable and encounter a hights degree of acceptance by the whole NICU staff. Apart from the fact that pain has to be quantified. the goals of pain assessment in infants are (a) to diagnose and predict the need for intervention, (b) $t$ : evaluate the efficacy of interventions and $(\mathfrak{c})$ to examine the impact of interventions on relevant outcomes (Stevens et al., 2000). To achieve these goals, numerous infant pain measures have beerl developed and published during 1992-2006 (Hummel and van Dijk, 2006; Duhn and Medves, 2004. van Dijk et al., 2004; Stevens and Franck, 2001; Franck et al., 2000; Stevens et al., 2000; Franck and Miaskowski 1997).

A first review (Cignacco, 2001) presented eight multidimensional instruments of which the quality of psychometric properties varied considerably (Chapter 2). Many conceptual and measurement issues of the developed tools remain. To this day there is no gold standard for the pain measurement in neonates. Although multidimensional tools (measuring physiological and behavioural indicators) are recommended for the use in a clinical setting (Mc Grath et al., 1985; Abu-Saad 1990. 1998), there are repeated reports of low correlation between the two groups of indicators (Chapter 7 . This dissociation suggests that physiological factors are only loosely coupled to behavioural patterns of pain expression (Barr, 1998). This renders any evaluation of the effectiveness of interventions difficult. However, compared to the "Premature Infants Pain Profile" (PIPP) (Ballantyne et al., 1999 1. the BPSN showed good psychometric properties in a first validation trajectory including preterm and term neonates even without ventilatory support or supported by CPAP (Chapter 3). Today the BPSN is widely used in NICUs in Switzerland and in Germany. According to the nurses' practical experience. the tool turns out to be a highly acceptable, feasible and convenient instrument for daily use in the clinical setting.

\subsubsection{Are existing pain assessment tools valid for the population of} mechanically ventilated preterm infants?

Although the well-established psychometric properties were highlighted in the first validation trajectory, the use of the BPSN, as well the use of the PIPP, in artificially ventilated preterm infants is questionable, as shown in the study evaluating the effect of morphine (Chapter 6). As stated in the Cochrane review of Bellù et al. (2005) one major problem regarding the primary outcome of pain relief are the differences in measuring pain in the different studies they analysed. When the subgroup analysis was performed to account for the issue of pain measurement it yielded different results, indicating problems of pain measuring. The problem of pain measurement tools (BPSN, PIPP, VAS ! used in the morphine vs. placebo study of chapter 6 seems to be their scientifically not wellestablished validity for the group of artificially ventilated preterm neonates. Although the mean 
difference of the BPSN was too small to reach significance, the result showing a difference of one point, was also not considered of clinical importance, as this has no clinical implications. Furthermore, the interrelation between the pain measured at the 4 time points and a specific treatment group was not statistically significant in the study, which compared an intermittent dose of morphine vs. placebo, either. Preterm infants from both groups showed the same reaction patterns over time and scored low on the pain score, indicating minimal or no pain. This fact confirmed results from former studies (Simons et al., 2003; Anand, 2004; Carbajal et al., 2005, van Dijk et al., 2002). The PIPP, often used for studies on pain management, seems to be questionable for this patient population. Nurses participating in this study had considerable difficulties in assessing pain with the PIPP score, which focuses on mimicry of the infant mainly. Measuring mimicry, however, was very often jeopardized by the tapes fixing the tube and by the general immaturity of the very low birth weight children $\left(<1^{\prime} 500 \mathrm{~g}\right)$. As PIPP measures acute pain and was tested mainly on pain resulting from heel stick, the discriminating ability might be to low.

Considering the known lack of behavioural responses in preterm infants, a detailed analysis of the BPSN calculating only changes in physiological indicators (heart rate and oxygen saturation) also produced no significant results. In this study, the preterm infants seemed not to respond to pain at all. The same phenomenon was also described by the recent study of Axelin et. al (2006), where physiological indicators did not react specifically to pain. Similar results were revealed by Johnston et al. (1997). When using the PIPP for pain measurement, approximately $20 \%$ of the preterm infants did not respond to pain. In our morphine study described in chapter 6 , the correlation between behavioural and physiological indicators over time was only significant for the baseline-measurement. The absence of correlation of behavioural and physiological patterns between two groups of pain indicators has already been described (Stevens and Johnston, 1994; Barr, 1998). Such findings raise the question whether the lack of pain response is due to the general immaturity of the children involved or rather to the questionable psychometric properties of the instruments used. This issue needs to be further investigated in the near future, as the patient group concerned must be considered at high risk of increased pain exposure.

\subsubsection{Factors influencing pain assessment}

Accurate pain assessment does not depend on the use of a validated tool only. As the survey about influencing factors of subjective pain intensity assessment of health care providers has shown, pain assessment is influenced by the profession (Chapter 4): nurses rated all procedures as more painful than physicians. The nurses' generally higher classification of pain intensity may be explained by their continuous observation of the neonate, which extends over hours and days. The difference in assessment between physicians and nurses confirmed findings of similar former studies (Porter et al., 1997; Simons et al., 2003; Stevens et al., 2005) and need to be critically discussed in terms of their impact on collaborative decision-making regarding pain management. A differing perception of pain intensity could be a source of conflict between nurses and physicians in daily clinical routine, impacting pain management in concrete clinical situations. Since the results of the present survey suggested a difference in pain assessment between the four NICU compared, it must also be discussed whether regular teaching sessions relating to pain management issues, which took place in one of the NICUs under investigation, could have influenced the pain intensity ratings of their whole staff. However, training intensity - which was not under investigation in the study described in Chapter 4 is a fact that should be considered in future research. 
Finally, the leadership role of nurses concerning pain assessment has to be stressed again. Although pain assessment is known as an important responsibility of nurses, the study of Jacob and Puntillo (1999) pointed out that - despite the fact that a pain assessment tool was already incorporated into the nursing flow sheet throughout the hospital - only $28 \%$ of nurses acknowledged that they used it. Meanwhile, 33\% indicated that they were not using any tool to assess pain at all. The transfer of knowledge and a successful implementation of new evidence in the clinical setting is one of the major concerns nursing directors and nursing experts have to address in the near future if the nursing profession wants to seriously contribute to improved patient outcome

\subsection{High pain exposure on neonates in NICUs}

latrogenic pain is very common in newborn infants, and yet we know very little about its long-term effects. A systematic analysis of studies shows that early experiences with pain are associated with heightened or dampened pain responses later in infancy, partly depending on the infant's level of maturity and cumulative experience with pain (Grunau, 2002; Grunau et al., 1998; Grunau et al., 1994). When the neonate is subjected to multiple sources of pain, alterations in the regulation of response to a painful stimulus take place (Johnston and Stevens, 1996). Repeated painful procedures have been shown to produce hyperalgesia and allodynia, arising from central sensitisation and plasticity of spinal cord synapses (Beggs and Fitzgerald, 2007). These processes can lead to a structural and functional reorganisation of the nervous system. While there is considerable evidence for activity dependent plasticity in developing nociceptive circuits and early injury induced changes in animal pain models (Fitzgerald, 2005; Baccei and Fitzgerald, 2006), evidence that early pain experience shapes pain perception in humans is insufficient to date.

As described in several earlier studies (Stevens et al., 2003, Simons et al., 2003; Johnston et al., 1997), preterm neonates do not receive adequate analgesia or sedation during their exposition to invasive, technology-driven intensive care. This fact needs highlighting, since our survey among health care providers at NICUs has shown that a majority of routine procedures in neonatal intensive care are subjectively considered as painful (Chapter 4). Considering a mean pain exposure rate of 26 procedures daily (Chapter 5), these facts need a critical appraisal conceming their relevance for provoking impaired neurological development of hospitalized neonates. Furthermore, as hypothesized, infants with the lowest gestational age ( 24 to 28 weeks of gestation) were subjected to the greatest number of painful procedures during the first 14 days of their life. We were also able to confirm that significantly fewer pharmacological agents were given with lower gestational age. These results needs to be discussed critically as this group of infants runs the highest risk of neurological impairment, possibly caused iatrogenically by the high number of pain exposures in connection with little analgesic given.

The generally high number of painful procedures confirmed by our study is probably due to the inclusion of all failed procedures, which were very consistently documented in the nursing charts of the two NICUs under investigation. Furthermore, we included procedures also that were hardly described in former studies (e.g. manipulations on CPAP prongs). Due to the lack of standardization of the listing of routine procedures a comparison with former similar studies is difficult and not reliable. Nevertheless, we believe that the established number draws a realistic picture for the daily clinical setting of the two sites participating in this study, 


\subsection{Interventions for pain relief}

The restrained use of pharmacological analgesic in NICUs is due to the mostly off-label or unlicensed use of the pharmacological agents and the fear of substantial side effects (Anand et al., 2004). However, opioids are the commonly used analgesics for critically ill infants in the NICU (Anand and Selanikio, 1996; Johnston et al., 1999). The most widely used agents in newborns are Morphine and Fentanyl (Meperidine) (Anand, 2000). Their application is generally part of a guideline developed in accordance with the policies of each clinic, which should very clearly state the medication type and name, the dose rate, the expected effect-time, the possible side effects, and the form of administration.

As endotracheal suctioning is a regularly performed intervention by nurses and an essential aspect of effective airway management, we performed a randomized controlled trial with 30 preterm neonates, searching an answer to the question whether an intermittent dose of i.v. morphine $(0.5 \mathrm{mg} / \mathrm{kg})$ should be given before each suctioning procedure, thus relieving the infants from pain experienced through the intervention. No standardized pain preventing procedures had been performed in the two NICUs under investigation at before the beginning of the current study. In line with former research reports (Anand, 2004; Simons et al., 2003; Carbajal, 2006), the trial revealed no analgesic effect in the morphine group compared to the placebo group. Possible reasons for the lack of analgesic effect have been discussed in chapter 6 . The use of morphine remains controversial. But as a matter of fact, in the clinical setting endotracheal suctioning is one of the most performed nursing procedures while infants are ventilated (Simons et al., 2003, Benis and Suresh, 2001). This calls for further painrelieving interventions, be they of pharmacological or non-pharmacological nature.

Non-pharmacological methods are increasingly being recommended for pain prevention and pain management. It is assumed that non-pharmacological interventions activate the gate control mechanism (Melzack and Wall, 1965). Some of them lead to endogenous endorphin dispersal, contributing to a modulation of the pain at the level of the spinal cord, and having the effect of alleviating pain (Franck and Lawhon, 1998). A frequently studied intervention consists of the administration of glucose as a pain preventing procedure. There is good evidence for its efficacy concerning pain relief (Stevens et al., 2004). In our systematic review we could show that nonpharmacological interventions have a pain-relieving effect among preterm and term neonates. It mitigates both physiological and behaviour-oriented reactions of the neonates. In particular "nonnutritive sucking", "swaddling" and "facilitated tucking" seem to have an evident pain-relieving effect. As stated by Axelin et al. (2006) and Ward-Larson et al. (2004) "facilitated tucking" even seems to be effective for ventilated preterm infants during endotracheal suctioning. This result is of importance since endotracheal suctioning represents one of the most frequent painful procedures in ventilated preterm infants (Simons et al., 2003; Benis and Suresh, 2001; Johnston et al., 1997; Barker and Rutter, 1995; Carbajal et al., 2006) (see also Chapter 5). Factors like gestational age, state of illness and state of consciousness seem to matter in the evaluation of the efficacy of nonpharmacological intervention too, as some of the studies could describe the effectiveness only among neonates of more than 31 weeks gestation or in term neonates (Butt and Kisilevsky, 2000; Fearon et al., 1997; Prasopkittikun and Tilokskulchai, 2003).

In our interventional study investigating the effect of multisensorial stimulation as a comforting technique after endotracheal suctioning, we couldn't show any pain relieving effect of this non-pharmacological intervention. This results has to be considered very critically according to the very small subgroups which were under investigation ( $n=9$ in the morphine group) and ( $n=7$ in the placebo group) (Chapter 6). In contrary, to the expected comforting effect, nurses performing the technique observed the infants mainly being over stimulated by this intervention by the different levels 
of stimuli. We therefore hesitate to recommend this intervention in ventilated preterm infants with a very low gestational age.

For other interventions the reports of efficacy are not conclusive since there were numerous methodological constraints to consider in the interpretation of the results: the generally too small sample, the non-blinding of the observers and the non-use of validated pain assessment instruments for the majority of the studies included in the review. The lack of standardisation of non-pharmacological intervention throughout the analyzed studies represents a further critical issue.

According to our systematic review, however, we recommend non-pharmacological intervention as an alternative to pharmacological agent for mild to moderate painful procedures especially in neonates over 31 weeks of gestation. It is nevertheless essential to point out that non pharmacological intervention does not replace pharmacological treatment in cases of severe and chronic pain.

\subsection{Implications for neonatal critical care nursing}

Nurses play a key role in making decisions regarding pain assessment and its management. As already mentioned, there are continuous limitations in the knowledge base and personal attitudes of nurses related to techniques of clinical pain management. As a consequence, pain in preterm and term neonates should be a key issue in the context of each and every neonate intensive care unit and must become a priority for all the nurses and physicians of a neonatal intensive care unit. Physicians and nursing scientists caring for neonates have the responsibility to access and apply currently available research and the best clinical practice. Within the context of improving pain management, these limitations of nursing knowledge and attitudes are a key clinical process that needs to be addressed by the following issues:

- Provision of in-service education in terms of specific and repetitive training in order to address current deficits of knowledge regarding "pain" and improve nurses' and physicians' use and understanding of research. This aims at an evidence-based improvement of the clinical practice.

- Development of guidelines for pain management in NICUs which are regularly updated for the specific clinical setting.

- Utilisation of a detailed, standardised pain assessment and intervention should be developed in every NICU.

- Identification and choice of pain assessment tools that may be used. It should be ensured that they are incorporated into the daily routine.

- Development of pre-printed flow records to ensure consistent assessment of pain and reassessment after pain intervention.

- Coaching and supervision of nurses at NICUs by clinical pain nurse specialists in order to achieve improvement and guarantee good nursing quality in pain management of neonates.

- Incorporation of pain management projects as a quality improvement activity.

- Information of the parents on the practice of pain assessment and management, to make sure they know their right of expecting adequate pain management for their child. 


\subsection{Particularities of patient recruitment in NICU}

Neonates, lacking competency, represent a unique group of research subjects and parents must give permission for their infant to participate in a clinical study. As described in the study of Ballard et al. (2004) obtaining consent in the perinatal period is challenging by asking a member of the vulnerable population (e.g. pregnant woman) to give consent on behalf of her unborn child, who is also considered vulnerable. The authors even conclude that valid consent in the antenatal/perinatal population is difficult, if not impossible to obtain.

Indeed, the recruitment and the achievement of parental informed consent was accompanied by enormous difficulties in studies performed for this thesis and was a critical point for the the low power of the study comparing the effect of morphine vs. placebo. The parents were either informed during prenatal hospitalisation because of a risk of premature birth or in the first 24 hours after a preterm birth with a child needing mechanical ventilation. Both situations were difficult to handle: The trial required randomisation 24 hours after admission into the NICU which limited the time available to parents for consideration. This may has caused pressure for parents in their decision making. Generally consent is a process that must be maintained over time. Parents were under intense emotional stress caused by the usually unexpected preterm delivery and the preterm status of their child, needing mechanical ventilation. The researcher had to assess in each individual situation very accurately if the study information was an adequate issue to expose the parents to and therefore $12 \%$ of the parents were not approached at all because of restricted communication opportunities due to migration status or too heavy psychosocial burden. In the prenatal situation parents having been informed were sometimes unnecessarily concerned about all the procedures being necessary after an eventually premature birth and were mostly worrying that their child could suffer of pain due to procedures like the endotracheal suctioning. Although there were less time constraints for parental decision than in the postpartum situation, parental consent was a psychological burden also, which can be underlined by the following citation of a mother "I understand that you are doing a very important research concerning the pain relief of this little children, but giving you consent in advance, before birth, is like anticipating a situation, I do not really wish my baby to get in."

It is an ethical principle in research, that parents fully understand the research intention and the aims. In their retrospective survey of parents having consented to include their child in a NEOPAINtrial Ballard et al., (2004) found that only 3\% of the parents met criteria for validity and only $5 \%$ remembered the potential risks of the study. A fully understanding of the study aim was difficult to achieve for parents for our studies too and requested several "question and answer sessions" before receiving consent. The difficulties in receiving informed consent for this patient population must be considered as a crucial point which can impact the power of studies in the setting of neonatal intensive care by too small sample sizes. The issue should be addressed before starting new research projects by preparing researcher and key personnel through special training sessions.

\subsection{Future directions for nursing research in neonatal pain management}

According to the results of the study described in this thesis, some future directive for nursing research in neonatal pain management should be recommended. First of all, a thorough validation of the instruments used in ventilated preterm infants (BPSN and PIPP) should be performed to establish their validity in this population, in order to consider modifications of the instruments according to the results. 
To avoid the high iatrogenic procedural pain exposure and considering that the side-effects of pharmacological agents in preterm and term neonates are considerably high while there is lack of studies describing pharmacokinetics in this population, we urgently recommend a systematic approach of non-pharmacological interventions before, during and after procedures are performed. It should be investigated if whether non-pharmacological interventions are having a pain relieving effect after long-lasting acute pain exposure. No data on this topic are available to date. Furthermore, randomised controlled trials of the efficacy of pain preventing non-pharmacological intervention should be performed, clearly standardizing the intervention under investigation and taking into account the blinding of raters. This would improve the actual evidence that is currently characterised by some methodological flaws. The performance and accurate handling of non-pharmacological interventions is imperative for the nursing profession to avoid poor neurological outcomes in the development of these patients.

To ensure a size of sample significant enough to allow a certain generalisation of the results, one ought to focus on multicentre randomised controlled trials in Switzerland. With regard to pharmacological pain relief, more pharmaceutical-driven research in neonates is urgently needed to better fulfil the rigorous safety-requirements of pharmacological testing and to achieve more evidence of the safety and efficacy of pharmacological agents currently on the market. This improvement of pharmacological testing should be promoted by European and/or national law. In addition, further research is needed to establish cut-off points and an algorithm for the administration of analgesic agents in children of this specific age group, to be included in consensus statements.

To improve pain management, particularly the sensitivity of health care providers on this issue, interventional studies providing insights into the effects of regular in-service education regarding the accuracy of pain assessment should be performed. Considering the differences in subjective pain intensity assessment of routine procedures established between nurses and physician, case-studies (e.g. with vignettes) exploring the impact on pain management could give some interesting insights in inter-individual perceptions and their possible influence on common decision making.

To answer the very complex question of the long-term effects of early pain exposure of neonates, a future emphasis on interdisciplinary research projects on this subject should be promoted in Switzerland too.

To support nursing science's major focus on the adaptation process of individuals and families to an illness or crisis, and to highlight the influence of the environment on their responses, future nursing research should also more thoroughly consider the parental situation during NICU care. As stated by different authors (Brunssen and Miles, 1996; Miles and Holdtich-Davis, 1997; Miles et al., 1993), seeing their infant in pain was one of the most stressful experiences parents reported, even long after discharge from a NICU. No data considering coping strategies of parents and the support they need from health care providers to get along with this stressful situation exists in Switzerland. It should be investigated whether parent's involvement in the use of non-pharmacological interventions (e.g. facilitated tucking during endotracheal suctioning or maternal touch during heel stick procedures) decreases parental stress and helps them cope with their difficult and disturbing transition to parenthood.

"Children's pain matters - for the child, for the family, and for the society."

(International Association of the Study of Pain, 2005) 


\section{References}

Abu-Saad HH. Toward development of an instrument to assess pain in children: Dutch study.

Advances in Pain Research and Therapy, Pediatric Pain. New York: Raven Press 1990; pp.101-106.

Abu-Saad HH, Bours GJJW, Stevens B, Hamers JPH. Assessment of pain in the neonate. Semin Perinatol 1998; 22:402-16.

Als H, Lawhon G, Duffy FH, McAnulty GB, Gibes-Grossmann R, Blickman JG: Individualized developmental care for the very low birth weight preterm infants: medical and neurofunctional effect. JAMA 1994; 272:853.

Als H, Lawhon G, Brown E, Gibes R, Duffy FH, Mc Anulty G, Blickman JG. Individualized behavioural and environmental care for the very low birth weight preterm infant at high risk for bronchopulmonary dysplasia: neonatal intensive care unit and developmental outcome. Pediatrics 1986; 78:1123-1132.

Als $\mathrm{H}$. Toward a synactive theory of development: Promise for the assessment of infants individuality. Infant Ment Health 1982; 3:229-243.

American Academy of Pediatrics, Committee on Fetus and Newborn and Section on Surgery. Canadian Paediatric Society. Fetus and Newborn Committee. Prevention and management of pain in the neonate: An Update. Pediatrics 2006; 118:2231-41.

American Academy of Pediatrics. Committee on Fetus and Newborn. Committee on Drugs. Section on Anesthesiology. Section on Surgery. Canadian Paediatric Society. Fetus and Newborn Committee. Prevention and management of pain in the neonate. Pediatrics 2000; 105:454-61.

Anand KJS, Whit Hall R, Nirmala D, Shephard B, Bergqvist L, Young T, Boyle E, Carbajal R, Bhutani $V$, Moore $M$, Kronsberg S, Barton $B$ for the NEOPAIN Trial Investigator Group. Effects of morphine analgesia in ventilated preterm neonates: primary outcomes from the NEOPAIN randomised trial. Lancet $2004 ; 363: 1673-1682$.

Anand KJS. Systemic analgesic therapy. In: Anand KJS, Stevens BJ, McGrath PJ. Pain in Neonates 2nd Revised and Enlarged Edition. Elsevier Amsterdam. 2000; 10:159-188.

Anand KJS. Consensus statement for the prevention and management of pain in the newborn. Arch Pediatr. Adolesc Med 2001; 155:173-180.

Anand KJS, Selanikio JD. SOPAIN study group. Routine analgesia practices in 109 neonatal intensive care units (NICUs) (abstract). Pediatr Res 1996; 39:192A.

Anand KJS, Carr DB. The neuroanatomy, neurophysiology and neurochemistry of pain, stress and analgesia in newborns and children. Pediatr Clin North Am 1989; 36:795-822. 
Andrews KA, Desai D, Dhillon HK, Wilkox DT, Fitzgerald M. Abdominal sensitivity in the first of life: comparison of infants with and without prenatally diagnosed unilateral hydronephis: Pain 2002; 100:35 46.

Andrews K, Fitzgerald $M$. The cutaneous withdrawal reflex in human neonates: sensitisats receptive fields and the effects of contralateral stimulation. Pain 1994; 56:95-101.

Axelin A, Salanterä S, Lehtonen L. Facilitated tucking by parents' in pain management of pretrests infants - a randomized crossover trial. Early Hum Dev 2006; 82:241-247.

Baccei M, Fitzgerald M. Development of pain pathways and mechanism. In: McMahon sy Lotzenburg M, editors. Wall and Melzack's Textbook of Pain. Eth ed. Amsterdam: Elserer London:Churchill Livingstone 2006; pp:143-58.

Ballantyne M, Stevens B, Mc Allister M, Dionne K, Jack A. Validation of the premature infant pasus profile in the clinical setting. Clin J Pain 1999; 15:297-303.

Ballard HO, Shook LA, Desai NS, Anand KJS. Neonatal research and the validity of informed consesese obtaines in the perinatal period. J Perinatol 2004; 24:409-415.

Barker DP, Rutter N. Exposure to invasive procedures in neonatal intensive care unit admissions. Ara Dis Child Fetal Neonatal Ed 1995;72 :F47-8.

Barr RG. Reflections on measuring pain in infants: The problem of dissociations in responsive systems and "honest signaling". Arch Dis Child Fet Neon Ed 1998; 79:F152-6.

Beggs S, Fitzgerald M. Development of peripheral and spinal nociceptive systems. In: Anand KJ4 Stevens B, McGrath PJ (Eds.): Pain in neonates and infants, 3rd Edition, 2007 Elsevier.

Bellù $\mathrm{R}$, de Waal KA, Zanini R. Opioid for neonates receiving mechanical ventilation. Cochratuete Database of Systematic Reviews 2005, Issue 1 CD004212. Review.

Benis MM, Suresh GK. Frequency of invasive procedures in very low birth weight (VLBW) infants the neonatale intensive care unit (NICU) (abstract). Pediatric Res. 2001; 49:392A.

Brunssen SH, Miles MS. Sources of environmental stress experience by mothers of hospitalized medically fragile infants. Neonatal Network 1996; 15:88-89.

Butt M, Kisilevsky S. Music modulates behaviour of premature infants following heel lance. Can Nurs Res 2000; 31:17-39.

Carbajal R, Mucha J, Milagro R, Arias J, Bao V, Rivadeneyra M, Zegarra, J, Bazan C, Cimerman . Annequin D.: Epidemiology of Painful Procedures and Analgesic Therapy in Neonates NICUs of a Developing Country, Peru: Poster presentation, Poster Abstract, 7th Internationilt Symposium on Pediatric Pain, Vancouver, June 2006, Pain Res Manage Vol 11 Suppl B. Summer 2006; E29.

Cignacco E, Hamers JPH, van Lingen RA, Stoffel L, Büchi S, Müller R, Schütz N, Zimmermann I Nelle $M$. Neonatal procedural pain exposure and pan management in ventilated preterma infants during the first 14 days of life (submitted manuscript)

Cignacco E, Müller R, Hamers JPH, Gessler P. Pain assessment in the neonates using the Bernese Paita Scale for Neonates. Early Hum Dev 2004; 78:125-31.

Cignacco E, Schmerzerfassung bei Neugeborenen. Eine Literaturübersicht. Pflege. Die wisser schaftliche Zeitschrift für Pflegeberufe 2001; 14:171-181. 
Coskun V, Anand KJS. Development of supraspinal pain processing. Anand KJS, Stevens BJ, McGrath PJ. Pain in Neonates 2ndRevised and Enlarged Edition, Elsevier Amsterdam 2000; 10:23-54.

Dodds E. Neonatal procedural pain: a survey of nursing staff. Paediatr Nurs 2003; 15:1 8-21.

Duhn LJ, Medves JM: A systematic integrative review of infant pain assessment tools. Adv Neonatal Care 2004; 3:126-140.

Fearon I, Kisilevsky B, Hains S, Muir D, Tranmer J. Swaddling after heel lance: Age specific effects on behavioral recovery in preterm infants. Dev Behav Pediatr 1997; 18:222-2.

Fitzgerald M. The development of nociceptive circuits. Nat Rev Neurosci 2005; 6:507-20.

Fitzgerald M, Millard C, McIntosh N. Cutaneous hypersensitivity following peripheral tissue damage in newborn infants and its reversal with topical anaesthesia. Pain 1989;39:31-6.

Franck LS, Greenberg CS, Stevens B. Pain assessment in infants and children. Acute pain in children. Pediatr Clin North Am 2000; 47:487-512.

Grunau R.: Early pain in preterm infants. A model of long-term effects. Clin Perinatol. 2002; 29:373-94, vii-viii.

Grunau R, Whifield MF, Petrie JH. Children's judgements about pain at age 8-10 years. Do extremely low birthweight $(<1000 \mathrm{~g})$ children differ from full birthweight peers? J Child Psychol Psyhiatr $1998 ; 39: 587.94$.

Grunau R, Whitfield MF, Petrie JH, Fryer EL. Early pain experience, child and family factors as precursors of somatization: A prospective study of extremely premature and fullterm children. Pain $1994 ; 56: 353-9$.

Harrison H. Pain relief for premature infants. Twins July/August 1987: 53.

International Association for the Study of Pain. Why children's pain matters. Pain Clinical Updates, $2005 ; 13: 4$.

Jacob E, Puntillo KA. A survey of nursing practice in the assessment and management of pain in children: Paediatr Nurs 1999; 25:278-286.

Johnston CC, Collinge JM, Henderson SJ, Anand KJ. A cross-sectional survey of pain and pharmacological analgesia in Canadian neonatal intensive care units. Clin J Pain 1997; $13: 308-12$.

Johnston CC, Stevens BJ: Experience in a neonatal intensive care unit affects pain response. Pediatrics 1996; 98:925-30.

Käppeli S. "... und in der Schweiz macht man eine Lehre." In: Ludwig I/WE'G Aarau (editors). Studieren geht über Probieren. 2006. hpsmedia GmbH, Hungen (Deutschland).

McGrath PA, de Veber LL, Hearn MT. Multidimensional pain assessment in children. Advances in Pain Research and Therapy. New York: Raven Press 1985; pp:387-92.

Miles MS, Holditch-Davis D. Parenting the prematurely born child: pathways of influence. Semin Perinatol 1997; 21:254-266.

Miles MS, Funk SG, Carlson J. Parent stressor scale: neonatal intensive care unit. Nurs Res 1993; 42:148-152.

Peiper A. Berliner Universitäts-Kinderklinik: Sinnesreaktionen der Neugeborenen, Berlin 1930. 
Porter FL, Wolf C, Gold J, Lotsoff D, Miller JP. Pain and pain managment in newborn infants a survey of physicians and nurses. Pediatrics 1997; 100:626-632.

Prasopkittikun T, Tilokskulchai F. Management of pain from heel stick in neonates. An analysis of research conducted in Thailand. J Perinat Neonat Nurs 2003; 7:304-12.

Simons SH, van Dijk M, Anand KS, Roofthooft D, van Lingen RA, Tibboel D. Do we still hurt newborn babies? A prospective study of procedural pain and analgesia in neonates. Arch Pediatr Adolesc Med 2003; 157:1058-1064.

Sparshott M. The development of a clinical distress scale for ventilated newborn infants: Indentification of pain and distress based on validated behavioural scores. Journal of Neonatal Nursing $1996 ; 5-10$.

Stevens B, Mc Grath P, Beyene J, Breau L, Camfield C, Finley A, Franck L, Gibbins S, Howlett A. Comparison of nurse and pain expert pain indicator ratings for infants at risk for neurological impairment. Program No. 232-P209. 2005 Abstract Viewer. Sydney, Australia: International Association for the Study of Pain.

Stevens B, Yamada J, Ohlsson A. Sucrose analgesia in newborn infants undergoing painful procedures. Cochrane Database Syst Rev 2004; 3:CD001069.

Stevens B, McGrath P, Gibbins S, Beyene J, Breau L, Camfield C, Finley A, Franck L, Howlett A, McKeever P, O'Brien $\mathrm{K}$, Ohlsson A, Yamada J. Procedural pain in newborns at risk for neurologic impairment. Pain 2003; 105:27-35.

Stevens, B Franck LS. Assessment and management of pain in neonates. Paediatr Drugs 2001; 3:539-558.

Stevens B, Johnston C, Gibbins S. Pain assessment in neonates. In: Anand KJS, Stevens BJ, Mc Grath PJ. Pain in Neonates. 2nd revised and enlarged edition. Elsevier Science 2000; pp:101-134.

Stevens B, Johnston CC. Physiologic response of premature infants to a painful stimulus. Nurs Res $1994 ; 43: 261-31$

Taddio A, Shah V, Gilbert-MacLeod C, Katz J. Conditioning and hyperalgesia in newborns exposed to repeated heel lances. J Am Med Assoc 2002; 288:857-61.

van Dijk M, Simons S, Tibboel D. Pain assessment in neonates. Paediatr Perinat Drug 2004; 6:97-103.

van Dijk M, Bouwmeester NJ, Duivenvoorden HJ, Koot HM, Tibboel D, Passchier J, de Boer JB. Efficacy of continuous versus intermittent morphine administration after major surgery in 0-3 year-old infants; a double-blind randomized controlled trial. Pain 2002; 98:305-13.

Ward-Larson C, Horn R, Gosnell F. The efficacy of facilitated tucking for relieving procedural pain of endotracheal suctioning in very low birthweight infants. Am J Matern Child Nurs 2004; 29(3): 151-156. 


\section{SUMMARY}

Although pain is a universal biological experience, the phenomenon of pain experience in neonates and especially preterm infants has been denied until the 1980s. Neurophysiologic basic science has achieved a tremendous increase of evidence in the last years. Today it is known that pain is associated with much suffering for the neonate hospitalized in a NICU. This early pain experience can seriously compromise the quality of life of neonates, particularly preterm neonates, if it is not recognised, prevented or accurately treated. The development of technical equipment and the increase in medical and nursing knowledge in neonatal intensive care increases the chances of survival even for low birth weight neonates born with very low gestational age. But this survival is not connected with benefits only. Questions are increasingly being raised as to the consequences of diagnostic and therapeutic treatment which is often associated with frequent pain exposures for the child in care. Notwithstanding the still growing evidence of pain and its consequences for the neonate, the phenomenon of pain remains a central issue in NICUs and should be considered as one of the most important nursing diagnoses in the environment of neonatal intensive care. Nurses are in a unique position to represent the interest of the neonate they care for, while parents are coping with sources of stress resulting from preterm birth itself, the requirements of the transitional process to parenthood and the potentially life threatening condition of their child.

This thesis, entitled "Pain in neonates: A nursing perspective", presents different steps in the approach to neonatal pain. The steps of the nursing process are an integral part of the studies described in this thesis such as assessment of pain, interventions for pain relief and the evaluation of the effectiveness of such interventions.

The introductory part of Chapter 1 presents the rationale for the different studies. The chapter focuses on the risk caused by serious changes during the sensitive developmental stages of the neurological system, particularly of preterm infants, and the deleterious consequences the repeated and long lasting pain exposure can have. The different steps of pain management - such as objective pain assessment, non-pharmacological and pharmacological interventions, and the ongoing evaluation of the effectiveness of interventions - as an integral part of the nursing process - are being highlighted.

Regarding the efforts to disentangle pain assessment from individual subjectivity numerous efforts have been undertaken in the last years in developing different pain assessment tools in order to objectivise neonatal pain. Chapter 2 gives an overview of 8 existing pain measurement tools. It critically reviews their content, of both behavioural and physiological indicators. This review serves as a preparatory work for the validation trajectory of the "Bernese Pain Scale for Neonates" (BPSN). The use of multidimensional tools is suggested to more accurately assess the pain expression of the neonate, measured by physiological and behavioural patterns. According to this review the Premature 
Infants Pain Profile (PIPP) and the Visual Analogue Scale were chosen for establishing concurrent validity of the BPSN.

Although numerous tools exist for the use in a clinical setting, many questions concerning their psychometric properties remain unanswered. Furthermore, to this date no tool has been validated, which considers the influence of contextual factors on the expression of pain; factors like the gestational age and the associated immaturity of the central nervous system or the influence of states of illness and consciousness have not been comprehensively explained yet. None of the existing instruments fulfil all criteria for an ideal measure. However, neonatal pain assessment is imperative. Further evaluation of reliability, validity, clinical utility, and feasibility of existing tools must occur to enhance the ability of health care to accurately assess an infant's pain.

Chapter 3 describes the validation trajectory of the "Bernese Pain Scale for Neonates". The BPSN is a multidimensional tool measuring 7 subjective and 2 objective indicators. It has been developed inductively by an interdisciplinary team at the NICU in Bern (Switzerland). Validity and reliability testing were performed in 12 preterm and term neonates, who were assessed in 4 different situations: (1) 10 minutes after feeding (baseline), (2) warming of the heel with a warm towel, (3) during heel lance, (4) and 15 minutes after the blood sampling from the heel. Video sequences (total sequences $=48$ ), masking technically the leg of the infants, were shown in such a way that the four independent nurses rating the videos were unaware of the respective situation the infant was in. In this first validation trajectory the BPSN showed good psychometric properties regarding construct validity and concurrent validity in comparison to the Premature Infants Pain Profile and the Visual Analogue Scale. The correlation of assessments between the different nurses was satisfactory as well, with good interrater- and intrarater-reliability. The intrarater-reliablity was tested by showing 24 randomised selected sequences again to the same nurses after a time interval of 14 days after first assessement. A good consistency and repeatability of the tool could be established. The BPSN was validated for use in a clinical setting and can be used for preterm and term neonates. It is one of the first pain assessment tools in German for preterm and term infants of a NICU and therefore enjoys high acceptance with nurses, also because of its clinical convenience in daily practice. Its validity in postoperative situation has not been tested, so BPSN is only recommended for non-postoperative situations.

Since it is known that accurate pain assessment does not only depend on the use of a validated tool but can be influenced by intrapersonal factors, knowledge and experience of health care providers, Chapter 4 explores the underlying factors influencing individual subjective pain intensity assessment of 27 different routine procedures in NICU. Furthermore, the procedures which are considered to be painful are highlighted. A survey was conducted involving 431 neonatal health care professionals from 4 tertiary level NICUs, using a 10-point Visual Analogue Scale and assuming the absence of analgesia for each mentioned procedures. The results delineate that neither experience, nor gender nor age influence subjective pain assessment, but that profession is a determinant factor. Nurses generally rate all procedures as more painful than physicians do. These results are in line with former, similar studies. This fact raises the question if whether differing subjective perception of procedures as painful or less painful might be a source of conflict in collaborative decision-making in the daily clinical routine. The nurses' generally higher classification of pain intensity may be explained by their continuous observation of the neonate, extending over hours and days, during which discrepancies from familiar behaviour can be identified more accurately and specifically interpreted as pain. $70 \%$ out of 27 routine procedures were considered as painful with scores of $\geq 4$ points on the VAS. $41 \%$ of these were classified as very painful with a median of $\geq 6$ points on the VAS. These results show that health care providers at the participating NICUs are aware of the pain intensity of such procedures and 
that they are unlikely to underestimate it, as some former studies suggested. Interestingly, although the four participating NICUs are comparable in fulfilling their tasks as third level NICU with respect $t$ the level of education, the mean score for all procedures shows a significant difference between the units. Since the training intensity of the professionals is not in question in the present study, it remains unclear if this difference is due to the regular pain management teaching sessions which took place in the past 5 years in one of the participating NICUs.

In Chapter 5 we evaluated the procedural pain exposure and pain management in 120 ventilated preterm infants in two NICUs during the first 14 days of their life, including the number of pain assessments performed and the kind of analgesia given in the daily clinical routine. We found that the number of total procedures these 120 preterm infants went through is disconcerting $\left(n=38^{\prime} 626\right.$ ) On average, these neonates underwent 35 procedures the first day and still 16 procedures on day 14 This is a considerably higher number of procedures than reported in former studies. The highest frequency $(24 \%)$ is documented for the procedure "manipulation on CPAP prongs insertion reinsertion", which is rarely described as a procedure in other studies. This could explain the high number of general procedures. But it is also to be considered that all failed procedures were systematically documented and included in our analysis. As hypothesized, infants with the lowest gestational age (24 to 28 weeks of gestation) are subjected to the greatest number of painful procedures during their first 14 days of life. We also found that significantly less pharmacological agents were given with lower gestational age. $99 \%$ of the preterms included in this study received an agent for pain relief, non-pharmacological or pharmacological, which has to be stated as a clear positive result. It seems that preterm infants in the included NICUs experience a more appropriate pain management compared to results of previous studies indicating deficits in non-pharmacological and pharmacological pain management. $71 \%$ of the studied infants even received glucose as a preventive intervention before a procedure, but only $9 \%$ out of them received it every day. This result indicates that nurses do not standardly administer glucose before a painful procedure although there is evidence on its efficacy. Our study is one of the first to highlight whether pain assessment tools for neonates are used systematically in daily practice. The two documented tools "Bernese Pain Scale for Neonates" and the "Neonatal Infant Pain Scale" were used 4 and 7 times per day respectively. This result shows that pain assessment is an integrative part of the daily clinical routine in the two NICUs under investigation.

Chapter 6 reports on the effect of an intermittent dose of morphine compared to placebo in 30 ventilated preterm infants during endotracheal suctioning as well as the effect of multi-sensorial stimulation after the painful stimulus. We hypothesized that an intermittent dose of morphine $(0.1 \mathrm{mg} / \mathrm{kg})$ would relieve the pain experienced during endotracheal suctioning and that multisensorial stimulation would have an effect as a comforting and pain relieving technique, especially in the placebo treated group. Pain was measured with three pain assessment tools: The "Bernese Pain Scale for Neonates" (BPSN), the "Premature Infant Pain Profile" (PIPP) and the "Visual Analogue Scale" (VAS). Furthermore, morbidities arising during the whole hospitalisation period were documented. An analgesic effect of morphine could not be detected as pain scores of infants receiving morphine 5 minutes before endotracheal suctioning did not differ from those of placebo-treated infants: BPSN 6.67 vs.7.62 (F 0.907; p = 0.349); PIPP 6.84 vs. 6.61 (F 0.736; $\mathrm{p}=0.736$ ); VAS 28.97 vs. 33.03 ( $\mathrm{F}$ $0.502 ; p=0.484$ ), respectively. Furthermore, no analgesic or comforting effect could be detected for the non-pharmacological intervention of multisensorial stimulation performed shortly after the procedure. Different reasons for this failure to relieve pain are discussed such as the assumption that the pain experienced during endotracheal suctioning might not be as severe as expected and that it should be considered as a mild to moderate pain which can be treated with the non-pharmacological 
intervention of "facilitated tucking", the effect of which was shown in a recent study. However, since endotracheale suctioning in adult care is considered as being painful and causing anxiety, a clear source of distress, the assumption of moderate pain in the neonates is not convincing. It is further to be established whether the lack of analgesic is due to specific hormonal responses of the neonate and the jeopardized behavioural patterns in neonates right after birth. It is known that low pain scores may be explained by the release of endorphins during the birth process, which have a protective effect for noxious stimuli. The immaturity of opioid receptors may also be a cause of lack of analgesic effect of morphine. A major concern arises with the question whether the instruments used in the present study are valid tools for this patient sample, since the mean difference between the groups was not only not significant for all the three instruments but also the scoring never reached the range of a "painful state". The psychometric properties of the three tools, which were nevcr properly being validated for this patient population, remain questionable. In contrast to former findings there is no statistical difference in the ventilation time between the two groups. The two groups are too small to give reliable statistical information concerning the incidence of morbidity or mortality. According to their amounts (in \%), constipation, urinary retention, delayed gastric emptying, chronic lung disease, intraventricular haemorrhage grade 3 and 4, sepsis, respiratory distress syndrome and a persistent ductus arteriousus are more frequent in the morphine group than in the placebo group over the whole hospitalisation period. Neither the use of morphine nor the multisensorial stimulation can be recommended as pain relieving and comforting interventions during or after the intervention of endotracheale suctioning. Furthermore the use of the three tools BPSN, PIPP and VAS needs to be discussed critically in this patient population. Future research should focus on non-pharmacological intervention options for relieving pain during endotracheal suctioning.

As up to $80 \%$ of the analgesics which are used on sick preterm and term neonates in a NICU are either not approved for the illness concerned (off-label use) or are administered in a form other than that officially approved (unlicensed use), non-pharmacological pain relieving interventions are increasingly being recommended. Chapter 7 describes the efficacy of some non-pharmacological interventions which are part of current nursing practice in a systematic review. The selected interventions are "non-nutritive sucking", "music", "swaddling", "positioning", "olfactory and multisensorial stimulation", "kangaroo care" and "maternal touch". The administration of sucrose - as one non-pharmacological intervention - has been excluded from the analysis since there is sufficient evidence about its efficacy. The review shows that some of the non-pharmacological interventions have a pain-relieving effect, particularly "non-nutritive sucking", "swaddling" and "facilitated tucking". These interventions modify both physiological and behaviour-oriented reactions of the neonates, even among the highly vulnerable group of ventilated preterm neonates with a restricted state of consciousness. However, the review shows that all analyzed studies have considerable limitations regarding their verification of efficacy since all interventions were tested exclusively with one-off painful procedural interventions. Knowing that neonates hospitalized in a NICU are subjected to a high number of painful procedures, the efficacy of non-pharmacological interventions on a longterm basis has not been described yet. Furthermore, methodological constraints were found in several studies, such as the non-use of validated pain assessment tools, the lack of information about the blinding of raters or the usually very small sample size which undoubtedly affects the ability to detect the effects of the interventions under investigation; contextual factors, such as the gestational age or the neonates' state of health, were also not considered. However, the review offers a first insight that non-pharmacological interventions, which can be easily performed by trained nurses or by parents themselves, are, to some degree, beneficial for neonates undergoing painful procedures. It needs to be 
emphasised, however, that non-pharmacological interventions cannot replace pharmacological treatment in cases of severe and chronic pain but has its effect for mild to moderate pain.

The results of our studies are discussed in Chapter 8 . Future directions are indicated. 


\section{SAMENVATTING}

Alhoewel pijn een algemene biologische gewaarwording is die bij ieder mens voorkomt, heeft het tot begin jaren ' 80 geduurd voordat werd onderkend dat ook pasgeborenen - en speciaal te vroeg geboren kinderen - pijn konden voelen. In de afgelopen jaren is hiervoor door basaal neurofysiologisch onderzoek steeds meer bewijs geleverd. Vandaag de dag is bekend dat baby's die opgenomen zijn op neonatale intensive care afdelingen (NICUs) veel te lijden hebben tengevolge van de pijn die zij ondervinden tengevolge van de noodzakelijke behandeling.

Indien niet herkend, voorkomen en behandeld kan deze vroege pijnbeleving leiden tot een ernstige aantasting van de kwaliteit van leven van pasgeborenen en in het bijzonder die van te vroeg geborenen.

Door de voortschrijdende ontwikkeling van technische apparatuur en de toename van medische en verpleegkundige kennis zijn de kansen om te overleven zelfs voor de kinderen met een laag geboortegewicht toegenomen. Deze overleving kent echter niet alleen positieve effecten maar ook negatieve aspecten.

In toenemende mate worden kanttekeningen geplaatst bij de consequenties van diagnostische en therapeutische ingrepen en behandeling waarbij de pasgeborene vaak blootgesteld wordt aan pijn.

Ondanks het feit dat er meer dan genoeg bewijs is voor het bestaan van pijn en de consequenties hiervan voor de pasgeborene blijft pijn een belangrijk gegeven op de NICU en pijn moet dan ook beschouwd worden als één van de meest belangrijke (verpleegkundige) diagnoses op de NICU. Verpleegkundigen verkeren in een unieke positie waar het gaat om het opkomen voor de belangen van het kind, in een periode waarin de ouders proberen om te gaan en vaak worstelen met de stress tengevolge van de vroeggeboorte, de overgang naar het ouderschap en de mogelijk levensbedreigende conditie van hun kind.

Dit proefschrift, getiteld "Pijnmanagement bij pasgeborenen vanuit een verpleegkundig perspectief" laat verschillende stappen in de benadering van pijn bij pasgeborenen zien.

De onderdelen van het verpleegkundig proces zoals pijnherkenning en pijnmeting, behandeling van pijn en evaluatie van de effectiviteit van behandelingsmethoden $c q$ therapieën zijn een integraal onderdeel van de onderzoeken die in dit proefschrift beschreven worden.

In hoofdstuk 1 wordt de onderbouwing van de verschillende studies beschreven. Het hoofdstuk spitst zich toe op het risico dat veroorzaakt wordt door grote veranderingen die optreden tijdens de gevoelige ontwikkelingsstadia van het neurologische systeem, met name bij te vroeg geboren baby's. Daarnaast ook op de schadelijke gevolgen die herhaalde en langer durende blootstelling aan pijn kan hebben. 
De verschillende onderdelen van pijnmanagement - zoals een objectieve pijnbeoordeling, medicamenteuze en niet-medicamenteuze behandeling en de continue evaluatie van de effectiviteit van die behandelingen zijn een integraal onderdeel van het verpleegkundig proces en worden als zodanig in dit hoofdstuk besproken.

Voor wat betreft de pogingen om pijn los te maken van de subjectiviteit van de beoordelaar zijn er in de laatste jaren meerdere initiatieven ontplooid om verschillende pijnmeetinstrumenten te ontwikkelen die neonatale pijn objectief kunnen beoordelen.

In hoofdstuk 2 wordt een overzicht gegeven van de 8 bestaande pijnmeetinstrumenten. Er werd een kritisch onderzoek gedaan naar hun inhoudelijke parameters, zowel de gedragsmatige als ook de fysiologische parameters. Dit overzicht diende als voorwerk voor het valideringstraject van de "Bernese Pain Scale for Neonates" (BPSN). Het gebruik van een instrument dat meerdere gebieden kan meten (in dit geval gedragsmatige en fysiologische parameters) zou, zo wordt in de literatuur aangegeven, de uitdrukking van pijn bij de pasgeborene nauwkeuriger kunnen beoordelen. Naar aanleiding van dit overzicht kozen wij de Premature Infants Pain Profile (PIPP) en de Visueel Analoge Schaal om de overeenstemmende validiteit van de BPSN te bepalen. Ofschoon er verschillende instrumenten bestaan voor gebruik in de klinische praktijk, blijven er veel vragen voor wat betreft hun psychometrische eigenschappen onbeantwoord. Tot op heden is er geen instrument gevalideerd dat de invloed van contextuele factoren op de pijnuitdrukking in ogenschouw neemt; factoren als zwangerschapsduur en de daarmee gepaard gaande immaturiteit van het CZS of de invloed van de mate van ziekzijn en de mate van bewustzijn zijn nog steeds niet op een begrijpelijke wijze verklaard. Geen van de bestaande pijnmeetinstrumenten beantwoorden aan alle criteria voor de ideale meting. Desalniettemin is pijnbeoordeling van neonatale pijn van zeer groot belang. Verdere evaluatie van de betrouwbaarheid, de validiteit, het gebruiksgemak in de praktijk en de uitvoerbaarheid van bestaande meetinstrumenten moet plaatsvinden om degenen die de zorg voor pasgeborenen hebben beter in staat te stellen om pijn bij pasgeborenen goed te kunnen beoordelen.

In hoofdstuk 3 wordt de validering (van de "Bernese Pain Scale for Neonates" beschreven, De BPSN is een multidimensioneel instrument dat 7 subjectieve en 2 objectieve parameters meet. Het is ontwikkeld in de praktijk met behulp van ervaring en gegevens uit de litteratuur door een groep mensen uit verschillende beroepsgroepen, werkzaam op de NICU in Bern (Zwitserland). De validiteit en de betrouwbaarheid werden getest bij 12 premature en à terme geboren pasgeborenen onder 4 verschillende omstandigheden: (1) als uitgangswaarde 10 minuten na de voeding, (2) verwarmen van de hiel met een warme doek, (3) tijdens een hielprik en (4) 15 minuten na het afnemen van bloed uit het voetje. Video-opnames van de verschillende fasen (in totaal 48 ) waarbij het been van de kinderen niet in beeld kwam, werden op een dusdanige manier getoond aan vier verschillende verpleegkundigen, die niet bij het onderzoek betrokken waren, dat ze niet wisten in welke situatie het kind zich op dat moment bevond.

In deze eerste validatiefase liet de BPSN goede psychometrische eigenschappen zien voor wat betreft de constructvaliditeit en de validiteit die de overeenstemming met de Premature Infants Pain Profile en de Visueel Analoge Schaal weergaf. De correlatie tussen de beoordelingen van de verschillende verpleegkundigen was bevredigend met goede betrouwbaarheid tussen de herhaalde scores van één persoon (intrarater) als ook tussen personen onderling (interrater). Door dezelfde verpleegkundigen na 14 dagen 24 van de 48 video-opnamen in een willekeurige volgorde weer te laten scoren werd de intrarater betrouwbaarheid getest. Het instrument bleek bij herhaling goed te werken en ook consequent te zijn. De BPSN werd gevalideerd voor klinisch gebruik en kan gebruikt worden voor zowel premature als op tijd geboren kinderen. Het is een van de eerste instrumenten in het Duits 
voor zowel premature als op tijd geboren kinderen op een NICU en kan zich daardoor verbetugen in een grote mate van gebruik door verpleegkundigen. Daarnaast blijkt hij makkelijk te zijn in het dagelijkse gebruik. De BPSN dient alleen voor niet-operatieve situaties gehruikt te worden, aangezien er nog niet voor postoperatieve situaties getest is.

Goede pijnmeting hangt niet alleen af van het feit of een instrument al dan niet gevalideerd is. maar kan ook beïnvloed worden door persoonlijke factoren. kennis en ervaring van werkers in de gezondheidszorg. Daarom werd in hoofdstuk 4 gekeken naar de onderliggende factoren die van invloed zijn op de individuele, subjectieve beoordeling van pijnintensiteit van 27 verschillende routine ingrepen of handelingen op de NICU. Daarnaast werd er extra aandacht geschonken aan die ingrepen die als pijnlijk beschouwd werden.

Er werd een enquête gehouden onder 431 mensen werkzaarn op 4 NICUs waarhij met behulp van een VAS bij alle routine ingrepen of handelingen pijn gescoord werd, er van uit gaande dat er geen pijnbestrijding werd gegeven. De resultaten onderstrepen dat het beroep veel invloed heeft op deze pijnmeting, maar dat daarentegen ervaring, geslacht of leeftijd niet van invloed waren. Verpleegkundigen scoren in het algemeen alle handelingen als pijnlijker dan artsen. Dit is in overeenstemming met resultaten van eerdere, soortgelijke onderzoeken. Het werpt wel de vraag op of verschillen in subjectieve waarneming wanneer beoordeeld moet worden of procedures pijnlijk of wat minder pijnlijk zijn kunnen leiden tot onenigheid in de gemeenschappelijk besluitvorming tijdens de verzorging van de patiënt Het feit dat verpleegkundigen de pijn meestal hoger scoren zou verklaard kunnen worden doordat zij het kind doorlopend observeren, gedurende uren en dagen. waardoor afwijkingen van het voor dat kind normale gedrag beter herkend kunnen worden en in verband gebracht kunnen worden met pijn. $70 \%$ van de 27 routine ingrepen en handelingen werd als pijnlijk beschouwd, waarbij de score $\geq 4$ was op de VAS. $41 \%$ van deze groep werd beschouwd als zeer pijnlijk met een mediaan score van $\geq 6$ punten (van maximaal 10). Deze resultaten geven aan dat het verzorgend personeel op de NICUs goed op de hoogte is van de pijnintensiteit die deze ingrepen en handelingen kunnen geven en dat zij die intensiteit zeker niet zullen onderschatten, zoals in sommige eerdere onderzoeken werd gevonden. Het was heel interessant om te zien dat de gemiddelde score voor alle procedures significant verschilde tussen de vier afdelingen terwijl alle deelnemende afdelingen vergelijkbaar zijn voor wat betreft hun taken als derdelijns centrum waar het gaat om de algemene zorg. Aangezien er geen vraag werd gesteld in deze studie over de mate van training of nascholing, is het niet duidelijk of dit verschil te wijten is aan het feit dat in een van de centra de laatste 5 jaar regelmatig les werd gegeven over pijnbehandeling en herkenning.

In hoofdstuk 5 werd de mate van blootstelling aan pijn bij procedures en de behandeling van deze pijn onderzocht in een groep van 120 te vroeg geboren baby's op twee NICUs gedurende de eerste 14 levensdagen. Daarbij werd ook gekeken naar het aantal keren dat pijn werd beoordeeld en naar wat voor pijnbestrijding er in de dagelijkse praktijk werd gegeven. Wij vonden dat er een verontrustend hoog aantal procedures was waaraan deze 120 te vroeg geboren kinderen werd blootgesteld, namelijk 38.626. Gemiddeld betekent dit dat zij op de eerste dag 35 en zelfs op dag 14 nog 16 handelingen ondergingen. Dit is een beduidend hoger aantal dan in eerdere studies werd vermeld. De hoogste frequentie, namelijk in $24 \%$ van de gevallen, werd vermeld voor de handeling inbrengen of verwisselen van de sprietjes (kleine slangetjes) van de CPAP; deze handeling werd echter in alle andere studies nauwelijks vermeld. Dit zou het hoge aantal van alle handelingen kunnen verklaren. Daartegenover staat dat wij ook alle mislukte handelingen (bijvoorbeeld een mislukte poging een infuus in te brengen) systematisch vastlegden en mee hebben gerekend in de uiteindelijke analyse. 
Zoals we van tevoren veronderstelden vonden de meeste handelingen en ingrepen plaats bij de jongste kinderen in de eerste 14 levensdagen namelijk bij de groep geboren na een zwangerschapsduur van 24 tot 28 weken. Wij vonden ook dat naarmate er een lagere zwangerschapsduur was er significant minder medicijnen ter bestrijding van pijn gegeven werden. Een in onze ogen positieve bevinding was dat $99 \%$ van de premature baby's in deze studie op enig moment een middel tegen de pijn kregen, hetzij medicamenteus of niet-medicamenteus. Het lijkt er op dat de kinderen in de vier onderzochte NICUs een betere behandeling en beoordeling van pijn krijgen dan in vergelijkbare eerdere studies waar nog grote hiaten in de (niet-) medicamenteuze pijnbehandeling werd beschreven. Glucose als preventieve handeling werd zelfs in $71 \%$ van de bestudeerde kinderen gegeven, maar slechts bij $9 \%$ van deze groep gebeurde dat ook elke dag. Dit resultaat geeft aan dat de verpleegkundigen niet bij elke pijnlijke ingreep standaard glucose geven, terwijl de werkzaamheid inmiddels is aangetoond. Onze studie is één van de eersten die beschrijft en onderzoekt of pijnmeetinstrumenten in de dagelijkse praktijk wel systematisch gebruikt worden. De twee gebruikte instrumenten, de BPSN en de "Neonatal Infant Pain Scale", werden respectievelijk 4 en 7 keer per dag per kind gebruikt. Deze resultaten geven aan dat in de twee onderzochte NICUs pijnmeting en behandeling een geïntegreerd onderdeel zijn van de dagelijkse klinische routine.

In hoofdstuk 6 werd bij 30 beademde te vroeg geboren baby's het effect van herhaalde morfine toediening tijdens endotracheaal (door de beademingsbuis) uitzuigen, vergeleken met het effect van een placebo. Daarnaast werd ook het effect van multisensorial stimulation (MS) na de pijnlijke prikkel beoordeeld. Onze hypothese was dat een dosis van $0,1 \mathrm{mg} / \mathrm{kg}$ morfine de pijn die optreedt tijdens endotracheaal uitzuigen zou bestrijden en dat MS vooral in de placebogroep een troostend en pijnverminderend effect zou hebben.

Pijn werd gemeten met behulp van drie pijnmeetinstrumenten: de "Bernese Pain Scale for Neonates" (BPSN), de "Premature Infant Pain Profile"(PIPP) en de "Visueel Analoge Schaal"(VAS).

Ziekten die optraden bij de kinderen tijdens de opnameperiode werden genoteerd.

Omdat de pijnscores van pasgeborenen die morfine kregen vijf minuten voor het endotracheale uitzuigen niet verschilden van die van kinderen die een placebo kregen, concludeerden wij dat er in deze situatie geen pijnstillend effect van morfine was. De niet-farmacologische interventie behandeling met MS die vlak na het uitzuigen plaats vond gaf evenmin een effect te zien. De verschilllende verklaringen voor dit gebrek aan effectiviteit van pijnbestrijding worden besproken evenals de aanname dat pijn tijdens endotracheaal uitzuigen niet zo ernstig is als verwacht en dat het beschouwd kan worden als lichte tot matige pijn, die behandeld zou kunnen worden met de nietmedicamenteuze behandeling "facilitated tucking" (begrenzen), waarvan het effect in een recent onderzoek werd aangetoond. Aangezien van endotracheaal uitzuigen bij volwassenen is aangetoond dat het pijnlijk is en angst veroorzaakt die op zich al duidelijk onwelbevinden veroorzaakt, lijkt de aanname van matige pijn bij pasgeborenen niet overtuigend. Verder onderzoek zal nog duidelijk moeten maken of het gebrek aan pijnstillend effect het gevolg is van specifieke hormonale reacties van de pasgeborene en aanpassing van gedragspatronen op bedreigingen van buiten vlak na de geboorte.

Lage scores op de pijnschaal kunnen verklaard worden door het tijdens de geboorte vrijkomen van endorfinen (lichaamseigen morfineachtige stoffen) die een beschermend effect tegen pijnlijke prikkels hebben. De onderontwikkeling van opioïd-receptoren (ontvangers) bij te vroeg geboren kinderen kan mede de oorzaak zijn van het ontbreken van een pijnstillend effect van morfine. Aangezien het gemiddelde verschil tussen de groepen bij de drie pijnmeetinstrumenten niet significant was en de score zelfs in geen enkel geval de waarde bereikte die "pijn" aangaf, vragen wij ons af of 
deze pijnmeetinstrumenten wel geschikt zijn voor deze patiëntengroep. Bij de psychumetrische eigenschappen van de drie instrumenten, die nooit echt werden gevalideerd voor deze patientrtengroep kunnen vraagtekens worden gezet.

In tegenstelling tot eerdere bevindingen is er geen statistisch verschil in de duur van de beademing tussen beide groepen. De twee groepen zijn te klein om betrouwbare statistische informatie te kunnen geven over de incidentie van ziekten en sterfte. Afgaande op het percentage van voorkomen gedurende de hele opnameperiode, komen obstipatie, urineretentie, vertraagde maagontlediging. bronchopulmonale dysplasie, graad 3 en 4 hersenbloedingen. sepsis (bloedvergiftiging), bet respiratoire distress syndroom en een open blijvende ductus Botalli frequenter voor in de morfinegroep. Geconcludeerd kan worden dat noch het gebruik van morfine, noch de MS aanbevolen kan worden als pijnbestrijdende, pijnverminderende of troostbiedende therapie tijdens of na endotracheaal uitzuigen. Daarnaast dient het gebruik van de drie eerder genoemde pijnmeetinstrumenten in deze patiëntenpopulatie nog eens kritisch tegen het licht gehouden worden Toekomstig onderzoek zal gericht moeten zijn op niet-medicamenteuze methoden om pijn tijdens endotracheaal uitzuigen te verminderen.

Aangezien tot $80 \%$ van de pijnstillers die aan zieke te vroeg geboren of op tijd geboren pasgeborenen worden voorgeschreven niet zijn goedgekeurd voor de betreffende ziekte toff-label gebruik) of worden toegediend in een andere vorm dan officieel is toegestaan (gebruik zonder licentie), wordt het gebruik van niet-medicamenteuze methoden om pijn te verlichten meer en meer aanbevolen.

In hoofdstuk 7 wordt de effectiviteit van enkele niet-medicamenteuze behandelingen die onderdeel uitmaken van de huidige verpleegkundige praktijk op een rij gezet en kritisch beschouwd. Het gaat hierbij om "niet-voedend zuigen", "muziektherapie", "inbakeren". "positioneren", "reuk- en zintuigstimulatie", "kangoeroeën" en "aanraken door de moeder". De toediening van sacharose, één van de niet-medicamenteuze behandelmethoden, werd niet meegenomen in de analyse, omdat er al voldoende bewijs voor de werkzaamheid is.

De resultaten van onze onderzoeken worden besproken in hoofdstuk 8, waarin tevens aanbevelingen voor toekomstig onderzoek worden gedaan. 


\section{ACKNOWLEDGEMENTS}

My long-lasting study would not have been completed without the support, the faith. the encouragement and the advice offered by many different people. In the first place. I would like to thank all the parents who. despite their difficult situations, listened to my concerns and gave me, with their compliance. their faith. Without them and their neonate infants, three of the researches at hand would not have been possible.

I owe a debt to the leaders of the Children's Clinic of the University Hospital in Bern, notably Prof. Dr. med. Richard Kraemer, medical director, and Mrs. Johanna Zawadynska, head of the nursing service. Without their assent, my nursing research projects could not have been conducted. Their consent was all the more important, as these projects constitute the first endeavours of clinical nursing research at the University Hospital in Berne. Both of them were ready to meet this new challenge.

The financial request granted by Mrs. Beatrice Buchmann, nursing director and Dr. Virpi Hantikainen, head of nursing research. both at the University Hospital in Bern, represented a milestone in the difficult preparatory phase of fund-raising. I wish to express my heartfelt thanks to these two women for their support and their trust in me. Further funds could be raised thanks to the two foundations "Ettore e Valeria Rossi" in Berne and the "Reach Out-Project" belonging to the "Eleonoren-Foundation of the Children's University Hospital in Zurich". Both foundations agreed to offer financial support. Without these means, I would not have been able to employ two study nurses with an hourly wage, who helped me with or even relieved me of the data collection to a great extent. I further gratefully acknowledge the financial aid of PD Dr. med. Mathias Nelle, head of Neonatology, Children's Clinic of the University Hospital in Berne, especially during the last six months of the research project. Without this support from the scientific funds of the neonatology, my research, or rather the costs connected to them, would not have been covered.

I am indebted primarily to Mrs. Yvonne Huber, nursing director of the Children's University Hospital in Zurich, and PD Dr. med. Oskar Bänziger, head of Neonatology at the Children's University Hospital in Zurich, for enabling data collection beyond the borders of the Canton of Berne. I also owe a debt to PD Dr. med. Peter Gessler, who spent many hours of work to include the neonates in Zurich in the study too. I would like to thank them all for their frankness and assistance during the process of my research.

I was very lucky to be able to enlist the assistance of very enthusiastic, interested and professional nursing staff for the task of study nurses: Mrs. Lilian Stoffel. Mrs. Vroni Schneckenburger, Mrs. Barbara Schibler in Berne and Mrs. Natascha Schütz in Zurich. My study would not have been brought to an end without their perseverance, the many cups of coffee we had together and their perpetual belief in the necessity and importance of these research projects. They made me continue and overcome my doubts in difficult moments. It was essential to share a common 
aim, the advancement of the well-being of neonates with a difficult start of life. I especially wish all the best of luck to Lilian Stoffel and Natascha Schütz, who have now begun to face the challenges of nursing science with their studies themselves. May they be successful in putting their new insights into nursing practice! I would further like to thank Mrs. Mägi Gadient, study nurse of the first hour at the Children's University Hospital in Zurich. She greatly supported me in the early and demanding stages of data collection in a hospital unknown to me before that time.

The active participation of all the teams of the different wards also contributed invaluably to the successful accomplishment of the study. I thank all the nursing staff of the neonatology teams, notably B2 and B3 in Berne and the teams of the intensive care units IPS A and IPS B, as well as the Neonatology unit in Zurich. I appreciate their readiness to participate in the study and to conduct the measurements via Bernese Pain Scale for Neonates and other instruments. Their talent for observation was essential for the success of all the individual studies. My thanks also go to the midwives of the prenatal ward E1 at the Women's Clinic, University Hospital Inselspital in Berne. They readily provided me with information about potential pregnant women participants for my study concerning morphine in ventilated preterm infants. I would like to thank the heads of the nursing units, Susanne Draber and Claudia Zimmermann in Beme, and Christine Maguire and Francoise Jossi in Zurich, for their great willingness to find constructive solutions in cooperation with me.

I also owe my gratitude to the two professors Prof. Dr. med. Bernhard Roth at the University Clinic in Cologne and Prof. Dr. med. Hans-Ulrich Bucher at the University Hospital in Zurich for their participation in the study of subjective assessment of pain intensity of routine interventions. Their consent enabled me to consult a comparatively big sample of professionals, which represents an advantage for scientific studies. I thank both the anaesthetists, Prof. Dr. med. Michele Curatolo and PD Dr. med. Steen Petersen from the University Hospital Berne, for their valuable advice in connection with the demanding revision of one of my published articles during the review process.

The work of the hospital pharmacy at the University Hospital in Berne needs to be acknowledged too. Their careful reconditioning and coded description of the study medication for the morphine trial helped considerably to achieve a qualitative gain of logistic aspects.

During all the years of my empirical working, there were four mentors who patiently supported me with their outstanding expertise and helpful advice in the accomplishment of my studies which at times seemed too immense. I thus wish to express my utmost appreciation to the following persons for their work and for their professional support during the different steps of my work, but in particular for their competent feedbacks as co-authors of numerous articles: Prof. Jan Hamers, University Maastricht, Section Nursing Science, Dr. med. Richard van Lingen, Senior neonatologist, Isala Clinics, Princess Amalia Department of Paediatrics in Zwolle, Prof. Dr. med. Luc Zimmermann, head neonatologist at the University Maastricht, Neonatology, Department of Paediatrics, and PD Dr. med. Mathias Nelle, head neonatologist, Children's Hospital, Division of Neonatology, University Hospital Beme. Particularly during the last months, they were literally flooded by scientific articles that were waiting to be revised and corrected by them. Assuming that I was losing my bearings, considerate e-mails reached me with the question whether I was actually still eating or sleeping from time to time. I sincerely hope that we can keep the contact alive between the Netherlands and Switzerland.

I thank Mrs. Heather Murray, Mrs. Sibylle Wüest and Mr. Kaspar Schlüer for the editing of the articles. They proofread my texts professionally and carefully. I would like to thank Mrs. Arlette T. Bernasconi for the thorough compilation and formatting of the whole manuscript and for her creativity in developing the book cover, which makes readers feel comfortable from the beginning. 
My final and most important thanks are for my husband Romano Müller Cignacco, for the years of our relationship, for all human and scientific support, for the personal encouragement and his faith in my competence and skills. He reassured me again and again and showed me the direction to continue. I thank him for all his support in every respect. I thank my family for their understanding, that I was not always capable of spending the necessary time with them as a family member.

During my last years' work and the systematic advancement of moving in a scientific context, I have encountered many interesting people, attending congresses and discussions in different countries. The commitment of each and everyone to engage in the improvement of the pain treatment of neonates and premature infants was a vital experience for me and enhanced my curiosity to reach satisfactory responses to my scientific questions and work. It was a great enrichment and a privilege to have been able to do this study, to have met all these people and worked with them. Thank you! 


\section{PUbliCATION LIST SINCE MASTER THESIS}

\section{7}

Cignacco E, Stoffel L. Wie schmerzhaft sind Routinemassnahmen in der Neonatologie? Die Hebamme 2007; 20:1 12-116.

Cignacco E. Schulterdystokie. Fachkompetenz und lückenlose Dokumentation notwendig. Schweizer Hebamme 2007; 1:4-7.

Cignacco E, Stoffel L, Nelle M. Palliativpflege bei sterbenden Neugeborenen. In: Knipping C. (Editor): Lehrbuch Palliative Care. 2007. 2. Auflage, Verlag Hans Huber, Bern.

Cignacco E, Hamers JPH, Stoffel L, van Lingen R, Gessler P, Mc Dougall F, Nelle M. Efficacy of non-pharmacological interventions for procedural pain in preterm and term neonates. A systematic literature review. European Journal of Pain 2007; 11: 139-152.

Cignacco E, Hamers JPH, van Lingen RA, Zimmermann L, Müller R. Nelle M. Lack of pain relief by morphine in ventilated preterms during endotracheal suctioning. A randomized controlled trial. 2007 (submitted)

Cignacco E, Hamers JPH, van Lingen RA, Stoffel L, Büchi S, Müller R, Schütz N, Zimmermann L. Nelle $M$. Neonatal procedural pain exposure and pain management in ventilated preterm infants during the first 14 days of life. 2007 (submitted)

Cignacco E, Hamers JPH, L.Zimmermann, Stoffel L., Schütz N, van Lingen R, Nelle M. Assessment of procedural pain intensity in NICUs. 2007 (submitted)

\section{6}

Meyer-Wittkopf M, Spescha P, Cignacco E, Raio L, Surbek D. Klinisch-ethische Entscheidungsfindungen im Rahmen eines Ethikzirkels bei schwerwiegenden Pränataldiagnostik-Befunden. PO-G 04.13, Geburtsh Frauenheilk 2006; 76: S1-S200 (Poster).

Büchi S., Cignacco E, Lüthi D, Spirig R. Erwartungen und Bedürfnisse schwangerer Tamilinnen in der Schwangerenvorsorge. Pflege die wissenschaftliche Zeitschrift 2006; 19: 295-302.

Cignacco E, Hamers J, Stoffel L, Schütz N, van Lingen R, Zimmermann L, Nelle M. Differences in the assessment of the intensity of procedural pain in NICUs. Poster Abstract, $7^{\text {th }}$ International Symposium on Pediatric Pain, Vancouver, June 2006. Pain Res Manage Vol 11 Suppl B Summer 2006, 41B (Poster).

Cignacco E, Stoffel L., Nelle M. Palliativpflege bei sterhenden Neugeborenen. In: Knipping C (Editor): Lehrbuch Palliative Care. 2006. 1. Auflage, Verlag Hans Huber, Bern. 
Cignacco E, Zbinden A, Surbek D. Aufrechterhaltung der Laktation bei Brustabszess. Eine Fallstudie. Pflege. Die wissenschaftliche Zeitschrift 2006; 4: 70-72.

Cignacco E (Editor): Hebammenarbeit in pathologischen Situationen. 2006, Verlag Hans Huber. Bern.

Cignacco E.. Präeklampsie - Die grosse Unbekannte. In: Cignacco E (Editor): Hebammenarbeit in pathologischen Situationen. 2006, Verlag Hans Huber, Bern.

Georg J, Cignacco E. Hebammendiagnosen und deren Bedeutung für die Professionalisierung des Hebammenberufes. In: Cignacco E (Editor): Hebammenarbeit in pathologischen Situationen. 2006, Verlag Hans Huber, Bern.

\section{5}

Cignacco E. Schmerz bei Frühgeborenen. Ein in der Klinik unterschätztes Phänomen mit Folgen. Ars Medici, Pädiatrie 2005; 5+6: 15-16.

Cignacco E (Editor): Johnson R, Taylor W. Lehrbuch der Hebammenfertigkeiten. 2005, Verlag Hans Huber, Bern.

Stoffel L, Cignacco E, Hamers JPH, van Lingen R, Mc Dougall J, Nelle M. Effektivität nichtmedikamentöser Interventionen zur Schmerzlinderung in der Neonatologie. Eine Literaturübersicht. Pflege. Die wissenschaftliche Zeitschrift 2005; 18: 147-158.

Cignacco E. Schmerz bei Frühgeborenen. Ein lang verkanntes Phänomen mit Folgen. Soziale Medizin $2005 ; 1: 8-9$.

\section{4}

Cignacco E, Büchi S, Oggier W. Hebammengeleitete Geburtshilfe in einem Schweizer Spital. Pflege. Die wissenschaftliche Zeitschrift 2004; 17:253-261.

Cignacco E, Stoffel L, Raio L, Schneider H, Nelle M. Richtlinie für die Palliativpflege sterbender Neugeborener. Zeitschrift für Geburtshilfe und Neonatologie 2004; 208:155-160.

Cignacco E, Gessler P, Müller R, Hamers JPH. Pain assessment in the neonate using the Bernese Pain Scale for Neonates. Early Human Development 2004, Vol 78/2: 125-131.

Cignacco E, Büchi S. Hebammengeburt. Ein neues Betreuungsmodell für die Schweiz. Die Hebamme $2004 ; 2: 84-89$.

Petersen S, Cignacco E. Schmerzbehandlung während der Geburt. The Medical Journal 2004; 2.

Gessler P, Cignacco E. Vorgehensweisen zur Schmerzerfassung bei Neugeborenen sowie Vergleich des Berner Schmerzscores für Neugeborene (BSN) mit dem Premature Infant Pain Profile (PIPP). Klinische Pädiatrie 2004; 216:16-20.

\section{3}

Cignacco E. Ethisches Dilemma. Deutsche Hebammen Zeitschrift 2003; 4: 53-58.

Cignacco E. Schmerz und Schmerzerfassung bei Früh- und Termingeborenen: Ein lang verkanntes Phänomen mit Folgen. Deutsche Hebammen Zeitschrift 2003; 1: 9-11. 
2002

Cignacco E, Gessler P, Müller R, Hamers JPH. Der Berner Schmerzscore für Neugeborene. Die Hebamme 2002; 3:160-164.

Cignacco E. Schmerzerfassung bei Neugeboren. Schweizer Hebamme 2002: 9: 12-13.

Cignacco E. Zwischen beruflicher Pflicht und ethischer Desorientierung. Schweizer Hebamme 2002; 4: 4-11.

Cignacco E. Between Professional Duty And Ethical Confusion: Midwives And Selective Termination Of Pregnancy. Nursing Ethics 2002; Vol 9, Number 2: 179-190.

\section{1}

Cignacco E. Schmerzerfassung bei Neugeborenen. Eine Literaturubersicht. Pflege. Die wissenschaftliche Zeitschrift für Pflegeberufe 2001; 14:171-181. 


\section{CURRICULUM VITAE}

Eva Cignacco was born in Basel, Switzerland on August 24th 1961. Her first professional education was then one as social worker. In 1990 she started a further education in the field of health care and got her diploma as a registered midwive in 1993. In the following years she worked as a midwive at the Women's Clinic of the University Hospital Bern (Switzerland) mainly caring for women witt pathological conditions during the whole perinatal period. In 1996 she started a two year postgraduate. program as clinical nurse specialist and was then working in her new position as clinical nurse specialist for obstetrics and for neonatology in the same clinic, mainly being responsible for quality and development of midwifery and nursing care. From 1998 to 2001 she studied Nursing Science at the University of Maastricht, The Netherlands and the University of Applied Science in Aarau. Switzerland obtaining a Master of Nursing Science. During this period she kept always her position as a clinical nurse specialist at the Women's Clinic of the University Berne (Switzerland). In 2004 she was elected as an official member of the ethical board for human research of the Canton Bern as a representative of the nursing profession. Since February 2007 she is working as research fellow at the Institute of Nursing Science at the University Basel, Switzerland where she is developing research projects on the subject of pain management in neonates.

She started the studies described in this thesis in summer 2000. 